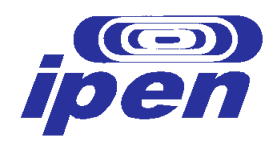

AUTARQUIA ASSOCIADA À UNIVERSIDADE DE SÃO PAULO

DESENVOLVIMENTO DE NANOMARCADORES PARA SEREM UTILIZADOS NA MARCAÇÃO DE HEMOGLOBINA S (ANEMIA FALCIFORME)

ELEN GONÇALVES DOS SANTOS

Dissertação apresentada como parte dos requisitos para obtenção do grau de Mestre em Ciências na Área de Tecnologia Nuclear Materiais.

Orientadora:

Dra. Maria Cláudia França da Cunha Felinto 

requisitos para obtenção do grau de Mestre em Ciências na Área de Tecnologia Nuclear Materiais.

Orientadora:

Dra. Maria Cláudia França da Cunha Felinto 
Dedico com todo amor à minha família - aqueles que me ergueram e me erguem quantas vezes forem necessárias e à minha Orientadora por todo aprendizado, carinho e amizade. 


\section{AGRADECIMENTOS}

À Dra. Maria Cláudia França da Cunha Felinto pela amizade, confiança, orientação e dedicação.

Ao Instituto de Pesquisas Energéticas e Nucleares (IPEN/CNEN-SP) pela oportunidade de poder desenvolver este projeto em seus laboratórios e pela bolsa concedida.

À Comissão de pós-graduação do Instituto de Pesquisas Energéticas e Nucleares (IPEN/CNEN-SP) pelos esclarecimentos acerca de créditos, matérias, prazos e por serem sempre prestativos.

Ao Dr. Hermi Felinto de Brito do laboratório dos Elementos f do Instituto de Química da Universidade de São Paulo (IQ-USP), pela obtenção dos espectros de luminescência.

À Dra. Cláudia Akemi, Dr. Roberval, Lucas, Gerson, Kai e Ana do Instituto de Química da Universidade de São Paulo (IQ-USP) pela grande ajuda nas análises e pela amizade.

À Central Analítica do Instituto de Química da Universidade de São Paulo (IQUSP), pela análise elementar de carbono e hidrogênio e pela obtenção dos espectros de infravermelho.

Ao Laboratório de Polímeros do Centro de Química e Meio Ambiente (CQMA) do Instituto de Pesquisas Energéticas e Nucleares (IPEN/CNEN-SP) pelas análises térmicas.

Ao Laboratório de Microscopia Eletrônica de Varredura do Instituto de Pesquisas Energéticas e Nucleares (IPEN/CNEN-SP) pela obtenção das micrografias dos compostos.

Ao Dr. Oscar Vega, pela grande amizade, incentivo e carinho. 
À Dra. Denise Zezell do laboratório de Lasers do Instituto de Pesquisas Energéticas e Nucleares (IPEN/CNEN-SP) pela parceria e espaço cedido para realizar as análises de FTIR.

À Felipe Guimarães do laboratório de Lasers do Instituto de Pesquisas Energéticas e Nucleares (IPEN/CNEN-SP) por realizar as análises de FTIR, pela amizade, enorme ajuda e grande dedicação.

À Dra. Maria Regina Toledo Guimarães, pelo apoio e carinho.

À Dra. Marina Baquerizo Martinez, diretora do laboratório de bioquímica do Hospital Universitário da Universidade de São Paulo, pela doação das amostras.

À Juliana Bannwart de Andrade Machado e Marilice Friedrich do Hospital Universitário da Universidade de São Paulo pela atenção e grande ajuda.

À Carmen, do Instituto Boldrini de Campinas, pela ajuda e dedicação.

Ao Laboratório de Hematologia da Escola Paulista de Medicina pela doação de amostras.

À Dra. Duclerc pelo espaço cedido para as análises.

Ao Dr. Luis Felipe Carvalho, Dr. Jorge Vaz, Dra. Ruth Luqueze pela ajuda e amizade.

À Dra. Fátima pelo apoio e incentivo no meu exame de capacidade.

À Dra. Maria Edileuza Felinto de Brito do Centro de Pesquisas Aggeu Magalhães (CPqAM/Fiocruz) pela valiosa ajuda e amizade.

Ao Brandão, pela grande amizade e por ter me dado a oportunidade de conhecer a Dra. Cláudia Felinto. 
Às meninas: Claudinha, Jacinete, Paula, Yara, Thatiana, Heloísa, Liana, Maria, Roseli, Ana, Thelma e Josiane, pela ajuda, amizade e por me aguentarem.

Aos meninos: Eduardo, Kadu, Edison, Fabio, Coutinho, João, Takeshi, Valdelei, Pedrão, Ricardinho, Renato, Valsir, pela amizade e momentos de alegria.

Aos meu queridos pais, irmãos, sobrinhos e Tia Cida por serem tudo na minha vida.

À Fernanda Arthuso por todo amor e dedicação.

Ao Leandro Duarte por toda ajuda e carinho.

À Jefferson pelo amor, apoio e carinho. 
"A imaginação é mais importante que o conhecimento."

"A tradição é a personalidade dos imbecis."

"Detesto, de saída, quem é capaz de marchar em formação com prazer ao som de uma banda. Nasceu com cérebro por engano; bastava-lhe a medula espinhal."

"Grandes almas sempre encontraram forte oposição de mentes medíocres."

"O homem erudito é um descobridor de fatos que já existem - mas o homem sábio é um criador de valores que não existem e que ele faz existir."

“A percepção do desconhecido é a mais fascinante das experiências. O homem que não tem os olhos abertos para o misterioso passará pela vida sem ver nada."

"A luta pela verdade deve ter precedência sobre todas as outras."

"Deus é a lei e o legislador do Universo."

Albert Einstein 


\title{
DESENVOLVIMENTO DE NANOMARCADORES PARA SEREM UTILIZADOS NA MARCAÇÃO DE HEMOGLOBINA S (ANEMIA FALCIFORME)
}

\author{
Elen Gonçalves dos Santos
}

\begin{abstract}
RESUMO
Materiais luminescentes, como os complexos de Terras Raras trivalentes, atuam como marcadores em citologia e imunologia, podendo ser utilizados como biomarcadores luminescentes, uma vez que, o desenvolvimento destes nanomateriais abre novas possibilidades para diversos campos, particularmente na medicina diagnóstica, além de estabelecer uma classe de sondas fluorescentes, para a qual não existem moléculas orgânicas equivalentes. Devido ao potencial de aplicação no mercado o presente trabalho teve como objetivo desenvolver materiais luminescentes, viabilizando a utilização de supermoléculas de lantanídeos como marcadores para diagnóstico de Anemia Falciforme $(\mathrm{HbS})$. Foram desenvolvidos e caracterizados seis marcadores luminescentes a base de Terras Raras. A principal técnica utilizada para detecção de $\mathrm{HbS}$ foi o fluoroimunoensaio que já é utilizado na investigação de enzimas, anticorpos, células e hormônios, entre outros. No decorrer do trabalho utilizou-se também a espectroscopia de absorção no infravermelho por Transformada de Fourier (FTIR), para detectar a HbS. Os métodos estudados foram aplicados para o diagnóstico desta doença, de origem gênica, extremamente comum do grupo das hemoglobinopatias e considerada uma questão de saúde pública no Brasil (ANVISA). A Anemia Falciforme quando diagnosticada precocemente reduz expressivamente a morbidade e mortalidade dos seus portadores. Comparando os resultados obtidos com as metodologias já existentes, concluiu-se que são métodos viáveis para detecção da $\mathrm{HbS}$ e quando totalmente desenvolvidas, estas técnicas contribuirão originalmente para produção do diagnóstico da Anemia Falciforme e terão impacto nas Políticas Públicas do Estado de São Paulo e conseqüentemente do Brasil.
\end{abstract}




\title{
DEVELOPMENT OF NANOBIOMARKERS FOR USE IN SICKLE CELL ANEMIA
}

Elen Gonçalves dos Santos

\begin{abstract}
Luminescent materials, such as the rare earth's complex, can be used as markers in cytology and immunology, being also used as luminescent biomarkers, once the development of these nanomaterials create new possibilities to many fields, particularly in diagnostic medicine. Besides, it establishes one kind of fluorescent probes, for which there are no equivalent organic molecules. Due to its potential in market's application, the objective of this work was to develop luminescent materials, allowing the use of these supermolecules of lanthanides as markers for the detection of Sickle Cell Disease (HbS). Six luminescent markers were developed and marked on rare's earth base. The main methodology used for the detection of $\mathrm{HbS}$ was fluoroimunoassay, which is already used in investigation of enzymes, antibodies, cells, hormones, and so on. During this work, absorption's spectrum in the infrared by Fourier's Transform (FTIR) was also used to detect the HbS. The studied methods were applied for the diagnosis of this disease, which has genetic origin, very typical of the hemoglobin-pathology group and considered to be a public health problem in Brazil (ANVISA). When early diagnosed, Sickle Cell Disease (SCD) has a significant decrease in morbidity and mortality. Comparing the obtained results to the already known methodologies, it was possible to conclude that they are viable methods to detect $\mathrm{HbS}$. Besides, when totally developed, these methods will contribute to the production of Sickle Cell Anemia's diagnostic, and they will have impact in São Paulo state's public measures, as well as in Brazil's ones.
\end{abstract}




\section{SUMÁRIO}

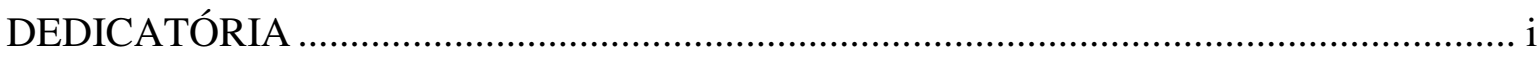

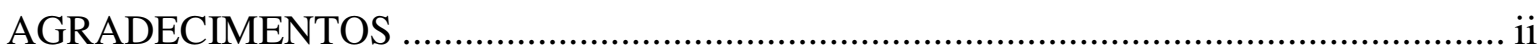

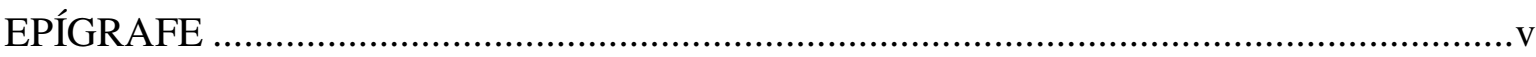

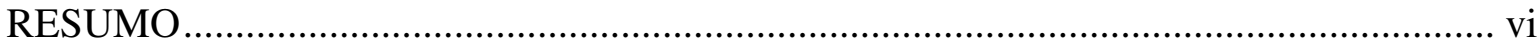

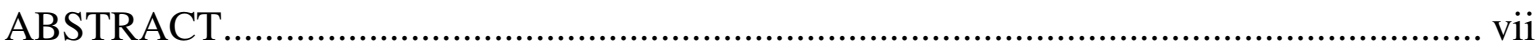

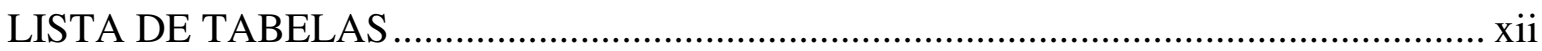

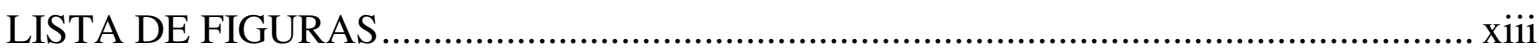

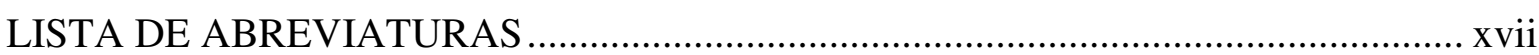

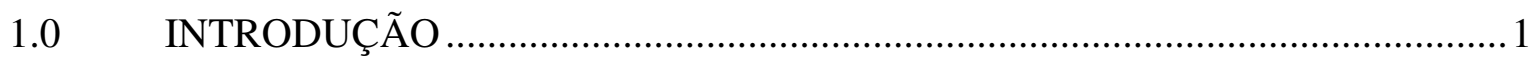

REFERÊNCIAS BIBLIOGRÁFICAS …................................................................. 7

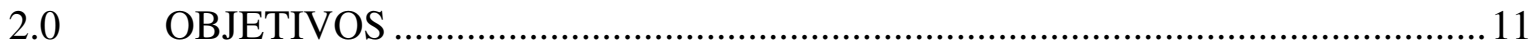

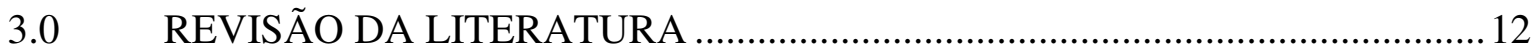

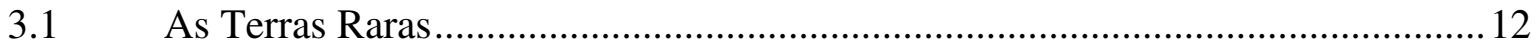

3.2 Espectro de emissão na região do visível ......................................................... 14

3.2.1 Luminescência dos íons Terras Raras............................................................... 18

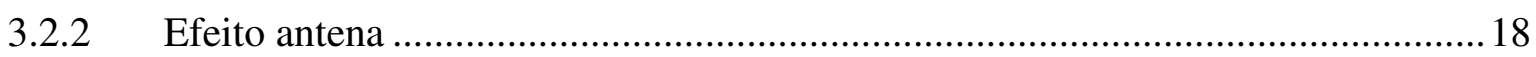

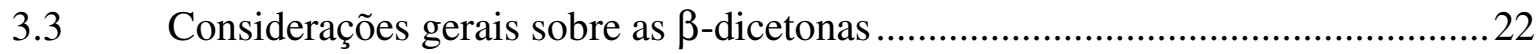

3.3.1 Tautomeria ceto-enólica das $\beta$-dicetonas ............................................................2 23

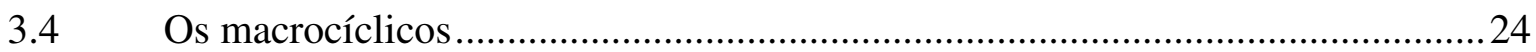

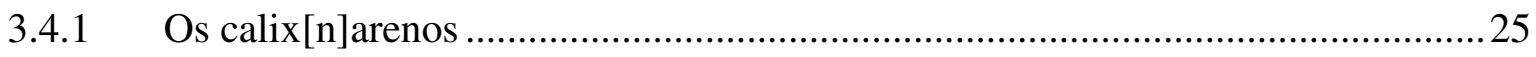

3.4.1.1 Representação e nomenclatura dos calix[n] arenos ............................................26

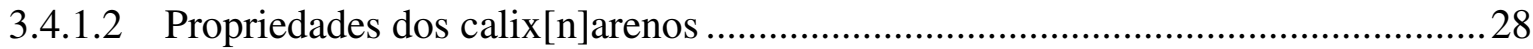

3.4.1.3 Funcionalização dos calixarenos e complexação com metais ................................30

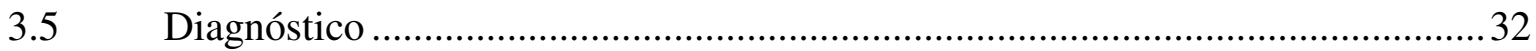

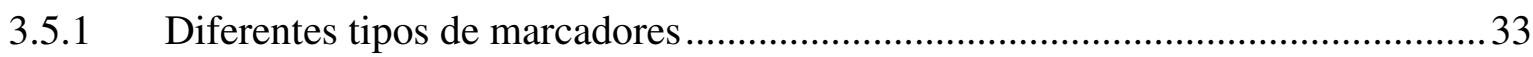

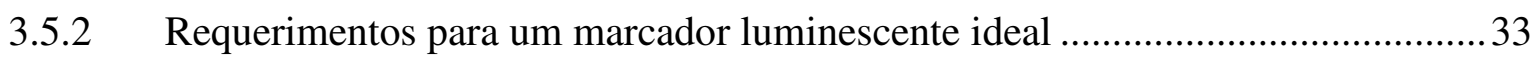

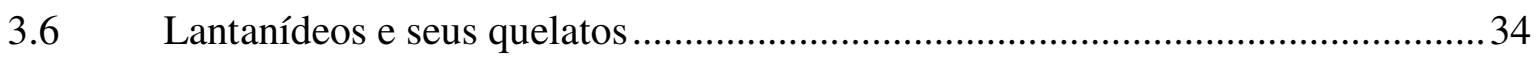

3.6.1 Tecnologias de ensaios baseadas em quelatos de lantanídeos ...............................36

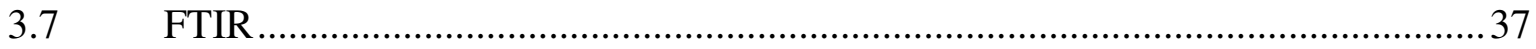

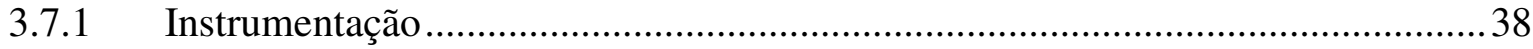

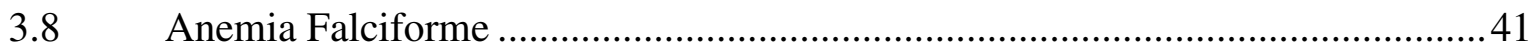

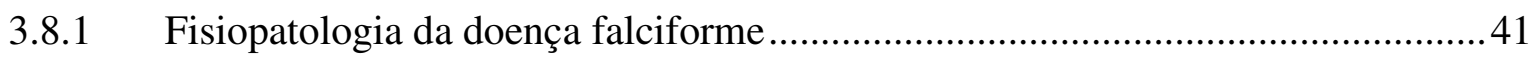




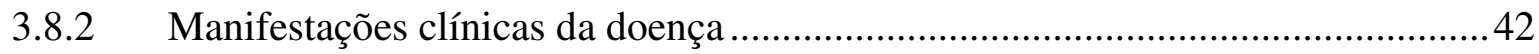

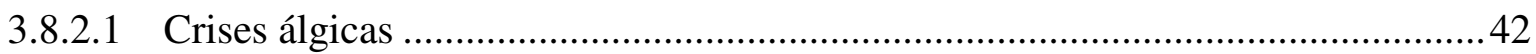

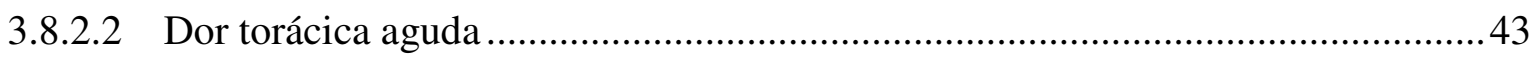

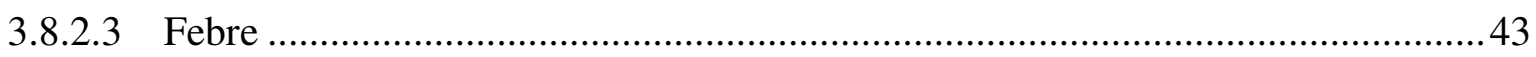

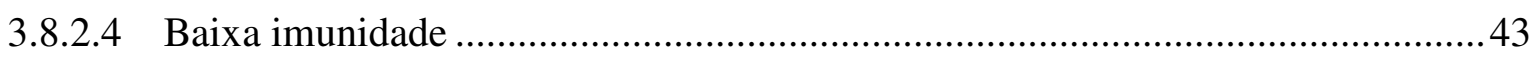

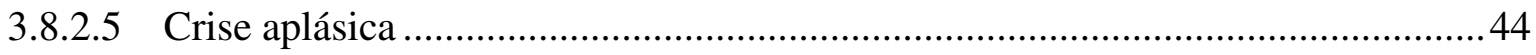

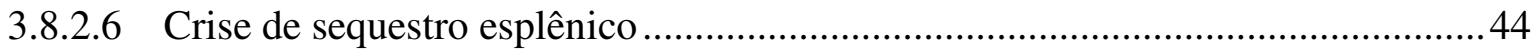

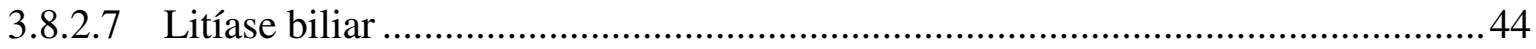

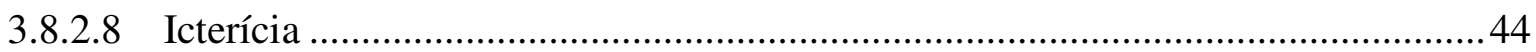

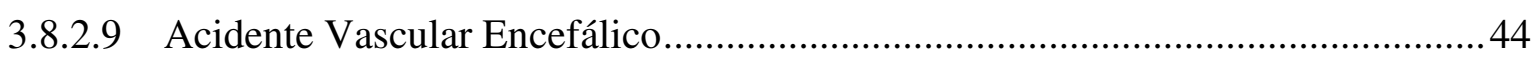

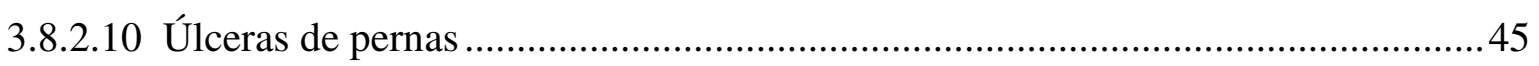

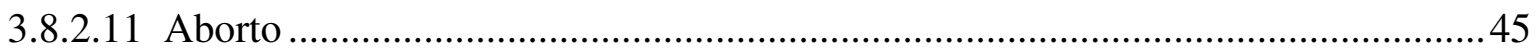

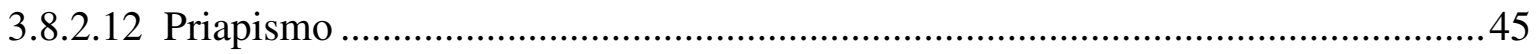

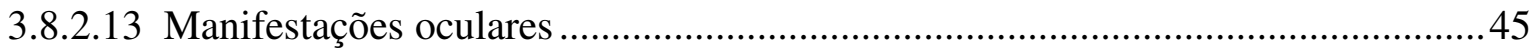

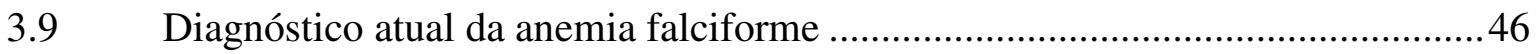

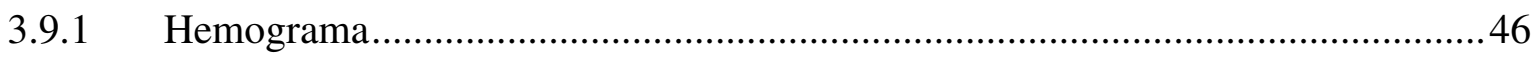

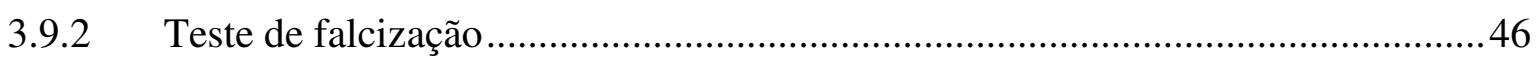

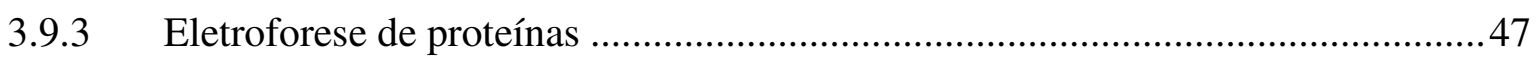

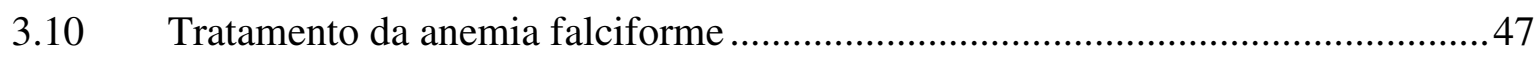

REFERÊNCIAS BIBLIOGRÁFICAS .......................................................... 48

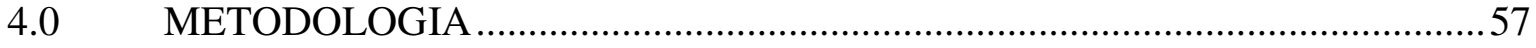

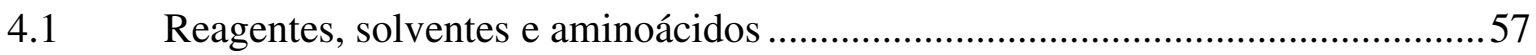

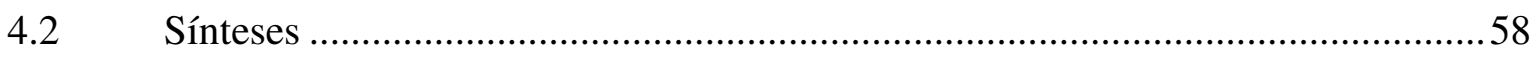

4.2.1 Síntese do quelato de $\beta$-dicetonas de lantanídeos ................................................58

4.2.2 Síntese do ligante octaacetato calix[8]areno.......................................................5

4.2.3 Síntese das supermoléculas de lantanídeos.........................................................5

4.3 Metodologia para caracterização dos quelatos precursores, do ligante e das

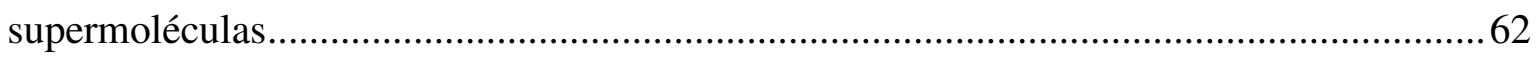

4.3.1 Análise elementar de carbono, hidrogênio e nitrogênio $(\mathrm{CHN})$...........................62

4.3.2 Método do vermelho de alizarina $\mathrm{S}$ para determinação de $\mathrm{Ln}^{3+}$..........................62

4.3.3 Espectroscopia de absorção molecular na região do infravermelho.......................62

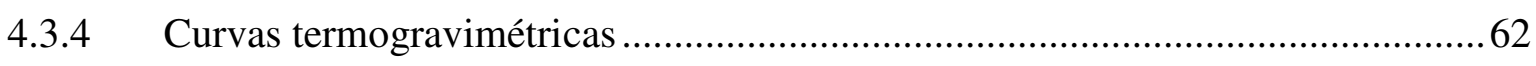

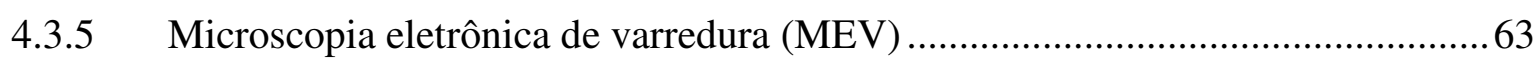

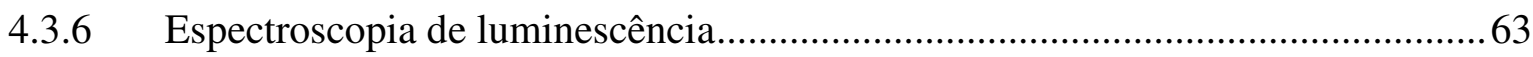


4.3.6.1 Espectros eletrônicos de excitação e emissão 63

4.3.6.2 Medidas do tempo de vida.....

4.3.7 Conjugação dos quelatos precursores e das supermoléculas de $\mathrm{Eu}^{3+} \mathrm{e} \mathrm{Tb}^{3+}$ com glutaraldeído

4.3.7.1 Curva de calibração dos aminoácidos Valina e Ácido Glutâmico. 64

4.3.8 Conjugação do marcador de $\mathrm{Eu}^{3+}$-TTA-Ligante-glutaraldeído às amostras sanguíneas 64

4.3.8.1 Conjugação do marcador de $\mathrm{Eu}^{3+}$-TTA-Ligante às amostras sanguíneas 65

4.3.9 Identificação das amostras sanguíneas por FTIR 66

4.3.9.1 Preparação para FTIR 66

4.3.9.2 Preparação das pastilhas $\mathrm{KBr}$ dos aminoácidos Valina e Ácido glutâmico para identificação por FT-IR .66

REFERÊNCIAS BIBLIOGRÁFICAS 68

5.0 RESULTADOS E DISCUSSÕES 69

5.1 Características quantitativas e estequiometria dos compostos 69

5.1.1 Análise elementar de carbono, hidrogênio, nitrogênio ( $\mathrm{CHN})$ e porcentagem de lantanídeos $\left(\% \mathrm{Ln}^{3+}\right)$.

5.1.2 Espectroscopia de absorção molecular na região do infravermelho. 71

5.1.2.1 Espectroscopia de absorção molecular na região do infravermelho do ligante....71

5.1.2.2 Espectroscopia de absorção molecular na região do infravermelho dos quelatos precursores e supermoléculas .73

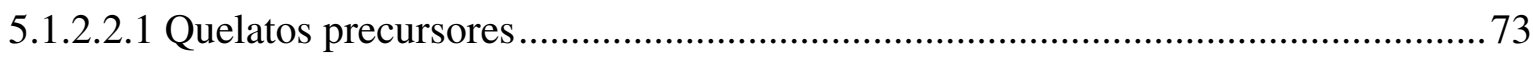

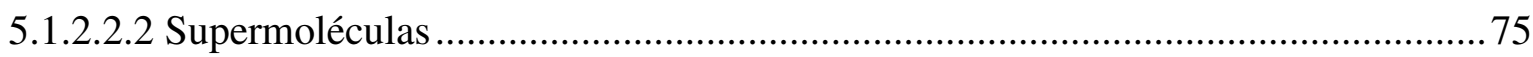

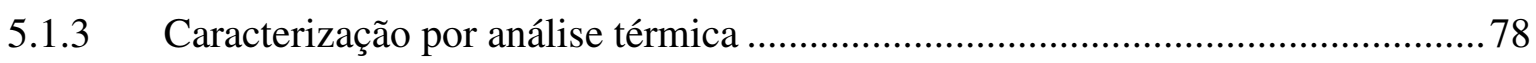

5.1.3.1 Decomposição térmica dos quelatos precursores ............................................... 78

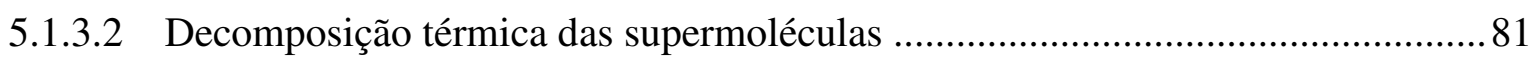

5.2 Microscopia eletrônica de varredura (MEV), do ligante, dos quelatos precursores e das supermoléculas 84

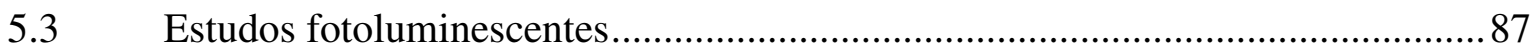

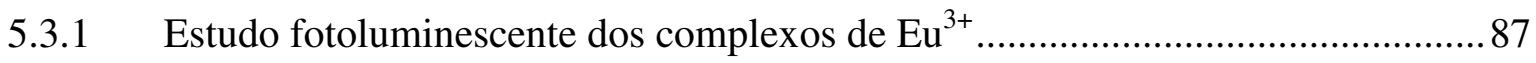

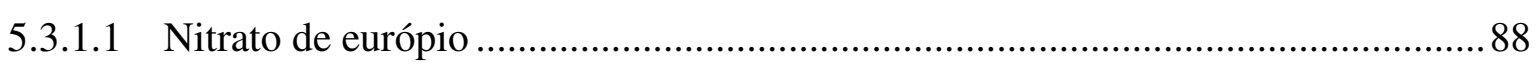

5.3.1.2 Fotoluminescência das supermoléculas de $\beta$-dicetonados de európio e seus quelatos precussores.

5.3.1.2.1 Espectros de Excitação .89 
5.3.1.2.2 Espectros de Emissão 92

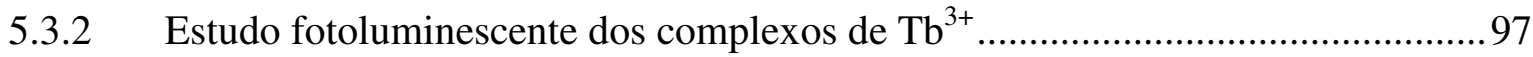

5.3.3 Tempo de vida luminescente das supermoléculas de $\mathrm{Eu}^{3+}$ e $\mathrm{Tb}^{3+}$

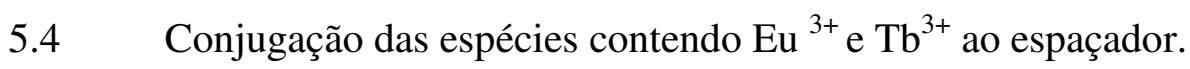
103

5.5 Fluoroimunoensaio 107

5.5.1 Curva de calibração dos aminoácidos 107

5.5.2 Resultados preliminares dos testes do protocolo de análise para $\mathrm{HbS}$ 108

$5.6 \quad$ FTIR 110

5.6.1 Determinação dos aminoácidos valina e àcido glutâmico pela técnica de FTIR 110

5.6.2 Resultados estatísticos das análises do grupo com anemia falciforme e do grupo controle por FTIR 111

5.7 Fase seguinte para obtenção do kit para análise de HbS.................................... 114 REFERÊNCIAS BIBLIOGRÁFICAS ........................................................... 115

6.0 CONCLUSÕES 117

6.1 PERSPECTIVAS FUTURAS 119

7.0 ANEXO. Amostras de anemia falciforme e amostras controle do material utilizado nas análises por FTIR. 


\section{LISTA DE TABELAS}

TABELA 3.1. Transições mais intensas nos espectros de luminescência dos $\operatorname{Ln}^{3+}$............34

TABELA 4.1. Reagentes, solventese aminoácidos usados nos experimentos.....................57

TABELA 5.2. Exemplo comparativo dos dados espectrais dos ligantes paratercbutilcalix[8]areno e acetato calix[8]areno na região do infravermelho.........................72

TABELA 5.3. Dados espectrais dos quelatos precursores na região do infravermelho. .... 76

TABELA 5.4. Dados espectrais das supermoléculas na região do infravermelho. ............76

TABELA 5.5. Dados de decomposição térmica dos quelatos precursores......................... 81

TABELA 5.6. Dados de decomposição térmica das supermoléculas................................ 84

TABELA 5.8. Energias de transição dos níveis ${ }^{5} \mathrm{D}_{3,4} \rightarrow{ }^{7} \mathrm{~F}_{\mathrm{J}^{\prime}}\left(\mathrm{J}^{\prime}=0-6\right)\left(\mathrm{em} \mathrm{cm}^{-1}\right)$ observados no espectro de emissão do quelato precursor $\mathrm{Tb}(\mathrm{ACAC})_{2} \cdot\left(\mathrm{NO}_{3}\right) \cdot\left(\mathrm{H}_{2} \mathrm{O}\right)_{2}$ a $77 \mathrm{~K} \ldots \ldots \ldots \ldots \ldots . . . . . .101$

TABELA 5.9. Valores de decaimento para os quelatos precursores e para as

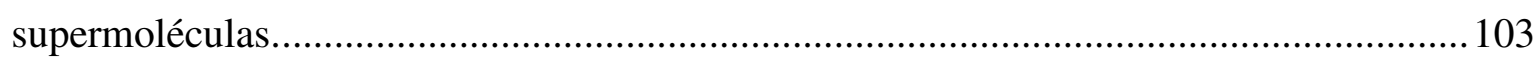




\section{LISTA DE FIGURAS}

FIGURA 1.1. Estrutura dos níveis de energia para os íons terras raras baseado nas energias do campo cristalino

FIGURA 3.1. Espectros de emissão de alguns íons lantanídeos.

FIGURA 3.2. Diagrama esquemático mostrando os principais processos de decaimento de moléculas poliatômicas. 14

FIGURA 3.3. Diagrama de coordenada configuracional.. 16

FIGURA 3.4. Mecanismos para transferência de energia intramolecular em quelatos de lantanídeos

FIGURA 3.5. Diagrama hipotético de níveis de energia usados para descrever o mecanismo de transferência de energia Ligante-TR ${ }^{3+}$.

FIGURA 3.6. Formas tautoméricas das $\boldsymbol{\beta}$-dicetonas

FIGURA 3.7. Representação do anel quelato para os compostos metálicos com as $\beta$ dicetonas.

FIGURA 3.8. Tautomerismos ceto-enólicos. 24

FIGURA 3.9. Fórmula estrutural do calix[4]areno "pai". 25

FIGURA 3.10. Modelo molecular tipo space filling para o tetrâmero cíclico (esquerda) e um vaso calix crater (direita). 26

FIGURA 3.11. Diagrama das representações do calix[4]areno. .27

FIGURA 3.12. Sequência de numeração para a nomenclatura dos calix[n]arenos. .28

FIGURA 3.13. A diferentes conformações dos calix[4]arenos.

FIGURA 3.14. Lower rim e upper rim dos calixarenos não funcionalizados (calixarenos "pai").

FIGURA 3.15. Exemplos de calixarenos funcionalizados.

FIGURA 3.16. Perfis de decaimento de emissão de uma mistura de quelatos de $\mathrm{Eu}, \mathrm{Tb}, \mathrm{Dy}$ e Sm em uma solução de crescimento baseado em pivaloiltrifluoroacetona. 35

FIGURA 3.17. Esboço do espectro eletromagnético. Distribuição da intensidade da radiação eletromagnética em relação ao seu comprimento de onda ou frequiência ${ }^{[72]}$ 37 
FIGURA 3.18. Esquema dos modos vibracionais. (+ e - indicam movimento perpendicular ao plano da página) ${ }^{[73]}$.... 38

FIGURA 3.19. Diagrama óptico de um espectrômetro dispersivo. 39

FIGURA 3.20. Diagrama óptico de um espectrômetro FTIR

FIGURA 3.21. Hemoglobina A e Hemoglobina S, respectivamente. 42

FIGURA 4.1. Fluxograma de rota de síntese das $\beta$-dicetonas de lantanídeos (III) ( $\operatorname{Ln}(\beta$ dicetona $\left.)_{2} \cdot\left(\mathrm{NO}_{3}\right) \cdot\left(\mathrm{H}_{2} \mathrm{O}\right)_{2}\right)$. 59

FIGURA 4.2. Fluxograma de rota de síntese do octaacetato $\subset$ calix[8]areno. 60

FIGURA 4.3. Fluxograma de rota de síntese das supermoléculas de $\beta$-dicetonas de lantanídeos (III) com o ligante macrocíclico octaacetatocalix[8]areno. 61

FIGURA 4.4. Placa de 96 poços utilizada para leitura em fluroimunoensaios. 65

FIGURA 4.5. Espectrofluorímetro para leitura das placas de fluoroimunoensaios, Victor ${ }^{2}-$ R, da Perkin Elmer. 65

FIGURA 4.6. Espectrômetro de infravermelho: ThermoNicolet, modelo 6700-FTIR. 67

FIGURA 5.1. Espectros de absorção na região do infravermelho do ligante para-tercbutilcalix[8]areno e octaacetatocalix[8]areno.

FIGURA 5.2. Espectros de absorção na região do infravermelho do quelato precursor: $\mathrm{Eu}(\mathrm{TTA})_{2}\left(\mathrm{NO}_{3}\right) \cdot\left(\mathrm{H}_{2} \mathrm{O}\right)_{2}$ e da supermolécula: $\quad\left[\mathrm{Eu}(\mathrm{TTA})_{2} \cdot\left(\mathrm{NO}_{3}\right) \cdot\left(\mathrm{H}_{2} \mathrm{O}\right)_{2}\right]_{2} \subset$ acetato calix[8]areno. .77

FIGURA 5.3. Espectros de absorção na região do infravermelho do quelato precursor: $\mathrm{Eu}(\mathrm{ACAC})_{2}\left(\mathrm{NO}_{3}\right) \cdot\left(\mathrm{H}_{2} \mathrm{O}\right)_{2}$ e da supermolécula: [Eu(ACAC $\left.)_{2}\left(\mathrm{NO}_{3}\right) \cdot\left(\mathrm{H}_{2} \mathrm{O}\right)_{2}\right]_{2}$ Cacetato calix[8]areno. 77

FIGURA 5.4. Espectros de absorção na região do infravermelho do quelato precursor: $\mathrm{Tb}(\mathrm{ACAC})_{2}\left(\mathrm{NO}_{3}\right) \cdot\left(\mathrm{H}_{2} \mathrm{O}\right)_{2}$ e da supermolécula $\left[\mathrm{Tb}(\mathrm{ACAC})_{2}\left(\mathrm{NO}_{3}\right) \cdot\left(\mathrm{H}_{2} \mathrm{O}\right)_{2}\right]_{2}$ Cacetato calix[8]areno. .78

FIGURA 5.5. Curvas TGA e DTGA dos quelatos precursores: (a) $\left[\mathrm{Eu}(\mathrm{TTA})_{2}\left(\mathrm{NO}_{3}\right) \cdot\left(\mathrm{H}_{2} \mathrm{O}\right)_{2}\right]_{2}, \quad$ (b) $\quad\left[\mathrm{Eu}(\mathrm{ACAC})_{2}\left(\mathrm{NO}_{3}\right) \cdot\left(\mathrm{H}_{2} \mathrm{O}\right)_{2}\right]_{2} \quad$ e $\quad$ (c) $\left[\mathrm{Tb}(\mathrm{ACAC})_{2}\left(\mathrm{NO}_{3}\right) \cdot\left(\mathrm{H}_{2} \mathrm{O}\right)_{2}\right]_{2}$, sob atmosfera de nitrogênio com vazão $50 \mathrm{~mL} /$ minuto e razão de aquecimento $10^{\circ} \mathrm{C} \mathrm{min}^{-1}$ 
FIGURA 5.6. Curvas TGA e DTGA das supermoléculas: (a) $\left[\mathrm{Eu}(\mathrm{TTA})_{2}\left(\mathrm{NO}_{3}\right) \cdot\left(\mathrm{H}_{2} \mathrm{O}\right)_{2}\right]_{2} \subset$ acetato calix[8]areno, (b) $\left[\mathrm{Eu}(\mathrm{ACAC})_{2}\left(\mathrm{NO}_{3}\right) \cdot\left(\mathrm{H}_{2} \mathrm{O}\right)_{2}\right]_{2} \subset$ acetato calix[8]areno e (c) $\left[\mathrm{Tb}(\mathrm{ACAC})_{2}\left(\mathrm{NO}_{3}\right) \cdot\left(\mathrm{H}_{2} \mathrm{O}\right)_{2}\right]_{2} \subset$ acetato calix[8]areno sob atmosfera de nitrogênio com vazão $50 \mathrm{~mL} /$ minuto e razão de aquecimento $10^{\circ} \mathrm{C} \min ^{-1}$ 83

FIGURA 5.7. Micrografias do (a) Acetato Calix[8]areno e (b,c e d) dos quelatos precursores.

FIGURA 5.8. Micrografias das supermoléculas (e, f e g). 86

FIGURA 5.9. Espectros de excitação (a) e emissão (b) dos nitratos de $\mathrm{Eu}^{3+}$ a temperatura ambiente $(300 \mathrm{~K})$ e a temperatura do nitrogênio líquido (77K). Excitação monitorada na ${ }^{5} \mathrm{D}_{0} \rightarrow{ }^{7} \mathrm{~F}_{2}\left(\lambda_{\text {exc }}=612 \mathrm{~nm}\right)$ e emissão monitorada em $394 \mathrm{~nm}$. 89

FIGURA 5.10. Espectros de excitação do quelato precursor: $\mathrm{Eu}(\mathrm{TTA})_{2}\left(\mathrm{NO}_{3}\right) \cdot\left(\mathrm{H}_{2} \mathrm{O}\right)_{2}$ (a) temperatura ambiente (300K) e (b) a temperatura do nitrogênio líquido (77K). Emissão monitorada $\mathrm{em}^{5} \mathrm{D}_{0} \rightarrow{ }^{7} \mathrm{~F}_{2}\left(\lambda_{\text {emissão }}=612 \mathrm{~nm}\right)$

FIGURA 5.11. Espectros de excitação da supermolécula: [Eu(TTA $\left.)_{2}\left(\mathrm{NO}_{3}\right) \cdot 2 \mathrm{H}_{2} \mathrm{O}\right]_{2} \subset$ acetatocalix[8]areno (a) temperatura ambiente (300K) e (b) a temperatura do nitrogênio líquido (77K). Emissão monitorada em ${ }^{5} \mathrm{D}_{0} \rightarrow{ }^{7} \mathrm{~F}_{2}\left(\lambda_{\text {emissão }}=612 \mathrm{~nm}\right)$.

FIGURA 5.12. Espectros de excitação do quelato precursor: $\mathrm{Eu}(\mathrm{ACAC})_{2}\left(\mathrm{NO}_{3}\right) \cdot\left(\mathrm{H}_{2} \mathrm{O}\right)_{2}$, (a) temperatura ambiente $(300 \mathrm{~K})$ e (b) a temperatura do nitrogênio líquido (77K). Emissão monitorada $\mathrm{em}^{5} \mathrm{D}_{0} \rightarrow{ }^{7} \mathrm{~F}_{2}\left(\lambda_{\text {emissão }}=612 \mathrm{~nm}\right)$.

FIGURA 5.13. Espectros de excitação da supermolécula: $\left[\mathrm{Eu}(\mathrm{ACAC})_{2}\left(\mathrm{NO}_{3}\right) \cdot 2 \mathrm{H}_{2} \mathrm{O}\right]_{2} \subset$ acetatocalix[8]areno (a) temperatura ambiente (300K) e (b) a temperatura do nitrogênio líquido (77K). Emissão monitorada em ${ }^{5} \mathrm{D}_{0} \rightarrow{ }^{7} \mathrm{~F}_{2}\left(\lambda_{\text {emissão }}=612 \mathrm{~nm}\right)$.

FIGURA 5.14. Espectros de emissão do quelato precursor: $\mathrm{Eu}(\mathrm{TTA})_{2}\left(\mathrm{NO}_{3}\right) \cdot\left(\mathrm{H}_{2} \mathrm{O}\right)_{2}$ (a) temperatura ambiente (300K) e (b) a temperatura do nitrogênio líquido (77K). Emissão monitorada em ${ }^{5} \mathrm{D}_{0} \rightarrow{ }^{7} \mathrm{~F}_{2}\left(\lambda_{\text {exc. }}=394\right.$ e $\left.320 \mathrm{~nm}\right)$ .93

FIGURA 5.15. Espectros de emissão da supermolécula: $\left[\mathrm{Eu}(\mathrm{TTA})_{2}\left(\mathrm{NO}_{3}\right)_{2}\left(\mathrm{H}_{2} \mathrm{O}\right)_{2}\right]_{2} \subset$ acetatocalix[8]areno (a) temperatura ambiente (300K) e (b) a temperatura do nitrogênio líquido $(77 \mathrm{~K})$. Emissão monitorada $\mathrm{em}^{5} \mathrm{D}_{0} \rightarrow{ }^{7} \mathrm{~F}_{2}\left(\lambda_{\text {emissão }}=612 \mathrm{~nm}\right)$. 94 
FIGURA 5.16. Espectros de emissão do quelato precursor: $\mathrm{Eu}(\mathrm{ACAC})_{2}\left(\mathrm{NO}_{3}\right) \cdot 2 \mathrm{H}_{2} \mathrm{O}$. (a) temperatura ambiente $(300 \mathrm{~K})$ e (b) a temperatura do nitrogênio líquido (77K). Emissão monitorada $\mathrm{em}^{5} \mathrm{D}_{0} \rightarrow{ }^{7} \mathrm{~F}_{2}\left(\lambda_{\text {emissão }}=612 \mathrm{~nm}\right)$.

FIGURA 5.17. Espectros de emissão da supermolécula: $\left[\mathrm{Eu}(\mathrm{ACAC})_{2}\left(\mathrm{NO}_{3}\right) \cdot\left(\mathrm{H}_{2} \mathrm{O}\right)_{2}\right]_{2} \subset$ acetatocalix[8]areno (a) temperatura ambiente (300K) e (b) a temperatura do nitrogênio líquido $(77 \mathrm{~K})$. Emissão monitorada $\mathrm{em}^{5} \mathrm{D}_{0} \rightarrow{ }^{7} \mathrm{~F}_{2}\left(\lambda_{\text {emissão }}=612 \mathrm{~nm}\right)$.

FIGURA 5.18. Diagrama de nível de energia para o íon $\mathrm{Tb}^{3+}$. Somente alguns níveis são apresentados.

FIGURA 5.19. Espectros de excitação do quelato precursor: $\mathrm{Tb}(\mathrm{ACAC})_{2}\left(\mathrm{NO}_{3}\right) \cdot\left(\mathrm{H}_{2} \mathrm{O}\right)_{2}$ (a) temperatura ambiente $(300 \mathrm{~K})$ e (b) a temperatura do nitrogênio líquido (77K). Emissão monitorada em ${ }^{5} \mathrm{D}_{0} \rightarrow{ }^{7} \mathrm{~F}_{2}\left(\lambda_{\text {emissão }}=546 \mathrm{~nm}\right)$.

FIGURA 5.20. Espectros de excitação da supermolécul: $\left[\mathrm{Tb}(\mathrm{ACAC})_{2}\left(\mathrm{NO}_{3}\right) \cdot\left(\mathrm{H}_{2} \mathrm{O}\right)_{2}\right] \subset$ octaacetatocalix[8]areno (a) temperatura ambiente $(300 \mathrm{~K})$ e (b) a temperatura do nitrogênio líquido $(77 \mathrm{~K})$. Emissão monitorada $\mathrm{em}^{5} \mathrm{D}_{0} \rightarrow{ }^{7} \mathrm{~F}_{2}\left(\lambda_{\text {emissão }}=546 \mathrm{~nm}\right)$. .99

FIGURA 5.21. Espectros de emissão do quelato precursor: $\mathrm{Tb}(\mathrm{ACAC})_{2}\left(\mathrm{NO}_{3}\right) \cdot\left(\mathrm{H}_{2} \mathrm{O}\right)_{2}$ (a) temperatura ambiente $(300 \mathrm{~K})$ e (b) a temperatura do nitrogênio líquido (77K). Emissão monitorada em ${ }^{5} \mathrm{D}_{0} \rightarrow{ }^{7} \mathrm{~F}_{2}\left(\lambda_{\mathrm{ex}}=546 \mathrm{~nm}\right)$.

FIGURA 5.22. Espectros de emissão da supermolécula: $\left[\mathrm{Tb}(\mathrm{ACAC})_{2}\left(\mathrm{NO}_{3}\right) \cdot\left(\mathrm{H}_{2} \mathrm{O}\right)_{2}\right]_{2} \subset$ acetatocalix[8]areno (a) temperatura ambiente (300K) e (b) a temperatura do nitrogênio líquido $(77 \mathrm{~K})$. Emissão monitorada $\mathrm{em}^{5} \mathrm{D}_{0} \rightarrow{ }^{7} \mathrm{~F}_{2}\left(\lambda_{\text {emissão }}=546 \mathrm{~nm}\right)$. 100

FIGURA 5.23. Curva de decaimento para os quelatos precursores e as supermoléculas de $\mathrm{Eu}^{3+} \mathrm{e} \mathrm{Tb}^{3+}$. 102

FIGURA 5.24. Espectros de excitação (a) e emissão (b) do quelato de Eu-TTAglutaraldeído. Espectros de excitação (c) e emissão (d) da supermolécula de Eu-TTAglutaraldeído.

FIGURA 5.25. Espectros de excitação (a) e emissão (b) do quelato de Eu-ACACglutaraldeído. Espectros de excitação (c) e emissão (d) da supermolécula de Eu-ACACglutaraldeído.

FIGURA 5.26. Espectros de excitação (a) do quelato de Tb-ACAC-glutaraldeído. Espectros de excitação (c) e emissão (d) da supermolécula de Tb-ACAC-glutaraldeído..106 
FIGURA 5.27. Curva de calibração do àcido glutâmico e da valina com os marcadores EuTTA-Calix[8]areno (nc) e Eu-TTA-Calix[8]areno-glutaraldeído (c)

FIGURA 5.28. Imagem representativa da placa de ELISA usada para fazer as contagens da curva de calibração da valina com os marcadores Eu-TTA-Calix[8]areno (nc) e EuTTA-Calix[8]areno-glutaraldeído (c). 108

FIGURA 5.29. Fluoroimunoensaio com os marcadores Eu-TTA-Calix[8]areno (nc) e EuTTA-Calix[8]areno-glutaraldeído (c). 0 e 25: Controle negativo; 1-24: HbS em diferentes porcentagens conforme 7.0 ANEXO. 109

FIGURA 5.30. Espectro de infravermelho dos aminoácidos em pastilha de $\mathrm{KBr}$ 110

FIGURA 5.31. Espectro detalhando as características gerais das amostras de sangue analisadas por FTIR.

FIGURA 5.32. Gráfico de PCA da estatística multivariável.

FIGURA 5.33. Gráfico PCA mostrando uma separação entre as amostras (abaixo de 50\% e acima de $60 \%$ de $\mathrm{HbS}$ ) em relação ao grupo controle.

FIGURA 5.34. Gráfico PCA que utiliza somente a diferenciação entre as amostras HbS. 113

FIGURA 5.35. Estatística das porcentagens de $\mathrm{HbA}, \mathrm{HbA}_{2}, \mathrm{HbS}$ e $\mathrm{HbF}$. A intensidade é dada em unidades de absorbância em função do número de onda. 114 


\section{LISTA DE ABREVIATURAS}

ACAC - Acetil acetona

ANVISA - Agência Nacional de Vigilância Sanitária

$\mathbf{C a F}_{2}$ - Fluoreto de cálcio

c - conjugado

$\mathbf{E u}^{3+}$ - Európio

FIA - Fluoroimunoassay

FTIR - Espectroscopia de absorção no infravermelho por Transformada de Fourier

HbA - Hemoglobina normal

$\mathbf{H b F}$ - Hemoglobina fetal

HbS - Hemoglobina "alterada"

KBr - Brometo de Potássio

nc - não conjugado

SCD - Sickle cell disease

$\mathbf{T b}^{3+}$ - Térbio

T.R. - Terras Raras

TTA - 2-tenoil-trifluoroacetona

WHO - Organização Mundial de Saúde

ZnSe - Seleneto de zinco 


\subsection{INTRODUÇÃO}

$\mathrm{O}$ interesse pela química de complexos de terras raras trivalentes $\left(\mathrm{TR}^{3+}\right)$ tem crescido muito nos últimos quinze anos, particularmente no que se refere à química de lantanídeos em solução, sendo este assunto tema de pesquisa em vários laboratórios no mundo ${ }^{[1]}$. Complexos de elementos terras raras têm sido aplicados na indústria radiofarmacêutica ${ }^{[2]}$ (por exemplo, usando-se ${ }^{90} \mathrm{Y}$ em radioimunoterapia), como agente de imagem em ressonância magnética por imagem (IRM) (uso de $\mathrm{Gd}^{3+}{ }^{[3]}$, agente de deslocamento de $\mathrm{RMN}^{[4]}$ (usando-se os íons $\mathrm{Pr}^{3+}, \mathrm{Eu}^{3+}$ e $\mathrm{Yb}^{3+}$ ), agente de relaxação para proteínas ${ }^{[5]}$ e sondas substituindo cátions de interesse biológico ${ }^{[6]}$. Complexos de terras

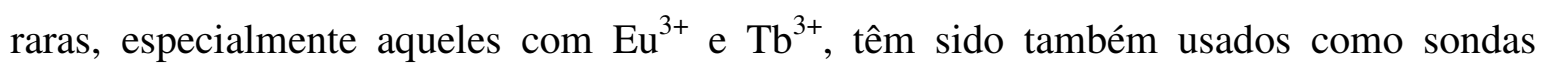
fluorescentes em ensaios fluoroimunológicos ${ }^{[7]}$ e em outras aplicações clínicas ${ }^{[8]}$. Estes complexos luminescentes são promissores, devido sua atuação como marcadores em citologia e imunologia, podendo ser utilizados também como biomarcadores luminescentes [9]. Eles têm também apresentado também potencial para atuar como possíveis drogas no tratamento do câncer ${ }^{[10]}$.

Os compostos com íons terras raras trivalentes $\left(\mathrm{TR}^{3+}\right)$ apresentam propriedades ópticas interessantes e úteis, que vêm sendo estudadas já há bastante tempo. Essas propriedades são sensíveis ao ambiente químico no qual o íon $\mathrm{TR}^{3+}$ se encontra em um determinado composto. Os fundamentos da teoria do campo ligante aplicada a esses compostos são bem conhecidos, e inúmeras aplicações e interpretações têm sido obtidas e desenvolvidas. Da mesma forma, a teoria das intensidades espectrais $4 \mathrm{f}-4 \mathrm{f}$ tem-se mostrado uma ferramenta muito útil na descrição e previsão de propriedades ópticas desses compostos, dentre os quais os complexos com ligantes orgânicos têm um papel de destaque e nesses últimos tempos, vêm recebendo, uma atenção especial.

Existe um interesse maior em complexos de $\mathrm{TR}^{3+}$ desde que WEISSMAN descobriu que nestes compostos a excitação pode ser efetuada sob condições aceitáveis, através da luz absorvida pelos ligantes com subseqüente transferência de energia para o centro metálico ${ }^{[11]}$. A transferência de energia, do cromóforo orgânico para o íon terra rara, proporciona um caminho efetivo para excitar a emissão fina e de tempo de vida longo. A excitação direta dos íons $\mathrm{TR}^{3+}$ é difícil devido à natureza proibida destas transições eletrônicas nestes íons. Uma das mais importantes aplicações dos complexos de terras raras 
é como marcadores luminescentes em diagnóstico clínico onde estes são uma alternativa às sondas radioativas ${ }^{[12-15]}$.

A espectroscopia eletrônica de absorção e emissão é uma técnica poderosa e muito útil na química de estado sólido e em solução de íons $\mathrm{TR}^{3+}$. A maior vantagem do comportamento espectroscópico dos íons $\mathrm{TR}^{3+}$ é que os elétrons $4 \mathrm{f}^{\mathrm{N}}$ interagem fracamente com os elétrons dos átomos circundantes e, conseqüentemente, as propriedades eletrônicas são apenas ligeiramente afetadas pela vizinhança química. Em particular, os orbitais 4f das espécies nos estados sólido, gasoso e em solução mantêm em grande parte, seu caráter atômico, facilitando a interpretação dos níveis de energia através de seus espectros (FIG. $1.1)^{[16-21]}$.

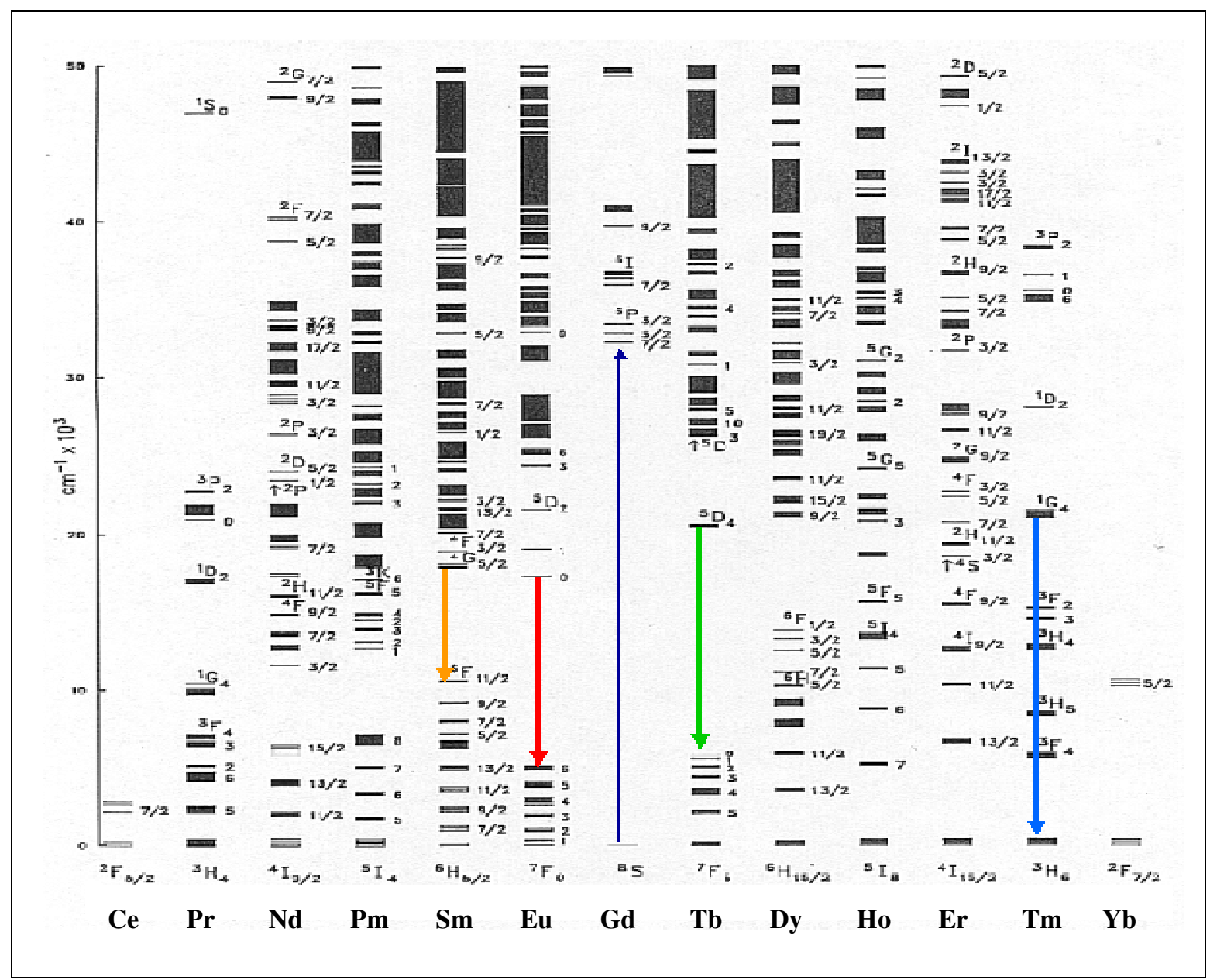

FIGURA 1.1. Estrutura dos níveis de energia para os íons terras raras baseado nas energias do campo cristalino ${ }^{[16]}$.

A pesquisa envolvendo compostos de coordenação de íons $\mathrm{TR}^{3+}$, como materiais luminescentes, tem sido alvo de interesse nestas duas últimas décadas. Isto se deve às várias aplicações encontradas para esse tipo de compostos, como por exemplo: fósforos 
eficientes, marcadores ópticos, fluoroimunoensaio, compostos bioinorgânicos fotossensíveis, eletroluminescência, sistemas ópticos de alta tecnologia e lasers ${ }^{[22-27]}$. Essas aplicações em particular, são devido à alta intensidade luminescente observadas quando estes compostos são excitados por radiação na região UV, o que os incluem na classe de Dispositivos Moleculares Conversores de Luz (DMCL).

Dentre os compostos de terras raras que apresentam luminescência; os mais

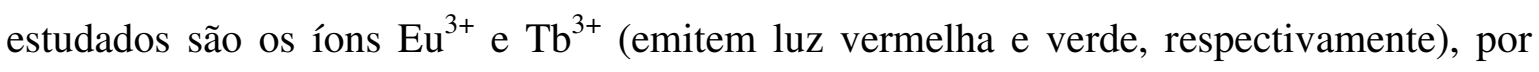
apresentarem maior intensidade luminescente na região do visível, devido às estruturas dos seus níveis de energia. Deve-se considerar, também, que existem compostos de $\mathrm{TR}^{3+}$ que emitem em outras regiões espectrais tais como: infravermelho próximo $\left(\mathrm{Yb}^{3+}, \mathrm{Nd}^{3+} \mathrm{e}^{3+}\right)$, laranja $\left(\mathrm{Sm}^{3+}\right)$, amarelo $\left(\mathrm{Dy}^{3+}\right)$, azul $\left(\mathrm{Tm}^{3+}\right)$ e UV-próximo $\left(\mathrm{Ce}^{3+} \mathrm{e} \mathrm{Gd}^{3+}\right)^{[28]}$.

A principal característica dos espectros de absorção e emissão dos íons $\mathrm{TR}^{3+}$ é a presença de bandas finas em compostos nos estados sólido (na forma de pó e cristais), gasoso e em solução. Em princípio, é possível investigar interações no estado sólido por medidas ópticas com um alto grau de precisão. Nas últimas três décadas foram preparadas centenas de compostos de $\mathrm{TR}^{3+}$ que apresentavam luminescência intensa conduzindo ao desenvolvimento de pesquisas nas áreas de simulações quantitativas das sequências de níveis de energia para configurações $\mathrm{f}^{\mathrm{N}}$, contribuindo com um grande número de parâmetros para diferentes componentes (eletrostática, covalente, etc.) em função da ligação química (circunvizinhança química). A fim de projetar marcadores ópticos, envolvendo principalmente íons európio e térbio trivalente, considera-se as seguintes características:

i) Proteção do íon $\mathrm{TR}^{3+}$ da interação com moléculas de solvente e ou grupos ligantes como os osciladores de alta freqüência;

ii) Grupos múltiplos absorvendo e transferindo energia eficientemente ao íon metálico (efeito antena);

iii) Alta estabilidade cinética;

iv) Solubilidade;

v) Baixa toxicidade se o sensor for usado "in vivo".

Os compostos de coordenação mais estudados são aqueles envolvendo os complexos que contém ligantes $\beta$-dicetonas, devido às suas habilidades de coordenação serem bem estabelecidas ${ }^{[29]}$. Vários tipos de ligantes podem formar adutos com os quelatos de $\mathrm{TR}^{3+}$ tris( $\beta$-dicetonatos), dentre eles: sulfóxidos, dimetilformamida, óxido de trifenilfosfina, 
além de heterocíclicos que tem átomos de nitrogênio (doador), tais como: piridina, 2,2'dipiridil, 1,10-fenantrolina 2,2': seis', 2',-terpiridina, entre outros ${ }^{[30-33]}$.

Com o intuito de obter materiais altamente luminescentes, têm-se preparado os sais de $\beta$-dicetonatos (ex: TTA e DBM) de terras raras hidratados, com posterior substituição das moléculas de água por ligantes (sulfóxidos, fosfinóxidos e amidas). Estes ligantes coordenados ao íon $\mathrm{TR}^{3+}$ possibilitaram uma melhor eficiência na transferência de energia ligante-metal $\left(\mathrm{L} \rightarrow \mathrm{TR}^{3+}\right)$. Esta coordenação envolve geralmente o denominado efeito antena, isto é, absorção da luz ultravioleta incidente pela parte orgânica, transferindo eficientemente energia para o centro luminescente (íons $\mathrm{TR}^{3+}$ ) e subseqüiente emissão.

A fluorescência resolvida no tempo e a labilidade dos quelatos de terras raras têm estabelecido um importante papel no desenvolvimento de novos ensaios bioanalíticos ultrasensíveis ${ }^{[34-36]}$. Durante os últimos anos, devido às características únicas dos quelatos de terras raras, uma das tendências notadas é a de produzir materiais marcados, tais como streptavidinas, que são proteínas macromoleculares conjugadas ${ }^{[37]}$, com um grau de labilidade muito alto, para detecção de compostos bioativos ou complexos poliméricos ${ }^{[38,}$ 39].

Supermoléculas de terras raras com ligantes macrocíclicos tem sido muito utilizadas como marcadores biológicos ${ }^{[40]}$, especialmente dos ligantes criptandos, devido estas cavidades protegerem os íons terras raras de interações com a água, evitando a supressão na luminescência destas espécies. Dentro da classe de ligantes encapsuladores os calixarenos apresentam um grande potencial de utilização. Os calixarenos são macrocíclicos formados de $\mathrm{n}$ unidades fenólicas ligadas entre elas por pontes metilênicas ao nível das posições "orto" da função hidroxila ${ }^{[41-43]}$. Eles geralmente são obtidos pela condensação do formaldeido por um alquil fenol em meio básico requerendo também altas temperaturas. A denominação "calixareno" foi dada por Gutshe devido à semelhança estrutural destes com um vaso grego denominado "calix crater".

Já a Espectroscopia de Absorção no Infravermelho por Transformada de Fourier (do inglês Fourier Transformed Infrared, FT-IR) é uma técnica que utiliza a região do infravermelho do espectro eletromagnético para caracterizar moléculas e biomoléculas. A chamada radiação infravermelha corresponde à parte do espectro eletromagnético situada entre as regiões do visível e das microondas, pois é onde ocorrem vibrações e torções características de diversos grupos funcionais ${ }^{[44]}$. As ligações químicas das substâncias possuem freqüências de vibração específicas, as quais correspondem a níveis vibracionais 
de energia. A radiação infravermelha provoca vibração de átomos ou grupos de átomo e estas vibrações podem ter amplitudes e freqüência diferentes. As energias de vibrações são quantizadas, ou seja, existem determinadas quantidades de energia que fazem os grupos $\operatorname{vibrar}^{[45]}$.

Nesse trabalho os esforços foram aplicados ao desenvolvimento de um material luminescente para diagnosticar a anemia falciforme.

A anemia falciforme é uma doença gênica extremamente comum do grupo das hemoglobinopatias. É causada por uma mutação no cromossomo $11^{[46]}$, determinando uma substituição do aminoácido ácido glutâmico (Glu) pela valina (Val) na posição 6 da cadeia $\beta$-globina ${ }^{[47]}$. Quando dois genes são afetados (homozigose), o indivíduo possui a anemia falciforme, contudo quando apenas um gene é afetado, ele é considerado portador da doença.

O mecanismo fisiopatológico da mutação do gene da hemoglobina normal ( $\mathrm{HbA})$ para o da hemoglobina $\mathrm{S}(\mathrm{HbS})$ ainda permanece desconhecido ${ }^{[48]}$. A anemia falciforme foi descrita em $1910{ }^{[48,49]}$ por Herrick. Provavelmente surgiu em países do centro oeste africano, da India e do leste da Ásia há cerca de 50 a 100 mil anos. Essa doença é mais freqüente em indivíduos da raça negra, mas não exclusiva, devido à miscigenação ${ }^{[50]}$. Embora não se conheça a real prevalência no mundo, estima-se que aproximadamente 7\% da população mundial seja acometida pelos transtornos das hemoglobinas ${ }^{[51,52]}$. No Brasil, provavelmente, é a doença hereditária mais prevalente ${ }^{[47]}$. Estima-se que existem pelo menos dois milhões de portadores da $\mathrm{HbS}$ - heterozigotos ${ }^{[53,54]}$. Devido a grande miscigenação populacional, a anemia falciforme afeta cerca de $0,04 \%$ da população geral e em torno de $0,1 \%$ a $0,3 \%$ da população negra. A Bahia é o estado com a maior frequiência dos casos. Acredita-se que as regiões Norte, Nordeste e Sudoeste abrigam a maior concentração da doença, uma vez que grande parte da população é de cor negra.

Na região Sudeste, a prevalência estimada de portadores (heterozigotos) é de $2 \%$ na população geral e, entre os negros, de $6 \%$ a $10 \%{ }^{[53]}$. Em Minas Gerais, foi relatada a incidência de um caso de anemia falciforme (homozigoto) para cada 2.800 nascimentos e no Rio de Janeiro, verificou-se a existência de um caso para cada 1.196 nascimentos ${ }^{[54]}$.

No Brasil o programa de doenças negligenciadas e a prevenção de doenças não transmissíveis como é o caso da anemia falciforme são fatos preocupantes.

Diante dos fatos apresentados acima, o Programa de fluoroimunoensaio da Rede de Nanotecnologia Molecular e Interfaces (RENAMI) e o laboratório de Química Supramolecular e Nanotecnologia do IPEN/CNEN-SP, vem trabalhando no intuito de 
apresentar alternativas nacionais para bioensaios barateando os custos dos exames clínicos. A substituição dos kits ou a implemetação de novos produtos no mercado tornarão esses benefícios mais acessíveis à população mais carente o que justifica os esforços nessa direção. 


\section{REFERÊNCIAS BIBLIOGRÁFICAS}

[01] SOINI, E.; HEMMILA, L.; DHALEN, P. Time-resolved fluorescence in biospecific assays. Ann. Biol. Chin., v. 48, n. 8, p. 567-571, 1990.

[02] FRITZBERG, A.R. Radiopharmaceuticals: Progress and Clinical Perpectives, Boca Raton CRC, 1986.

[03] PARKER, D. Targeting metal-complexes. Chem. Br. v. 30, n. 10, p. 818-822, 1994.

[04] SINK, R.M.; BUSTER, D.C.; SHERRY, A.D. Synthesis and characterization of a series of macrocyclic chelates containing $\mathrm{O}$-donors and $\mathrm{N}$-donors - prospects for use as NMR shift agents for alkali-metal cations. Inorg. Chem., v. 29, n. 19, p. 36453649, 1990.

[05] DICK, L.R.; GERALDES, C.F.G.C.; SHERRY, A.D.; GRAY, C.W.; GRAY, D.M. C-13 NMR of methylated lysines of FD gene-5 protein - evidence for a conformational change involving lysine-24 upon binding of a negatively charged lanthanide chelate Biochem., v. 28, n. 19, p. 7896-7904, 1989.

[06] SHERRY, A.D.; MALLOY, C.R.; JEFFREY, F.M.H.; CACHERIS, W.P.; GERALDES, C.F.G.C. Dy(DOTP)5 - a new, stable Na-23 shift-reagent. J. Mag. Reson., v. 76, n. 3, p. 528-533, 1988.

[07] BÜNZLI, J.-C. G., Lanthanoid Probes in Life. Amsterdan: Elsevier, 1989.

[08] EVANS, C.H. Biochemistry of the lanthanides, Plenum Press. New York, 1990.

[09] LEIF, R.C.; VALLARINO, L.M. Cell separation science and technology.: Washington DC: American Chemical Society, 1991.

[10] WANG K., L.; LI, R.C.; CHENG, Y.; ZHU, B. Lanthanides - the future drugs? Coord. Chem. Rev., v. 190, p. 297-308, 1999.

[11] WEISSMAN, S. I. Intramolecular energy transfer the fluorescence of complexes of europium. J. Chem. Phys., v. 10, p. 214-217, 1942.

[12] MATHIS, G. Rare-earth cryptates and homogeneous fluoroimmunoassays with human sera. Clin. Chem., v. 39, n. 9, p. 1953-1959, 1993. 
[13] MAYER, A.; NEUENHOFER, S. Luminescent labels - more than just an alternative to radioisotopes. Angew. Chem. Int. Ed. Engl., v. 33, n. 10, p. 1044-1072, 1994.

[14] HEMMILA, I. Luminescent lanthanide chelates - a way to more sensitive diagnostic methods. J. Alloys Compd. v. 225, n. 1-2, p. 480-485, 1995.

[15] DICKSON, E.F.G.; POLLAK, A.; DIAMANDIS, E. P. Time-resolved detection of lanthanide luminescence for ultrasensitive bioanalytical assays. J. Photochem. Photobiol. B Biol., v. 27, n. 1, p. 3-19, 1995.

[16] CARnAlL, W. T.; GOODMAN, G. L.; RAJANK, K. AND RANA, R. S., A systematic analysis of the spectra of the lanthanides doped into single crystal $\mathbf{L a F}_{3}$. Argonne (United States) Argonne Solution National Laboratory, 1988.

[17] WYBOURNE, B. G. Spectroscopic properties of rare earths. New York: Interscience, 1965.

[18] KRUPA, J. C.; Spectroscopic properties of tetravalent actinide ions in solids. Inorg. Chem. Acta., v. 139, n. 1-2, p. 223-241, 1987.

[19] CARNALL, W.T.; CROSSWHITE, H.; The chemistry of the actindes elements. New York Chapman and Hall, 1986.

[20] BRITO, H.F.; LIU, G.K. Crystal field influence on the S-8(7/2) ground state splitting of Bk4+ in CeF4. J. Chem. Phys., v. 112, n. 9, p. 4334-4341, 2000.

[21] CARNALL, W. T., A systematic analysis of the spectra of trivalent actinide chlorides in D3h site symmetry. J. Chem. Phys., v. 96, n. 12, p. 8713-8726, 1992.

[22] HEMMILA, I.; MUKKALA, V. M.; TAKALO, H.; Development of luminescent lanthanide chelate labels for diagnostic assays. J. Alloys Compd., v. 249, n. 1-2, p. 158-162, 1997.

[23] KAWA, M.; FRECHET, J.M.J. Self-assembled lanthanide-cored dendrimer complexes: enhancement of the luminescence properties of lanthanide ions through site-isolation and antenna effects. Chem. Mat., v. 10, n. 1, p. 286-296, 1998.

[24] ELBANOWSKI, M.; MAKOWSAKA, B. The lanthanides as luminescent probes in investigations of biochemical systems. J. Photochem. Photobiol. A-Chem., v. 99, n. 2-3, p. 85-92, 1996.

[25] MATSUMOTO, K.; YUAN; J.G.; WANG, G.L.; KIMURA, H. Simultaneous determination of alpha-fetoprotein and carcinoembryonic antigen in human serum by time-resolved fluoroimmunoassay. Anal. Biochem., v. 276, n. 1, p. 81-87, 1999.

[26] YUAN, J.L.; MATSUMOTO, K.; KIMURA, H.; A new tetradentate beta-diketonateeuropium chelate that can be covalently bound to proteins for time-resolved fluoroimmunoassay. Anal. Chem., v. 70, n. 3, p. 596-601, 1998.

[27] YUAN, J.L.; MATSUMOTO, K. Functionalization of fluorescent lanthanide complexes and their applications to biotechnology. Bunseki Kagaku, v. 48, n. 12, p. 1077-1083, 1999. 
[28] SÁ, G.F.; MALTA, O.L.; DONEGA, C.M.; SIMAS, A.M.; LONGO, R.L.; SANTACRUZ, P. A.; SILVA JR., E.F.; Spectroscopic properties and design of highly luminescent lanthanide coordination complexes. Coord. Chem. Rev., v. 196, 165$195,2000$.

[29] MEHROTRA, R.C.; BOHRA, R.; GAUR, D.P. Metal $\boldsymbol{\beta}$-diketonates and allied derivatives. New York: Academic Press, 1978.

[30] BRECHER, C.; SAMELSON, H.; LEMPICKI, A. Laser phenomena in europium chelates .3. Spectroscopic effects of chemical composition and molecular structure J.Chem.Phys., v. 42, n. 3, p. 1081, 1965.

[31] SINHA, A.P.B. Spectroscopy in Inorganic Chemistry. London: Academic Press, 1971.

[32] BLASSE, G.; GRABMAIER, B. C. Luminescent materials. Heidelberg: Springer Verlag, 1994.

[33] LIS, S.; ELBANOWSKI, M.; MAKOWSKA, B.; HNATEJKO, Z. Energy transfer in solution of lanthanide complexes. J. Photochem. Photobiol. A-Chem., v. 150, n. 13, p. 233-247, 2002.

[34] KRICKA L.J.; Selected strategies for improving sensitivity and reliability of immunoassays. Clin Chem., v. 40, n. 3, p. 347-357, 1994.

[35] HEMMILA, I.; MUKKALA, V.M. Time-resolution in fluorometry technologies, labels, and applications in bioanalytical assays. Crit. Rev. Clin. Lab. Sci., v. 38, n. 6, p. 441-519, 2001.

[36] DICKSON, E.F.G.; POLLAK A.; DIAMANDIS E.P. Time-resolved detection of lanthanide luminescence for ultrasensitive bioanalytical assays. J Photochem Photobiol B Biol., v. 27, n. 1, p. 3-19, 1995.

[37] MORTON, R.C.; DIAMANDIS, E.P. Streptavidin-based macromolecular complex labeled with a europium chelator suitable for time-resolved fluorescence immunoassay applications. Anal. Chem., v. 62, n. 17, p. 1841-1845, 1990.

[38] SCORILAS, A., BJARTELL, A.; LILJA, H., MOLLER, C.; DIAMANDIS, E.P. Streptavidin-polyvinylamine conjugates labeled with a europium chelate: applications in immunoassay, immunohistochemistry and microarrays. Clin Chem., v. 46, n. 9, p. 1450-1455, 2000.

[39] QIN, Q.P.; LOVGREN, T.; PETTERSSON, K.; Development of highly fluorescent detection reagents for the construction of ultrasensitive immunoassays. Anal Chem., v. 73, n. 7, p. 1521-1529, 2001.

[40] MATHIS G. Rare earths. Madri: Editorial Complutense, 1998.

[41] VICENS, J., BÖHMER, V. Calixarenes: a versatile class of macrocyclic compounds. Kluwer: Academic Publishers, 1991.

[42] GUTSCHE, C. D. Calixarenes Cambridge: Royal Society of Chemistry, 1989. 
[43] FELINTO, M.C.F.C.; ALMEIDA,V.F. Solvent extraction separation of uranium (VI) with acetatecalix[n]arene and beta-diketone (HTTA). J. Alloys Comp., v. 303, p. 524-528, 2000.

[44] PAVIA, D. L.; LAMPMAN, G. M.; KRIZ, G. S.; VYVYAN J. A.; Introduction to Spectroscopy (2000), Brooks/Cole Pub Co: 3-12.

[45] SILVERSTEIN, R. M.; KIEMLE, D. J.; WEBSTER, F. X.; Identificação Espectrométrica de Compostos Orgânicos (2000), LTC: 60-74.

[46] SAIZ, A; RODRIGUEZ, J. A. Respuesta inmune humoral anti-streptococcus pneumoniae en pacientes con anemia de celulas falciformes: Descripcion de un caso. Rev. Asoc. Colomb. Alerg. Inmunol;8(3):54-54, sept. 1999.

[47] BANDEIRA FMGC, LEAL MC, SOUZA RR, FURTADO VC, GOMES YM, MARQUES NM. Características de recémnascidos portadores de hemoglobina $S$ detectados através de triagem em sangue de cordão umbilical. J Pediatr (Rio de J). 1999;75(3):167-71.

[48] GALIZA NETO, GENTIL CLAUDINO DE et al. Análise dos haplótipos do gene da SS-globina no Ceará . J. Bras. Patol. Med. Lab., Out 2005, vol.41, no.5, p.315-321.

[49] GÓMEZ-CHIARI M, PUIGBERT JT, ARAMBURU JO. Drepanocitosis: experiência de um centro. An Pediatr. 2003;58:95-9.

[50] WHO. Working Group - Hereditary anemias: genetics basis, clinical features, diagnosis and treatment. Bull WHO, v. 60, p. 643-60, 1982.

[51] BOK YOO, HUGO HYUNG et al. Síndrome aguda do tórax como primeira manifestação de anemia falciforme em adulto. J. Pneumologia, Jul. 2002, vol.28, no.4, p.237-240.

[52] WEATHERALL DJ, CLEGG JB. Inherited haemoglobin disorders: an increasing global health problem. Bull World Health Organ 2001;79(8):704-12.

[53] PAIXÃO MC, CUNHA FERRAZ MH, JANUARIO JN, VIANA MB, LIMA JM. Realibility of isoelectrofocusing for the detection of $\mathrm{Hb} \mathrm{S}, \mathrm{Hb} C$, and $\mathrm{Hb} \mathrm{D}$ in a pioneeringpopulation-based program of the newborn screening in Brazil. Hemoglobin 2001;25(3):297-303.

[54] LOBO CLC, BUENO LM, MOURA P, OGEDA LL, CASTILHO S, CARVALHO SMF. Triagem neonatal para hemoglobinopatias no Rio de Janeiro, Brasil. Ver Panam Salud Pública 2003;13:154-9. 


\subsection{OBJETIVOS}

O presente trabalho teve como objetivo geral estudar e desenvolver supermoléculas de $\beta$-dicetonatos de lantanídeos com macrocíclicos para serem utilizadas como marcadores na detecção de Hemoglobina $\mathrm{S}$ em amostras sanguíneas. Com o desenvolvimento de nanomateriais luminescentes para aplicação em ensaios biológicos para diagnóstico, serão avaliadas as propriedades luminescentes das supermóleculas em estado sólido e solução e sua capacidade de atuação como marcador de aminoácidos.

Como objetivos específicos do projeto tem-se:

- A síntese e caracterização dos nanomateriais luminescentes.

- A avaliação das suas propriedades espectroscópicas em estado sólido e em solução.

- A conjugação destes materiais aos analitos alvo e avaliação de sua capacidade de atuação como biomarcadores;

- Análises de FT-IR para quantificação de Hemoglobina S.

O presente estudo almeja contribuir originalmente para produção de diagnósticos, com a finalidade de formular políticas públicas para o desenvolvimento econômico, cultural e social. 


\subsection{REVISÃO DA LITERATURA}

\subsection{As Terras Raras}

A Comissão de Nomenclatura em Química Inorgânica da IUPAC (International Union of Pure and Applied Chemistry) recomenda a expressão "metais de terras raras" para os elementos Sc, Y e de La a Lu (a palavra "rara" refere-se ao processo de difícil separação destes elementos). Enquanto que o termo "série do lantânio" é reservado para os elementos de número atômico de 57 a 71 (La a Lu) a expressão "série lantanídica" é ainda mais restrita porque exclui o elemento lantânio, indo do elemento de número atômico 58 ao elemento de número atômico 71. Justifica-se a inclusão do Sc na série das terras raras devido sua similaridade química, embora sua estrutura eletrônica seja bem diferente.

Caracteriza-se a série lantanídica pelo preenchimento sucessivo e progressivo dos orbitais internos $4 \mathrm{f}$. No estado metálico estes elementos possuem o caráter eletrônico do xenônio: [Xe] $=1 s^{2} 2 s^{2} 2 p^{6} 3 s^{2} 3 p^{6} 3 d^{10} 4 s^{2} 4 p^{6} 4 d^{10} 5 s^{2} 5 p^{6}$ e apresentam no estado fundamental a seguinte configuração eletrônica: [Xe] $4 \mathrm{f}^{n-1} 5 \mathrm{~d}^{1} 6 \mathrm{~s}^{2}$ (La, Ce, Gd, e Lu) e [Xe] $4 \mathrm{f}^{n} 6 \mathrm{~s}^{2}$ para os demais elementos da série.

O fenômeno da contração lantanídica surge devido à blindagem imperfeita que um elétron $4 \mathrm{f}$ exerce sobre outro elétron $4 \mathrm{f}$ produzindo um aumento de carga nuclear efetiva e consequentemente uma redução no raio com o aumento do número atômico. No caso dos íons $\mathrm{Ln}^{3+}$ existe uma diminuição dos seus raios ao longo da série em aproximadamente $22 \%$, causando diferenças apreciáveis nas suas propriedades ${ }^{[1-7]}$, tais como: diminuição do número de coordenação; aumento do caráter ácido; diminuição da temperatura de decomposição; decréscimo do caráter iônico; maior estabilidade do estado de oxidação $3^{+}$.

O principal fator que distingue os íons $\mathrm{Ln}^{3+}$ dos outros íons metálicos é o fato de que seus elétrons de valência se encontram nos orbitais $4 \mathrm{f}$, que são mais internos e estão blindados pelas camadas 5 s e 5 p, conferindo-lhe uma química de natureza iônica. Fatores 
eletrostáticos e considerações estéricas parecem ser mais importantes na determinação da estabilidade, estrutura e química dos complexos de lantanídeos, do que as interações entre orbitais do metal e do ligante ${ }^{[1-8]}$.

Os íons lantanídeos absorvem radiação eletromagnética na região espectral que se estende do ultravioleta próximo, passando pelo visível, até o infravermelho próximo. As transições eletrônicas que ocorrem nestas regiões espectrais como resultado das subcamadas $4 \mathrm{f}$ incompletas, são as transições internas $4 \mathrm{f} \rightarrow 4 \mathrm{f}$, transição $4 \mathrm{f}^{n} \rightarrow 4 \mathrm{f}^{n-1} 5 \mathrm{~d}$, ou transição de transferência de carga ${ }^{[9]}$ dependendo do centro metálico e de seu estado de oxidação, bem como do ligante em questão.

Os íons lantanídeos apresentam um potencial iônico relativamente baixo, caracterizando uma polarizabilidade baixa, fato este que se reflete na interação metalligante, induzindo um caráter predominantemente iônico à ligação. Os tamanhos radiais dos íons $\operatorname{Ln}^{3+}$ levam os complexos a apresentarem número de coordenação variando de 6 a 12 (solução e estado sólido), sendo os números 8 e 9 os mais comumente observados ${ }^{[4]}$.

Os íons lantanídeos podem ser considerados como ácidos "duros" de acordo com a classificação de PEARSON ${ }^{[10]}$. Íons que apresentam esta propriedade, tendem a ligar-se à bases "duras", especialmente aquelas que contêm oxigênio e/ou nitrogênio como átomos doadores.

A blindagem efetiva dos elétrons $4 \mathrm{f}$ pela camada $5 \mathrm{~s}^{2} 5 \mathrm{p}^{6}$ faz com que os estados das configurações $4 \mathrm{f}^{\mathrm{n}}$ sejam pouco afetados pela vizinhança química ao redor dos íons lantanídeos tripositivos ${ }^{[11]}$. O orbital 4f das espécies no estado sólido mantém, em grande parte, seu caráter atômico, facilitando a interpretação dos níveis de energia através de seus espectros (FIG. 3.1).

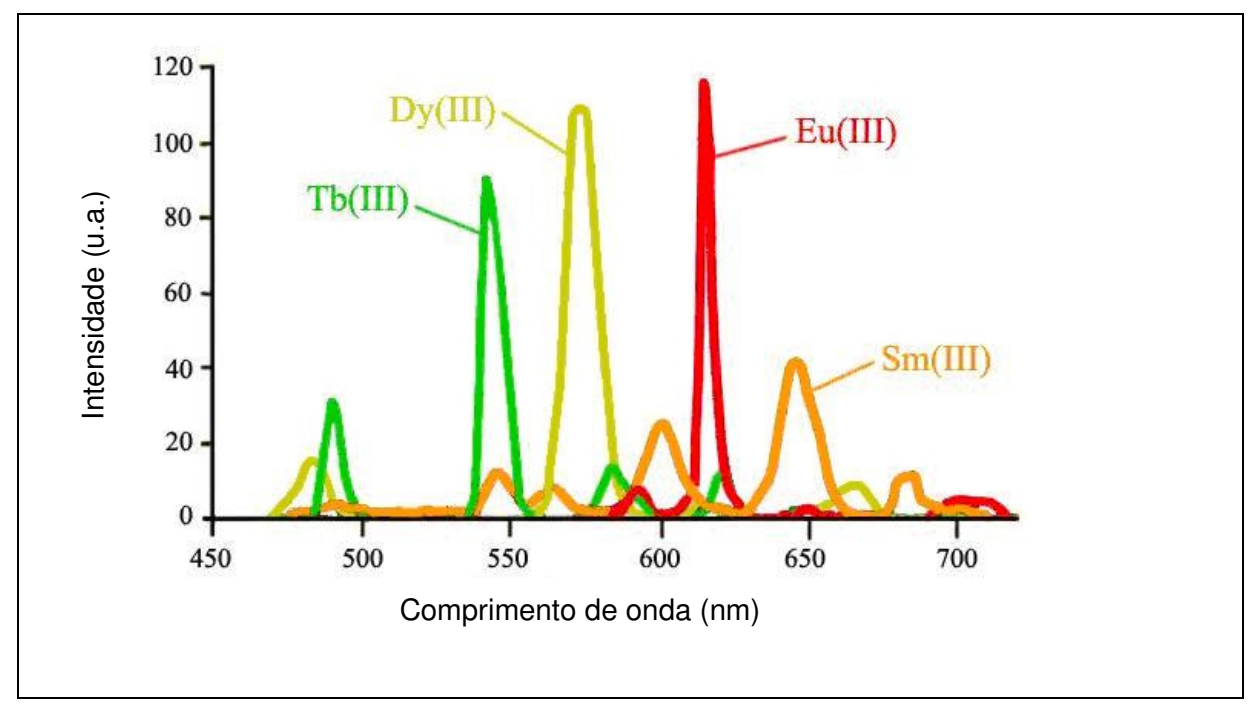

FIGURA 3.1. Espectros de emissão de alguns íons lantanídeos. 


\subsection{Espectro de emissão na região do visível}

Materiais luminescentes são compostos capazes de emitir radiações quando submetidos à excitação por radiação ultravioleta, raios $\mathrm{X}$, bombardeamento de elétrons, fricção ou alguma outra forma de excitação ${ }^{[9,10]}$.

A fotoativação conduz moléculas a estados eletrônicos excitados e estas, ao voltarem para o estado fundamental, são desativadas por processos físicos e químicos. Os processos físicos podem ser divididos em radiativos e não radiativos e classificados como processos de relaxação intramolecular ou intermolecular. Entre os processos radiativos incluem-se a luminescência (fosforescência e fluorescência) e transferência de energia. Nos processos não radiativos estão incluídos a relaxação vibracional (molecular e de rede), a conversão interna, o cruzamento intersistema e as transferências de energia por ressonância ou troca ${ }^{[12-14]}$.

Quando um quantum de luz incide sobre uma molécula este é absorvido em cerca de $10^{-15}$ segundos, acontecendo uma transição ao estado eletrônico mais alto. Esta absorção de radiação é altamente específica, sendo absorvida apenas por uma estrutura característica.

Neste processo, a molécula é levada a um estado singleto excitado $S_{1}, S_{2}, S_{3}$, etc. Estas transições de absorção normalmente originam-se no nível vibracional mais baixo do estado eletrônico fundamental ${ }^{[15]}$.

Na FIG. 3.2 representa-se o diagrama de Jablonski mostrando os processos de fluorescência e fosforescência molecular. Neste diagrama estão representados os principais níveis de energia eletrônicos e vibracionais das moléculas poliatômicas e as relaxações radiativas e não radiativas. Este diagrama também é utilizado para entendimento de sistemas inorgânicos ${ }^{[12]} \mathrm{e}$, atualmente, de supermoléculas ${ }^{[14]}$.

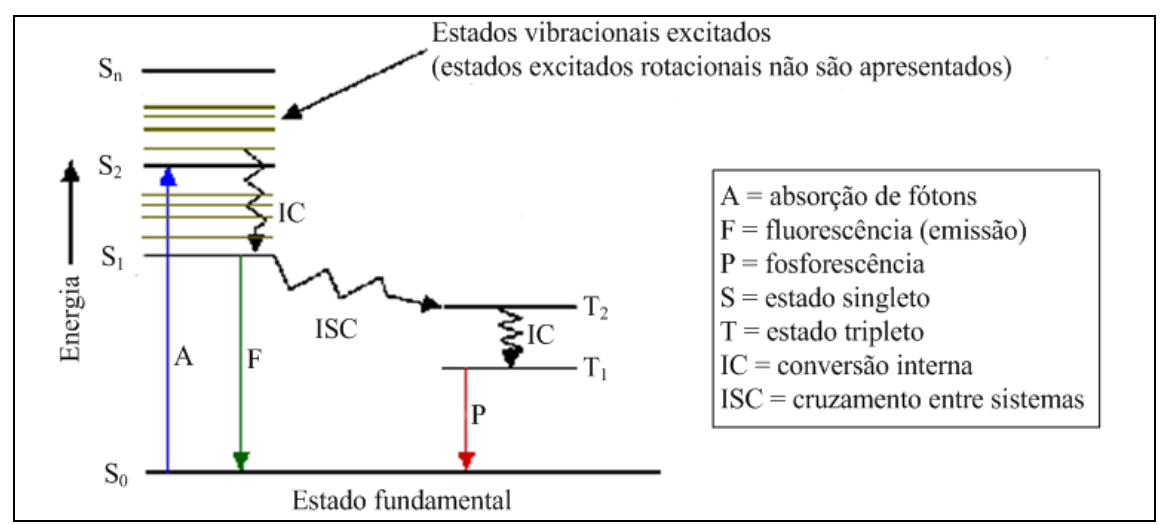

FIGURA 3.2. Diagrama esquemático mostrando os principais processos de decaimento de moléculas poliatômicas. 
As multiplicidades de estados são importantes nos processos de relaxação radiativa uma vez que a natureza do processo de emissão depende delas.

A molécula pode estar no estado excitado durante um período de $10^{-4}$ segundos, no qual qualquer energia em excesso é rapidamente dissipada e o nível vibracional mais baixo do estado singleto excitado $\left(S_{1}\right)$ é atingido. Se a energia absorvida na transição não for dissipada por colisões com outras moléculas, o elétron retorna ao estado fundamental $\left(\mathrm{S}_{0}\right)$ com emissão de energia. Geralmente, quando os estados eletrônicos, onde se origina e termina a emissão, tem a mesma multiplicidade $(\Delta S=0)$, a luminescência é chamada de fluorescência. Este processo, comumente, ocorre entre o primeiro estado singleto excitado $\left(S_{1}\right)$ e o singleto fundamental $\left(S_{0}\right)$. Como parte da energia absorvida é perdida no breve período anterior à emissão, a energia emitida tem um comprimento de onda maior que o comprimento de onda da energia absorvida.

Se os estados nos quais a emissão se inicia e termina apresentam multiplicidade de spin diferente $(\Delta S \neq 0)$, o processo é chamado fosforescência. Tal fenômeno envolve um cruzamento intersistema (processo não radiativo), visto que a transição do estado fundamental ao estado tripleto excitado é proibida (altamente improvável), com emissão do primeiro estado tripleto excitado, $\mathrm{T}_{1}$, ao estado singleto fundamental, $\mathrm{S}_{0}{ }^{[14-16]}$.

Para os processos não radiativos envolvendo estados eletrônicos diferentes duas denominações são utilizadas: conversão interna, se os estados têm a mesma multiplicidade de spin e, conversão intersistema, para o estado com multiplicidades de spin diferentes.

Estes processos dependerão das posições relativas dos diferentes níveis de energia eletrônica em energia vibracional (relaxação vibracional).

É comum se fazer à distinção entre fluorescência e fosforescência baseando-se no tempo de vida da emissão. Como as transições permitidas ocorrem somente para $\Delta \mathrm{S}=0$, tempos de vida de emissão da ordem de $10^{-10}$ a $10^{-7}$ segundos são observados na fluorescência, enquanto que tempos de vida da ordem de $10^{-3}$ a 10 segundos são observados na fosforescência ${ }^{[12,14-16]}$. O critério que utiliza regras de seleção é preferencialmente empregado, ou seja, iguais multiplicidades de spin (fluorescência) e diferentes multiplicidades de spin (fosforescência) ${ }^{[12]}$, embora o termo geral luminescência evite confusões.

Emissões de estados eletrônicos diferentes do estado excitado mais baixo de uma dada multiplicidade são raros em sistemas orgânicos e inorgânicos, ocorrendo predominantemente desativação não radiativa ${ }^{[17]}$. 
DEMAS ${ }^{[17]}$ faz comparações entre sistemas orgânicos e inorgânicos tanto para processos radiativos como para processos não radiativos. Quando não há variação nas multiplicidades de spin as velocidades dos sistemas são semelhantes. Mas, se $\Delta S \geq 1$ as constantes de velocidade são muito diferentes. Estas diferenças se justificam pela relaxação das regras de seleção (principalmente a regra de spin), devido às constantes de acoplamento spin-órbita (íons metálicos que têm maiores número atômicos), que provocam misturas dos estados singleto e tripleto. Nos sistemas orgânicos que contêm átomos com baixos números atômicos os cruzamentos intersistema são formalmente proibidos.

Um diagrama esquemático apresentado na FIG. 3.3, ilustra as curvas de energia potencial de estados eletrônicos, fundamental e excitado em função da distância internuclear e pode ser usado como modelo para sólidos luminescentes ${ }^{[1,18-19]}$. Estes modelos são baseados no que se denomina diagrama de coordenadas configuracionais e representam a energia potencial $(\mathrm{E})$ do centro luminescente em função da distância (R) deste centro aos íons ao seu redor, nos estados fundamental e excitado. No diagrama representa-se o estado eletrônico fundamental por " $\mathrm{S}_{0}$ " e o estado eletrônico excitado é " $\mathrm{S}_{1}$ ". As linhas horizontais indicam os níveis vibracionais.

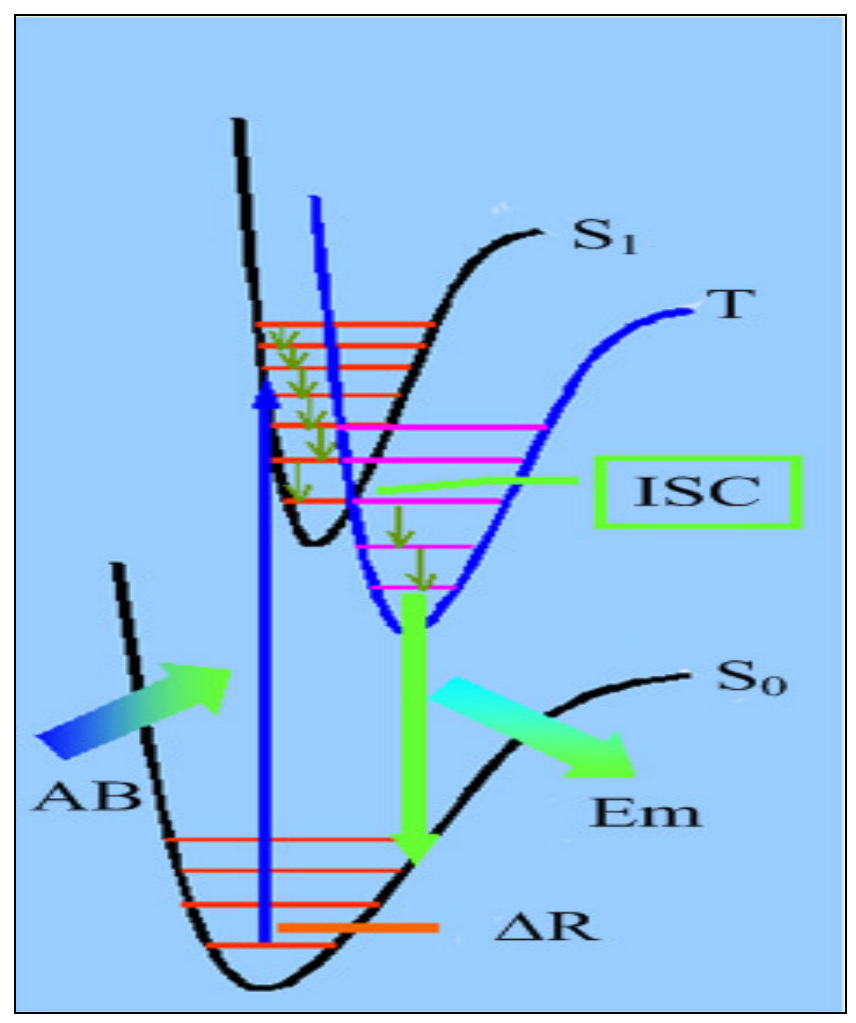

FIGURA 3.3. Diagrama de coordenada configuracional. 
A absorção óptica $(\mathrm{AB})$ corresponde à transição do estado eletrônico fundamental " $\mathrm{S}_{0}$ " ao estado excitado " $\mathrm{S}_{1}$ ". A emissão $(\mathrm{Em})$ é a transição reversa. Quando $\Delta \mathrm{R} \neq 0$, a emissão mostra um deslocamento Stokes, ou seja, o comprimento de onda da emissão é maior do que o comprimento de onda de absorção.

A transição de absorção a temperaturas baixas se dá no nível vibracional mais baixo $(\mathrm{n}=0)$ em " $\mathrm{S}_{0}$ ”, começando com o valor $\mathrm{R}_{0}$. Esta transição está indicada pela linha $\mathrm{AB}$ na FIG. 3.3 e corresponde ao máximo da banda de absorção. Entretanto, pode-se começar em valores de $\mathrm{R}$ diferentes de $\mathrm{R}_{0}$, embora a probabilidade seja menor, levando a $\mathrm{um}$ alargamento da banda de absorção. O estado excitado " $\mathrm{S}_{1}$ " é atingido após absorção de radiação com energia apropriada (normalmente na região do ultravioleta) e a seguir, por relaxação, decai até o nível vibracional mais baixo do estado excitado, dissipando o excesso de energia como calor da rede cristalina. Deste estado ou níveis próximos, o sistema retorna ao estado eletrônico " $\mathrm{S}_{0}$ " emitindo radiação que é caracterizado no espectro por uma banda larga. Finalmente, o sistema relaxa ao nível vibracional mais baixo " $\mathrm{S}_{0}$ ".

As bandas de emissão situam-se numa região de menor energia do que as de absorção. Este deslocamento é conhecido como deslocamento Stokes, sendo uma conseqüência direta dos processos de relaxação que ocorrem após a transição óptica. Apenas as transições zero-fônon, ou seja, aquelas dos níveis vibracionais mais baixos dos estados eletrônicos " $\mathrm{S}_{0}$ " $(\mathrm{n}=0)$ e " $\mathrm{S}_{1}$ ” (n'=0), ocorrem com a mesma energia nos espectros de absorção e emissão. Nesta consideração, bandas de emissão em espectros atômicos são encontradas apenas quando as curvas de coordenada configuracional são idênticas quanto à forma e têm a mesma distância de equilíbrio como no caso dos íons terras raras ${ }^{[1,18,20-21]}$.

Processo não radiativo do estado eletrônico excitado ao fundamental é possível através do ponto de interseção ISC entre as curvas. Desta forma, através do diagrama de coordenadas configuracionais pode-se entender a supressão térmica na emissão, pois o centro luminescente pode ocupar um nível vibracional mais alto, situado no ponto de interseção ISC, através do fornecimento de energia de ativação, $\Delta \mathrm{E}$, com o aumento de temperatura. Nessa situação, o sistema retorna ao estado eletrônico fundamental de forma não radiativa, dissipando calor no processo ${ }^{[1]}$. Para sistemas deste tipo quanto menor a temperatura, maior a intensidade de emissão. 


\subsubsection{Luminescência dos íons Terras Raras}

A luminescência dos íons $\mathrm{TR}^{3+}$ consiste de bandas de emissão finas (correspondentes às transições internas f-f-), do tipo espectros atômicos, pois os estados eletrônicos são minimamente afetados pela vizinhança química ao centro metálico, uma vez que os elétrons 4f são blindados pelo arranjo $5 \mathrm{~s}^{2} 5 \mathrm{p}^{6}$. Desta forma, as propriedades dos íons terras raras são quase sempre mantidas após a formação de compostos com ligantes orgânicos, ao contrário do que ocorre com os compostos de metais de transição. Os espectros de fluorescência comparam-se aos espectros de absorção, estando ambos ligados a esta blindagem experimentada pelos orbitais $4 \mathrm{f}$ e, portanto, nem todas as transições possíveis resultam em fluorescência, enfatizando a importância dos efeitos relacionados ao ambiente químico e os efeitos de simetria ${ }^{[4,22-23]}$.

Os íons $\mathrm{TR}^{3+}$, particularmente aqueles do meio da série, tais como samário, európio, térbio e disprósio, formam complexos que quando submetidos à excitação na região ultravioleta próxima ${ }^{[4,21-23]}$ freqüentemente emitem na região do visível, devido às transições internas f-f.

A fluorescência característica dos quelatos de terras raras pode ocorrer a partir ${ }^{[23-24]}$ do ligante excitado perturbado pelo cátion; do cátion excitado perturbado pelo ligante; da transferência de energia intramolecular não radiativa do ligante excitado ao cátion, e posterior emissão.

A excitação eletrônica de compostos de terras raras ao estado singleto excitado mais baixo $\left(S_{1}\right)$ de um ligante resulta na observação de luminescência e, este fenômeno consiste de fluorescência molecular, fosforescência molecular e emissão correspondente às transições internas f-f (FIG. 1.1).

\subsubsection{Efeito antena}

O processo de sensibilização da luminescência de compostos de coordenação de íons $\mathrm{TR}^{3+}$ foi reportado primeiramente por WEISSMAN em $1942^{[25]}$, que demonstrou que sob excitação na região de absorção dos ligantes estes sistemas exibiam emissões características do íon metálico central. Notou-se que um ligante orgânico apresentando alto coeficiente de absortividade molar, quando coordenado ao íon metálico é capaz de transferir energia eficientemente para o íon terra rara, intensificando sua luminescência. Além disso, o ligante pode ser escolhido no sentido de fornecer ao sistema determinada 
funcionalidade com desejadas propriedades, tais como: solubilidade, atividade eletroquímica, afinidade de ligação a outros sistemas moleculares, respostas a estímulos externos, etc ${ }^{[11,26]}$.

Nos estudos sobre os processos de transferência de energia intramolecular, três mecanismos pelos quais a energia absorvida pelo ligante pode ser transferida para $\mathrm{o} \mathrm{TR}^{3+}$ têm sido propostos ${ }^{[25-26]}$. Estes mecanismos estão ilustrados na FIG. 3.4.

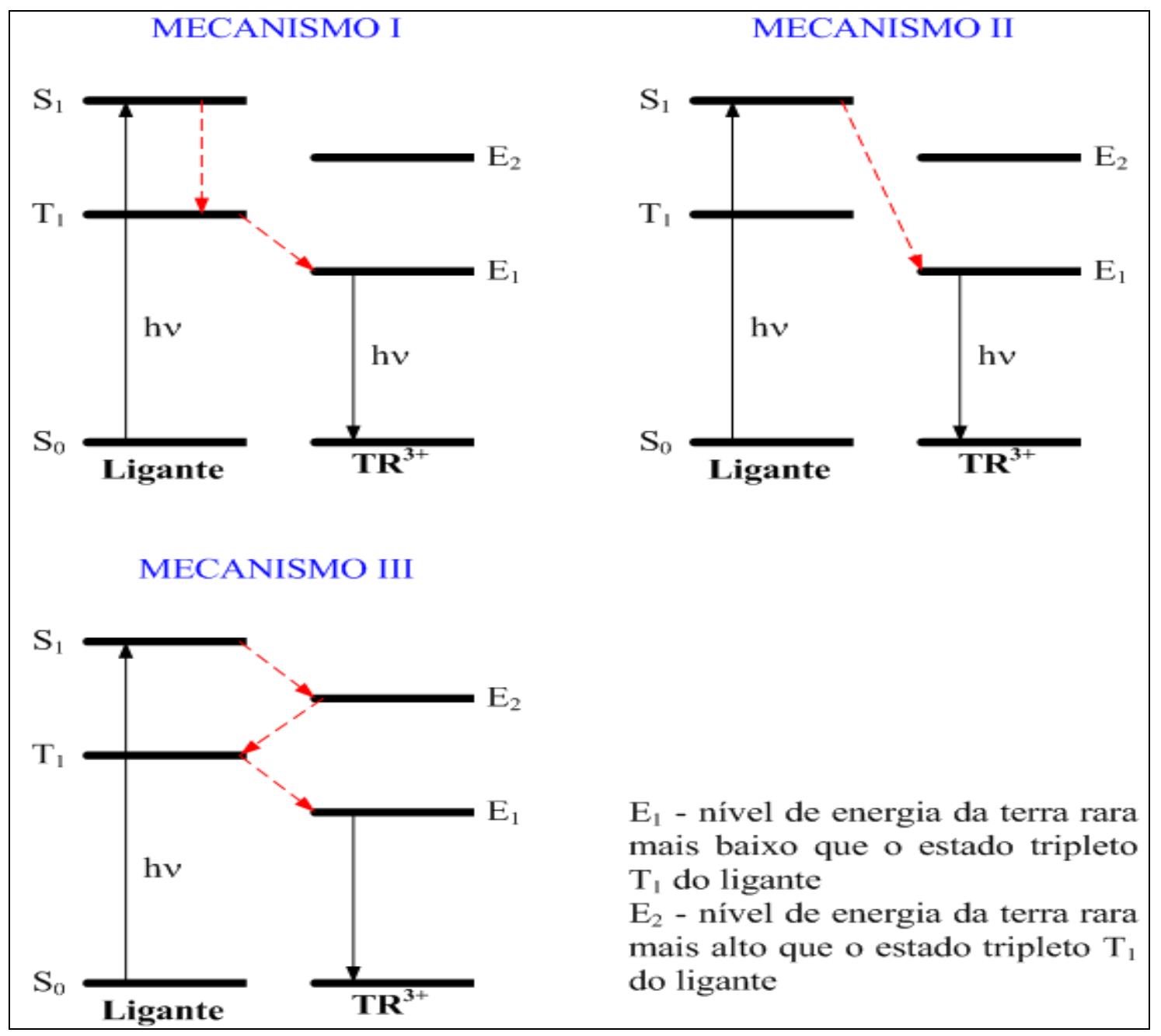

FIGURA 3.4. Mecanismos para transferência de energia intramolecular em quelatos de lantanídeos ${ }^{[29]}$.

Mecanismo I - A energia é absorvida pelo ligante (FIG. 3.4) para o estado excitado (singleto, S1) que após cruzamento intersistema para o estado tripleto (T), ocorre transferência de energia Ligante- $\mathrm{TR}^{3+}$ a partir do primeiro estado excitado $\mathrm{T}$ para o nível emissor $\left(\mathrm{E}_{1}\right)$ do íon $\mathrm{TR}^{3+}$. Posteriormente, ocorre emissão de luz através das transições intraconfiguracionais $4 \mathrm{f}^{\mathrm{N}}$ característica do íon $\mathrm{TR}^{3+[27-29]}$. 
Mecanismo II - Neste caso, o estado T não participa do processo de transferência de energia (FIG 3.4) sendo considerado apenas a transferida de energia diretamente do estado excitado $\mathrm{S}_{1}$ para o nível emissor $\left(\mathrm{E}_{1}\right)$ do íon $\mathrm{TR}^{3+}$, FIG. $3.4^{[30]}$.

Mecanismo III - Observa-se na FIG. 3.4 que além dos níveis de energias já considerados $\left(S_{1}, T\right.$ e $\left.E_{1}\right)$, existe a participação de um nível excitado $\left(E_{2}\right)$ do íon $\mathrm{TR}^{3+}$ com energia maior do que a do estado T. O processo de transferência de energia é então descrito pelas seguintes etapas: i) transferência de energia do estado $S_{1}$ para o nível excitado $E_{2}$ do metal; ii) transferência de energia do nível $\mathrm{E}_{2}\left(\mathrm{TR}^{3+}\right)$ para o estado tripleto $\mathrm{T}$ do ligante e iii) transferência de energia do estado $\mathrm{T}$ para o nível $\mathrm{E}_{1}$ do íon $\mathrm{TR}^{3+}{ }^{331]}$.

Como pode ser observado na FIG. 3.4, os estados eletrônicos do ligante (antena) e dos íons terras raras podem ser descritos separadamente, desde que a interação (covalente) entre o ligante e o íon $\mathrm{TR}^{3+}$ é muito fraca, conduzindo somente a pequenas misturas de seus estados.

Apesar do mecanismo I mostrar-se mais concordante com os resultados experimentais, a existência de estados $\mathrm{T}$ com energias acima do nível excitado Em do íon $\mathrm{TR}^{3+}$ pode promover uma transferência de energia $\mathrm{T} \rightarrow \mathrm{E}_{2}$. Deve-se considerar ainda que adicionalmente aos processos descritos nos mecanismos supracitados, outros processos fotofísicos podem ocorrer nos sistemas promovendo relaxações eletrônicas, dentre estes se destacam:

i) Fluorescência do ligante resultante de uma transição $S_{1} \rightarrow S_{0}$;

ii) Decaimento não radiativo via mecanismos de conversão interna do estado $S_{1}$ para o estado $\mathrm{S}_{0}$;

iii) Decaimento não radiativo do estado $\mathrm{T}$ excitado para o estado fundamental $\mathrm{S}_{0}$ via cruzamento intersistema;

iv) Fosforescência via transição do estado tripleto para o estado fundamental $S_{0}$.

Observa-se que nos complexos com íons terras raras, a fosforescência dos ligantes sensibilizadores (antenas) seja observada quando os níveis excitados do íon metálico central estão localizados energeticamente acima do primeiro estado excitado $\mathrm{T}$ do ligante (ex.: íon $\mathrm{Gd}^{3+},{ }^{8} \mathrm{~S}_{7 / 2} \rightarrow{ }^{6} \mathrm{P}_{7 / 2} \sim 32.000 \mathrm{~cm}^{-1}$ ) ou quando os íons $\mathrm{TR}^{3+}$ não apresentarem elétrons $4 \mathrm{f}$ opticamente ativos (ex.: $\mathrm{La}^{3+} \mathrm{e} \mathrm{Lu}^{3+}$ ). No entanto, quando existe ligantes onde o estado $\mathrm{T}$ com energia acima dos níveis emissores dos íons $\mathrm{TR}^{3+}$ a transferência de energia intramolecular Ligante-metal é geralmente operante resultando na luminescência oriunda 
do íon terra rara. Deve-se salientar que, sob excitação indireta (via ligante) a transferência de energia Ligante-Metal está intimamente relacionada com a posição dos estados $\mathrm{T}$ da antena e dos níveis excitados do íon $\mathrm{TR}^{3+}{ }^{[21]}$.

A FIG. 3.5 ilustra os principais processos fotofísicos envolvendo mecanismos de transferência de energia intramolecar em compostos de coordenação contendo íons $\mathrm{TR}^{3+}$. Estes processos estão consistentes com os estudos experimentais e teóricos ${ }^{[32]}$.

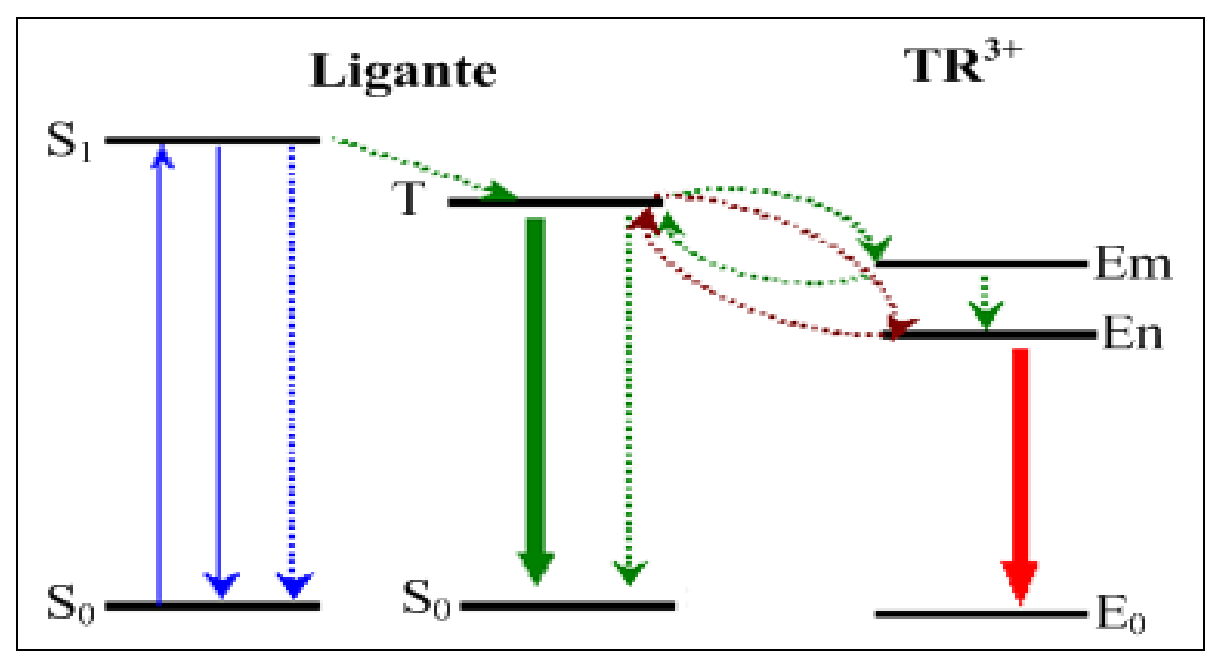

FIGURA 3.5. Diagrama hipotético de níveis de energia usados para descrever o mecanismo de transferência de energia Ligante-TR ${ }^{3+}$.

Na FIG. 3.5 as setas sólidas representam os processos radiativos e as pontilhadas estão associadas aos processos de decaimento não radiativos ${ }^{[34]}$.

Do ponto de vista da luminescência do íon metálico, os íons $\mathrm{TR}^{3+}$ coordenados têm sido classificados em três grupos ${ }^{[21]}$ :

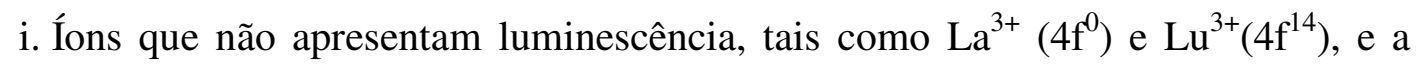
aqueles no qual este fenômeno é raramente observado por apresentarem os estados excitados em alta energia, $\mathrm{Gd}^{3+}\left(4 \mathrm{f}^{7}\right)$;

ii. Íons que exibem luminescência intensa por apresentarem níveis de energia abaixo dos estados tripletos dos ligantes e, adicionalmente, apresenta grande diferença de energia entre os níveis excitados e fundamentais $\left(\mathrm{Sm}^{3+}, \mathrm{Eu}^{3+}, \mathrm{Tb}^{3+} \mathrm{e}\right.$ $\left.\mathrm{Dy}^{3+}\right)$

iii. Aqueles íons, tais como: $\mathrm{Pr}^{3+}, \mathrm{Nd}^{3+}, \mathrm{Ho}^{3+}, \mathrm{Er}^{3+}, \mathrm{Tm}^{3+}$ e $\mathrm{Yb}^{3+}$, que exibem intensidades de luminescência muito fraca devido a grande contribuição dos processos não radiativos resultantes da pequena diferença entre as energias dos estados. 
Nos processos de transferência de energia intramolecular, para que o ligante seja considerado uma "antena eficiente" (bom sensibilizador luminescente) é necessário que ele contenha um grupo que contribua para sua alta absortividade (grupo cromóforo) e apresente condição de ressonância entre seus estados dos ligantes e os níveis emissores do íon terra rara. Adicionalmente, o ligante não pode apresentar canais de supressão de luminescência, tais como, modos vibracionais de alta freqüência e estados eletrônicos com energia abaixo do nível emissor do íon $\mathrm{TR}^{3+}$ Neste contexto, várias classes de ligantes têm sido testadas como antenas, sendo os anions $\beta$-dicetonatos os que apresentam maior interesse ${ }^{[33-34]}$.

\subsection{Considerações gerais sobre as $\beta$-dicetonas}

As $\beta$-dicetonas têm sido estudadas como materiais para transferência de energia e têm apresentado grande interesse nas últimas duas décadas. Uma propriedade importante que estas moléculas apresentam é o tautomerismo, como apresentado na FIG. 3.6.

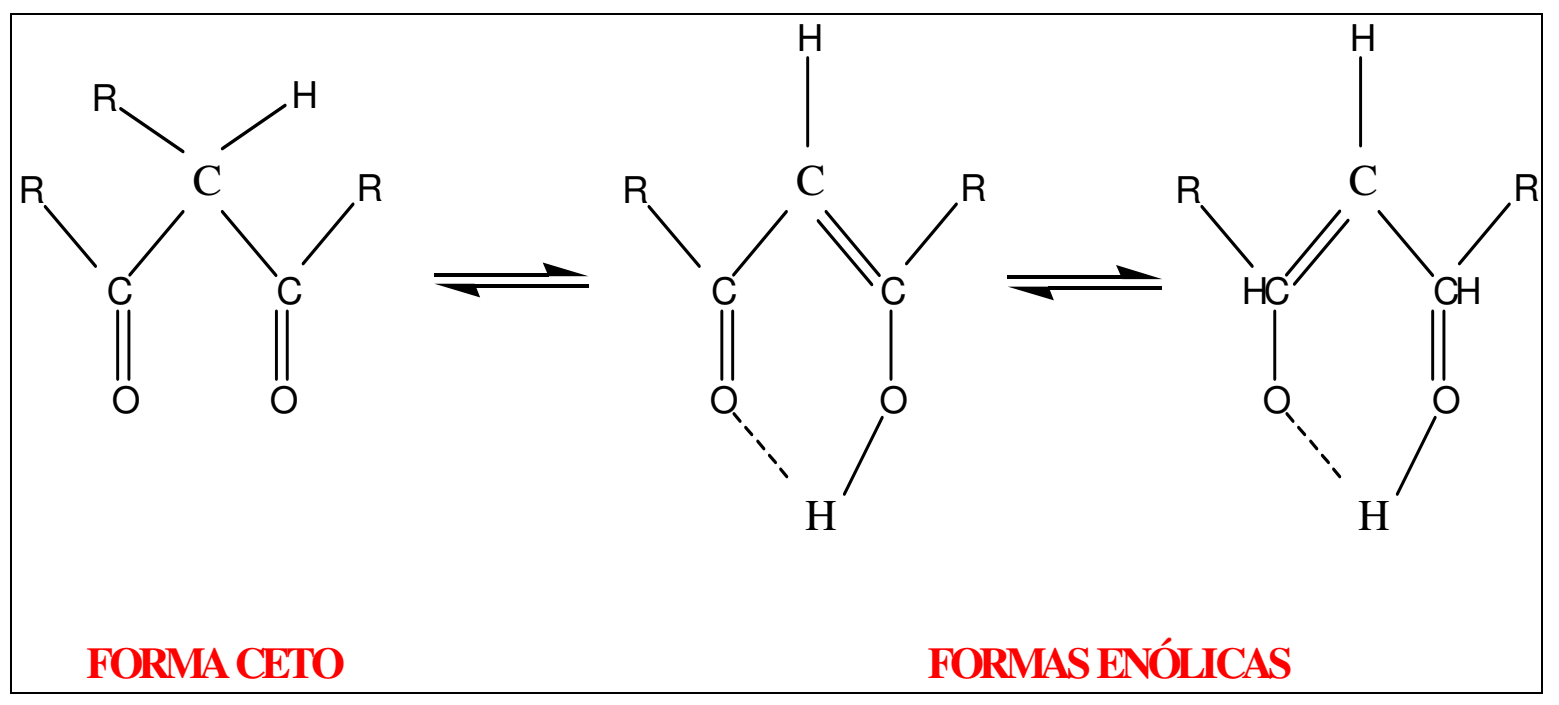

FIGURA 3.6. Formas tautoméricas das $\beta$-dicetonas.

$\mathrm{O}$ átomo de hidrogênio do grupo $\mathrm{CHR}_{3}$ sofre ativação pelo grupo adjacente $\mathrm{C}=\mathrm{O}$, e o sistema conjugado surge por um "deslocamento prototrópico".

As formas tautoméricas existem entre si em equilíbrio, possuindo uma configuração cis e uma configuração syn. Sob condições apropriadas o átomo de hidrogênio do ligante na forma enólica pode ser substituído por um cátion metálico produzindo um anel quelato 
de seis membros, deslocando o equilíbrio ceto-enólico para direita e favorecendo a forma enólica, conforme mostrado na FIG. 3.7.

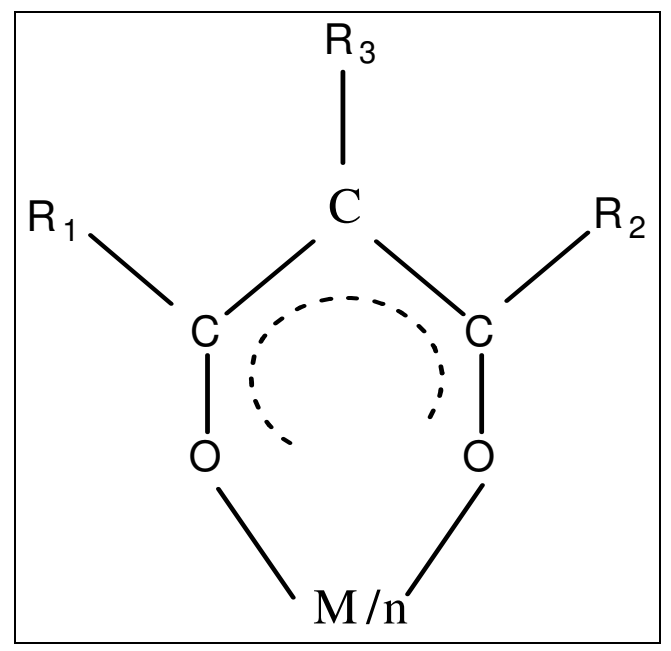

FIGURA 3.7. Representação do anel quelato para os compostos metálicos com as $\beta$ dicetonas.

Um grande número de $\beta$-dicetonas com diferentes substituintes $R_{1}, R_{2}$ e $R_{3}$ são citados na literatura e algumas abreviações são utilizadas para identificar cada tipo de $\mathrm{R}^{[34-}$ 37].

A síntese das $\beta$-dicetonas, na maioria dos casos, segue o método de Claisen no qual a cetona que contém um átomo de hidrogênio $\alpha$ sofre acilação com ácido acético, cloreto de ácido ou éster na presença de uma base.

\subsubsection{Tautomeria ceto-enólica das $\boldsymbol{\beta}$-dicetonas}

Tautômeros são compostos cujas estruturas diferem consideravelmente uma da outra pela disposição dos átomos, mas que se encontram em equilíbrio. O tipo mais freqüente de tautomeria é apresentado em estruturas que diferem quanto ao ponto onde se ligam certos átomos de hidrogênio.

As formas ceto-enólicas surgem com facilidade, em conseqüência da polaridade da ligação $\mathrm{O}-\mathrm{H}$.

O íon hidrogênio separa-se facilmente do átomo de oxigênio com formação de um ânion híbrido, regressor, esse próton tanto pode fixar-se no átomo de oxigênio como no átomo de carbono do ânion. Estes fatos levam-nos a considerar os seguintes caminhos: se o 
próton pode retornar ao oxigênio, pode voltar a sair facilmente; se fixar no átomo de carbono ou tender a manter-se onde está.

As $\beta$-dicetonas apresentam os tauterismos ceto-enólicos ${ }^{[34,37]}$ representados na FIG. 3.8. Estas formas tautoméricas existem em equilíbrio entre si, mas sob condições apropriadas o átomo de hidrogênio do ligante na forma enólica pode ser substituído por um cátion metálico.

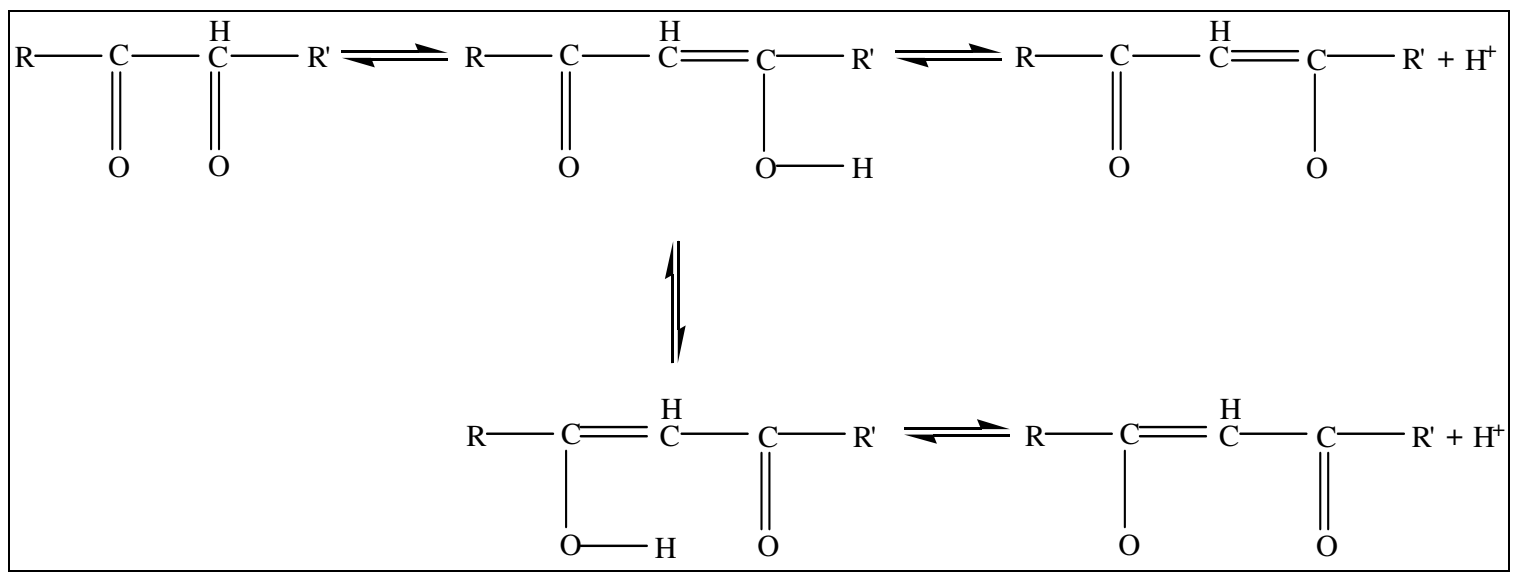

FIGURA 3.8. Tautomerismos ceto-enólicos.

\subsection{Os macrocíclicos}

O contínuo interesse em projetar novos receptores macrocíclicos para íons metálicos é uma conseqüência do uso destes como modelos para ligações proteína-metal, como agente seqüestrante específico para metais pesados tóxicos e como substâncias efetivas práticas para serem utilizadas como agentes terapêuticos. Existem numerosas classes de ligantes macrocíclicos e duas rotas de síntese para se obter um complexo do tipo "hospedeiro-convidado": (i) reações diretas do íon metálico com o receptor (ii) reações de coordenação assistida (template reactions) promovida pelo metal no qual o ligante se forma com melhores rendimentos do que quando a interação ocorre com o íon metálico que direciona para o arranjo estérico da reação de ciclização (efeito template). 


\subsubsection{Os calix[n]arenos}

Os calix[n]areno são macrocíclicos formados por $\mathrm{n}$ unidades fenólicas ligadas entre si por pontes metilênicas nas posições orto à hidroxila. O termo " $n$ " descreve a quantidade de unidades fenólicas que estão no anel e que pode variar de 3 a $20^{[38]}$.

A FIG. 3.9 apresenta a fórmula estrutural de uma molécula de calix[n]areno. Estas moléculas podem ser funcionalizadas, a fim de que se obtenha diversidade de tamanho das cavidades destas e, com isso se consiga uma seletividade destas moléculas na complexação de íons metálicos.

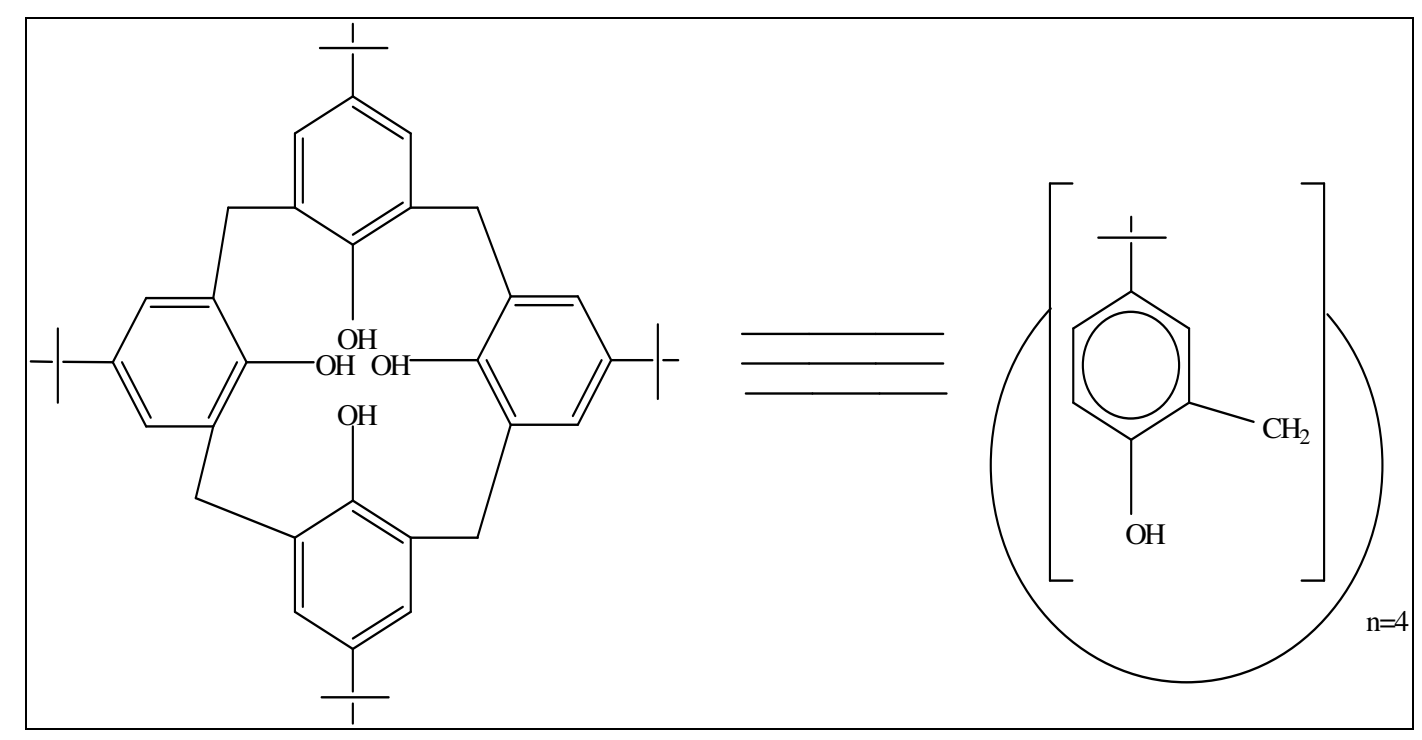

FIGURA 3.9. Fórmula estrutural do calix[4]areno "pai".

A denominação “calix[n]areno" foi primeiro dada por GUTSCHE ${ }^{[39]}$ e provém de sua forma de cone truncado e semelhança estrutural destes com um vaso grego denominado calix crater. O termo calix significa em grego cálice ou vaso e areno indica a presença de grupos aromáticos (FIG. 3.10). 


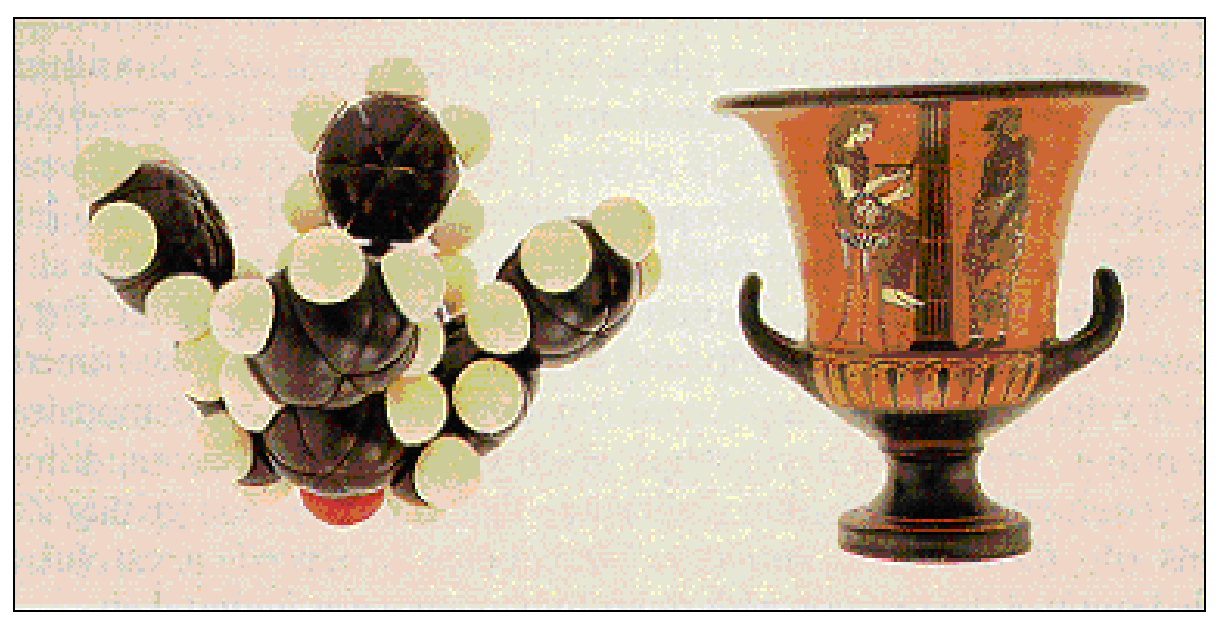

FIGURA 3.10. Modelo molecular tipo space filling para o tetrâmero cíclico (esquerda) e um vaso calix crater (direita).

A geometria de cone truncada se mantém devido à interação que ocorre entre o hidrogênio e o oxigênio dos grupos hidroxilas, permitindo assim o uso destes, devidamente funcionalizados, como receptores de moléculas neutras e íons metálicos. Porém devido ao seu tamanho e sua natureza cíclica os calix[n]arenos podem existir em várias formas conformacionais.

A multiplicidade das formas com que os calix[n]arenos podem ser obtidos, a diversidade de tamanho de suas cavidades, e a sua seletividade na complexação de íons e moléculas neutras abrem um grande campo dentro da Química Supramolecular, possibilitando várias aplicações práticas destes macrocíclicos.

\subsubsection{Representação e nomenclatura dos calix[n]arenos}

Durante anos foram propostas diversas formas para representação dos calix[n]arenos, no entanto, poucas foram aceitas como padrão.

As representações mais comuns dos calix[n]arenos conhecidos como calix[n]arenos "pai” (calix[n]arenos não funcionalizados) podem ser vistas na FIG. 3.11. A representação mais freqüente em publicações é a forma simplificada (D). 


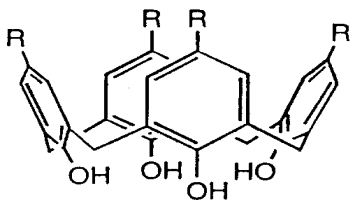

(A)

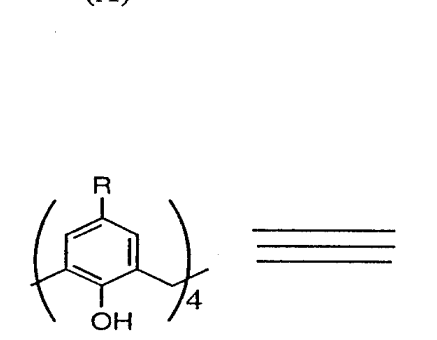

(D)

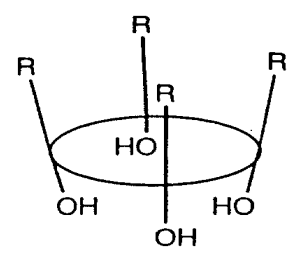

(B)

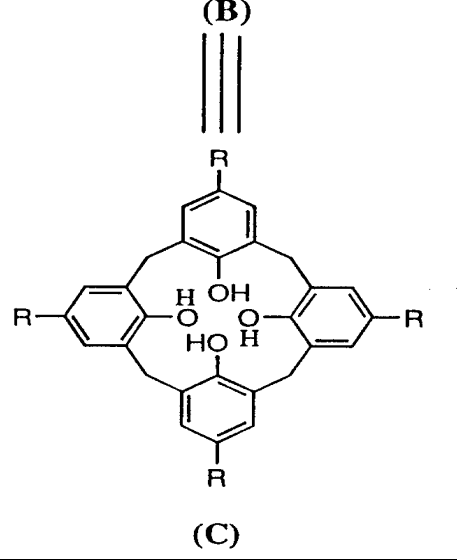

FIGURA 3.11. Diagrama das representações do calix[4]areno.

O sistema de nomenclatura, pela IUPAC, para os calix[n]arenos, resulta em grandes nomes os quais tornam a sua utilização rotineira impraticável, como se pode verificar na molécula de calix[n]areno (ciclo tetrâmero) representada pela FIG. 3.12, cuja nomenclatura IUPAC é 5,11,17,23-tetrakis(1,3-dimetil)pentaciclo-[19.3.1.1. ${ }^{3,7} 1^{9,13} 1^{15,19}$ ] octacosa-1(25), $3,5,7(28), 9,11,13(27), 15,17,19(26) 21,23$-dodecano-25,26,27,28-tetraol ${ }^{[40]}$.

Um método menos complicado que facilita a nomenclatura dos calix[n]arenos, mostra a estrutura básica destes ciclos tetrâmeros e simplifica em demasia os seus nomes, é o caso do exemplo citado que se torna 5,11,17,23-tetra-terc-butil-25,26,27,28tetrahidroxicalix[4]areno. Os números são designados para indicar as quatro unidades que se repetem ao longo da molécula.

Outro método menos formal para descrever a nomenclatura desta estrutura, é considerar esta unidade básica e chamá-la de para-terc-butilcalix[4]areno ou simplesmente de calix[4]areno.

Outros calix[n]arenos, tais como os hexâmeros e octâmeros, também se utilizam da mesma nomenclatura IUPAC, bem como dos nomes menos complicados, tais como calix[6]areno e calix[8]areno (FIG. 3.12). 


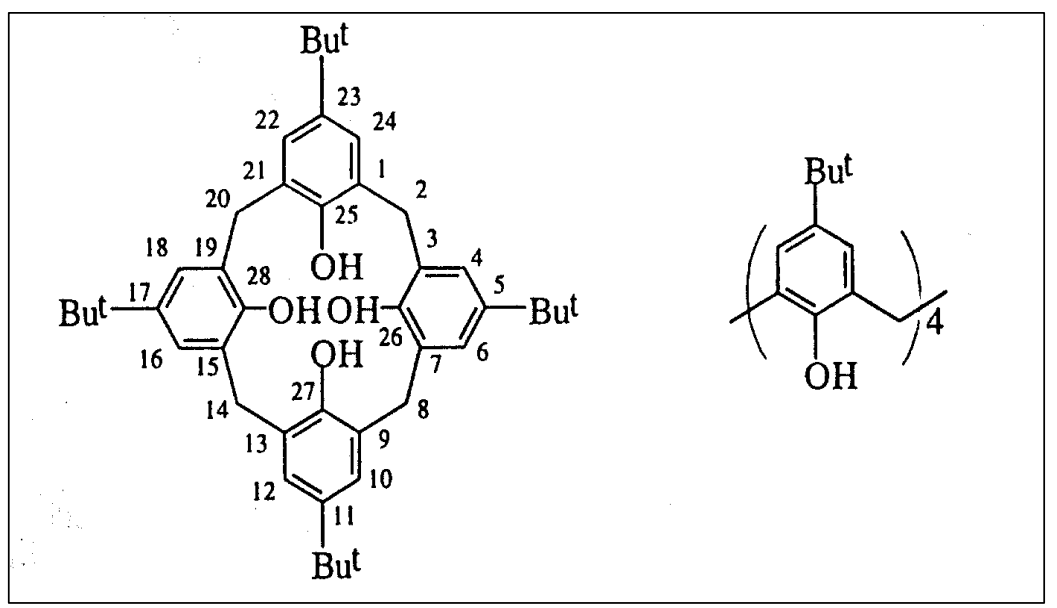

FIGURA 3.12. Sequência de numeração para a nomenclatura dos calix[n]arenos.

\subsubsection{Propriedades dos calix[n]arenos}

Os calix[n]arenos diferenciam-se dos seus correspondentes oligômeros lineares pelos seus altos pontos de fusão e relativa insolubilidade em muitos solventes orgânicos. Os diferentes pontos de fusão servem de parâmetro para a separação e identificação desses calix[n]arenos, uma vez que as outras propriedades que possuem são muito similares entre os calix[n]arenos. Por exemplo, o calix[4]areno possui ponto de fusão em torno de $342^{\circ} \mathrm{C} \mathrm{a}$ $344^{\circ} \mathrm{C}$, o calix[6]areno em torno de $380^{\circ} \mathrm{C}$ a $381^{\circ} \mathrm{C}$ e o calix [8] areno em torno de $411^{\circ} \mathrm{C} \mathrm{a}$ $412^{\circ} \mathrm{C}$, embora seus espectros de ressonância magnética nuclear de prótons sejam muito similares.

A mudança por substituintes na posição para nos calix[n]arenos pode ter um efeito significativo no ponto de fusão. Isto tem sido verificado em vários p-n-alquilcalix[6]arenos, que apresentam ponto de fusão de aproximadamente $110^{\circ} \mathrm{C}$. O mesmo acontece com as substituições no oxigênio dos grupos fenólicos com éteres, ésteres, ácidos ou outras funcionalizações. Geralmente, os pontos de fusão diminuem quando das funcionalizações, contudo existem algumas exceções, como por exemplo, o tetraacetatocalix[4] areno que apresenta ponto de fusão em torno de $383^{\circ} \mathrm{C}$ a $386^{\circ} \mathrm{C}$.

Uma importante característica no espectro de infravermelho dos para-tercbutilcalix[n]arenos, é a baixa freqüência da vibração $\mathrm{OH}$, a qual ocorre a $3150 \mathrm{~cm}^{-1}$ para o tetrâmero e $3300 \mathrm{~cm}^{-1}$ para o pentâmero, ficando os outros com os valores neste intervalo. Isto é o resultado de uma forte ligação intramolecular de hidrogênio, que é mais forte para o tetrâmero e mais fraca para o pentâmero.

Para os calix[4]arenos podem existir quatro confôrmeros, os quais foram nomeados

por GUTSCHE ${ }^{[39]}$ como cone, cone parcial, 2 alternado e 1,3 alternado, como 
representados na FIG 3.13. A conformação cone pode ser descrita como a que possui todos os grupos fenólicos voltados para baixo, a conformação cone parcial tem três grupos fenólicos voltados para baixo e as duas conformações alternadas tem dois grupos fenólicos para baixo e dois para cima, sendo que na conformação 1,2 alternado os grupos fenólicos, que estão voltados para baixo, encontram-se adjacentes um ao outro e, na 1,3 alternada estão em faces opostas da molécula de calix[n]areno.

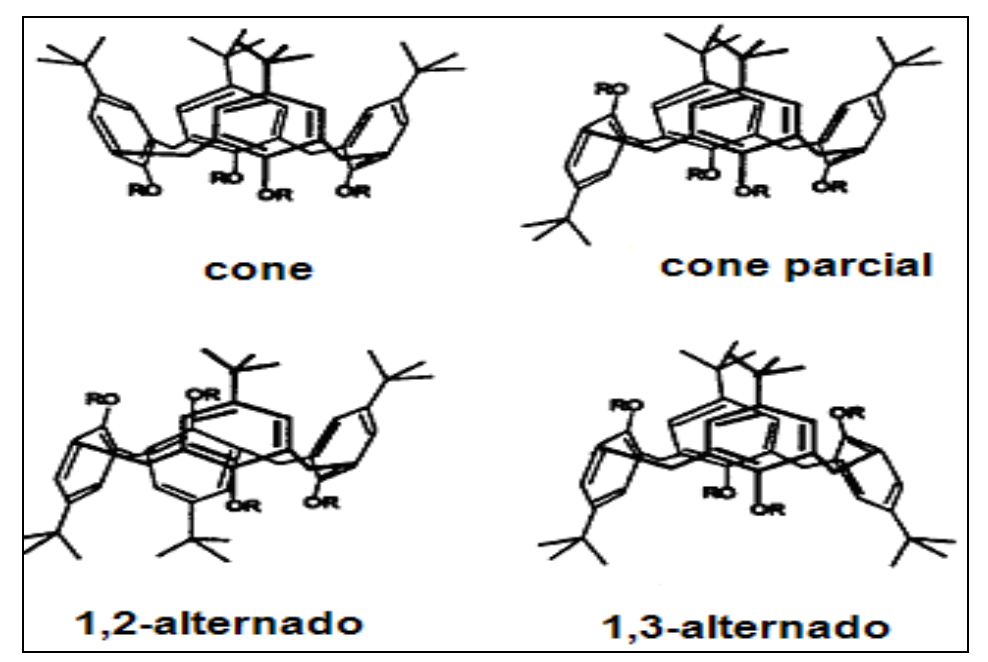

FIGURA 3.13. A diferentes conformações dos calix[4]arenos.

Uma das propriedades dos calix[n]arenos que chamou a atenção foi a sua baixa solubilidade em muitos solventes orgânicos. Este é um dos fatores pelos quais alguns calix[n]arenos são tão difíceis de se isolar, purificar e mesmo caracterizar.

$\mathrm{O}$ recurso que se emprega para melhorar a propriedade de solubilidade dos calix[n]arenos é a funcionalização destes, isto é, realizar substituições na posição da hidroxila e ou do radical terc-butil localizados no grupamento fenólico do anel, fazendo com que se tenha uma maior diversidade de solventes orgânicos empregada para solubilizá-lo; principalmente nos trabalhos de extração com solventes ${ }^{[39,41]}$.

Os calixarenos "pais", ou os para-terc-butilcalix[n]arenos não funcionalizados, são os macrocíclicos formados de unidades fenólicas possuindo os hidróxidos na posição orto em relação ao grupamento metilênico. Eles possuem duas cavidades em forma de cesto: uma de preferência hidrofílica delimitada pelos grupos hidroxila: parte debaixo do anel, lower-rim. Uma outra de preferência lipofílica delimitada pelos grupamentos terc-butílicos em relação a posição para dos hidróxidos: parte de cima do anel, upper-rim (FIG. 3.14). 


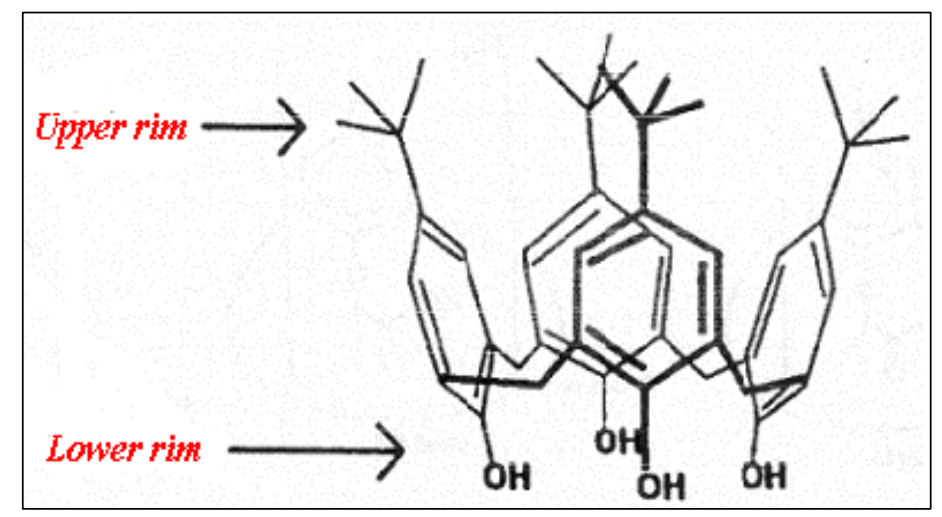

FIGURA 3.14. Lower rim e upper rim dos calixarenos não funcionalizados (calixarenos "pai").

A mobilidade das unidades fenólicas em volta dos grupos metilênicos da parte de cima da cavidade permite aos calixarenos adotarem diferentes conformações em solução. AIME e seus colaboradores ${ }^{[40]}$ têm denominado muitos por compostos tetrâmeros segundo a imersão de uma ou duas unidades fenólicas em relação ao plano médio da molécula. GUTSCHE $^{[39]}$ as têm denominado cone; cone parcial; 1,2 alternado e 1,3 alternado.

No estado sólido as fortes ligações de hidrogênio intramolecular bloqueiam o composto tetrâmero "pai" dentro da conformação de cone. Este fato é que levou GUTSHE a batizá-los como calixarenos, devido a sua semelhança com um cálice (calix em grego).

\subsubsection{Funcionalização dos calixarenos e complexação com metais}

Os calixarenos "pai” obtidos pelos métodos anteriormente descritos podem sofrer modificações que facilitam sua solubilidade tanto em água como em solventes orgânicos e melhorando sua purificação e caracterização. As modificações nos calixarenos "pai” são possíveis, pois estes exibem algumas reações típicas de fenóis como esterificação, esterilização, sulfonação e nitração. É o caso da sulfonamida-calixarenos, nitro-alixareno, sulfonato-calixarenos, amônio-calixarenos e carboxil-alixarenos ${ }^{[41-45]}$ representados na FIG. 3.15. 


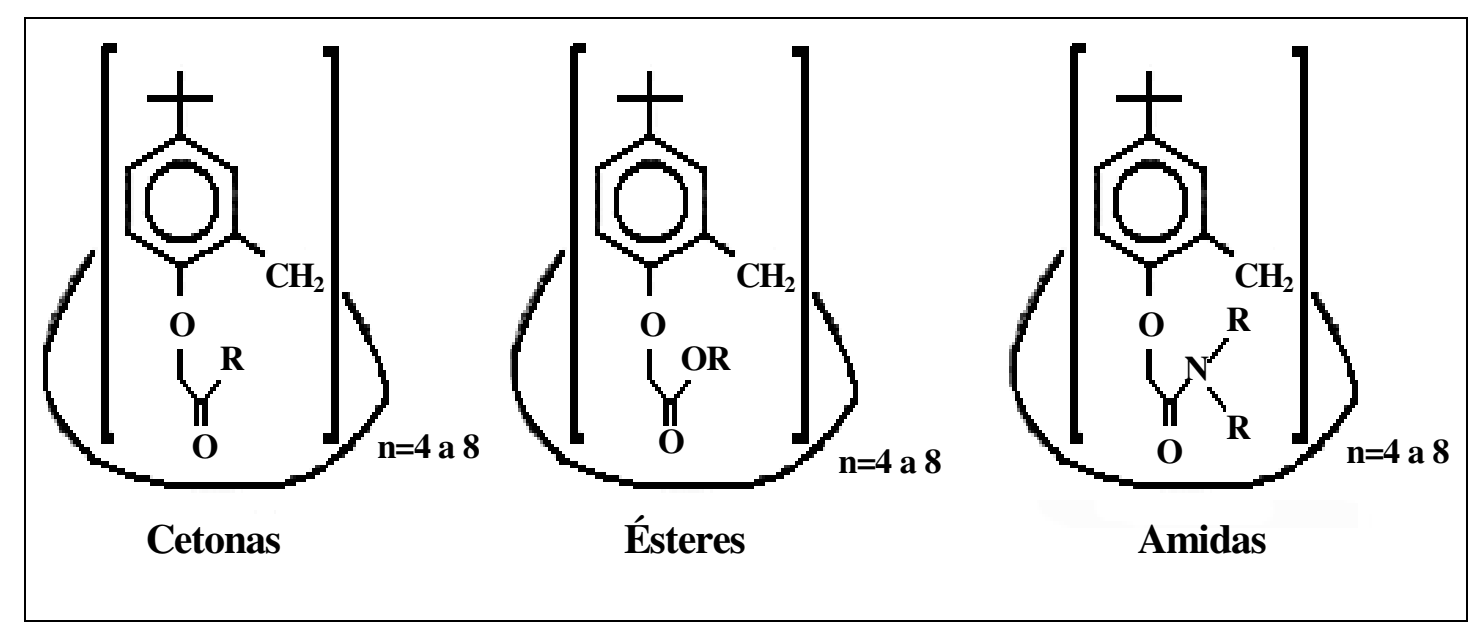

FIGURA 3.15. Exemplos de calixarenos funcionalizados.

As propriedades de complexação dos calixarenos com metais podem ser comparadas com as de antibióticos cíclicos naturais que contêm sítios de complexação com ésteres carboxílicos, uma vez que ésteres de calixarenos podem "esconder" o íon metálico em seu interior, revelando ao meio a sua "face" lipofílica.

Comparando as propriedades complexantes de etóxi-carbonil-metano-para-tercbutilcalix[6]arenos e etóxi-carbonil-metano-para-terc-butilcalix[8]arenos ${ }^{[46]}$ sobre picratos de metais alcalinos e alcalino-terrosos, observa-se uma eficiência muito maior nos primeiros, que apresentam grupos éster do que naqueles com grupo éter. Dentro de uma mesma classe de derivados, há uma correlação entre o tamanho da cavidade e o tamanho do cátion.

Pesquisadores avaliaram uma série de derivados funcionalizados nos grupos hidroxílicos: ésteres, cetonas ${ }^{[47]}$, as amidas e sulfamidas ${ }^{[48]}$, observando que ésteres e cetonas de calix[4]arenos mostram seletividade para íon $\mathrm{Na}^{+}$, enquanto que os derivados de calix[6]arenos e calix[8]arenos são seletivos para íon $\mathrm{Cs}^{+}$. Os ionóforos com átomos de nitrogênio e enxofre extraem metais de transição, com clara seletividade para prata, o que motivou a construção de eletrodos seletivos ${ }^{[49]}$.

A alta seletividade para sódio exibida por alguns ionóforos motivou a construção de eletrodos específicos para sódio ${ }^{[50]}$, com baixa sensibilidade ao potássio, posteriormente aplicados com sucesso na determinação de íons sódio em plasma humano.

A seletividade com metais motivou a síntese de um calix[4]areno que pudesse responder, por fluorimetria, à presença de íons, através da adição de duas unidades de pireno ou 9-antraceno na parte fenólica. Observou-se que o produto também responde à polaridade do meio. 
Macrocíclicos como os calixarenos, com ou sem adição de grupos moleculares para atuar como antena, são capazes de transferir energia para o íon lantanídeo, $\mathrm{Ln}^{3+}$, sob excitação no nível de energia adequado. Atualmente um grande interesse por sensores para íons lantanídeos e para FIA's tem sido demonstrado, mas algumas das atribuições necessárias são: o complexo tem que ser estável; tem que apresentar alta absortividade molar e o cátion tem que ser blindado dos efeitos de supressão causados pelo solvente e aumentar o tempo de vida do estado excitado.

Embora os calixarenos formem complexos estáveis com os elementos f poucos trabalhos têm sido publicados neste campo e um design de ligantes calixarenos para suprir as necessidades dos fatores que governam a seletividade de grupos não estão completamente entendidos ou resolvidos ${ }^{[47-50]}$.

\subsection{Diagnóstico}

O diagnóstico como um todo representa um mercado muito grande, bem estabelecido e em contínua expansão. Particularmente no clima atual de "prevenir ao invés de curar" a necessidade de se obter limites de detecção cada vez mais baixos em diversas áreas de aplicação soma-se a um requerimento para monitoramento contínuo e controle com baixo custo em áreas tradicionais ${ }^{[51]}$. Um dos maiores mercados diagnósticos do mundo é, sem dúvida, aquele com testes clínicos e dentro deste campo, os marcadores desempenham um papel chave.

Em termos gerais, como definição da IUPAC, um marcador ou rotulador ${ }^{[52]}$ é um composto químico que é distinguido pelo observador, mas não pelo sistema e que é usado para identificar um traçador ${ }^{[53]}$ que é um membro marcado de uma população usada para medir certas propriedades inerentes àquela população. Na prática, biomoléculas (como as proteínas, ácidos nucléicos, polissacarídeos ou lipídeos) marcadas com um material luminescente ligam-se seletivamente a um antígeno particular, carboidrato, seqüência de ácido nucléico ou em hepitopo previamente proporcionando o meio de detecção destes alvos biológicos ${ }^{[54]}$. 


\subsubsection{Diferentes tipos de marcadores}

Em geral, os marcadores podem ser divididos em três grupos principais: marcadores radioativos, marcadores enzimáticos e marcadores luminescentes ${ }^{[55]}$.

Os marcadores radioativos são os menos acessíveis e tem a vantagem do não impedimento estérico. Eles proporcionam uma medida quase sem background, tornando estes marcadores muito sensíveis que mesmo quando em quantidades extremamente pequenas podem ser detectados. Infelizmente, esses marcadores possuem um tempo de utilização limitado devido ao decaimento radioativo. Além disso, o manuseio e a disposição do material radioativo requerem um alto grau de monitoramento e de segurança o que leva a custos altos.

As enzimas são os marcadores mais largamente difundidos, onde o tipo de ensaio enzimático mais conhecido é o ensaio ELISA. O ensaio enzimático tem uma alta sensibilidade desde que o produto detectável da reação seja continuamente produzido. A principal desvantagem dos ensaios enzimáticos são a necessidade da adição de reagentes, o requerimento de etapas de lavagens repetidas e a necessidade de um tempo de incubação que pode levar à denaturação das proteínas. Finalmente, o uso de proteínas de cadeias longas pode causar impedimento estérico nos eventos de ligação.

Marcadores luminescentes têm ganhado muita popularidade nos últimos anos. Eles possuem uma alta sensibilidade desde que cada evento de ligação continuamente gere um sinal devido à regeneração de fótons emitidos. Além disso, matrizes de marcadores luminescentes são comercialmente acessíveis em vários comprimentos de onda. Quando se utiliza um marcador luminescente, vários parâmetros podem ser medidos: intensidade de luminescência, tempo de vida, anisotropia, espectros de emissão.

\subsubsection{Requerimentos para um marcador luminescente ideal}

Um marcador luminescente ideal deve possuir as seguintes propriedades: absortividade molar e rendimento quântico altos para obtenção de uma intensidade de luz alta; fotoestabilidade; solubilidade em água; acessível comercialmente a baixos custos; alta reatividade para perfazer ligações covalentes às proteínas à temperatura ambiente em condições amenas de reação; não interagir com qualquer espécie presente que leve à mudança nas propriedades fotofísicas, como absortividade molar, tempo de vida ou 
rendimento quântico; uma absorbância máxima em uma faixa de comprimento de onda longo (não ultravioleta) para eliminar background de ondas curtas de fluorescência e que seja preferencialmente não tóxico ${ }^{[55]}$.

\subsection{Lantanídeos e seus quelatos}

Os lantanídeos têm um número de propriedades que podem ser exploradas em medidas bioanalíticas. O gadolínio, paramagnético, é comumente utilizado como agente de contraste em imagem por ressonância magnética (RMI), os isótopos radioativos dos lantanídeos são aplicados como agentes seletivos para tecidos ou alvos em radioterapia ${ }^{[56]}$ e ainda somando-se a fotoluminescência, a detecção eletroluminescente de térbio resolvida no tempo é extremamente sensitiva e pode ser utilizada para imunoensaios por geração de elétron resolvido temporalmente ${ }^{[57]}$.

A luminescência dos quelato de $\mathrm{Ln}^{3+}$ por sensibilização do ligante tem excepcionalmente tempo de decaimentos longos que transformou estes marcadores nos mais utilizados para diagnostico por $\mathrm{TR}^{3+}$ [58-59].

$\mathrm{Na}$ TAB. 3.1 estão sumarizadas algumas das propriedades de fluorescência dos lantanídeos mais usados por esta técnica e na FIG. 3.16 é mostrado o perfil de emissão de quatro lantanídeos com maior fluorescência na forma de seus $\beta$-dicetonatos.

TABELA 3.1. Transições mais intensas nos espectros de luminescência dos $\operatorname{Ln}^{3+}$.

\begin{tabular}{cccccc}
\hline Ln(III) & $\begin{array}{l}\text { Nível } \\
\text { emissor }\end{array}$ & Transição & $\begin{array}{c}\text { Linha de } \\
\text { emissão }(\mathbf{n m})\end{array}$ & $\begin{array}{c}\text { Tempo de } \\
\text { decaimento } \\
(\boldsymbol{\mu s})\end{array}$ & $\begin{array}{c}\text { Rendimento } \\
\text { quântico }\end{array}$ \\
\hline $\mathrm{Eu}$ & ${ }^{5} \mathrm{D}_{0}$ & ${ }^{7} \mathrm{~F}_{1}$ & 590 & $500-730$ & Até $85 \%$ \\
& & ${ }^{7} \mathrm{~F}_{2}$ & $613-615$ & & \\
& & ${ }^{7} \mathrm{~F}_{4}$ & $690-695$ & & Até $40 \%$ \\
$\mathrm{~Tb}$ & ${ }^{5} \mathrm{D}_{4}$ & ${ }^{7} \mathrm{~F}_{6}$ & 490 & $100-1500$ & \\
& & ${ }^{7} \mathrm{~F}_{5}$ & 545 & & $2 \%$ \\
$\mathrm{Sm}$ & ${ }^{4} \mathrm{G}_{5 / 2}$ & ${ }^{6} \mathrm{H}_{7 / 2}$ & 598 & 50 & \\
& & ${ }^{6} \mathrm{H}_{9 / 2}$ & 643 & & \\
$\mathrm{Dy}$ & ${ }^{4} \mathrm{~F}_{9 / 2}$ & ${ }^{6} \mathrm{H}_{13 / 2}$ & 575 & & \\
$\mathrm{Nd}$ & ${ }^{4} \mathrm{~F}_{5 / 2}$ & ${ }^{4} \mathrm{I}_{9 / 2}$ & 900 & & \\
\hline
\end{tabular}




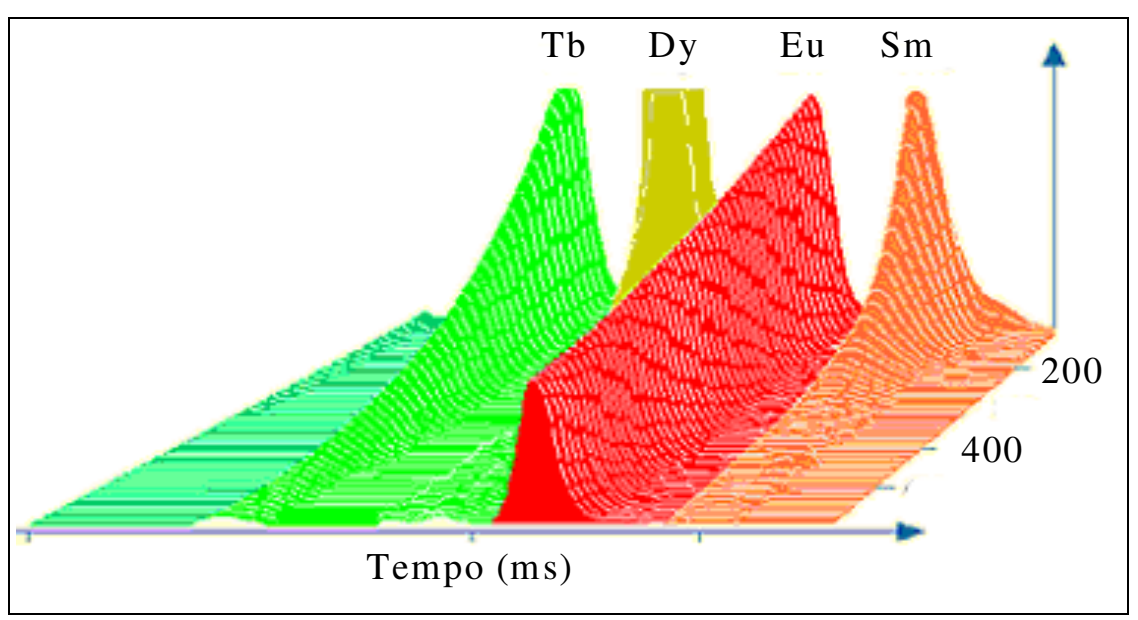

FIGURA 3.16. Perfis de decaimento de emissão de uma mistura de quelatos de $\mathrm{Eu}, \mathrm{Tb}$, Dy e Sm em uma solução de crescimento baseado em pivaloiltrifluoroacetona ${ }^{[55]}$.

A rota de supressão de luminescência mais efetiva para os quelatos de Eu é pelo acoplamento vibrônico dos níveis das moléculas de $\mathrm{H}_{2} \mathrm{O}$ de mais alta energia e seus overtones que combina com o gap de energia dos estados excitados dos lantanídeos. $\mathrm{O}$ número de moléculas de água, coordenadas na esfera interna de coordenação do íon, está inversamente relacionada com o tempo de decaimento do quelato ${ }^{[60]}$. Concordando com isso pode-se dizer que um quelato ideal é composto de um agente quelante onde o acesso de moléculas de água na primeira esfera de coordenação é proibida. Adicionalmente, sistemas para proteção de supressão estão sendo usados com quelatos com coordenação incompleta tais como óxido de trioctilfosfina (TOPO) para as $\beta$-dicetonas e fluoreto de potássio para os criptatos ${ }^{[61]}$. Usar superfícies secas também tem sido uma alternativa para aumentar a luminescência ${ }^{[62]}$. As vibrações $\mathrm{N}-\mathrm{H}$ e $\mathrm{C}-\mathrm{H}$ podem originar processos de desativação dos estados excitados embora de maneira menos eficiente do que o $\mathrm{OH}^{[63-65]}$.

Para o térbio, a luminescência é fortemente suprimida por ligantes que possuem estados tripletos muito baixos, por um mecanismo de retrodoação de energia. Diferindo do $\mathrm{Eu}^{3+}$ que aceita energias de excitação do nível ${ }^{5} \mathrm{D}_{1}, \mathrm{o} \mathrm{Tb}^{3+}$ aceita energia de excitação diretamente do seu nível emissor ${ }^{5} \mathrm{D}_{4}$. Em um quelato de $\mathrm{Tb}^{3+}$ otimizado o nível tripleto do ligante deve ficar acima de $20000 \mathrm{~cm}^{-1}$ para minimizar a supressão deste ${ }^{[66-67]}$.

$\mathrm{Eu}^{3+}, \mathrm{Tb}^{3+}$ e $\mathrm{Sm}^{3+}$ são os íons mais utilizados como marcadores, mas o $\mathrm{Dy}^{3+}$ também pode ser usado pelo menos em sistemas DELFIA (Dissociative Enhancement Lanthanide Fluoroimmunoassays) ${ }^{[68-70]}$. 


\subsubsection{Tecnologias de ensaios baseadas em quelatos de lantanídeos}

Desde as primeiras idéias apresentadas nos anos $70^{[71]}$, um grande número de quelatos têm sido sintetizados. A idéia primogênita era baseada em assumir que o quelato de $\beta$-dicetona pode ser usado sem alterações. LEIF e colaboradores ${ }^{[71]}$ descreveram um ensaio onde um isotiocianato derivado da orto-fenantrolina foi sintetizado para acoplamento e WIEDER sintetizou o isotiocianato derivado da $\beta$-dicetona como um ligante bifuncional. Desde então, o conhecimento de quelatos e uma série de necessidades por ensaios biológicos novos têm aumentado e quelatos com estabilidade apropriada e rendimento de fluorescência alto têm sido encontrados.

A tecnologia dos quelatos de lantanídeos pode ser classificada de acordo com o caminho seguido para se fazer o ensaio, o tipo de energia utilizada, de acordo com a estrutura do agente complexante e do caminho utilizado para o aumento de fluorescência. Desta maneira classifica-se a tecnologia de quelatos como:

- Ensaios por aumento do sinal de fluorescência - usa-se íons metálicos como marcador e uma troca de ligantes ou formação de um novo quelato para desenvolver a fluorescência depois que o ensaio é feito;

- Detecção de ligantes fluorogênicos pela formação de quelatos fluorescentes depois do ensaio pela adição de excesso de lantanídeos ou quelatos não fluorescentes;

- Adição de um agente sensibilizador da fluorescência (antena) em um agente quelante já conhecido, tais como o ácido dietileno triaminopentaacético (DTPA);

- Criar as condições de estabilidade pela incorporação de vários ligantes fluorogênicos em uma estrutura (podandos e calixarenos) ou fechar a estrutura para formar compostos do tipo gaiolas policíclicas (criptatos);

- Criar um quelante muito forte associando grupos quelantes através de um braço de ligação a um ligante fluorogênico.

Os grupos mais comuns utilizados para captação de energia podem ser divididos em quatro subgrupos: $\beta$-dicetonas, carboxilatos e estruturas correlatas, priridinas e compostos heterociclicos derivados e seus oligômeros,metais ligados a proteínas ou peptídeos. 


\subsection{FTIR}

A Espectroscopia de Absorção no Infravermelho por Transformada de Fourier (do inglês Fourier Transformed Infrared - FTIR) é uma técnica que utiliza a região do infravermelho do espectro eletromagnético para caracterizar moléculas e biomoléculas (FIG. 3.17). A chamada radiação infravermelha corresponde à parte do espectro eletromagnético situada entre as regiões do visível e das microondas, pois é onde ocorrem vibrações e torções características de diversos grupos funcionais ${ }^{[72]}$. A porção mais comumente usada está situada entre 4000 e $400 \mathrm{~cm}^{-1}$ (1014 e $1012 \mathrm{~Hz}{ }^{[73]}$, (FIG. 3.17).

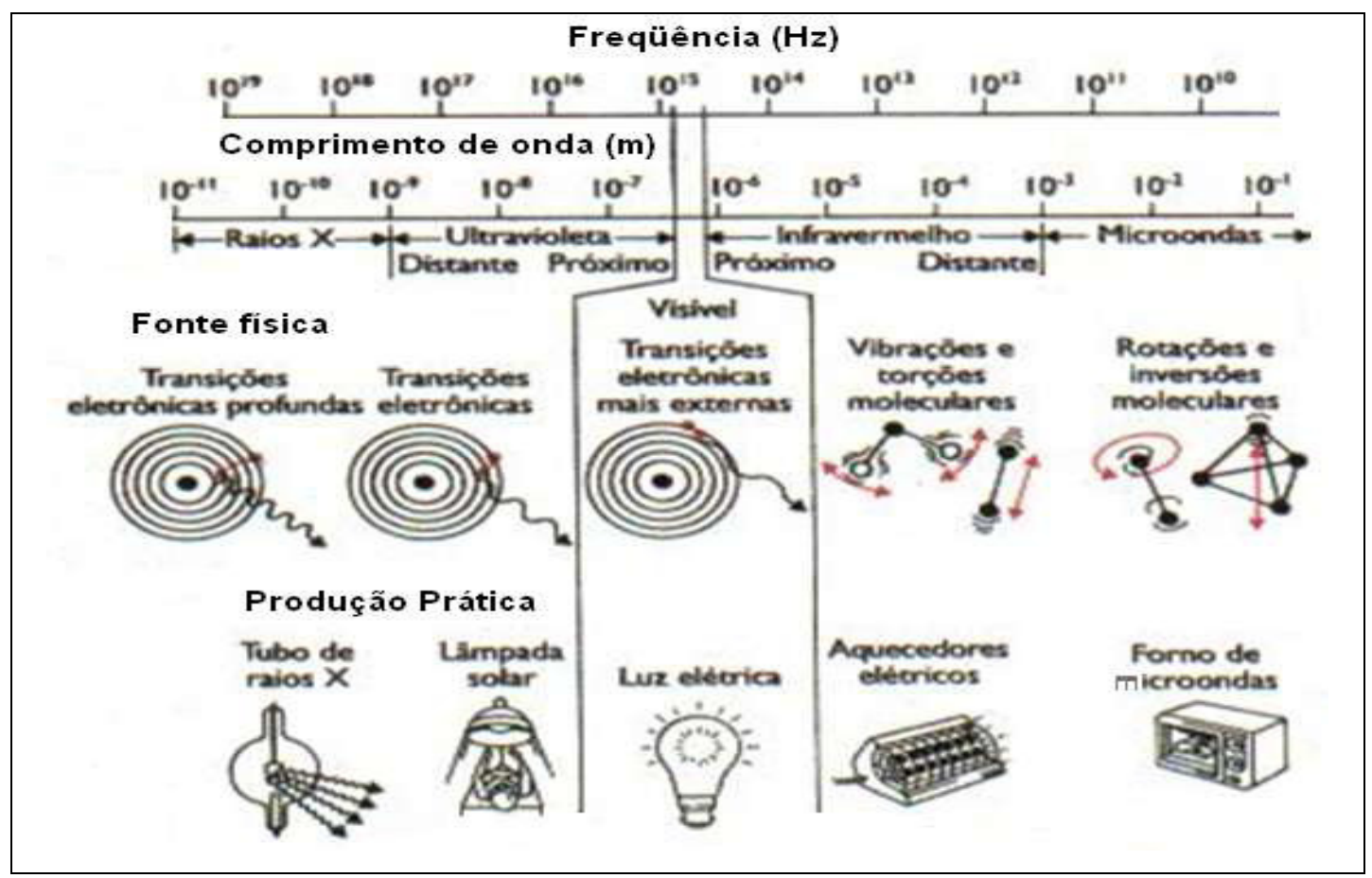

FIGURA 3.17. Esboço do espectro eletromagnético. Distribuição da intensidade da radiação eletromagnética em relação ao seu comprimento de onda ou frequiência ${ }^{[72]}$.

As ligações químicas das substâncias possuem frequiências de vibração específicas, as quais correspondem a níveis vibracionais de energia. A radiação infravermelha provoca vibração de átomos ou grupos de átomos e estas vibrações podem ter amplitudes e freqüência diferentes. As energias de vibrações são quantizadas, ou seja, existem determinadas quantidades de energia que fazem os grupos vibrarem ${ }^{[74]}$.

As vibrações moleculares podem ser classificadas em deformações axiais ou estiramento e deformações angulares como mostra a FIG. 3.18. Uma vibração de 
deformação axial é um movimento ao longo do eixo da ligação que faz com que a distância interatômica aumente e diminua alternadamente. As vibrações de deformação angular correspondem a variações de ligações que têm um átomo em comum ou o movimento de um grupo de átomos em relação ao resto da molécula.

Somente as vibrações que levam à alteração do momento de dipolo da molécula são observadas no infravermelho ${ }^{[73]}$.

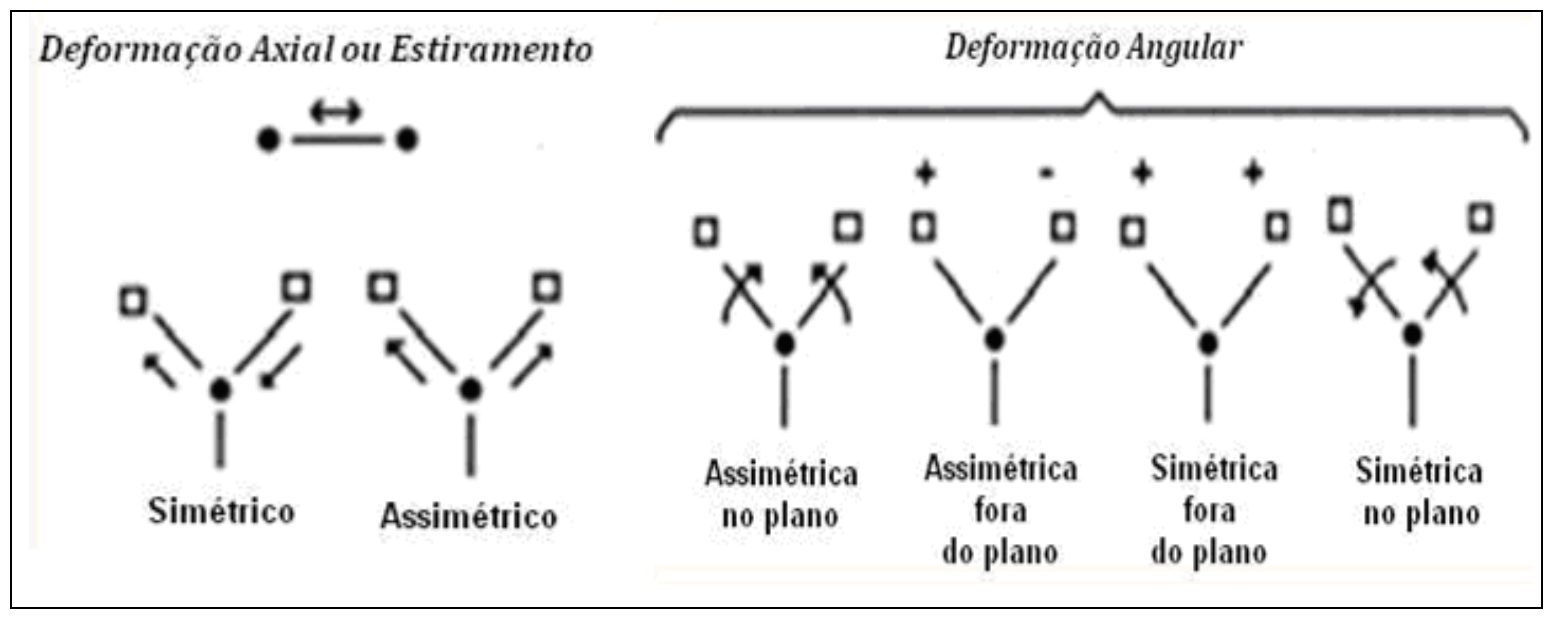

FIGURA 3.18. Esquema dos modos vibracionais. (+ e - indicam movimento perpendicular ao plano da página) ${ }^{[73]}$.

\subsubsection{Instrumentação}

Dois tipos de espectrômetros são empregados na espectroscopia de infravermelho: os mais antigos do tipo dispersivo (FIG. 3.19) e os modernos com transformada de Fourier (FIG. 3.20).

Até o início dos anos 80 a maioria dos instrumentos era do tipo dispersivo baseados em redes de difração, mas desde então estes vêem sendo substituídos pelos de transformada de Fourier, que fornece uma escala de número de ondas altamente reprodutível, com melhor resolução e sensibilidade mais alta do que o outro ${ }^{[75]}$.

O projeto óptico dos instrumentos dispersivos é de feixe duplo, em que o feixe de infravermelho passa alternadamente através da amostra e da referência. Eles trabalham com prisma ou grade de difração, para dispersar a luz policromática em várias faixas de comprimento de onda, obtendo assim uma radiação monocromática.

Esta radiação após atravessar a amostra é refletida por um sistema de espelhos e passa por fendas estreitas indo em direção ao detetor e deste para um registrador. Este tipo 
de sistema apresenta fraca potência de radiação infravermelho, dificultando sua medição e necessitando de grades de difração apuradas, pois a sua precisão é afetada pelo frequente desalinhamento do sistema óptico, resultando em uma relação sinal ruído lento ${ }^{[76]}$, (FIG. $3.19)$.

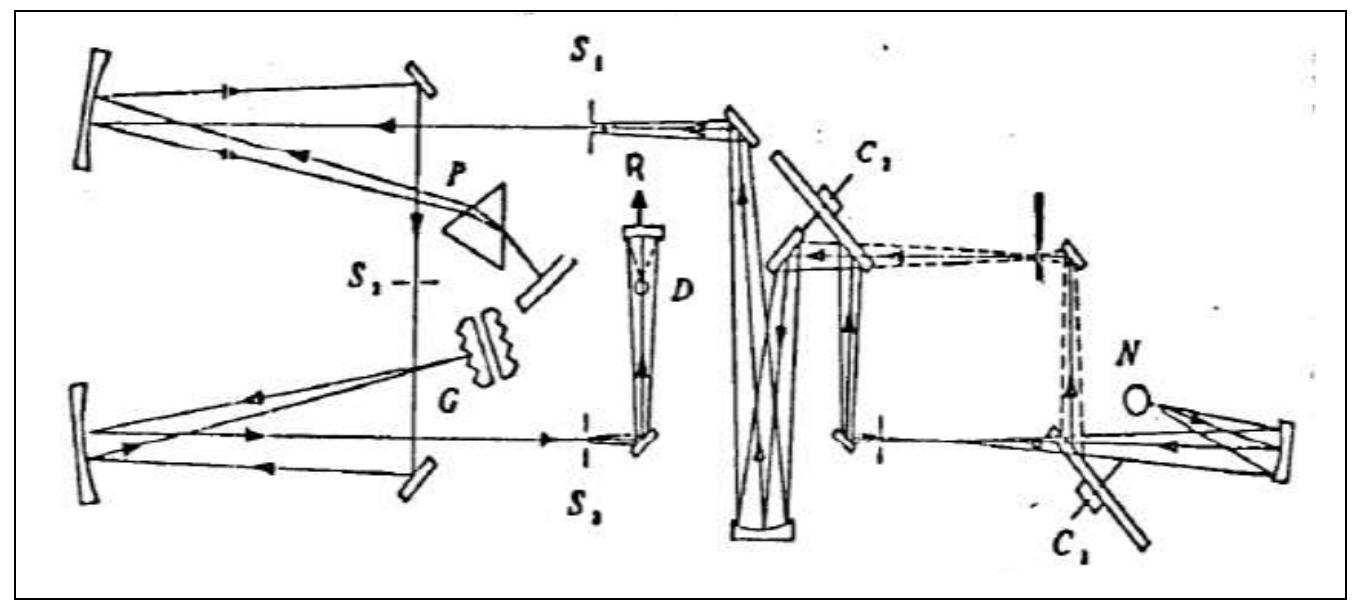

FIGURA 3.19. Diagrama óptico de um espectrômetro dispersivo.

Na FIG. 3.19 têm-se um diagrama óptico de um espectrômetro dispersivo onde os feixes gerados pela freqüência $(\mathrm{N})$ passam pelo interruptor circular $(\mathrm{C} 1)$ em que uma metade, um semicírculo é um espelho e a outra metade acha-se aberta que gira com velocidade sincronizada cont rolada (desdobramento no tempo). À medida que $\mathrm{C} 1$ gira a parte que tem o espelho fica alternadamente fora e dentro do feixe. Quando o interruptor C1 se encontra fora do feixe a radiação da fonte é refletida por um espelho convergente e passa através da amostra. Quando o interruptor $\mathrm{C} 1$ fica dentro do feixe a radiação é refletida e contorna a amostra como um feixe de referência. Os espelhos planos refletem ambos os feixes no segundo interruptor $\mathrm{C} 2$ (em sincronismo com $\mathrm{C} 1$ ), onde são reunidos, indo em direção a entrada S1 para o primeiro monocromador. A abertura das fendas é ajustada para termos a melhor combinação de resolução e potência de radiação. O feixe sofre uma dispersão inicial pelo prisma (P), após passar por uma fenda intermediária sofre dispersão adicional pela grade de difração $(G)$, o feixe duplamente dispersado atravessa a fenda de saída (S3) e alcança o detetor (D). Este sinal é amplificado e vai para o registrador (R) ${ }^{[76]}$.

Os instrumentos com transformada de Fourier não apresentam nenhum elemento dispersivo e todos os comprimentos de onda são detectados e medidos simultaneamente. 
Em vez de um monocromador, um interferômetro é usado para produzir padrões de interferência que contêm a informação espectral do infravermelho.

Os mesmos tipos de fontes empregadas nos dispersivos são utilizados nos de transformada de Fourier. Os transdutores tipicamente são os fotocondutivos. Para se obter a potência radiante em função de medidas precisas do comprimento de onda, um dispositivo denominado interferômetro de Michelson, modula o sinal da fonte de maneira que este possa ser decodificado por uma técnica matemática denominada transformada de Fourier $^{[77]}$.

No interferômetro de Michelson (FIG. 3.20), a radiação de uma fonte policromática hipotética é dividida em dois feixes, cada um correspondendo idealmente a $50 \%$ do original, no "beamsplitte" (divisor de feixe). Um dos feixes (A) segue em direção ao espelho de posição fixa no qual reflete de volta para o "beamsplitter", onde parte deste feixe reflete de volta para a fonte e parte vai para o detector. O outro feixe (B) parte do "beamsplitter" em direção ao espelho móvel. O espelho móvel também reflete o feixe B, parte de volta para a fonte e parte para o detector. Se a posição do espelho móvel é tal que o feixe B percorre a mesma distância que o feixe A antes de chegar ao detector $(\delta=\mathrm{n} \lambda$, onde $\mathrm{n}=0,1,2, \ldots)$, então os dois feixes estão em fase, reforçando um ao outro (interferência construtiva) e, neste caso, a energia que chega ao detector será máxima. Por outro lado, se a posição do espelho móvel for tal que o caminho do feixe B seja diferente daquele do feixe A por $(n+1) \lambda / 2$, então os dois feixes estarão $90^{\circ}$ fora de fase, cancelando um ao outro. A energia que chega ao detector, nesse caso, será mínima.

Portanto, à medida que o espelho móvel percorre determinada distância, um interferograma é formado, como mostrado na FIG. 3.20. A intensidade da radiação que chega ao detector, $\mathrm{I}(\delta)$, varia como uma função coseno da retardação óptica $\delta{ }^{[77]}$. 


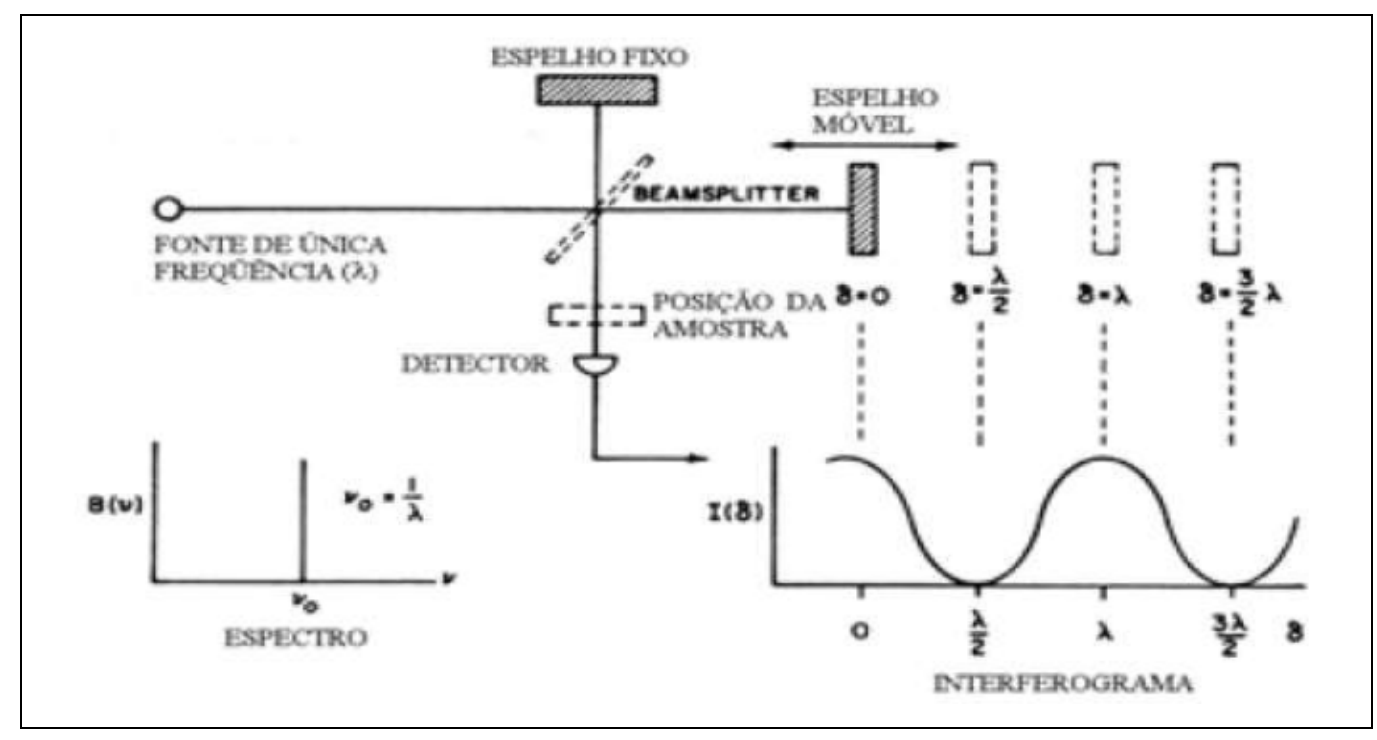

FIGURA 3.20. Diagrama óptico de um espectrômetro FTIR.

\subsection{Anemia Falciforme}

\subsubsection{Fisiopatologia da doença falciforme}

A simples substituição pontual do aminoácido ácido glutâmico pela valina na posição seis da cadeia beta da hemoglobina irá modificar a estrutura molecular da hemoglobina A (HbA), considerada normal, para hemoglobina S (HbS), considerada alterada FIG. 3.21. A denominação de hemoglobina S deriva do inglês "sickle", que significa formato de foice ${ }^{[78,79]}$. A hemoglobina $S$ difere tanto no aspecto estrutural como no aspecto elétrico da molécula de hemoglobina A. Com a perda do ácido glutâmico, que é substituído pela valina, há perda de duas cargas elétricas por molécula de hemoglobina. Esta modificação leva a hemoglobina $\mathrm{S}$ a uma alteração de estabilidade e solubilidade. A alteração de estabilidade é a forte tendência a formação de polímeros pela baixa tensão de oxigênio, devido à interação dos receptores fenilalanina e leucina com a valina. A formação dos polímeros depende de algumas variáveis, sendo o grau de oxigenação e a concentração de hemoglobina $S$ no sangue as principais. Isto explica a quase inexistência de sinais de anemia falciforme em recém-nascidos ou outras hemoglobinopatias associadas, devido a maior concentração de hemoglobina fetal (HbF). A alteração de solubilidade associada à instabilidade leva a desidratação celular devido às perdas de íons potássio $\left(\mathrm{K}^{+}\right)$e de água. 
Os principais mecanismos destas perdas ocorrem pela ativação excessiva do canal de transporte dos íons potássio e cloro $\left(\mathrm{K}^{+} \mathrm{Cl}^{-}\right)$, estimulados pela acidificação e pelo edema. Isto ocorre com conseqüente aumento da concentração dos íons cálcio $\left(\mathrm{Ca}^{++}\right)^{[78]}$. Outra consequiência é a perda da elasticidade da célula devido ao incremento da concentração de $\mathrm{HbS}$ intracelular, resultando no aumento da viscosidade no citosol, à polimerização da HbS e à rigidez da membrana. Todos os fatores acima citados, associados a uma maior adesão da hemácia em aspecto de foice (falcizada), favorecem a formação de microtrombos na circulação sanguínea, principalmente em vasos de menor calibre. Estes microtrombos são os responsáveis pelo quadro clínico do paciente com anemia falciforme, incluindo os sintomas descritos a seguir ${ }^{[80]}$.

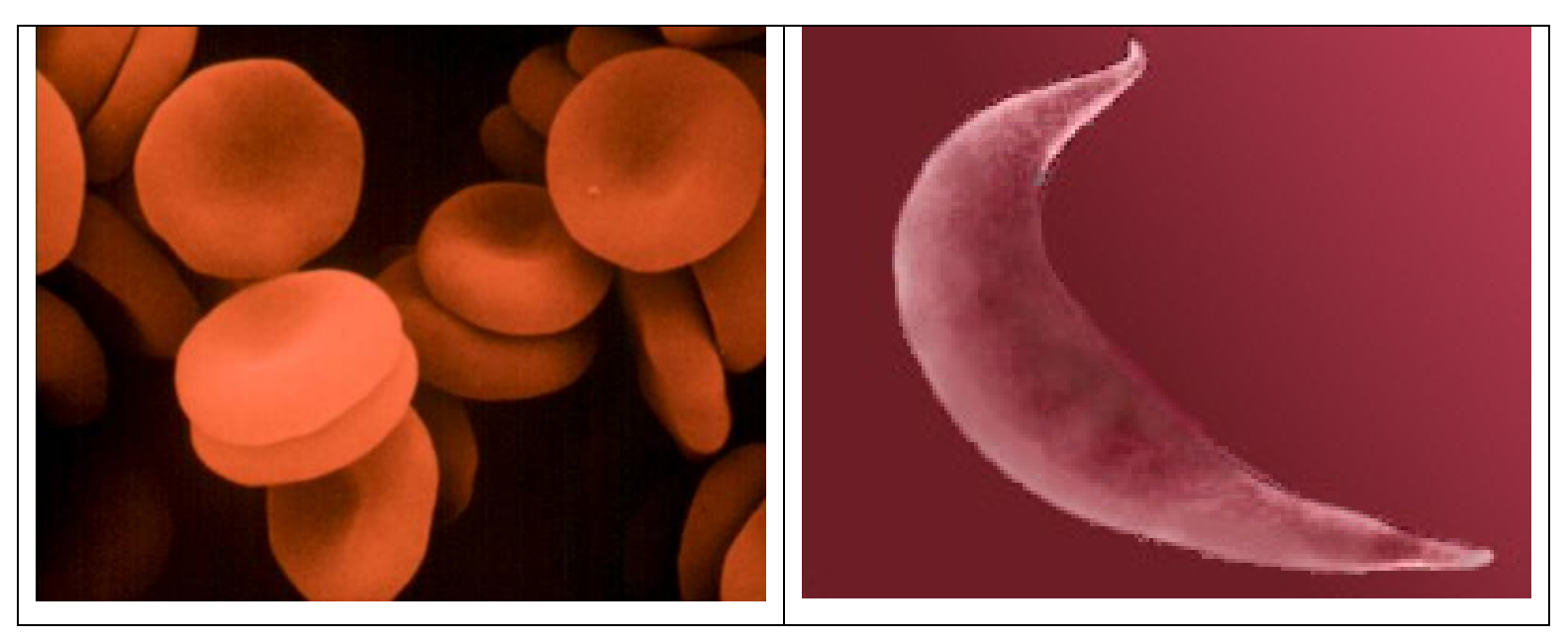

FIGURA 3.21. Hemoglobina A e Hemoglobina S, respectivamente.

\subsubsection{Manifestações clínicas da doença}

As manifestações da anemia falciforme são variáveis, pois seu aspecto de aparecimento depende do grau de hemoglobina $\mathrm{S}$ e do grau de oxigenação da hemácia. Dentre os principais sintomas relacionados à anemia falciforme, alguns merecem destaque, tais como:

\subsubsection{Crises álgicas}

Geralmente é a primeira manifestação clínica da anemia falciforme. É decorrente da obstrução do fluxo sanguíneo pelas hemácias falcizadas ${ }^{[81]}$. As crises dolorosas ocorrem 
entre quatro a seis dias, podendo persistir por semanas. Hipóxia, infecção, febre, acidose, desidratação e exposição ao frio extremo podem precipitar as crises álgicas.

Em pacientes idosos, a dor é mais comum em extremidades, abdômen e costas, podendo estas ser desencadeadas por depressão ou exaustão ${ }^{[82]}$. Em crianças, a dor mais comum é a dactilite ou síndrome mão-pé ${ }^{[81,82]}$. Manifestações músculo esqueléticas coexistem, sendo difícil o diagnóstico diferencial com osteomielite, artrite séptica, sinovite e febre reumática. A dor abdominal pode simular abdômen agudo cirúrgico ou infeccioso, ou processos ginecológicos ${ }^{[83]}$.

\subsubsection{Dor torácica aguda}

Caracterizada por dor aguda de forte intensidade, acompanhada de febre, tosse, dispnéia moderada a grave ${ }^{[84,85]}$. Geralmente é causada por infecção, embolia de medula óssea necrótica, vaso-oclusão pulmonar e seqüestro esplênico. A mortalidade é alta se medidas suportivas não forem tomadas ${ }^{[86]}$.

\subsubsection{Febre}

Devido à alta associação de infecções em pacientes com anemia falciforme, a febre é um dos sinais mais comuns ${ }^{[81,84]}$.

O risco de septicemia ou até mesmo meningite por Streptococcus pneumoniae ou Haemophilus influenzae chega a ser 600 vezes maior em crianças com anemia falciforme. Tais infecções podem provocar morte em poucas horas ${ }^{[85,86]}$. Pneumonias, infecções renais e osteomielites também ocorrem com freqüência maior em crianças e adultos com doença falciforme ${ }^{[86]}$. Episódios de febre devem ser encarados como situações de risco ${ }^{[81]}$.

\subsubsection{Baixa imunidade}

Os processos vaso-oclusivos repetidos no baço levam a asplenia funcional, uma redução da função esplênica, que diminui a capacidade imunológica ${ }^{[87]}$. A diminuição da capacidade imunológica faz com que haja mais susceptibilidade de infecções por Pneumococcus pneumoniae e Haemophilus influenzae ${ }^{[85]}$. Deve-se iniciar um programa eficaz de imunizações em crianças com anemia falciforme, antes dos cinco anos de idade $[81,82,84]$. 


\subsubsection{Crise aplásica}

Caracterizada por sintomas de anemia aguda sem aumento do baço, podendo até mesmo ser acompanhada de sinais de choque hipovolêmico. Ocorre geralmente após processos infecciosos e a infecção pelo Parvovírus B19 é a de maior gravidade ${ }^{[88,89]}$.

\subsubsection{Crise de sequestro esplênico}

É o acúmulo de grande volume de hemácias no baço levando a uma esplenomegalia e a uma diminuição súbita na hemoglobina plasmática, podendo levar a choque hipovolêmico. É a causa mais comum de mortes em crianças com anemia falciforme, ocorrendo geralmente a partir dos cinco meses de vida, sendo rara após os dois anos ${ }^{[88]}$.

\subsubsection{Litíase biliar}

Ocorre em $14 \%$ das crianças menores de dez anos, em $30 \%$ dos adolescentes e em $75 \%$ dos adultos portadores de anemia falciforme. Os cálculos biliares são múltiplos e em $60 \%$ dos casos são radiopacos. Podem ser assintomáticos por muito tempo ou causar sintomas crônicos como empaxamento, náuseas, vômitos e dor no quadrante superior direito ${ }^{[90]}$. As complicações mais comuns são a colecistite, obstrução do ducto biliar e, mais raramente, pancreatite aguda ${ }^{[87]}$.

\subsubsection{Icterícia}

Devido a menor sobrevida dos eritrócitos na doença falciforme. A degradação aumenta os níveis séricos de bilirrubina, sendo freqüente a presença de icterícia. Esta pode ser exacerbada em situações de aumento da taxa de hemólise, como a que ocorre em infecções associadas ${ }^{[81]}$.

\subsubsection{Acidente Vascular Encefálico}

Ocorre em $10 \%$ dos pacientes com doença falciforme ${ }^{[91]}$ devido à isquemia e infarto decorrentes da obstrução de artérias cerebrais. As manifestações neurológicas são geralmente focais e podem incluir hemiparesia, hemianestesia, deficiência do campo 
visual, afasia e paralisia de nervos cranianos. Sinais mais generalizados como coma e convulsões podem ocorrer ${ }^{[92]}$. A recidiva do acidente vascular cerebral provoca danos maiores e aumenta a mortalidade ${ }^{[93]}$.

\subsubsection{0 Úlceras de pernas}

Presentes entre 8 a $10 \%$ dos portadores de doença falciforme, sendo mais comum após os dez anos de vida ${ }^{[94]}$. As úlceras geralmente se localizam no terço inferior das pernas, próximas aos maléolos medial e lateral. Podem aparecer sobre a tíbia ou dorso do pé [95]. Está associada a crises vaso-oclusivas e a microtraumatismos ${ }^{[94,95]}$.

\subsubsection{Aborto}

$\mathrm{Na}$ doença falciforme a gravidez promove maior risco para a gestante e o aborto espontâneo ocorre freqüentemente. Apesar dos riscos, não se contra-indica uma gravidez desejada. Todas as mulheres devem, porém, ser informadas do risco de abortamento ${ }^{[96]}$.

\subsubsection{Priapismo}

É a ereção dolorosa do pênis, que pode ocorrer em episódios breves e recorrentes ou em episódios longos, podendo causar impotência sexual. Ocorre com relativa freqüência, devido à baixa tensão de oxigênio e estase pela congestão venosa do pênis em ereção, o que cria condições para trombose e oclusão vascular, podendo deixar seqüelas orgânicas e causar impotência. Pode acompanhar-se de dor abdominal, dor perineal, disúria, retenção urinária, edema escrotal e aumento de próstata ${ }^{[97,98,99]}$.

\subsubsection{Manifestações oculares}

As alterações oculares podem afetar a conjuntiva, retina, coróide e câmara anterior do olho, e caracterizam-se pela tortuosidade e dilatação das vênulas. Tais alterações decorrem da falcização dos eritrócitos ${ }^{[100]}$. Existem dois tipos de retinopatia nos pacientes com doença falciforme: proliferativa e a não-proliferativa. A retinopatia não-proliferativa inclui oclusões vasculares, hemorragia da retina e alterações maculares. Essas alterações geralmente não afetam a acuidade visual. Já a retinopatia proliferativa se caracteriza por 
uma neovascularização retiniana, acometendo pacientes com idade entre 20 e 40 anos ${ }^{[101,}$ 102].

\subsection{Diagnóstico atual da anemia falciforme}

O diagnóstico da anemia falciforme é realizado principalmente em pacientes de cor negra ou afro-descendentes, porém ela afeta grande parte da população brasileira, devido à grande miscigenação racial.

\subsubsection{Hemograma}

No caso de traço falcêmico, o hemograma pode apresentar discreta anemia ou se apresentar normal. O hemograma apresenta uma anemia hemolítica, na maioria das vezes normocrômica e normocítica. Em alguns casos pode ser hipocrômica ou macrocítica. Há sinais indiretos de hemólise devido os achados de hiperbilirrubinemia indireta e reticulocitose ${ }^{[86]}$. A presença de leucocitose com moderada neutrofilia não se correlaciona necessariamente com infecção. Trombocitose é mais comum em quadros de crises de vasooclusão, enquanto que a trombocitopenia é mais comum nos quadros de seqüestro esplênico $^{[88]}$.

Ao exame microscópio de sangue periférico, a presença de anisopoiquilocitose e policromasia são bastante comuns. Dentre estes, destacam-se a presença de hemácias em forma de foice e um grande número de eritroblastos em várias formas maturativas. Quando se observa eritroblastos de tamanhos aumentados, há a presença de reticulocitose ou a carência de folato associados ao quadro de anemia ${ }^{[86,103]}$.

\subsubsection{Teste de falcização}

O teste é realizado coletando-se aproximadamente $3 \mathrm{ml}$ de sangue periférico em tubos contendo EDTA de pacientes em jejum de no mínimo 4 horas. Tais tubos podem ser refrigerados por até 24 horas. Em seguida, faz-se a incubação das hemácias com metabissulfito de sódio a $2 \%$ por certo período de tempo (varia conforme kit laboratorial) e o preparo é analisado em microscópio. A presença de grande quantidade de eritrócitos alterados confirma a presença de hemoglobina $\mathrm{S}^{[104,105]}$. 


\subsubsection{Eletroforese de proteínas}

Eletroforese é uma técnica baseada na separação de partículas em um determinado gel, a base de agarose ou poliacrilamida, de acordo com sua massa e carga. É utilizado para separação de diversas moléculas orgânicas, como lipoproteínas, proteínas, RNA e DNA [106]. Para a confirmação diagnóstica de anemia falciforme, a técnica mais eficaz é a eletroforese em gel de agarose em $\mathrm{pH}$ alcalino (variando de 8 a 9). É realizada em meio básico, pois permite análises qualitativas e quantitativas das frações da hemoglobina. Associa-se a técnica da eletroforese em gel de agarose em $\mathrm{pH}$ ácido para diferenciar a heterozigose entre hemoglobina $\mathrm{S}$ e hemoglobina $\mathrm{D}$, que apresentam migrações similares em $\mathrm{pH}$ alcalino ${ }^{[107]}$.

\subsection{Tratamento da anemia falciforme}

O tratamento precoce é indispensável para a sobrevida de crianças com o diagnóstico de anemia falciforme, pois é uma das doenças que mais levam a óbito. Vale lembrar que cerca de $25 \%$ a $30 \%$ das crianças menores de cinco anos morrem devido a complicações dessa doença ${ }^{[108]}$. As opções atualmente disponíveis e consideradas eficazes para o tratamento da anemia falciforme são o transplante de medula óssea (TMO) e a hidroxiuréia. O transplante é considerado medida curativa, porém sua aplicação é restrita, devido à necessidade de doador compatível e a alta taxa de complicações ${ }^{[109,110,111]}$. 


\section{REFERÊNCIAS BIBLIOGRÁFICAS}

[1] BLASSE, G.; GRABMAIER, B. C. Luminescent materials. Berlin: Springer, 1994.

[2] DIEKE, G. H. Spectra and energy levels of rare earth ions in crystals. New York: Interscience Publishers, 1968.

[3] TECOTZKY, M. Industrial applications of rare earth phosphors. In: $15^{\text {th }}$ RARE EARTH CONFERENCE, Missouri, 1981.

[4] THOMPSON, L. M. Complexes. In: GSCHNEIDNER, K. A.; LEROY, E. Handbook on the physics and chemistry of the rare earth. Naew York: North Holand Publishing Company, v. 3, p. 209-297,1978.

[5] SABBATINI, N.; GUARDIGLI, M.; MANET, I; UNGARO, R.; CASNATI, A.; ZIESSEL, R.; ULRICH, G.; ASFARI, Z.; LEHN, J. M. Lanthanide complexes of encapsulating ligands: luminescent devices at the molecular level. Pure and Appl. Chem. v. 67, p. 135-140, 1995.

[6] SABBATINI, N.; MECATI, A.; GUARDIGLI, M.; BALZANI, V.; LEHN, J. M.; ZIESSEL, R.; UNGARO, R. Lanthanide luminescence in supramolecular species. J. of Lumin. v. 48, p. 463-468, 1991.

[7] ABRÃO, A. Química e tecnologia das terras raras. Rio de Janeiro: Cetem, 1994.

[8] COTTON, S. Lanthanides and actinides. New York: Oxford University Press, 1991.

[9] FORSBERG, J. H. Complexes of lanthanide(III) ions with hidrogen donor ligands. Coord. Chem. Rev. v. 10, p.195-226, 1973.

[10] BLASSE, G.; BRIL, A. Characteristic luminescnce. Philips Techn. Rev. v. 31, p. 303-331, 1970.

[11] BÜNZLI, J. C. G.; CHOPPIN, G. R. Lanthanide probes in life, chemical and earth science. Amsterdan: Elsevier, 1989. 
[12] DAVOLOS, M. R. Complexos de manganês(II) e fosfinóxidos: absorção e luminescência. São Paulo, 1983. Tese de Doutorado. Instituto de Química, Universidade de São Paulo.

[13] MATOS, J. R. Estudo comparativo dos compostos de adição entre metanossulfonatos de lantanídeos(III) e aminóxidos aromáticos como ligantes. São Paulo, 1989. Tese de Doutorado. Instituto de Química, Universidade de São Paulo.

[14] BECKER, R. S. Theory and interpretation of fluorescence and phosphorescence. New York: Wiley Interscience, 1969.

[15] GUILBALT, G. G. Practical fluorescence. New York: Marcel Dekker, 1973.

[16] SIMONS, J. P. Photochemistry and spectroscopy. London: Wiley Interscience, 1971.

[17] DEMAS, J. N. Photophysical pathways in metal complexes. J. of Chem. v. 60, p. 803-808, 1983.

[18] BLASSE, G. Luminescence of inorganic solids: from isolated centers to concentrated systems. Progress in Sol. State Chem. v.18, p. 79-171, 1988.

[19] BLASSE, G. Chemistry and physics of R-ativated phosphors. In: GSCHNEIDNER, K. A.; LEROY, E. Handbook on the physics and chemistry of the rare earth. New York: North Holand Publishing Company, v. 4, p. 237-274, 1979.

[20] BALZANI, V.; SABBATINI, N.; SCANDOLA, F. $2^{\text {nd }}$ sphere photochemistry and photophysics of coordination compounds. Chem. Rev. v. 86, p. 319-337, 1986.

[21] BUONOCORE, G. E.; LI, H.; MARCINIAK, B. Quenching of excited states by lanthanide ion and chelates in solutions. Coord. Chem. Rev. v. 99, p.55-87, 1990.

[22] MOELLER, T. The chemistry of the lanthanides. New York: Reinhold Publishing Corporation, 1963.

[23] SINHA, S. P. Complexes of rare earths. New York: Pergamon Press, 1966.

[24] CARNALL, W. T.; GOODMAN, G. L.; RAJANK, K.; RANA, R .S. A systematic analysis of the spectra of the lanthanides doped into single crystal $\mathrm{LaF}_{3}$ solution. Chicago: Argonne National Laboratory Report, 1988.

[25] WEISSMAN, S. I. Intramolecular energy transfer the fluorescence of complexes of europium. J. of Chem. Phys. v. 10, p. 214-217, 1942.

[26] DE LA TORRE, M.A.C.; GOMEZ-HENS, A.; Anal. Chim. Acta, 407, 53 (2000).

[27] TOBITA, S.; ARAKAWA, M.; TANAKA, I. The paramagnetic metal effects on the ligand localized S1-T1 intersystem crossing in the rare earth metal complexeswith mehtyl salycilate. J. of Phys. Chem. v. 89, p. 5649-5654, 1985. 
[28] CROSBY, G. A.; ALIRE, R. M.; WHAN, R. E. Intramolecular energy transfer in rare earth chelates: role of triplet state. J. Phys. Chem. v. 34, p. 743-748, 1961.

[29] WHAN, R. E.; CROSBY, G. A. Luminescence studies of rare earth complexes: benzoylacetonate dibenzoylmethide chelates. J. of Mol. Spectroscopy. v. 8, n. 4, p. 315-327, 1962.

[30] KLEINERM, M. Energy migration in lanthanide chelates. J. of Chem. Phys. v. 51, p. 2370-2381, 1969.

[31] BHAUMIK, M. L.; ELSAYED, M. A.. Mechanism and rate of intramolecular energy transfer process in rare earth chelates. J. of Chem. Phys. v. 42, p. 787-788, 1965.

[32] SÁ, G.F.; MALTA, O.L.; DONEGA, C.M.; SIMAS, A.M.; LONGO, R.L.; SANTACRUZ, P. A.; SILVA JR., E.F.; Spectroscopic properties and design of highly luminescent lanthanide coordination complexes. Coord. Chem. Rev., v. 196, 165$195,2000$.

[33] SABBATINI, N.; GUARDIGLI, M.; LENH, J.M.; Luminescente lanthanide complexes as photochemical supramolecular devices. Coord. Chem. Rev. v.123, n.1-2 p.201-228 (1993).

[34] TEOTONIO, E.E.S. Síntese e investigação das propriedades fotoluminescentes de dispositivos moleculares conversores de luz (DMCL) de complexos dicetonatos de terras raras com ligantes amidas. São Paulo, 2004. Tese de Doutorado. Instituto de Química, Universidade de São Paulo.

[35] BINNEMAN K., Rare-earth beta-diketonates, Handbook on the Physics and Chemistry of Rare Earths. Elsevier, 2005.

[36] MEHROTRA R. C., BOHRA R. ;GAUR D. P. Metal B-Diketonates and Allied Derivatives. London: Academic Press, 1978.

[37] MENEZES, J. F. S. Estudo fotoluminescente de tristenoiltrifluoroacetonatos de lantanídeos com sulfóxidos. São Paulo, 1999. Tese de Doutorado. Instituto de Química, Universidade de São Paulo.

[38] SHINKAI, S.; MORI, S.; TSUBAKI, T.; SONE, T.; MANABE, O. New water soluble host molecules derived from calix[6]arene. Tetrahedron Lett. v. 25, p. 5315-5318, 1984.

[39] GUTSCHE, C. D. Calixarenes. Saint Louis: Royal Society of Chemistry, 1989.

[40] AIME, S.; BOTTA, M.; PARKER, D.; WILliAMS, J. A. G. Extent of hydration octadentate lanthanide complexes incorporating phosphinate donors: solution relaxometry and luminescence studies. J. of Chem. Soc. Dalton Transactions. v. 1, p. 17-23, 1996. 
[41] SHINKAI, S.; TSUBAKI, T.; SONE, T.; MANABE, O. A new synthesis of paranitrocalix[6]arene. Tetrahedron Lett. v. 26, p. 3343-3344, 1985.

[42] CHANG, S. K.; KWON, S. K.; CHO, I. Calixarene based amide ionophores for group IIA metal cations. Chem. Lett. v. 5, p. 947-948, 1987.

[43] MOSHFEGH, A. A.; BADRI, R.; HOJJATIE, M.; KAVIVANI, M.; NADERI, B; NAZMI, A. H.; RAMEZANIAN, M.; ROOZPEIKAR, B.; HAKIMELAHI, G. H. Helvetica Chim. Acta. v. 65, p. 1221-1228, 1982.

[44] NOMURA, E.; TANIGUCHI, H.; KAWAGUCHI, K.; OTSUJI, Y. Catalytic ability of flexible octopus calix[6]arene in ester forming reactions and its structural properties. J. of Org. Chem. v. 58, p. 4709-4715, 1993.

[45] SCHWING, M. J.; ARNAUD, F.; MARQUES, E. Cation binding properties of alkyl calixaryl derivatives: a new family of molecular receptors. Pure and Appl. Chem. v. 61, p. 1597-1603, 1989.

[46] MANDOLINI, L.; UNGARO, R., Calixarene in Action. Imperial College Press, 1999.

[47] VICENS, J.; ASFARI, Z. HARROWFIELD J. M. (Ed) Calixarenes 50 $^{\text {th }}$ anniversary: commemorative issue. Dordrecht-Kluwer, 1994.

[48] PEACHEY, B. J. The synthesis and characterization of new calix[n]arenes and their use as solvent extraction agents for the lanthanides and actinides. Western. Tese de Doutorado. University of Western, 1995.

[49] TANG, J.; WAI, C. M. Solvent extraction of lanthanides with a crown ether carnoxylic acid. Anal. Chem. v. 58, p. 3233-3235, 1986.

[50] GUTSCHE, C. D.; DHAWAN, B.; LEVINE, J. A.; NO, K. H., BAUER, L. J. Calixarenes conformational isomers of the ethers and esters of calix[4]arenes. Tetrahedron. v. 39, p. 409-426, 1983.

[51] HALL, E. A. H.. Biosensors in context. In Biosensors, Buckingham: Open University Press, p. 3-29. 1990.

[52] KAROL, P. J. Label. In Glossary of terms for radiochemistry and nuclear techniques (http://www.iupac.org/V7_karol/Main.html), 2001.

[53] KAROL, P. J. Tracer. In Glossary of terms for radiochemistry and nuclear techniques (http://www.iupac.org/V7_karol/Main.html), 2001.

[54] HAUGLAND, R. P. Ultrasensitive detection technology. In Handbook of fluorescent probes and research chemicals, $8^{\text {th }}$ edition (http://www.probes.com/handbook/sections/0600.html), Molecular Probes, Eugene, 2001 
[55] HEMMILÄ I, HARJU R. TIME-RESOLVED FLUOROMETRY. IN I HEMMILÄ, T STÅHLBERG AND P MOTTRAM (eds). Bioanalytical Applications of Labelling Technologies, EG\&G Wallac, Turku, pp.83-119(1994).

[56] KETRING, A. R. 153Sm-EDTMP and 186Re-HEDP as bone therapeutic radiopharmaceuticals. International Journal of Radiation Applications and Instrumentation B. v. 14, p. 223-232, 1987.

[57] KULMALA, S.; ALA-KLEME, T.; LATVA, M.; LOIKAS, K.; TAKALO, H. Hot electron-induced electrogenerated chemiluminescence of rare earth(III) chelates at oxide-covered aluminum electrodes. J. of Fluorescence. v. 8, p. 59-65, 1998.

[58] DICKSON, E. F.; POLLAK, A.; DIAMANDIS, E. P. Time-resolved detection of lanthanide luminescence for ultrasensitive bioanalytical assays. Journal of Photochem. and Photobiol. B. v. 27, p. 3-19, 1995.

[59] SAMMES, P. G.; YAHIOGLU, G. Modern bioassays using metal chelates as luminescent probes. Natural Product Reports. v. 13, p. 1-28, 1996.

[60] HORROCKS, W. D.; SUDNICK, D. R. Lanthanide ion probes of structure in biology. Laser-induced luminescence decay constants provide a direct measure of the number of metal-coordinated water molecules. J. of Am. Chem. Soc. v. 101, p. 334340, 1979.

[61] MATHIS G. Rare earth cryptates and homogeneous fluoroimmunoassays with human sera. Clin. Chem. v. 39, p. 1953-1953, 1993.

[62] HEMMILÄ, I.; BATSMAN, A. Time-resolved immunofluorometry of HCG. Clin. Chem. v. 34, p. 1163-1164, 1988.

[63] FAULKNER, S.; BEEBY, A.; DICKINS, R. S.; PARKER, D.; WILLIAMS, J. A. G. Generating a warm glow: lanthanide complexes which luminesce in the near-IR. J. of Fluorescence. v. 9, p. 45-49, 1999.

[64] BUONOCORE, G.E.; LI, H.; MARCINIAK, B. Quenching of excited-states by lanthanide ions and chelates in solution. Coord. Chem. Rev. v. 99, p. 55-87, 1990.

[65] WOLBERS, M.P.O.; VAN VEGGEL, F.C.J.M.; HEERINGA, R.H.M.; HOFSTRAAT, J.W.; GEURTS, F.A.J.; VAN HUMMEL, G.J.; HARKEMA, S.; REINHOUDT, D. N. Biscalix[4]arene ligands for dinuclear lanthanide ion complexation. Liebigs Annalen-Recueil. v. 12, p. 2587-2600, 1997.

[66] HEMMILÄ, I.; MUKKALA, V. M.; TAKALO, H. Development of luminescent lanthanide chelate labels for diagnostic assays. J. of Alloys and Comp. v. 249, p. 158-162, 1997.

[67] LATVA, M.; TAKALO, H.; MUKKALA, V. M.; MATACHESCU, C.; RODRIGUEZUBIS, J. C.; KANKARE, J. Correlation between the lowest triplet state energy level of the ligand and lanthanide (III) luminescence quantum yield. J. of Lumin. v. 75, p. 149-169, 1997. 
[68] HEMMILÄ I. Optimized chelate-labels for homogeneous and heterogeneous screening assays in HORI, W.; SAVAGE, L. M. (eds.) High-Throughput Screening II. Novel Assay Design, Rapid Target Development and Accelerated Level Optimization. Southborough: IBC Library Series. 1997.

[69] HEMMILÄ I. Lanthanides as probes for time-resolved fluorometric immunoassays. Scandinavian J. of Clin. and Laboratory Investigation. v. 48, p. 389-399, 1988.

[70] HEMMILÄ I. Photoluminescence immunoassays in JOHNSTONE, A. P.; TURNER, M. W. (ed.) Immunochemistry: a practical approach. New York: IRL Press. 1997.

[71] LEIF, R. C.; CLAY, S. P.; GRATZNER, H. G.; HAINES, H. G.; RAO, K. V.; VALLARINO, L. M. in Markers for instrumental evaluation of cells of the female reproductive tract: existing and new markers In: WIED, G. L.; BHAR, G. F.; BARTELO, P. H. (eds.)The automation of uterine cancer cytology. Chicago: Tutorials of Cytology. 1976.

[72] PAVIA, D. L.; LAMPMAN, G. M.; KRIZ, G. S.; VYVYAN J. A. Introduction to Spectroscopy. Brooks/Cole Pub Co: 3-12, 2000.

[73] SILVERSTEIN, R. M.; KIEMLE, D. J.; WEBSTER, F. X. Identificação Espectrométrica de Compostos Orgânicos, LTC: 60-74. 2000

[74] COLTHUP N.B.; DALY L.H.; WIBERLEY S.H.; Introduction to Infrared and Raman Spectroscopy, Academic Press, New York and London, 275, 1964.

[75] MENDHAM, J.; DENNEY, R. C.; BARNES, J. D.; THOMAS, M. J. K. V. Análise Química Quantitativa. 6 Ed. Rio de Janeiro: LTC Editora, 2002.

[76] HARRIS, D. C.; Análise Química Quantitativa. 5ª ed. Rio de Janeiro: LTC, 2001.

[77] SKOOG, D.A.; WEST, D.M.; HOLLER, F.J.; Fundamentals of Analytical

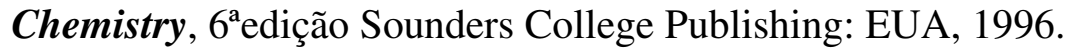

[78] GALIZA NETO, GENTIL CLAUDINO DE, PITOMBEIRA, MARIA DA SILVA. Aspectos moleculares da anemia falciforme. J. Bras. Patol. Med. Lab., 2003(1):3951-56.

[79] BUNN, H.F. e FORGET, B.G. Hemoglobin: molecular, genetic and clinical aspects. 1. ed. W.B. Saunders Company, 1986, 690p.

[80] BALLAS, S.K. e MOHANDAS, N. Pathophisiology of vaso-occlusion. Hematology/Oncology Clinics of North America, 10(6), 1996.

[81] EJINDU VC, HINE AL, MASHAYEKHI M, SHORVON PJ, MISRA RR. Musculoskeletal manifestations of sickle cell disease. Radiographics. $2007 \mathrm{Jul}$ Aug; 27(4):1005-21. Review. 
[82] ALMEIDA A, ROBERTS I. Bone involvement in sickle cell disease. $\mathrm{Br} \mathrm{J}$ Haematol. 2005 May; 129(4):482-90. Review.

[83] MEDDEB N, GANDOURA N, GANDOURA M, SELLAMI S. Osteoarticular manifestations of sickle cell disease. Tunis Med. 2003 Jul; 81(7):441-7. Review.

[84] BENNETT OM, NAMNYAK SS. Bone and joint manifestations of sickle cell anaemia. J Bone Joint Surg Br. 1990 May; 72(3):494-9.

[85] ARDILES T, DARK D. Pulmonary complications of sickle cell disease in adults. Mo Med. 2007 May-Jun; 104(3):250-4. Review.

[86] SIDDIQUI AK, AHMED S. Pulmonary manifestations of sickle cell disease. Postgrad Med J. 2003 Jul; 79(933):384-90. Review.

[87] FRENETTE PS, ATWEH GF. Sickle cell disease: old discoveries, new concepts, and future promise. J Clin Invest. 2007 Apr; 117(4):850-8. Review.

[88] WILLIAM BM, CORAZZA GR. Hyposplenism: a comprehensive review. Part I: basic concepts and causes. Hematology. 2007 Feb; 12(1):1-13. Review

[89] SERVEY JT, REAMY BV, HODGE J. Clinical presentations of parvovirus B19 infection. Am Fam Physician. 2007 Feb 1; 75(3):373-6. Review.

[90] KHATTAB AD, RAWLINGS B, ALI IS. Care of patients with haemoglobin abnormalities: history and biology. Br J Nurs. 2006 Oct 12-25; 15(18):994-8. Review.

[91] MAZUMDAR M, HEENEY MM, SOX CM, LIEU TA. Preventing Stroke Among Children With Sickle Cell Anemia: An Analysis of Strategies That Involve Transcranial Doppler Testing and Chronic Transfusion. Pediatrics. 2007 Sep

[92] ADAMS RJ, MCKIE VC, HSU L, FILES B, VICHINSKY E, PEGELOW C, ABBOUD M, GALLAGHER D, KUTLAR A, NICHOLS FT, BONDS DR, BRAMBILLA D. Prevention of a first stroke by transfusions in children with sickle cell anemia and abnormal results on transcranial Doppler ultrasonography. N Engl J Med. 1998 Jul 2; 339(1):5-11

[93] ADAMS RJ. Lessons from the Stroke Prevention Trial in Sickle Cell Anemia (STOP) study. J Child Neurol. 2000 May; 15(5):344-9. Review.

[94] NOLAN VG, ADEWOYE A, BALDWIN C, WANG L, MA Q, WYSZYNSKI DF, FARRELL JJ, SEBASTIANI P, FARRER LA, STEINBERG MH. Sickle cell leg ulcers: associations with haemolysis and SNPs in Klotho, TEK and genes of the TGFbeta/ BMP pathway. Br J Haematol. 2006 Jun; 133(5):570-8.

[95] SERJEANT GR, SERJEANT BE, MOHAN JS, CLARE A. Leg ulceration in sickle cell disease: medieval medicine in a modern world. Hematol Oncol Clin North Am. 2005 Oct; 19(5):943-56, viii-ix. Review. 
[96] XU K, SHI ZM, VEECK LL, HUGHES MR, ROSENWAKS Z. First unaffected pregnancy using preimplantation genetic diagnosis for sickle cell anemia. JAMA. 1999 May 12; 281(18):1701-6.

[97] GBADOE AD, GERALDO A, GUEDENON K, KOFFI S, AGBETIAFA K, AKPAKO P. Stuttering priapism in children with sickle cell anemia in Togo. Arch Pediatr. 2007 Jul; 14(7):861- 3. Epub 2007 Apr 24.

[98] ELLIOTT L, ASHLEY-KOCH AE, DE CASTRO L, JONASSAINT J, PRICE J, ATAGA KI, LEVESQUE MC, BRICE WEINBERG J, ECKMAN JR, ORRINGER EP, VANCE JM, TELEN MJ. Genetic polymorphisms associated with priapism in sickle cell disease. Br J Haematol. 2007 May; 137(3):262-7.

[99] HSU L, DIWAN B, WARD JM, NOGUCHI CT. Pathology of "Berkeley" sicklecell mice includes gallstones and priapism. Blood. 2006 Apr 15; 107(8):3414-5.

[100]CUSICK M, TOMA HS, HWANG TS, BROWN JC, MILLER NR, ADAMS NA. Binasal visual field defects from simultaneous bilateral retinal infarctions in sickle cell disease. Am J Ophthalmol. 2007 May; 143(5):893-6.

[101]ADEWOYE AH, RAMSEY J, MCMAHON L, SAKAI O, STEINBERG MH. Lacrimal gland enlargement in sickle cell disease. Am J Hematol. 2006 Nov; 81(11):888-9.

[102] WITKIN AJ, ROGERS AH, KO TH, FUJIMOTO JG, SCHUMAN JS, DUKER JS. Optical coherence tomography demonstration of macular infarction in sickle cell retinopathy. Arch Ophthalmol. 2006 May; 124(5):746-7.

[103]SONATI, E. et al. Hereditary hemoglobinopathies in a population from Southeast Brazil. Hemoglobin, v. 20, n. 2, p. 175 - 179, 1996.

[104]RUIZ M.A., ANGELA I. Proposta de um protocolo para portadores de doença falciforme. Boletim. 1988; 10:183-190.

[105] VICHINSKY E., LUBEN B.H. Suggested guidelines for the treatment of children with sickle cell anemia. Hematology/ Oncologym clinics of North America. 1987; 11:183-498.

[106] VELLA, F. Acid agar gel electrophoresis of human hemoglobins. Am. J. Clin. Pathol v. 49, p.440, 1968.

[107]NAOUM P. Eletroforese: técnicas e diagnósticos. São Paulo: Santos; p. 91, 1990.

[108]DI NUZZO DVP, FONSECA SF. Anemia falciforme e infecções. Jornal de Pediatria; 80(5):347-354, 2004.

[109]BUCHANAN GR, et al. Sickle Cell Disease. American society of Hematology; 3547, 2004. 
[110]FERSTER A, et al. Five years of experience with hydroxyurea in children and young adults with sickle cell disease. Blood; 97(11):3.628-3.632, 2001.

[111]SCHNOG JB, et al. Sickle cell disease; a general overview. The Journal of Medicine;62(10):364-374,2004. 


\subsection{METODOLOGIA}

\subsection{Reagentes, solventes e aminoácidos}

As substâncias utilizadas neste trabalho foram empregadas sem tratamento prévio. $\mathrm{Na}$ TAB. 4.1 encontra-se a relação dos principais reagentes e solventes usados nos experimentos.

TABELA 4.1. Reagentes, solventese aminoácidos usados nos experimentos.

\begin{tabular}{|c|c|}
\hline Reagentes, solventes e aminoácidos & Procedência \\
\hline$>$ para-terc-butilcalix [8]arenos, pureza $>95 \% ; \mathrm{C}_{11} \mathrm{H}_{16} \mathrm{O}$ & Aldrich \\
\hline$>$ anidrido acético, p. a.; $\mathrm{C}_{4} \mathrm{H}_{6} \mathrm{O}_{3}$ & Merck \\
\hline$>$ ácido sulfúrico, p.a. $95-98 \% ; \mathrm{H}_{2} \mathrm{SO}_{4}$ & Merck \\
\hline$>$ metanol, p. a. ; $\mathrm{CH}_{3} \mathrm{OH}$ & Merck \\
\hline$>$ clorofórmio, p.a.; $\mathrm{CHCl}_{3}$ & Merck \\
\hline$>$ hidróxido de amôneo; $\mathrm{NH}_{4} \mathrm{OH}$ & Merck \\
\hline$>$ etanol, p.a. $99,8 \% ; \mathrm{C}_{2} \mathrm{H}_{6} \mathrm{O}$ & Aldrich \\
\hline$>$ acetona,p.a. $99,5 \% ; \mathrm{C}_{3} \mathrm{H}_{6} \mathrm{O}$ & Merck \\
\hline$>$ hidróxido de sódio, p.a.; $\mathrm{NaOH}$ & Merck \\
\hline$>$ ácido nítrico, p.a. $70 \% ; \mathrm{HNO}_{3}$ & Vetec \\
\hline$>$ óxido de európio (III), 99,99\% & Sigma \\
\hline$>$ ácido clorídrico, p.a. 37\%; KCl & Merck \\
\hline$>$ 2-tenoil-trifluoroacetona, $(\mathrm{TTA}) ; \mathrm{C}_{8} \mathrm{H}_{6} \mathrm{SO}_{2} \mathrm{~F}_{3}$ & Merck \\
\hline$>$ acetil acetona (ACAC); $\mathrm{C}_{5} \mathrm{H}_{8} \mathrm{O}_{2}$ & Merck \\
\hline$>$ brometo de potássio; $\mathrm{KBr}$ & Merck \\
\hline$>$ glutaraldeído; $\mathrm{C}_{5} \mathrm{H}_{8} \mathrm{O}_{2}$ & Vetec \\
\hline$>$ valina; $\left(\mathrm{CH}_{3}\right)_{2} \mathrm{CHCH}\left(\mathrm{NH}^{3+}\right) \mathrm{CO}_{2}^{-}$ & Merck \\
\hline$>$ àcido glutâmico; $\mathrm{C}_{5} \mathrm{H}_{9} \mathrm{NO}_{4}$ & Merck \\
\hline$>$ seleneto de zinco; $\mathrm{ZnSe}$ & Pike Technologies \\
\hline$>$ fluoreto de cálcio; $\mathrm{CaF}_{2}$ & Pike Technologies \\
\hline
\end{tabular}


Neste trabalho as atividades experimentais foram divididas em cinco partes; a síntese das supermóleculas de $\beta$-dicetonatos de Lantanídeoas $\left(\operatorname{Ln}^{3+}\right)$, a caracterização destas supermoléculas, o estudo das suas propriedades luminescentes, a conjugação das supermoléculas ao espaçador e alguns ensaios biológicos.

\subsection{Sínteses}

\subsubsection{Síntese do quelato de $\beta$-dicetonas de lantanídeos}

Os quelatos de $\beta$-dicetonatos (acetil acetona, ACAC ou 2-tenoiltrifluoroacetona, TTA) de $\mathrm{Eu}^{3+}$ $\mathrm{e} \mathrm{Tb}^{3+}$ foram obtidos dissolvendo-se soluções aquosas do nitrato de lantanídeo (1mol/L) e adicionandose o mesmo volume de uma solução alcoólica de $\beta$-dicetonato ( $2 \mathrm{~mol} / \mathrm{L})$. Esta solução final foi aquecida até temperatura de $60^{\circ} \mathrm{C}$ sob agitação, por duas horas, até formação de um precipitado. Seguiu-se a evaporação dos solventes, dissolução em acetona e a recristalização do precipitado por evaporação conforme mostrado na FIG. $4 \cdot 1^{[1-2]}$.

\subsubsection{Síntese do ligante octaacetato calix[8]areno}

O acetato calix[8]areno foi sintetizado segundo reação de acetilação apresentada na FIG. 4.2. Para a síntese do acetato calix[8]areno o para-terc-butilcalix[8]areno foi refluxado à temperatura de ebulição do anidrido acético, $140^{\circ} \mathrm{C}$, na presença de ácido sulfúrico concentrado, pois este é um "para dirigente" em anéis aromáticos, para fixação de grupo acetato. A solução em refluxo apresentou coloração marrom clara durante o intervalo de aquecimento, permanecendo assim até as etapas de purificação dos cristais de octaacetato calix[8]areno formados. Seguindo-se o refluxo, iniciou-se o processo de evaporação da solução até a completa precipitação dos cristais do octaacetato calix[8]areno e purificação. Na FIG. 4.2 estão resumidas as etapas de obtenção do ligante octaacetato calix[8]areno.

\subsubsection{Síntese das supermoléculas de lantanídeos}

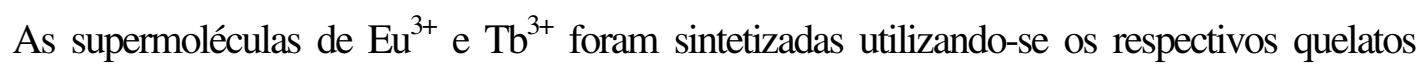
precursores e o ligante octaacetato calix[8]areno, ambos dissolvidos em álcool etílico na proporção molar 2:1 e posterior junção das duas soluções. A solução resultante foi deixada sob agitação para a evaporação do solvente e posterior obtenção dos cristais. As etapas de obtenção das supermoléculas estão resumidas no fluxograma na FIG. 4.3. 

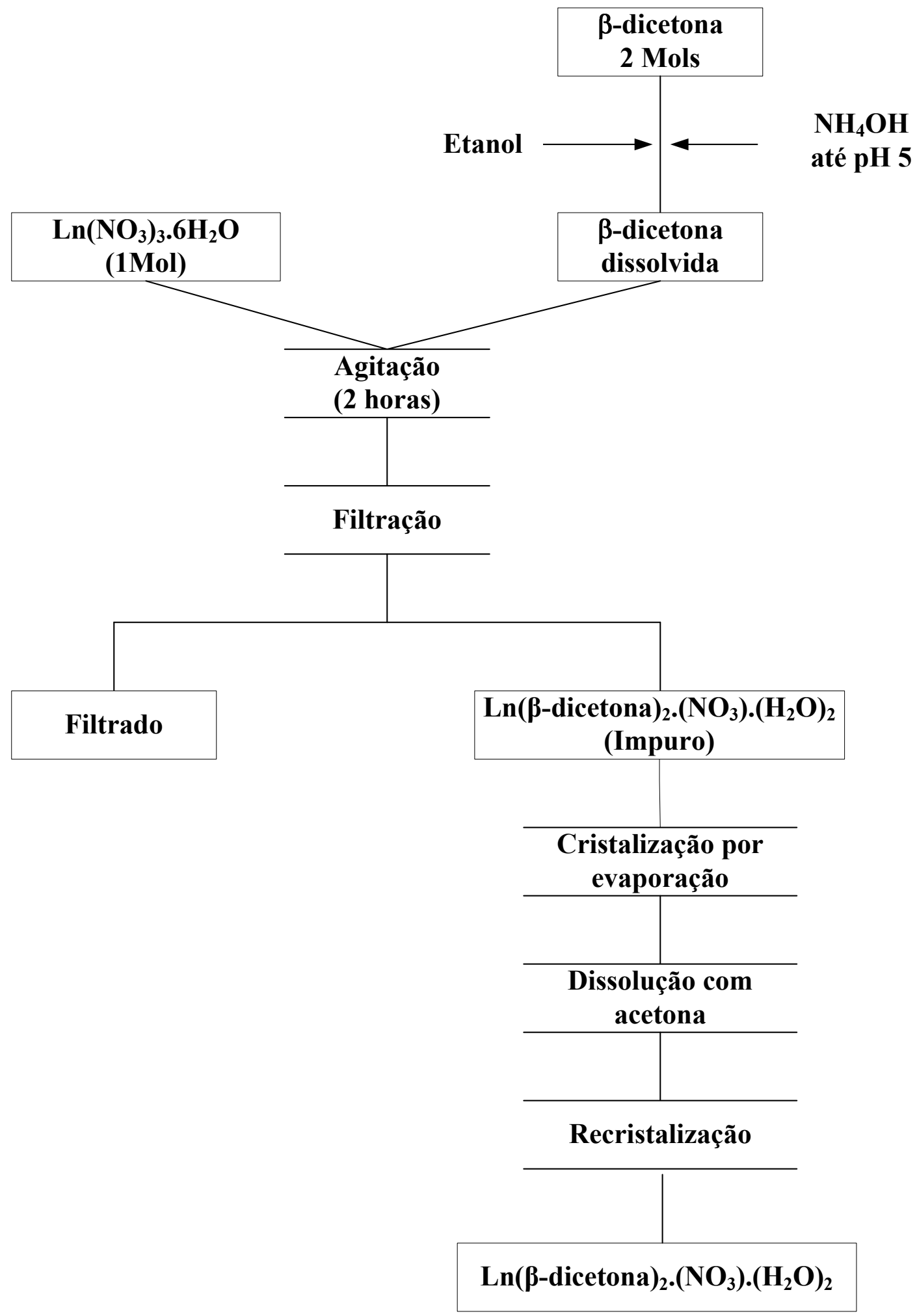

FIGURA 4.1. Fluxograma de rota de síntese das $\beta$-dicetonas de lantanídeos (III) $(\operatorname{Ln}(\beta$ dicetona $\left.)_{2} \cdot\left(\mathrm{NO}_{3}\right) \cdot\left(\mathrm{H}_{2} \mathrm{O}\right)_{2}\right)$. 

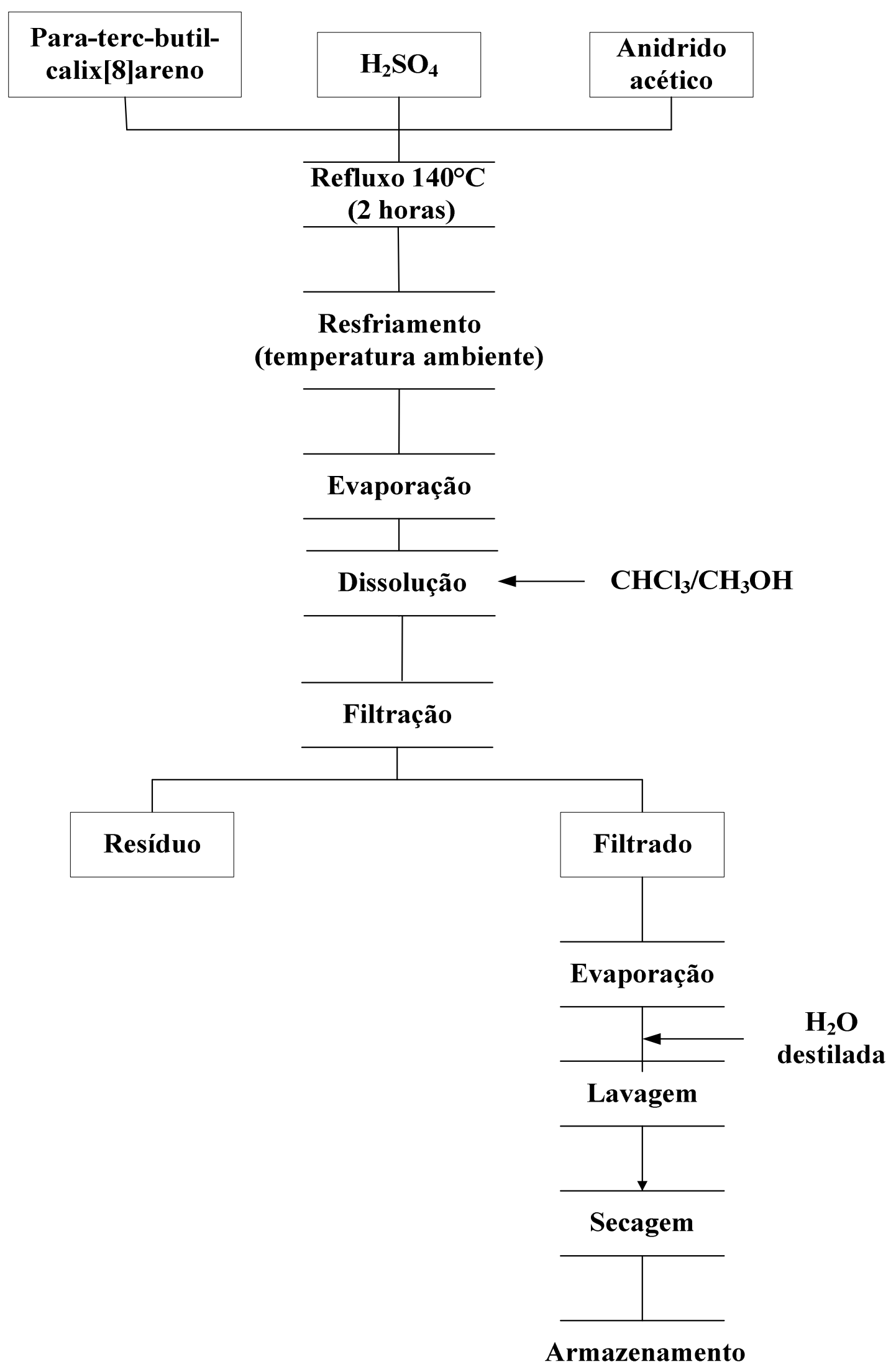

FIGURA 4.2. Fluxograma de rota de síntese do octaacetato $\subset$ calix[8]areno. 


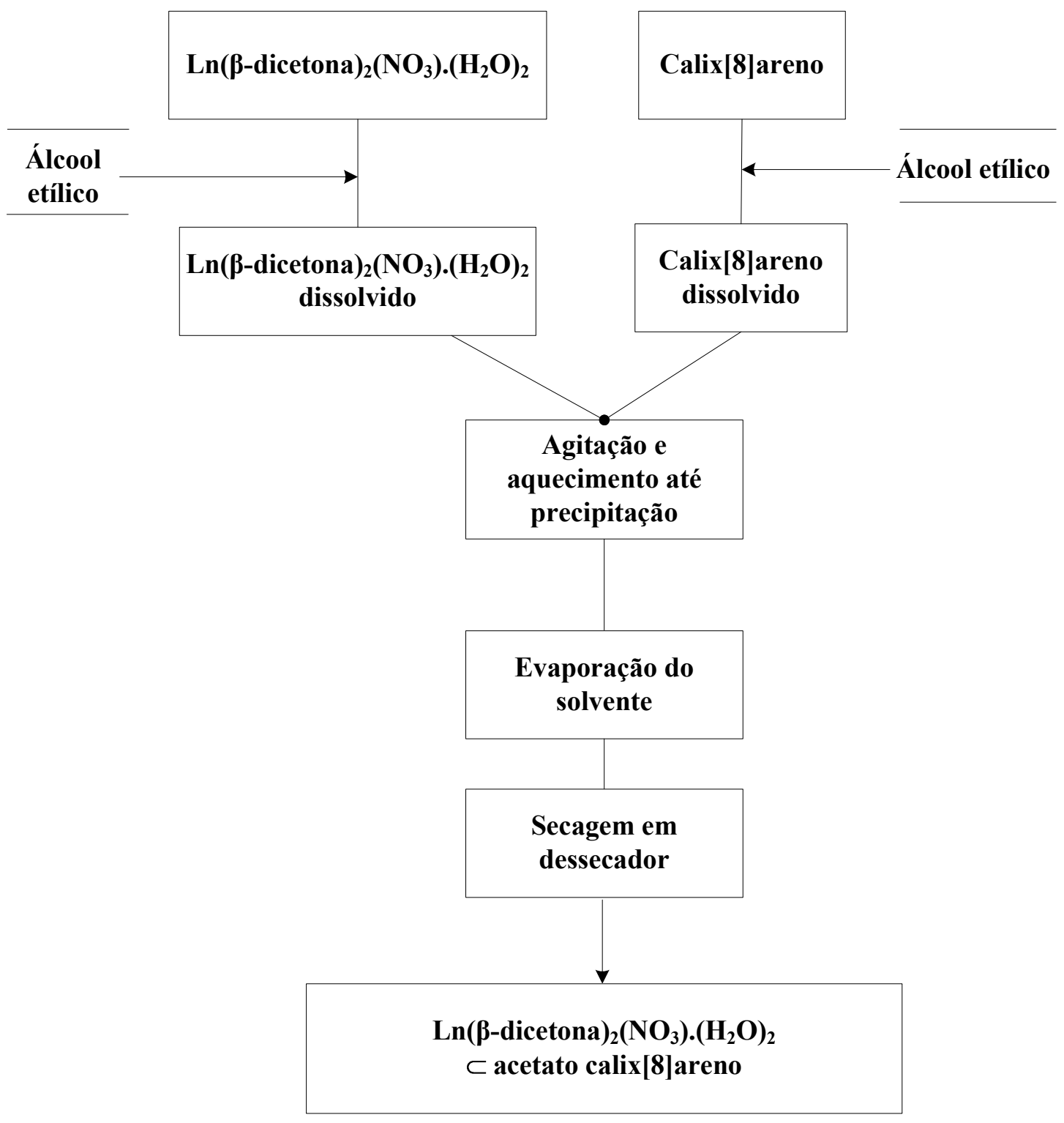

FIGURA 4.3. Fluxograma de rota de síntese das supermoléculas de $\beta$-dicetonas de lantanídeos (III) com o ligante macrocíclico octaacetatocalix[8]areno. 


\subsection{Metodologia para caracterização dos quelatos precursores, do ligante e das supermoléculas}

Os quelatos precursores, o ligante e as supermoléculas foram caracterizados utilizando-se as seguintes técnicas: análise elementar de carbono, hidrogênio e nitrogênio, determinação espectrofotométrica da porcentagem de lantanídeo (III), espectroscopia de absorção na região do infravermelho, análise térmica, microscopia eletrônica de varredura, espectroscopia eletrônica de emissão e excitação e medidas de tempo de vida.

\subsubsection{Análise elementar de carbono, hidrogênio e nitrogênio (CHN)}

Os teores de carbono, hidrogênio e nitrogênio do ligante, quelatos de lantanídeos e supermoléculas, foram determinados no laboratório de microanálise na Central Analítica do IQ-USP, por processos microanalíticos, no qual utilizou-se o analisador de CHN da Perkin-Elmer, modelo 240.

\subsubsection{Método do vermelho de alizarina $S$ para determinação de $\operatorname{Ln}^{3+}$}

O vermelho de alizarina S é um agente cromóforo utilizado na determinação de lantanídeos, com os quais desenvolve um complexo avermelhado. É empregado em uma solução aquosa a 0,1\% abrangendo um intervalo de concentração de 10 a $120 \mu \mathrm{g}$ de lantanídeo/10mL. Os demais reagentes são: fenolftaleína $(225 \mathrm{mg} / \mathrm{L}) ; \mathrm{HNO}_{3}(0,04 \mathrm{~mol} / \mathrm{L}) ; \mathrm{NaOH}(2 \mathrm{~mol} / \mathrm{L})$ e tampão ácido acético $(2 \mathrm{~mol} / \mathrm{L}) /$ acetato de sódio $(2 \mathrm{~mol} / \mathrm{L})(\mathrm{pH} \sim 4,7)^{[3]}$.

\subsubsection{Espectroscopia de absorção molecular na região do infravermelho}

Os espectros de absorção na região do infravermelho foram registrados na faixa espectral de $4.000 \mathrm{a} 400 \mathrm{~cm}^{-1}$ utilizando pastilhas de KBr em um espectrômetro FTIR-BOMEM, Modelo MB-102.

\subsubsection{Curvas termogravimétricas}

Obtiveram-se as curvas termogravimétricas (TGs) em um Mettler Toledo TGA/SDTA 851 com termobalança, sob atmosfera de nitrogênio com vazão $50 \mathrm{~mL} /$ minuto, utilizando-se cadinho de alumina como recipiente para amostra. Fez-se a termocomposição com razão de aquecimento de $10^{\circ} \mathrm{C} \cdot \mathrm{min}^{-1}$ e registrando-se as curvas DTGs a partir da diferenciação eletrônica do sinal TG. 


\subsubsection{Microscopia eletrônica de varredura (MEV)}

Para analisar a morfologia das amostras, utilizou-se um microscópio eletrônico de varredura, da marca PHILIPS XR-30, do Centro de Ciências e Tecnologia de Materiais (CCTM) do IPEN-CNEN/SP. As amostras foram pulverizadas sobre um suporte metálico adequado e recobertas com ouro pela técnica de sputtering. Esta técnica consiste em recobrir uma amostra, carregada positivamente em uma câmara de alto vácuo, através de elétrons ejetados que estão carregados negativamente. Por uma diferença de potencial aplicada, os elétrons aceleram para o eletrodo positivo, colidindo com uma molécula de gás, liberando íons e elétrons livres. Os íons positivos são então acelerados para o alvo, negativamente carregado, recobrindo desta forma a amostra ${ }^{[4]}$.

\subsubsection{Espectroscopia de luminescência}

\subsubsection{Espectros eletrônicos de excitação e emissão}

Os espectros eletrônicos de excitação e emissão, dos complexos em estado sólido e solução, a temperatura ambiente $\left(\sim 300 \mathrm{~K}\right.$ ou $\left.25^{\circ} \mathrm{C}\right)$ e do nitrogênio líquido $(\sim 77 \mathrm{~K} \mathrm{ou} \mathrm{-}$ $196^{\circ} \mathrm{C}$ ), no intervalo espectral de 250 a $720 \mathrm{~nm}$, foram obtidos em um espectrofluorímetro, SPEX-FLUOROLOG 2, com monocromadores duplos 0,22 m do tipo SPEX 1680, utilizando-se uma lâmpada de Xenônio de 450 W como fonte de radiação.Todo o aparato foi controlado por um sistema do tipo DM3000F.

\subsubsection{Medidas do tempo de vida}

As curvas de decaimento de luminescência foram registradas a temperatura ambiente. Para tal utilizou-se um fosforímetro SPEX 1934D acoplado ao espectrofluorímetro com fonte de excitação e uma lâmpada pulsada de xenônio de $150 \mathrm{~W}$. Todos esses aparatos foram controlados por um sistema do tipo DM3000F.

\subsubsection{Conjugação dos quelatos precursores e das supermoléculas de $\mathrm{Eu}^{3+} \mathrm{e}^{\mathbf{T}} \mathrm{b}^{3+}$ com glutaraldeído}

Os complexos de Eu-TTA-glutaraldeído/Eu-TTA-Ligante-glutaraldeído, EuACAC-glutaraldeído/Eu-ACAC-Ligante-glutaraldeído e Tb-ACAC-glutaraldeído/TbACAC-Ligante-glutaraldeído foram obtidos adicionando-se glutaraldeído a uma solução 
dos complexos acima $(25 \mu \mathrm{g} / \mathrm{mL})$ relação v/v 1:2. A solução foi encubada e deixou-se overnight a $4^{\circ} \mathrm{C}$ sendo posteriormente utilizada para marcação das amostras biológicas.

\subsubsection{Curva de calibração dos aminoácidos Valina e Ácido Glutâmico}

Preparou-se uma solução estoque em agua bidestilada dos respectivos aminoácidos a $0,01 \mathrm{~g} / \mathrm{mL}$ e em seguida soluções em água bidestilada, dos respectivos aminoácidos, a 10, 20, 50, 75, 100 e 200ng/mL. Em uma placa de fluoroimunoensaio (ELISA), FIG. 4.4, fezse a curva de calibração seguindo o protocolo abaixo:

1) Em cada poço da placa em sextuplicata: $100 \mu \mathrm{L}$ do $\left[\mathrm{Eu}(\mathrm{TTA})_{2}\left(\mathrm{NO}_{3}\right) \cdot\left(\mathrm{H}_{2} \mathrm{O}\right)_{2}\right]_{2} \subset$ octaacetato calix[8]areno conjugado mais $100 \mu \mathrm{L}$ das soluções dos aminoácidos nas respectivas concentrações ( $10,20,50,75,100$ e $200 \mathrm{ng} / \mathrm{mL})$.

2) A fim de comparar o sinal, também repetiu-se o procedimento acima com $\left[\mathrm{Eu}(\mathrm{TTA})_{2}\left(\mathrm{NO}_{3}\right) \cdot\left(\mathrm{H}_{2} \mathrm{O}\right)_{2}\right]_{2} \subset$ octaacetato calix[8]areno sem glutaraldeído.

3) Fez-se a leitura no espectrofluorímetro Victor $^{2}$ R com filtro de corte de 340nm, FIG. 4.5 .

4) Obtiveram-se as curvas de calibração dos aminoácidos para análise dos resultados.

\subsubsection{Conjugação do marcador de $\mathrm{Eu}^{3+}$-TTA-Ligante-glutaraldeído às amostras sanguíneas}

A conjugação do marcador às amostras sanguíneas de pacientes com anemia falciforme e grupo controle, seguiu o protocolo desenvolvido abaixo e foi aplicada apenas para o composto $\left[\mathrm{Eu}(\mathrm{TTA})_{2}\left(\mathrm{NO}_{3}\right) \cdot\left(\mathrm{H}_{2} \mathrm{O}\right)_{2}\right]_{2} \subset$ octaacetato calix[8]areno.

1) Em cada poço da placa em quintuplicata: $100 \mu \mathrm{L}$ do $\left[\mathrm{Eu}(\mathrm{TTA})_{2}\left(\mathrm{NO}_{3}\right) \cdot\left(\mathrm{H}_{2} \mathrm{O}\right)_{2}\right]_{2} \subset$ coctaacetato calix[8]areno conjugado com glutaraldeido mais $100 \mu \mathrm{L}$ da amostra sanguinea diluida 1:50 com água bidestilada.

2) Deixou-se as placas à temperatura ambiente; sob agitação durante 10 min.

3) Fez-se a leitura no espectrofluorímetro Victor $^{2} \mathrm{R}$ com filtro de corte de $340 \mathrm{~nm}$.

4) Analisou-se os resultados. 


\subsubsection{Conjugação do marcador de $\mathrm{Eu}^{3+}$-TTA-Ligante às amostras sanguíneas}

A fim de comparar o sinal, também repetiu-se o procedimento acima com $\left[\mathrm{Eu}(\mathrm{TTA}) 2(\mathrm{NO} 3) \cdot\left(\mathrm{H}_{2} \mathrm{O}\right)_{2}\right]_{2} \subset$ octaacetato calix[8]areno sem glutaraldeído.

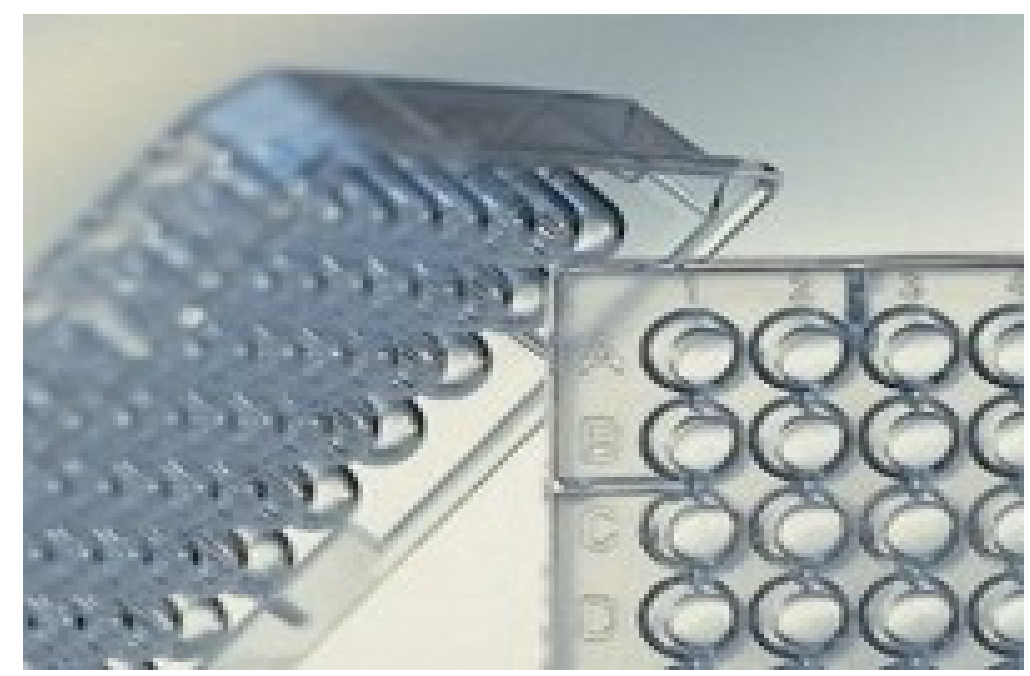

FIGURA 4.4. Placa de 96 poços utilizada para leitura em fluroimunoensaios.

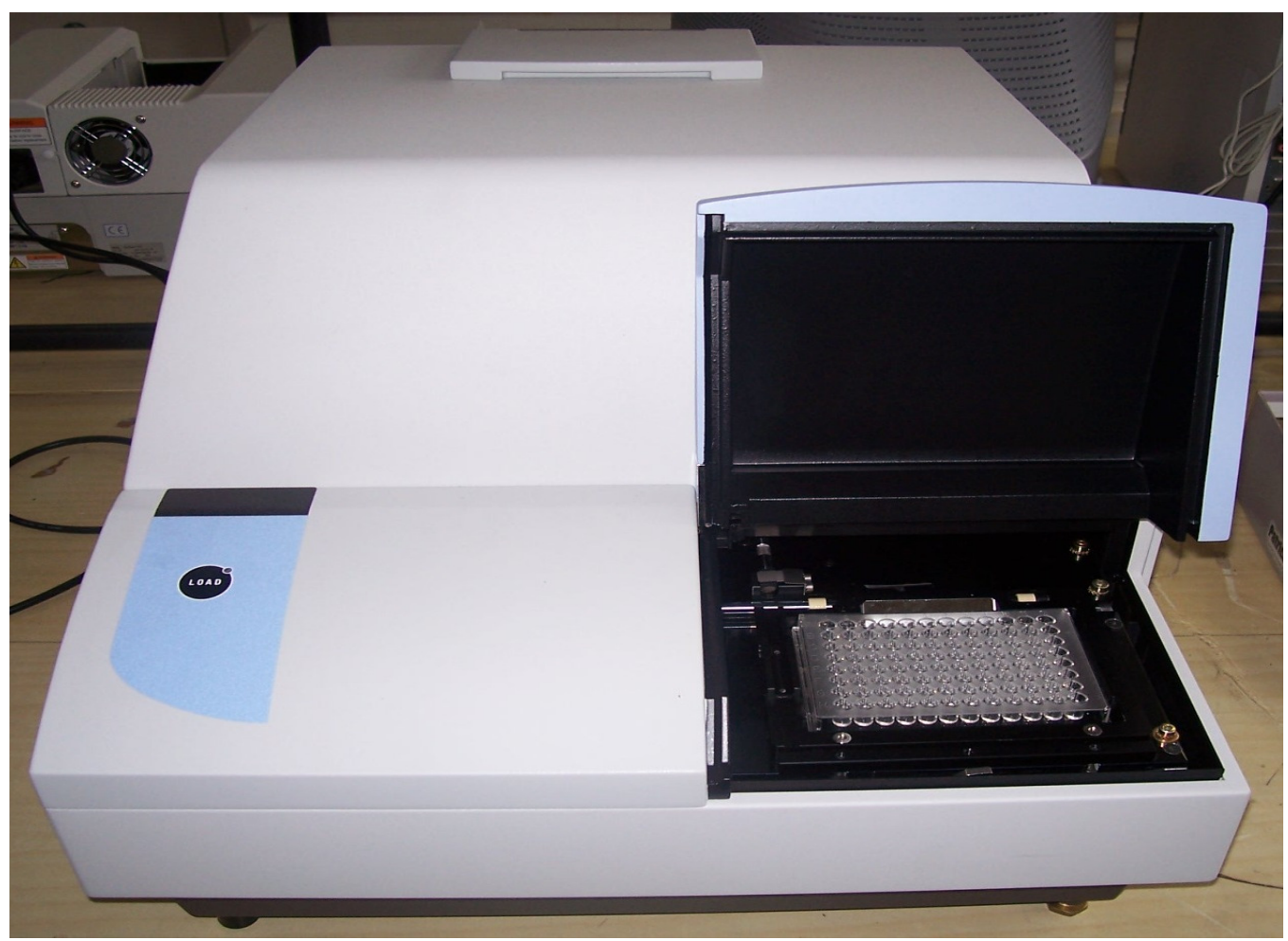

FIGURA 4.5. Espectrofluorímetro para leitura das placas de fluoroimunoensaios, Victor ${ }^{2}$ R, da Perkin Elmer. 


\subsubsection{Identificação das amostras sanguíneas por FTIR}

\subsubsection{Preparação para FTIR}

Neste trabalho utilizamos um espectrômetro de absorção no infravermelho por transformada de Fourier cobrindo a região espectral: 4000-400 cm $\mathrm{cm}^{-1}$ marca ThermoNicolet, modelo 6700-FTIR, acoplado com microscópio espectrômetro infravermelho Nicolet, modelo Continu $\mu \mathrm{m}-\mathrm{XL}$, ano 2007, adquirido pelo Centro de Laser e Aplicações do IPEN via projeto CEPID/FAPESP nº 05/51689-2- Centro de Pesquisa em Óptica e Fotônica. Para processamento dos resultados o pacote computacional estatístico utilizado foi o Minitab®, que supre as operações necessárias para a obtenção de componentes principais e agrupamento hierárquico, inclusive o tratamento prévio de padronização e escalonamento dos dados.

No experimento, utilizou-se janelas de $\mathrm{ZnSe}$ (seleneto de zinco) e $\mathrm{CaF}_{2}$ (fluoreto de cálcio), formando-se um filme fino da amostra. O equipamento foi mantido em sala com temperatura e umidade controladas. A faixa espectral utilizada compreendeu entre $4000 \mathrm{e}$ $400 \mathrm{~cm}^{-1}$.

\subsubsection{Preparação das pastilhas $\mathrm{KBr}$ dos aminoácidos Valina e Ácido glutâmico para identificação por FTIR}

$\mathrm{O} \mathrm{KBr}$ foi previamente dessecado em estufa à $120^{\circ} \mathrm{C}$ até peso constante e triturado em almofariz de ágata. Posteriormente foram colocados $100 \mathrm{mg}$ do $\mathrm{KBr}$ e $2 \mathrm{mg}$ do aminoácido no pastilhador seguido de compressão em prensa hidráulica Perkin Elmer® modelo 4037 com pressão de 4 toneladas por 10 minutos, para obtenção das pastilhas finas e transparentes. O equipamento foi mantido em sala com temperatura e umidade controladas. A faixa espectral utilizada compreendia números de onda entre 4000 e 400 $\mathrm{cm}^{-1}$. 


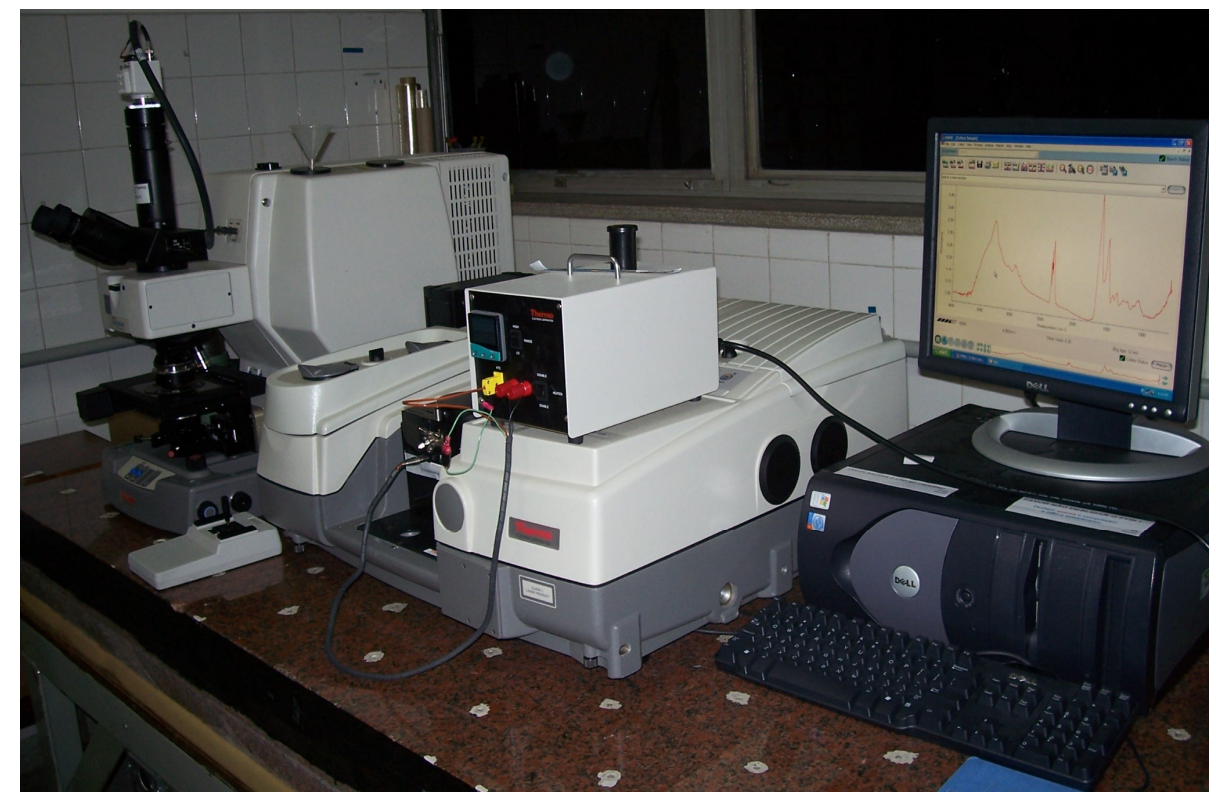

FIGURA 4.6. Espectrômetro de infravermelho: ThermoNicolet, modelo 6700-FTIR. 


\section{REFERÊNCIAS BIBLIOGRÁFICAS}

[01] BLASSE, G.; GRABMAIER, B. C. Luminescent materials. Berlin: Springer, 1994.

[02] MALTA, O.L.; BRITO, H.F.; MENEZES, J.F.S.; SILVA, F.R.G.E.; ALVES, S.; FARIAS, F.S.; DE ANDRADE, A.V.M. Spectroscopic properties of a new lightconverting device Eu(thenoyltrifluoroacetonate)(3) 2(dibenzyl sulfoxide). A theoretical analysis based on structural data obtained from a sparkle model. J. of Lumin. v. 75, n. 3, p. 255-268, 1997.

[03] RINEHART, R. W. Spectrophotometric determination of some rare earths and ytrium with Alizarin Red S. Anal. Chem. v. 26, n 11, p. 1820-1822, 1954.

[04] GOSDSTEIN, J. I.; NEWBURY, D. E.; ECHLIN, P.; JOY, D. C.; LYMAN, C. E.; LIFSHIN, E.; SAWYER, L.; MICHAEL, J. R. Scanning electron microscopy and X-ray microanalysis. New York: Kluwer Academic, 2003. 


\subsection{RESULTADOS E DISCUSSÕES}

\subsection{Características quantitativas e estequiometria dos compostos}

Os compostos sintetizados neste trabalho, ligante, quelatos precursores e supermoléculas, mostram comportamento pouco higroscópico em condições ambientes $\left(\sim 25^{\circ} \mathrm{C}\right)$.

\subsubsection{Análise elementar de carbono, hidrogênio, nitrogênio (CHN) e porcentagem de lantanídeos $\left(\% \mathrm{Ln}^{3+}\right)$}

O ligante, os quelatos precursores, e as supermoléculas foram caracterizados por análise elementar de carbono, hidrogênio e nitrogênio e foi determinada a porcentagem de európio e térbio nos quelatos e supermoléculas.

O ligantes octaacetato calix[8]areno foi caracterizado por análise elementar de carbono e hidrogênio. Observa-se que os valores calculados e experimentais encontram-se em concordância, o que demonstra o alto grau de pureza do ligante sintetizado. Na TAB. 5.1 foram listados estes valores. Já para os quelatos precursores, $\operatorname{TR}(\beta \text {-dicetona })_{2}\left(\mathrm{NO}_{3}\right) \cdot\left(\mathrm{H}_{2} \mathrm{O}\right)_{2}$ (onde $\beta$-dicetona $=$ ACAC e TTA) e as supermoléculas, foram determinadas também a percentagem de $\mathrm{TR}^{3+}$ utilizando o método espectrofotométrico da alizarina S. Os resultados obtidos mostraram concordância com os dados teóricos (TAB. 5.1).

De acordo com os dados obtidos propõe-se as estequiometrias TR( $(\beta \text {-dicetona })_{2}$. $\left(\mathrm{NO}_{3}\right) \cdot\left(\mathrm{H}_{2} \mathrm{O}\right)_{2}$ para o quelato e $\left[\left(\operatorname{TR}(\beta \text {-dicetona })_{2} \cdot\left(\mathrm{NO}_{3}\right) \cdot\left(\mathrm{H}_{2} \mathrm{O}\right)_{2}\right] \subset\right.$ octaacetatocalix[8]areno para as supermoléculas estudadas. 


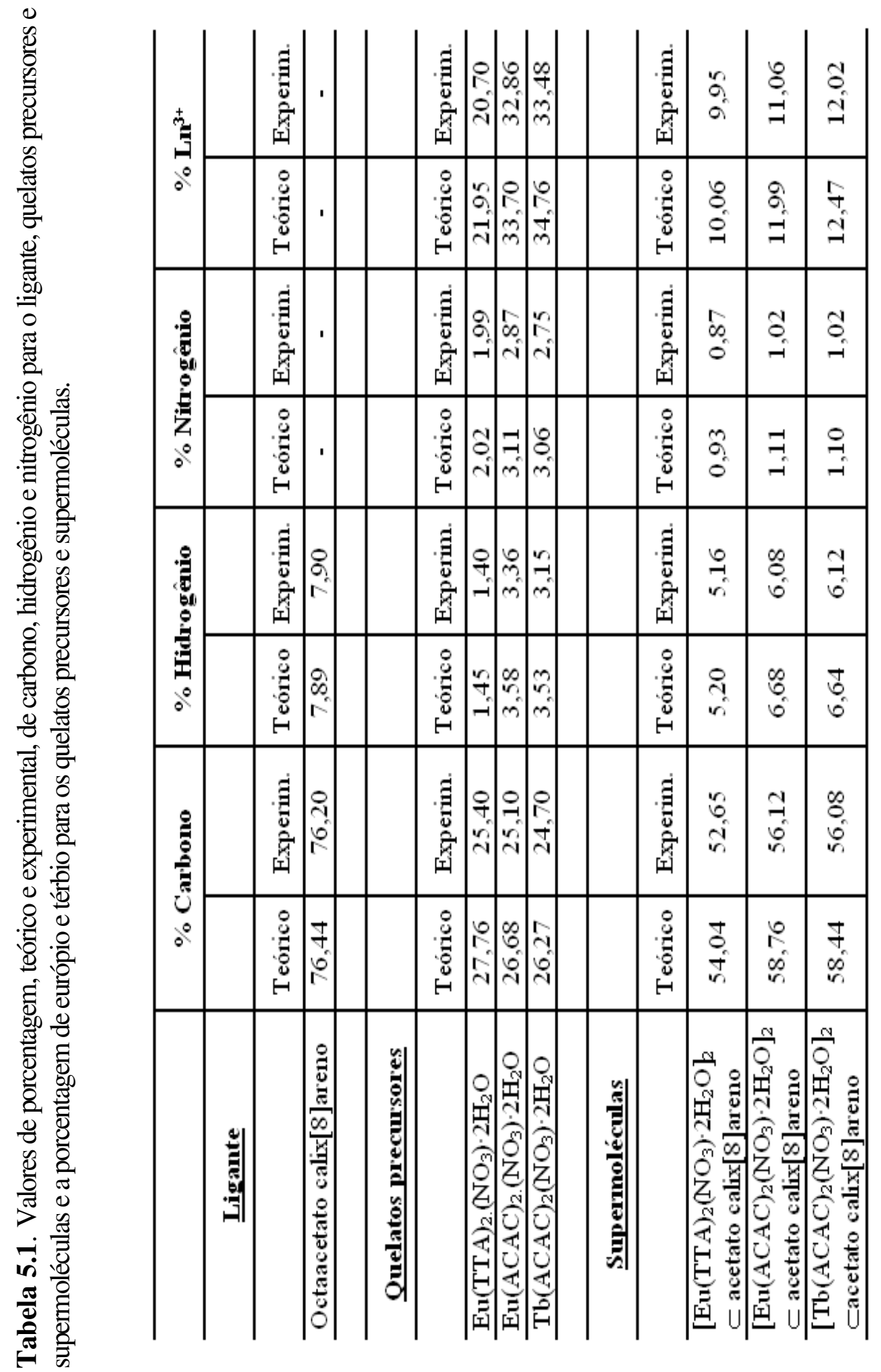




\subsubsection{Espectroscopia de absorção molecular na região do infravermelho}

\subsubsection{Espectroscopia de absorção molecular na região do infravermelho do ligante}

Uma das propriedades características dos calixarenos, em seus espectros vibracionais de absorção na região do infravermelho, é o aparecimento de uma banda de estiramento do grupo $\mathrm{OH}$ na região de baixa frequiência, próximo a $3150 \mathrm{~cm}^{-1}$ para o tetrâmero cíclico e demais calixarenos. $\mathrm{Na}$ região de "impressão digital" dos calixarenos, todos parecem semelhantes especialmente na região entre $1500-900 \mathrm{~cm}^{-1}$. Na região de $500-900 \mathrm{~cm}^{-1}$, entretanto, os modelos variam um pouco. As absorções que parecem ser características de cada calixareno individualmente encontram-se na região de $693 \mathrm{~cm}^{-1}$ e $571 \mathrm{~cm}^{-1}$ para o pentâmero cíclico, $762 \mathrm{~cm}^{-1}$ para o hexâmero cíclico e $796 \mathrm{~cm}^{-1}$ no heptâmero cíclico. O octâmero cíclico se distingue dos demais por uma absorção bem menos resolvida na região de 500 $600 \mathrm{~cm}^{-1}$. Uma banda próxima a $400 \mathrm{~cm}^{-1}$ é para diferenciar o tetrâmero cíclico do hexâmero e octâmero cíclicos ${ }^{[1]}$. Estes resultados têm sido atribuídos especialmente às fortes ligações de hidrogênio intramoleculares destes compostos, característica esta discutida por GUTSCHE. As ligações de hidrogênio em moléculas circulares são responsáveis por algumas características "ímpares" dos calixarenos. Isto foi confirmado no trabalho de GUTSCHE ${ }^{[2]}$, onde utilizaram a técnica de FTIR, confirmando as características intramoleculares das ligações e mostraram que essas interações são fortes para o tetrâmero cíclico e fracas para o pentâmero. $\mathrm{O}$ espectro de absorção na região do infravermelho do ligante acetato calix[8]areno e do p-terc-butil calix[8]areno estão apresentados na FIG. 5.1.

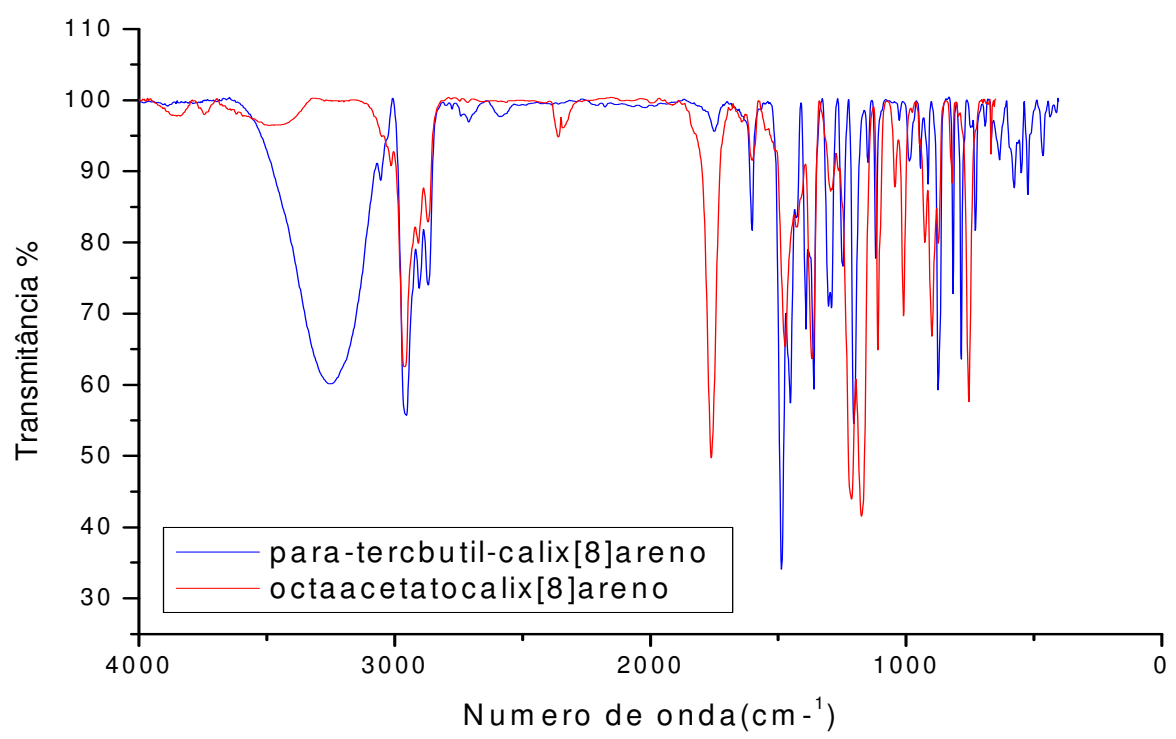

FIGURA 5.1. Espectros de absorção na região do infravermelho do ligante para-tercbutilcalix[8]areno e octaacetatocalix[8]areno. 
Na TAB. 5.2 estão atribuídas as freqüências características dos estiramentos observados nos espectros de absorção na região do infravermelho do para-tercbutil-calix[8]areno e octaacetato calix[8]areno. O desaparecimento das bandas de estiramento vO-H do para-terc-butil-calix[8]areno em $3200 \mathrm{~cm}^{-1}$ e o surgimento de bandas de estiramento $v \mathrm{C}=\mathrm{O}$ para acetato calix[8]areno evidenciaram a funcionalização destes compostos. Na região de "finger-print" bandas características foram atribuídas aos estiramentos e deformações dos anéis aromáticos que compõem a molécula do calixareno. A banda na região 609 relativo ao rock de O-H desaparece também para o calixareno funcionalizado.

TABELA 5.2. Exemplo comparativo dos dados espectrais dos ligantes paratercbutilcalix[8]areno e acetato calix[8]areno na região do infravermelho.

\section{Ligantes $\left(\mathrm{cm}^{-1}\right)$}

\begin{tabular}{lcc}
\hline \multicolumn{1}{c}{ Atribuições } & $\begin{array}{c}\text { Para-terc-butil-calix[8]areno } \\
\text { (Ligante não funcionalizado) }\end{array}$ & $\begin{array}{c}\text { Octaacetatocalix[8]areno } \\
\text { (Ligante funcionalizado) }\end{array}$ \\
\hline$v_{\text {sim. Anel }}$ & 1599 & 1600 \\
$\delta$ do anel & $1552-1522$ & $1552-1520$ \\
$\delta_{\text {assim. }} \mathrm{CH}_{3}$ & 1454 & 1460 \\
& 1479 & \\
$\delta_{\text {sim. }} \mathrm{CH}_{3}$ & 1392 & $1372-1381$ \\
$\delta$ fora do plano do anel & $752-721$ & $752-720$ \\
Vibração do anel fora do plano & 687 & 688 \\
& $1249-1205$ & 1180 \\
Finger print ligação C - H no & 1117 & 1112 \\
plano aromático & $941-914$ & 600 \\
& $876-816$ & $608-520$ \\
& 523 & 1760 \\
Estiramento C $=\mathrm{O}$ & - & 1224 \\
Estiramento O-C (O) - C & - & 1012 \\
Estiramento C-O & $1024-1001$ & 1068 \\
Estiramento C - O assimétrico & 1070 & - \\
acoplado com C-C & & - \\
Rock O-H & 609 & \\
Estiramento O-H & 3238 & \\
\hline
\end{tabular}




\subsubsection{Espectroscopia de absorção molecular na região do infravermelho dos quelatos precursores e supermoléculas}

\subsection{Quelatos precursores}

As bandas de absorção no infravermelho provenientes do estiramento $v \mathrm{C}=\mathrm{O}$ foram investigadas extensivamente havendo, portanto, muitos dados acerca dos fatores que influenciam sua frequiência e intensidade. A enolização parcial em cetonas simples saturadas causa um decréscimo na intensidade da banda $\vee \mathrm{C}=\mathrm{O}$ e o aparecimento de bandas de estiramento $\mathrm{C}=\mathrm{O}$ e de $\mathrm{O}-\mathrm{H}$. Um grupo carbonil secundário pode aparecer em função da ligação de hidrogênio entre as espécies ceto enólicas.

A absorção no infravermelho de metal acetilacetonatos foi extensivamente pesquisada por LECOMTE $^{[3]}$ e MORGAN ${ }^{[4]}$, onde eles observaram uma banda de absorção forte na região de 1562 $\mathrm{cm}^{-1} \mathrm{em}$ uma série de acetilacetonatos. Esta banda foi atribuída a uma absorção característica do grupo carbonil, devido à ressonância entre $\mathrm{C}-\mathrm{O}-\mathrm{M}$ e $\mathrm{C}=\mathrm{O} \ldots \mathrm{M}$. Em todos os quelatos havia uma segunda banda próxima de $1515 \mathrm{~cm}^{-1}$, que é atribuída à ligação $\mathrm{C}=\mathrm{C}$. Estas atribuições foram confirmadas por BELLAMY e BRANCH ${ }^{[5]}$, que estudaram vários quelatos metálicos com diferentes dicetonatos. As freqüências observadas encontram-se entre as faixas de $1608-1525 \mathrm{~cm}^{-1}$ e 1390 $1309 \mathrm{~cm}^{-1}$. Um deslocamento da banda carbonil foi observado por LECOMTE ${ }^{[3]}$. Neste delocamento, as bandas de absorção em torno de $1600 \mathrm{~cm}^{-1}$ são deslocadas para as regiões de $1560 \mathrm{~cm}^{-1}$ e $1515 \mathrm{~cm}^{-1}$, atribuídas às bandas do grupo carbonil $\mathrm{e} \mathrm{C}=\mathrm{C}$, respectivamente.

BELLAMMY e BRANCH ${ }^{[5]}$ tentaram correlacionar as posições da banda do grupo carbonil com a estabilidade dos quelatos, não havendo, portanto, uma relação definitiva concordante com os deslocamentos propostos.

Investigações dos espectros de absorção no infravermelho de outros quelatos do tipo 1,3 dicetonatos são mais escassos do que de quelatos do tipo 1,3 acetilacetonatos. Estudos experimentais foram relatados para quelatos de cobre com os ligantes: tenoiltrifluoroacetona, benzoilacetona, dibenzoilmetano, trifluoroacetilacetona e hexafluoroacetilacetona. Poucos estudos têm sido feitos sobre espectros de infravermelho de 1,3 dicetonatos, incluindo acetilacetona, dibenzoilacetona e derivados de fluoro-1, 3-dicetonatos.

Informações exatas sobre a origem das bandas dos compostos metálicos coordenados são relativamente escassas e as atribuições são feitas qualitativamente.

A maioria dos espectros na região do infravermelho dos $\beta$-dicetonatos fluorados apresenta uma banda fraca e larga na região de $2800-2200 \mathrm{~cm}^{-1}$. Em alguns casos, estas bandas deslocam-se para regiões de altas frequiências e sobrepõem as bandas $v \mathrm{C}-\mathrm{H}\left(2900-3000 \mathrm{~cm}^{-1}\right)$, sendo, portanto, 
atribuída ao grupo hidroxil quelato do $\beta$-dicetonato $(\mathrm{C}=\mathrm{O} \ldots \mathrm{H}-\mathrm{O})$, indicando a presença da ligação de hidrogênio intramolecular nestes $\beta$-dicetonatos.

Os $\beta$-dicetonatos, normalmente, existem como misturas das formas tautoméricas cetônicas e enólicas. No entanto, a forma enólica da cetona conjugada não apresenta absorção e em seu lugar aparece uma banda larga na região de $1640-1580 \mathrm{~cm}^{-1}$ mais intensa do que a absorção normal de carbonilas pertencentes à forma enólica da cetona não conjugada. Essa absorção intensa e o seu deslocamento provêm da formação da ligação de hidrogênio intramolecular que é estabilizada por ressonância.

É interessante observar que não existem bandas de absorção por volta de $1725-1709 \mathrm{~cm}^{-1}$, região característica da banda carbonil na forma ceto, evidenciando a ausência da forma cetônica e confirmando a presença da forma enólica.

A banda tiofeno do HTTA em $1587 \mathrm{~cm}^{-1}$ referente ao anel aromático apresenta-se em todos os quelatos. É interessante notar que os compostos de $\beta$-dicetonatos de cobre apresentam bandas de absorção do grupo carbonil nas regiões de $1508 \mathrm{~cm}^{-1}$ e $1570 \mathrm{~cm}^{-1}$. No entanto, nos quelatos de terras raras é observado apenas uma banda de absorção do tiofeno entre $1510 \mathrm{~cm}^{-1} \mathrm{e} 1515 \mathrm{~cm}^{-1}$.

Os modos de estiramento vs $\mathrm{CF}_{3}$ no HTTA livre encontram-se na faixa de $1202-1175 \mathrm{~cm}^{-1}$, entretanto, nos quelatos deslocam-se para a região entre $1307 \mathrm{~cm}^{-1}$ e $1175 \mathrm{~cm}^{-1}$. Os modos de estiramento vas $\mathrm{CF}_{3}$ apresentam absorção intensa em torno de $1112 \mathrm{~cm}^{-1}$ no HTTA livre, porém, nos quelatos encontram-se na região de $1147-1137 \mathrm{~cm}^{-1}$.

A banda referente ao modo vibracional C $-\mathrm{F}$ mostra uma absorção em $1605 \mathrm{~cm}^{-1}$ para o HTTA livre, enquanto que para os quelatos de terras raras há um pequeno deslocamento para região de baixa energia de aproximadamente $5 \mathrm{~cm}^{-1}\left(1065-1060 \mathrm{~cm}^{-1}\right)$.

As principais alterações observadas entre o HTTA livre e os quelatos de terras raras vêm dadas por: desaparecimento da banda de absorção $\mathrm{O}-\mathrm{H}$... $\mathrm{O}$; deslocamento da v C - H (anel hidrogênio quelato) para altas frequiências; aumento da perturbação parcial do caráter duplo e um deslocamento da densidade eletrônica em direção ao metal fortalecendo a estrutura coordenada.

Já o grupo $\mathrm{NO}_{3}{ }^{-}$, presente nas moléculas estudadas, pode atuar como ligante monodentado ou bidentado ao íon metálico, ou ainda como grupo iônico não coordenado ${ }^{[3,4]}$. O tipo de grupo nitrato presente nos quelatos é geralmente investigado considerando a combinação das bandas $(v 1+v 4)$, que aparece na faixa espectral de $1700-1800 \mathrm{~cm}^{-1} \mathrm{e}$ as bandas largas em torno de $1300-1500 \mathrm{~cm}^{-1}$.

No primeiro caso o parâmetro de deslocamento $(\Delta v)$ é igual a $\sim 30 \mathrm{~cm}^{-1}$ indicando o modo de coordenação do nitrato ser bidentado. Estes dados espectrais são reforçados pela presença de duas bandas em torno de 1207 e $1139 \mathrm{~cm}^{-1}$ atribuídas ao grupamento $\mathrm{NO}_{3}^{-}$apresentando simetria $\mathrm{C} 2 \mathrm{v}$ 
coordenado ao íon $\mathrm{Ln}^{3+}$ no caso do complexo com TTA. Para os complexos com ACAC estas bandas desapareceram.

Na TAB. 5.3 estão atribuídas as frequiências características dos estiramentos observados nos espectros de absorção na região do infravermelho do quelato precursor, $\mathrm{Eu}(\mathrm{TTA})_{2} \cdot\left(\mathrm{NO}_{3}\right) \cdot\left(\mathrm{H}_{2} \mathrm{O}\right)_{2}$, $\mathrm{Eu}(\mathrm{ACAC})_{2} \cdot\left(\mathrm{NO}_{3}\right) \cdot\left(\mathrm{H}_{2} \mathrm{O}\right)_{2} \mathrm{~Tb}(\mathrm{ACAC})_{2} \cdot\left(\mathrm{NO}_{3}\right) \cdot\left(\mathrm{H}_{2} \mathrm{O}\right)_{2}$. Nas FIG. 5.2 a 5.4 apresentam-se os espectros de infravermelho destes quelatos com resolução $\mathrm{em}^{-1}$.

\subsection{Supermoléculas}

Quanto aos espectros de infravermelho, os compostos apresentam deslocamentos das bandas de estiramento do anel para região de maior energia, aproximadamente $5 \mathrm{~cm}^{-1}$, e deslocamento das bandas de deformação do anel para regiões de menor energia.

Os compostos com o ligante para-terc-butilcalix[8]areno têm as bandas atribuídas ao estiramento $v \mathrm{C}-\mathrm{O}$ e apresentam-se desdobradas ou em regiões de mais baixa energia. As bandas atribuídas ao estiramento $\mathrm{C}=\mathrm{O}$ e $\mathrm{C}=\mathrm{C}$ apresentam-se intensificadas devido à sobreposição com as bandas $v$ C - F do HTTA. Na FIG. 5.3 apresentam-se os espectros de infravermelho das supermoléculas.

Bandas de estiramento de grupamentos $\mathrm{O}-\mathrm{H}$ apareceram na região de $3400 \mathrm{~cm}^{-1}$ para as supermoléculas. Os estiramentos $v \mathrm{C}=\mathrm{O}$ do calixareno que apareceu em $1760 \mathrm{~cm}^{-1}$ apresentam-se deslocados para região de $\left[\mathrm{Eu}(\mathrm{TTA})_{2}\left(\mathrm{NO}_{3}\right) \cdot\left(\mathrm{H}_{2} \mathrm{O}\right)_{2}\right]_{2} \subset$ acetato calix[8]areno $\left(1763 \mathrm{~cm}^{-1}\right)$; $\left[\mathrm{Eu}(\mathrm{ACAC})_{2}\left(\mathrm{NO}_{3}\right) \cdot\left(\mathrm{H}_{2} \mathrm{O}\right)_{2}\right]_{2} \subset$ acetato calix[8]areno $\left(1763 \mathrm{~cm}^{-1}\right)$ e $\left[\mathrm{Tb}(\mathrm{TTA})_{2}\left(\mathrm{NO}_{3}\right) \cdot\left(\mathrm{H}_{2} \mathrm{O}\right)_{2}\right]_{2} \subset$ acetato calix[8]areno $\left(1762 \mathrm{~cm}^{-1}\right)$ nos complexos.

As bandas de nitrato v1 e v4 que aparecem nos quelatos em TAB. 5.3 são deslocadas ou permanecem nas supermoléculas em/para a região conforme TAB. 5.4. O parâmetro de deslocamento $\Delta v$ é igual (ou continua igual) a $\sim 30 \mathrm{~cm}^{-1}$ indicando que o modo de coordenação continua bidentado. Estes dados são reforçados pela presença de duas bandas em torno de 1218 a $1175 \mathrm{~cm}^{-1}$ atribuídas ao grupo $\mathrm{NO}_{3}{ }^{-}$que apresenta simetria $\mathrm{C} 2 \mathrm{v}$ quando coordenado ao íon $\mathrm{Tb}^{3+} \mathrm{e} \mathrm{Eu}^{3+}$.

Estas bandas foramobservadas apenas para as supermoléculas e podem estar sobrepostas com bandas de vsCF3 no caso da supermolécula de TTA e v (C-O) para todas as supermoléculas. 
TABELA 5.3. Dados espectrais dos quelatos precursores na região do infravermelho.

\begin{tabular}{|c|c|c|c|}
\hline \multicolumn{4}{|c|}{ Quelatos precursores $\left(\mathrm{cm}^{-1}\right)$} \\
\hline Atribuições & $\operatorname{Eu}(\mathrm{TTA})_{2} \cdot\left(\mathrm{NO}_{3}\right)_{\cdot} \cdot\left(\mathrm{H}_{2} \mathrm{O}\right)_{2}$ & $\mathrm{Eu}(\mathrm{ACAC})_{2} \cdot\left(\mathrm{NO}_{3}\right)_{\cdot} \cdot\left(\mathrm{H}_{2} \mathrm{O}\right)_{2}$ & $\mathrm{~Tb}(\mathrm{ACAC})_{2} \cdot\left(\mathrm{NO}_{3}\right) \cdot\left(\mathrm{H}_{2} \mathrm{O}\right)_{2}$ \\
\hline \multirow{2}{*}{$\begin{array}{l}v(\mathrm{C}=\mathrm{O})+ \\
(\mathrm{C}=\mathrm{O})\end{array}$} & 1791 & \multirow[t]{2}{*}{---} & \multirow[t]{2}{*}{1762} \\
\hline & 1719 & & \\
\hline \multirow{2}{*}{$\begin{array}{l}v(\mathrm{C}=\mathrm{O})+ \\
(\mathrm{C}=\mathrm{C})\end{array}$} & 1678 & \multirow[t]{2}{*}{1638} & \multirow[t]{2}{*}{1637} \\
\hline & 1637 & & \\
\hline \multirow{2}{*}{$\begin{array}{l}\mathrm{v}_{1} \mathrm{NO}_{3}^{-} \\
\mathrm{v}_{2}\end{array}$} & 1544 & 1568 & 1560 \\
\hline & 1384 & 1385 & 1383 \\
\hline$v_{3}$ & 1358 & 1361 & 1364 \\
\hline$v_{4}$ & 1310 & 1315 & 1310 \\
\hline \multirow{2}{*}{$\begin{array}{l}v(\mathrm{O}-\mathrm{H}) \\
v(\mathrm{C}-\mathrm{O})\end{array}$} & 3373 & 3198 & 3398 \\
\hline & 1139 & 1038 & \multirow[t]{2}{*}{1038} \\
\hline$v(C-U)$ & 1087 & & \\
\hline \multirow{2}{*}{$v \mathrm{C}-\mathrm{F}$} & 855 & 926 & \multirow{2}{*}{825} \\
\hline & 748 & - & \\
\hline \multirow[t]{3}{*}{$v_{\text {ass. }} \mathrm{CF}_{3}$} & 725 & & \multirow{2}{*}{---} \\
\hline & 688 & & \\
\hline & 1205 & - & \multirow[t]{3}{*}{-} \\
\hline \multirow[t]{2}{*}{$v_{\mathrm{s}} \mathrm{CF}_{3}$} & 1169 & & \\
\hline & 1139 & & \\
\hline
\end{tabular}

TABELA 5.4. Dados espectrais das supermoléculas na região do infravermelho.

\begin{tabular}{|c|c|c|c|}
\hline \multicolumn{4}{|c|}{ Supermoléculas $\left(\mathrm{cm}^{-1}\right)$} \\
\hline Atribuições & $\begin{array}{c}{\left[\mathrm{Eu}(\mathrm{TTA})_{2}\left(\mathrm{NO}_{3}\right) \cdot\left(\mathrm{H}_{2} \mathrm{O}\right)_{2}\right]_{2}} \\
\subset \text { acetato calix }[8] \text { areno }\end{array}$ & $\begin{array}{c}{\left[\mathrm{Eu}(\mathrm{ACAC})_{2}\left(\mathrm{NO}_{3}\right) \cdot\left(\mathrm{H}_{2} \mathrm{O}\right)_{2}\right]_{2}} \\
\text { c acetato calix }[8] \text { areno }\end{array}$ & $\begin{array}{c}{\left[\mathrm{Tb}(\mathrm{TTA})_{2}\left(\mathrm{NO}_{3}\right) \cdot\left(\mathrm{H}_{2} \mathrm{O}\right)_{2}\right]_{2}} \\
\text { c acetato calix[8]areno }\end{array}$ \\
\hline $\begin{array}{l}v(\mathrm{C}=\mathrm{O})+ \\
(\mathrm{C}=\mathrm{O})\end{array}$ & $\begin{array}{l}1709 \\
1763\end{array}$ & 1763 & $\begin{array}{l}1762 \\
1710\end{array}$ \\
\hline $\begin{array}{l}v(\mathrm{C}=\mathrm{O})+ \\
(\mathrm{C}=\mathrm{C})\end{array}$ & 1681 & 1634 & 1633 \\
\hline $\mathrm{v}_{1} \mathrm{NO}_{3}^{-}$ & 1542 & 1556 & 1558 \\
\hline$v_{2}$ & 1384 & 1384 & 1384 \\
\hline$v_{3}$ & 1368 & 1370 & 1369 \\
\hline$v_{4}$ & 1309 & 1333 & 1331 \\
\hline$v(\mathrm{O}-\mathrm{H})$ & 3410 & 3396 & 3405 \\
\hline$v(\mathrm{C}-\mathrm{O})$ & $\begin{array}{l}1148 \\
1110 \\
1062 \\
1043\end{array}$ & $\begin{array}{l}1110 \\
1042\end{array}$ & $\begin{array}{l}1110 \\
1043\end{array}$ \\
\hline$v \mathrm{C}-\mathrm{F}$ & 950 & --- & --- \\
\hline$v_{\text {ass. }} \mathrm{CF}_{3}$ & $\begin{array}{l}836 \\
819 \\
797\end{array}$ & --- & --- \\
\hline $\mathrm{v}_{\mathrm{s}} \mathrm{CF}_{3}$ & $\begin{array}{l}929 \\
899 \\
877\end{array}$ & --- & --- \\
\hline
\end{tabular}




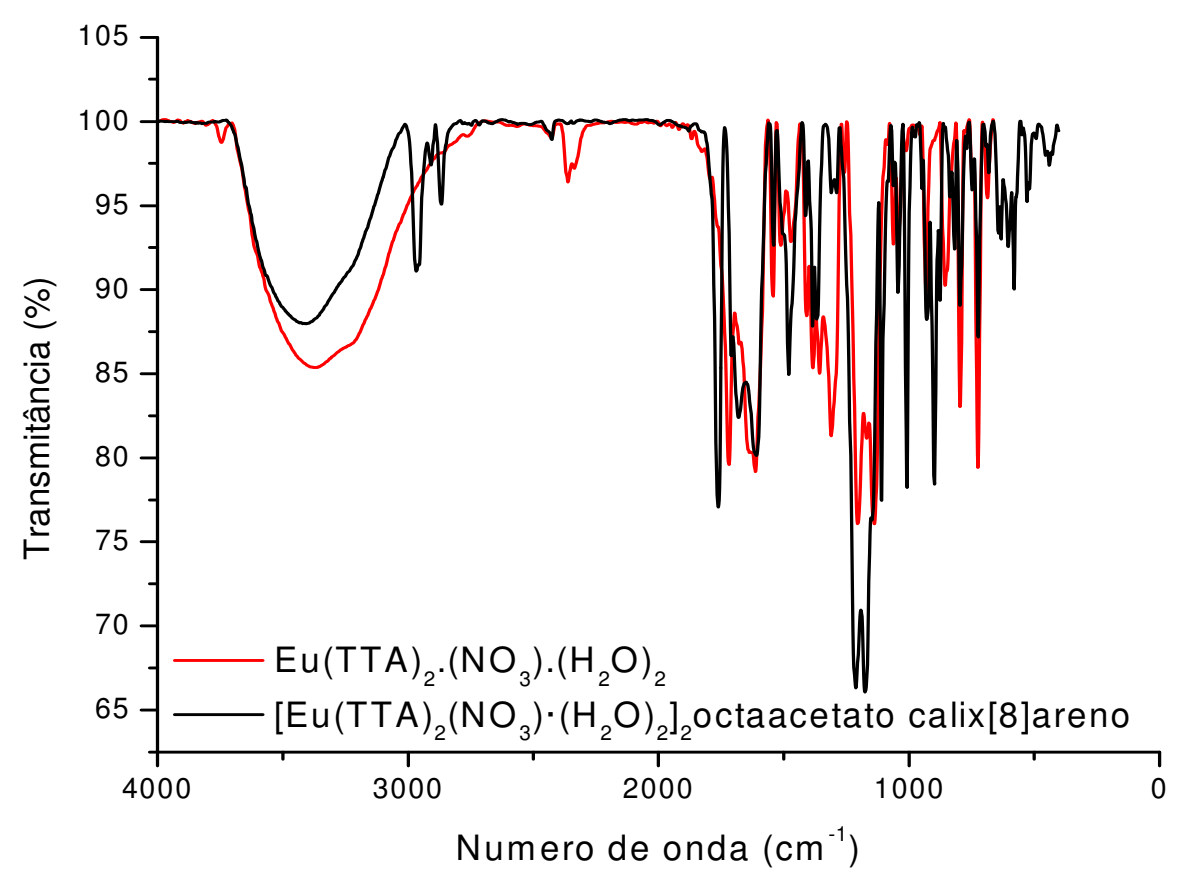

FIGURA 5.2. Espectros de absorção na região do infravermelho do quelato precursor: $\mathrm{Eu}(\mathrm{TTA})_{2}\left(\mathrm{NO}_{3}\right) \cdot\left(\mathrm{H}_{2} \mathrm{O}\right)_{2}$ e da supermolécula: $\left[\mathrm{Eu}(\mathrm{TTA})_{2} \cdot\left(\mathrm{NO}_{3}\right) \cdot\left(\mathrm{H}_{2} \mathrm{O}\right)_{2}\right]_{2}$ Cacetato calix[8]areno.

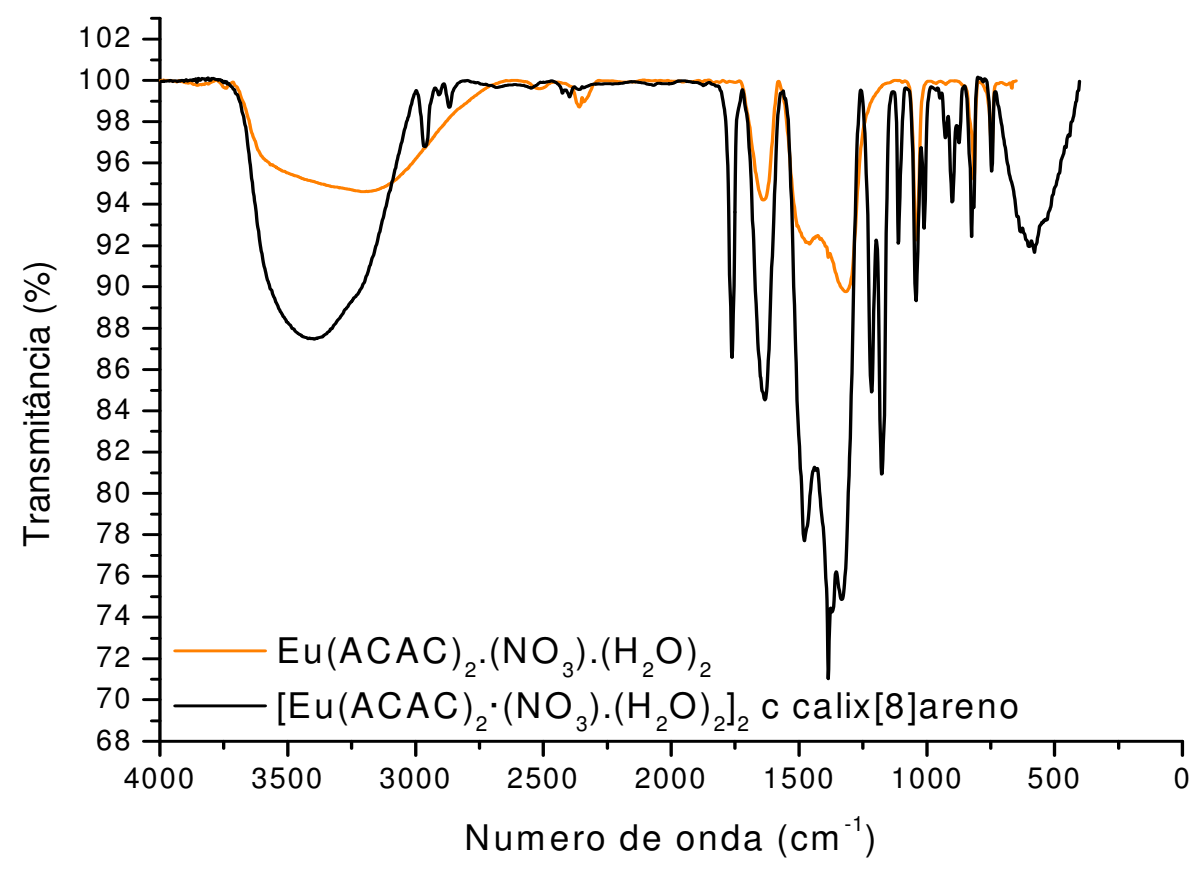

FIGURA 5.3. Espectros de absorção na região do infravermelho do quelato precursor: $\mathrm{Eu}(\mathrm{ACAC})_{2}\left(\mathrm{NO}_{3}\right) \cdot\left(\mathrm{H}_{2} \mathrm{O}\right)_{2}$ e da supermolécula: [Eu(ACAC $\left.)_{2}\left(\mathrm{NO}_{3}\right) \cdot\left(\mathrm{H}_{2} \mathrm{O}\right)_{2}\right]_{2}$ Cacetato calix[8]areno. 


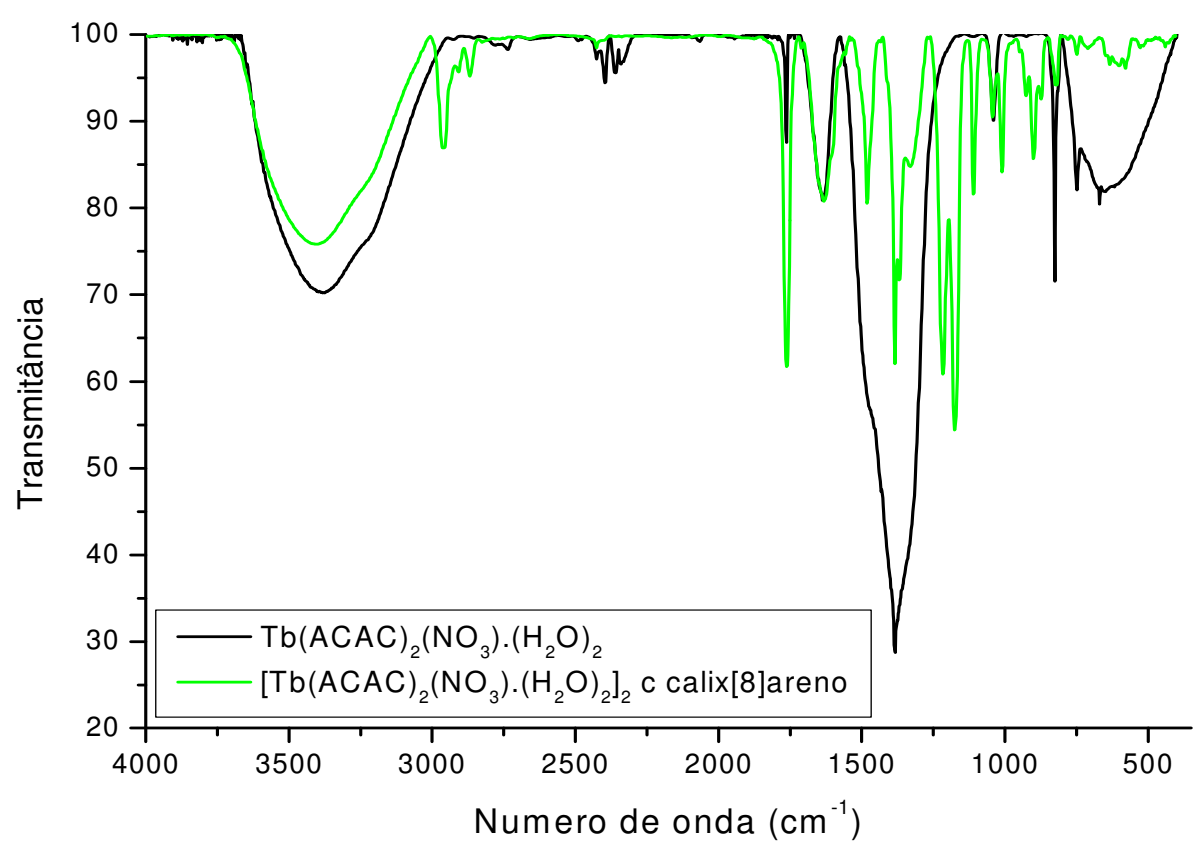

FIGURA 5.4. Espectros de absorção na região do infravermelho do quelato precursor: $\mathrm{Tb}(\mathrm{ACAC})_{2}\left(\mathrm{NO}_{3}\right) \cdot\left(\mathrm{H}_{2} \mathrm{O}\right)_{2}$ e da supermolécula $\left[\mathrm{Tb}(\mathrm{ACAC})_{2}\left(\mathrm{NO}_{3}\right) \cdot\left(\mathrm{H}_{2} \mathrm{O}\right)_{2}\right]_{2}$ Cacetato calix[8]areno.

\subsubsection{Caracterização por análise térmica}

\subsubsection{Decomposição térmica dos quelatos precursores}

A FIG. 5.5 apresenta as curvas TGA e DTGA para os quelatos precursores estudados. As curvas foram registradas no intervalo de 0 a $1000^{\circ} \mathrm{C}$. Na TAB. 5.5 estão listados os eventos observados para os quelatos precursores.

Para o composto $\left[\mathrm{Eu}(\mathrm{TTA})_{2}\left(\mathrm{NO}_{3}\right) \cdot\left(\mathrm{H}_{2} \mathrm{O}\right)_{2}\right]_{2}$, (FIG. 5.5 a) observaram-se 5 eventos de perda de massas onde os 2 primeiros estão relacionados a perda de água de hidratação e coordenação ligadas de várias formas. Esta perda de massa dá-se no intervalo de 0 a $200^{\circ} \mathrm{C}$ e equivale a $9,5 \%$ de massa inicial. Os demais picos entre $200-600^{\circ} \mathrm{C}$ são referentes à decomposição térmica fracionada dos ligantes $\beta$ dicetonas e nitrato.

As inflexões observadas nas curvas de decomposição térmica TGA para todos os quelatos no intervalo de temperatura de 50 a $600^{\circ} \mathrm{C}$ são evidenciadas na curva DTGA e concordam com comportamentos exotérmicos para os eventos relacionados à decomposição dos quelatos.

Para o composto $\left[\mathrm{Eu}(\mathrm{ACAC})_{2}\left(\mathrm{NO}_{3}\right) \cdot\left(\mathrm{H}_{2} \mathrm{O}\right)_{2}\right]_{2}$, (FIG. 5.5 b) observaram-se 6 eventos de perda de massas onde os 2 primeiros estão relacionados a perda de água de hidratação e coordenação ligadas 
de várias formas. Esta perda de massa dá-se no intervalo de 0 a $200^{\circ} \mathrm{C}$ e equivale a $9,5 \%$ de massa inicial. Os demais picos entre $200-600^{\circ} \mathrm{C}$ são referentes à decomposição térmica fracionada dos ligantes $\beta$-dicetonas nitrato.

As inflexões observadas nas curvas de decomposição térmica TGA para todos os quelatos no intervalo de temperatura de 50 a $600^{\circ} \mathrm{C}$ são evidenciadas na curva DTGA e concordam com comportamentos exotérmicos para os eventos relacionados à decomposição dos quelatos.

Para o composto $\left[\mathrm{Tb}(\mathrm{ACAC})_{2}\left(\mathrm{NO}_{3}\right) \cdot\left(\mathrm{H}_{2} \mathrm{O}\right)_{2}\right]_{2}$, (FIG. 5.5 c) observaram-se 7 eventos de perda de massas onde os 2 primeiros estão relacionados a perda de água de hidratação e coordenação ligadas de várias formas. Esta perda de massa dá-se no intervalo de 0 a $200^{\circ} \mathrm{C}$ e equivale a 9,5\% de massa inicial. Os demais picos entre $200-600^{\circ} \mathrm{C}$ são referentes à decomposição térmica fracionada dos ligantes $\beta$-dicetonas e nitrato.

As inflexões observadas nas curvas de decomposição térmica TGA para todos os quelatos no intervalo de temperatura de 50 a $600^{\circ} \mathrm{C}$ são evidenciadas na curva DTGA e concordam com comportamentos exotérmicos para os eventos relacionados à decomposição dos quelatos.

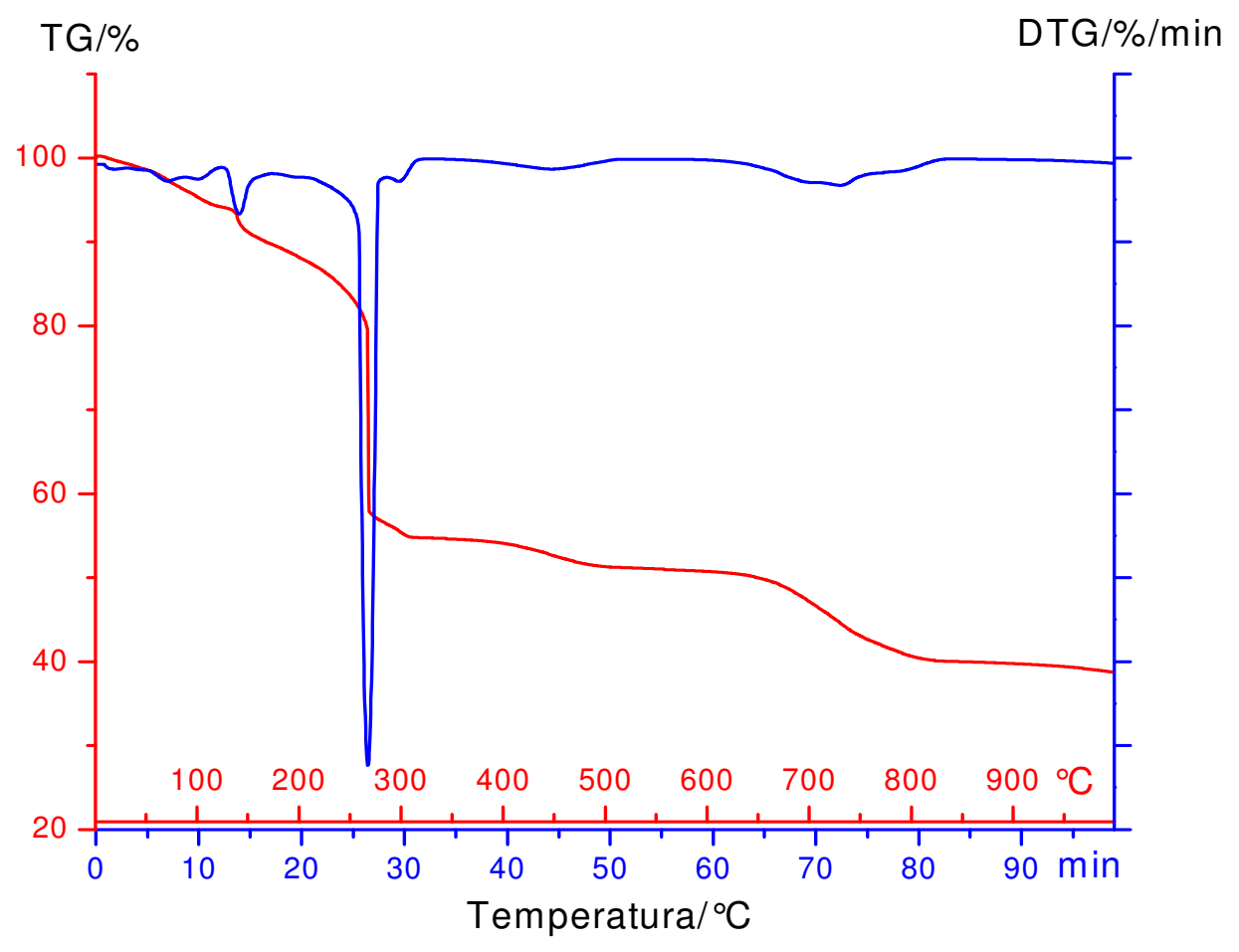

(a) $\left[\mathrm{Eu}(\mathrm{TTA})_{2} \cdot\left(\mathrm{NO}_{3}\right) \cdot\left(\mathrm{H}_{2} \mathrm{O}\right)_{2}\right]_{2}$ 


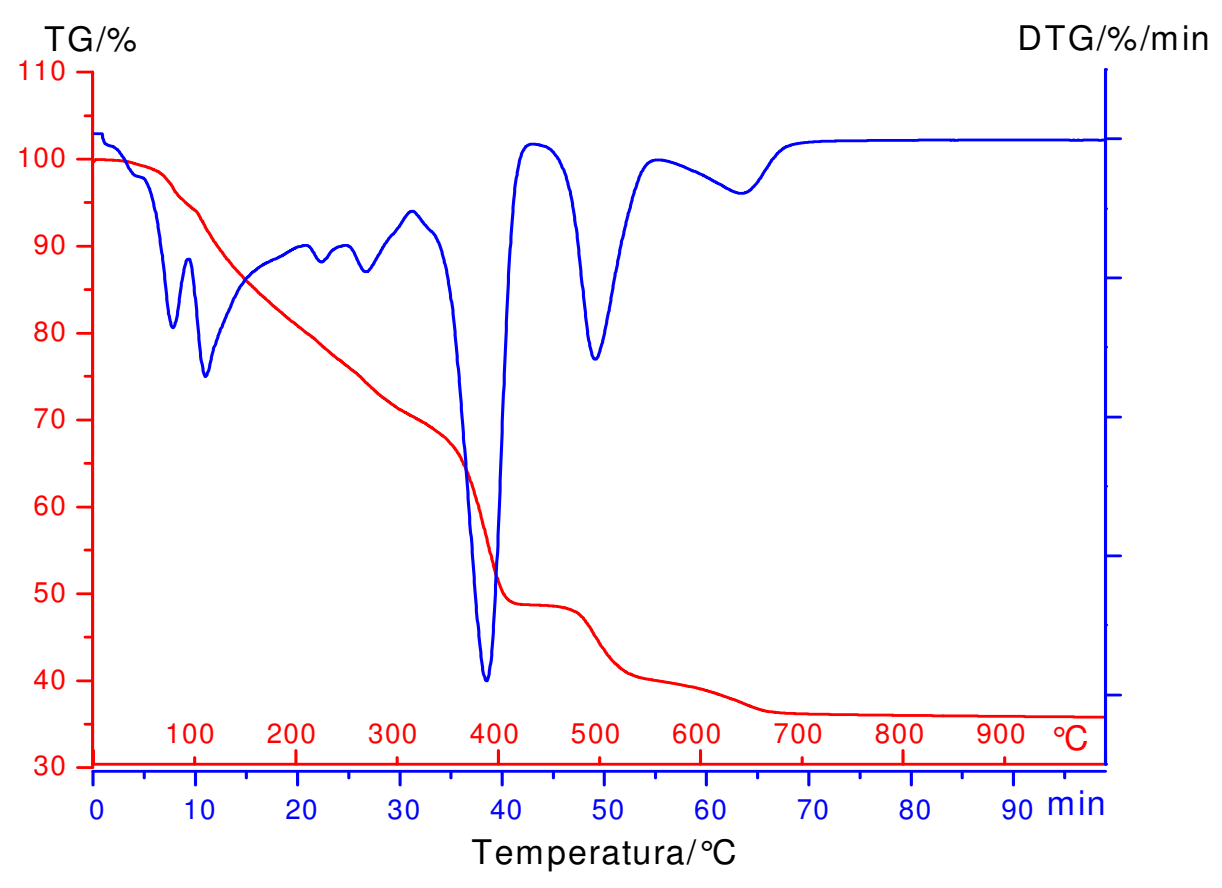

(b) $\left[\mathrm{Eu}(\mathrm{ACAC})_{2} \cdot\left(\mathrm{NO}_{3}\right) \cdot\left(\mathrm{H}_{2} \mathrm{O}\right)_{2}\right]_{2}$

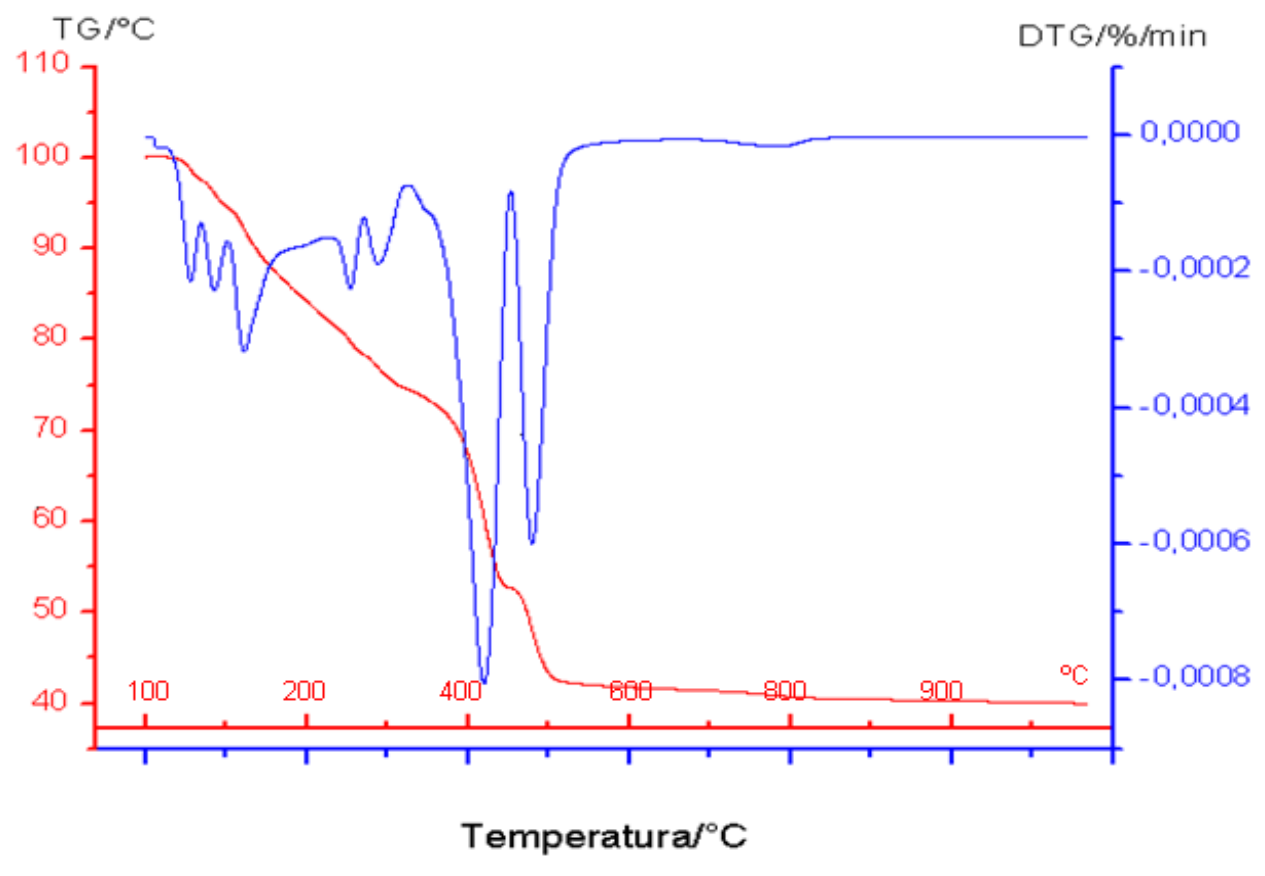

(c) $\left.\mathrm{Tb}(\mathrm{ACAC})_{2} \cdot\left(\mathrm{NO}_{3}\right) \cdot\left(\mathrm{H}_{2} \mathrm{O}\right)_{2}\right]_{2}$

FIGURA 5.5. Curvas TGA e DTGA dos quelatos precursores: (a) $\left[\mathrm{Eu}(\mathrm{TTA})_{2}\left(\mathrm{NO}_{3}\right) \cdot\left(\mathrm{H}_{2} \mathrm{O}\right)_{2}\right]_{2}$, (b) $\left[\mathrm{Eu}(\mathrm{ACAC})_{2}\left(\mathrm{NO}_{3}\right) \cdot\left(\mathrm{H}_{2} \mathrm{O}\right)_{2}\right]_{2}$ $\mathrm{e}$ $\left[\mathrm{Tb}(\mathrm{ACAC})_{2}\left(\mathrm{NO}_{3}\right) \cdot\left(\mathrm{H}_{2} \mathrm{O}\right)_{2}\right]_{2}$, sob atmosfera de nitrogênio com vazão $50 \mathrm{~mL} / \mathrm{minuto}$ e razão de aquecimento $10^{\circ} \mathrm{C} \mathrm{min}^{-1}$. 
TABELA 5.5. Dados de decomposição térmica dos quelatos precursores.

\begin{tabular}{ccc}
\hline Quelatos precursores & Temperatura $\left({ }^{\circ} \mathbf{C}\right)$ & Perda de massa $(\%)$ \\
\hline$\left[\mathrm{Eu}(\mathrm{TTA})_{2} \cdot\left(\mathrm{NO}_{3}\right) \cdot\left(\mathrm{H}_{2} \mathrm{O}\right)_{2}\right]_{2}$ & $45-84$ & 1,9 \\
& $85-243$ & 7,6 \\
& $243-335$ & 13,9 \\
& $335-448$ & 18,5 \\
& $448-971$ & 35,6 \\
& & \\
{$\left[\mathrm{Eu}(\mathrm{ACAC})_{2} \cdot\left(\mathrm{NO}_{3}\right) \cdot\left(\mathrm{H}_{2} \mathrm{O}\right)_{2}\right]_{2}$} & $33-172$ & 18,6 \\
& $172-335$ & 7,5 \\
& $335-434$ & 24,5 \\
& $434-970$ & 25,4 \\
& & 10 \\
& $50-165$ & 19 \\
& $165-337$ & 24 \\
& $337-431$ & 11 \\
\hline
\end{tabular}

\subsubsection{Decomposição térmica das supermoléculas}

A FIG. 5.6 apresentam as curvas TG e DTG para as supermoléculas estudadas. As curvas foram registradas no intervalo de 0 a $1000^{\circ} \mathrm{C}$. Na TAB. 5.6 estão listados os eventos observados para as supermoléculas.

Para o composto $\left[\mathrm{Eu}(\mathrm{TTA})_{2}\left(\mathrm{NO}_{3}\right) \cdot\left(\mathrm{H}_{2} \mathrm{O}\right)_{2}\right]_{2} \subset$ octaacetato calix[8]areno, observaram-se 5 eventos principais de perda de massas onde os 2 primeiros estão relacionados a perda de água de hidratação e coordenação ligadas de várias formas. Esta perda de massa dá-se no intervalo de 0 a $200^{\circ} \mathrm{C}$ e equivale a 9,5\% de massa inicial. Os demais picos entre $200-900^{\circ} \mathrm{C}$ são referentes à decomposição térmica fracionada dos ligantes, TTA, nitrato e octaacetato calix[8]areno.

As inflexões observadas nas curvas TGA foram evidenciadas nas curvas DTGA, indicando eventos exotérmicos na decomposição dos materiais. Na Tabela 5.6 estão listados os eventos de perda de massa registrados e observados na decomposição térmica das supermoléculas.

Para o composto $\left[\mathrm{Eu}(\mathrm{ACAC})_{2}\left(\mathrm{NO}_{3}\right) \cdot\left(\mathrm{H}_{2} \mathrm{O}\right)_{2}\right]_{2} \subset$ octaacetato calix[8]areno, observaram-se 5 eventos principais de perda de massas onde os 2 primeiros estão relacionados a perda de água de hidratação e coordenação ligadas de várias formas. Esta perda de massa dá-se no intervalo de 0 a $250^{\circ} \mathrm{C}$ e equivale a 9,5\% de massa inicial. Os demais picos entre $200-700^{\circ} \mathrm{C}$ são referentes à decomposição térmica fracionada dos ligantes, ACAC, nitrato e octaacetato calix[8]areno. 
As inflexões observadas nas curvas TGA foram evidenciadas nas curvas DTGA, indicando eventos exotérmicos na decomposição dos materiais. Na Tabela 5.6 estão listados os eventos de perda de massa registrados e observados na decomposição térmica das supermoléculas.

Para o composto $\left[\mathrm{Tb}(\mathrm{ACAC})_{2}\left(\mathrm{NO}_{3}\right) \cdot\left(\mathrm{H}_{2} \mathrm{O}\right)_{2}\right]_{2} \subset$ octaacetato calix[8]areno, observaram-se 6 eventos principais de perda de massas onde os 2 primeiros estão relacionados a perda de água de hidratação e coordenação ligadas de várias formas. Esta perda de massa dá-se no intervalo de 0 a $200^{\circ} \mathrm{C}$ e equivale a 9,5\% de massa inicial. Os demais picos entre $200-600^{\circ} \mathrm{C}$ são referentes à decomposição térmica fracionada dos ligantes, ACAC, nitrato e octaacetato calix[8]areno.

As inflexões observadas nas curvas TGA foram evidenciadas nas curvas DTGA, indicando eventos exotérmicos na decomposição dos materiais. Na Tabela 5.6 estão listados os eventos de perda de massa registrados e observados na decomposição térmica das supermoléculas.

Tanto para os quelatos precursores quanto para as supermoléculas observam-se dois perfiz distintos de decomposição térmica um referente aos derivados de TTA e umsegundo referente ao grupo do ACAC.

Comparando-se as TGAs dos precursores com a sua respectiva supermoléculas para o TTA a adição do ligante octaacetato calix[8]areno é evidenciada pela presença de dois picos entre 400 e $600^{\circ} \mathrm{C}$ que não foi registrado no quelato precursor. Já para os derivados da $\beta$-dicetona ACAC, nota-se a supressão do último pico observado nos quelatos precursores, depois de $600^{\circ} \mathrm{C}$, para as supermoléculas.

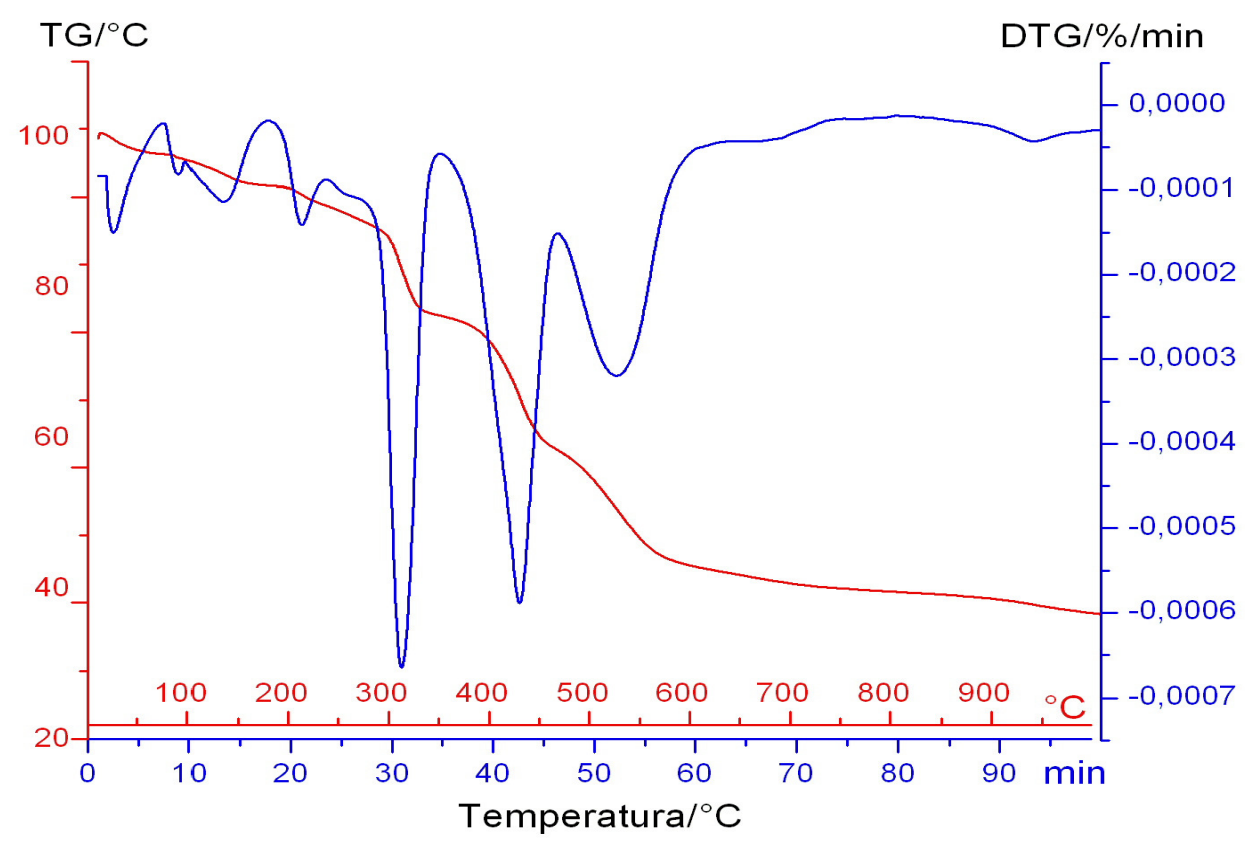

(a) $\left[\mathrm{Eu}(\mathrm{TTA})_{2}\left(\mathrm{NO}_{3}\right) \cdot\left(\mathrm{H}_{2} \mathrm{O}\right)_{2}\right]_{2} \subset$ acetato calix $[8]$ areno 


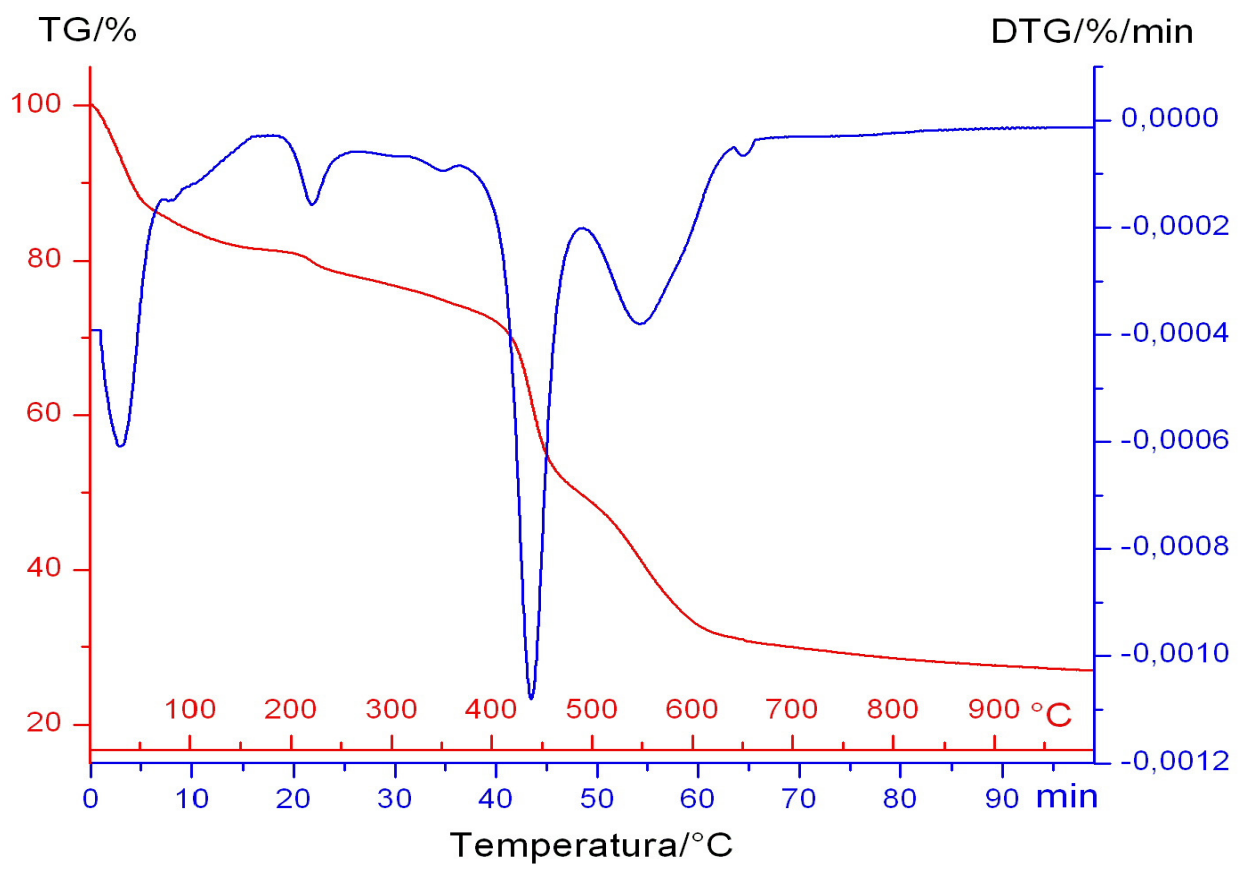

(b) $\left[\mathrm{Eu}(\mathrm{ACAC})_{2}\left(\mathrm{NO}_{3}\right) \cdot\left(\mathrm{H}_{2} \mathrm{O}\right)_{2}\right]_{2} \subset$ acetato calix[8]areno

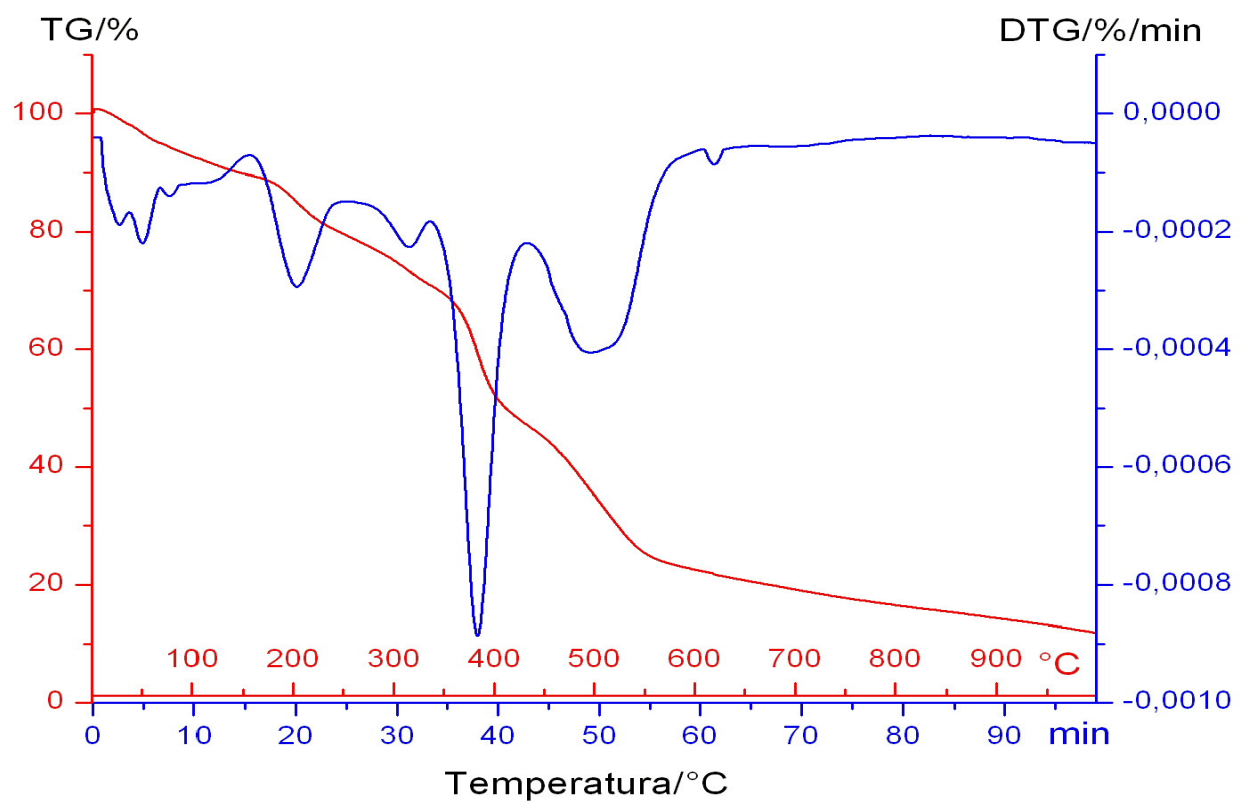

(c) $\left[\mathrm{Tb}(\mathrm{TTA})_{2}\left(\mathrm{NO}_{3}\right) \cdot\left(\mathrm{H}_{2} \mathrm{O}\right)_{2}\right]_{2} \subset$ acetato calix $[8]$ areno

FIGURA 5.6. Curvas TGA e DTGA das supermoléculas: (a) $\left[\mathrm{Eu}(\mathrm{TTA})_{2}\left(\mathrm{NO}_{3}\right) \cdot\left(\mathrm{H}_{2} \mathrm{O}\right)_{2}\right]_{2} \subset$ acetato calix [8]areno, (b) $\left[\mathrm{Eu}(\mathrm{ACAC})_{2}\left(\mathrm{NO}_{3}\right) \cdot\left(\mathrm{H}_{2} \mathrm{O}\right)_{2}\right]_{2}$ cacetato calix [8]areno e (c) [Tb(ACAC $\left.)_{2}\left(\mathrm{NO}_{3}\right) \cdot\left(\mathrm{H}_{2} \mathrm{O}\right)_{2}\right]_{2} \subset$ acetato calix [8]areno sob atmosfera de nitrogênio com vazão $50 \mathrm{~mL} /$ minuto e razão de aquecimento $10^{\circ} \mathrm{C} \mathrm{min}^{-1}$. 
TABELA 5.6. Dados de decomposição térmica das supermoléculas.

\begin{tabular}{|c|c|c|}
\hline Supermolécula & Temperatura $\left({ }^{\circ} \mathbf{C}\right)$ & Perda de massa $(\%)$ \\
\hline $\begin{array}{l}{\left[\mathrm{Eu}(\mathrm{TTA})_{2} \cdot\left(\mathrm{NO}_{3}\right) \cdot\left(\mathrm{H}_{2} \mathrm{O}\right)_{2}\right]_{2} \subset} \\
\text { acetato calix }[8] \text { areno }\end{array}$ & $\begin{array}{l}45-84 \\
85-243 \\
243-335 \\
335-448 \\
448-971\end{array}$ & $\begin{array}{l}1,9 \\
7,5 \\
13,9 \\
18,4 \\
35,6\end{array}$ \\
\hline $\begin{array}{l}{\left[\mathrm{Eu}(\mathrm{ACAC})_{2} \cdot\left(\mathrm{NO}_{3}\right) \cdot\left(\mathrm{H}_{2} \mathrm{O}\right)_{2}\right]_{2} \subset} \\
\text { acetato calix }[8] \text { areno }\end{array}$ & $\begin{array}{l}33-172 \\
172-335 \\
335-434 \\
434-970\end{array}$ & $\begin{array}{l}18,6 \\
7,5 \\
24,5 \\
25,5\end{array}$ \\
\hline $\begin{array}{l}{\left[\mathrm{Tb}(\mathrm{ACAC})_{2} \cdot\left(\mathrm{NO}_{3}\right) \cdot\left(\mathrm{H}_{2} \mathrm{O}\right)_{2}\right]_{2} \subset} \\
\text { acetato calix }[8] \text { areno }\end{array}$ & $\begin{array}{l}50-165 \\
165-337 \\
337-431 \\
431-959\end{array}$ & $\begin{array}{l}10 \\
18,9 \\
24,5 \\
10,9\end{array}$ \\
\hline
\end{tabular}

\subsection{Microscopia eletrônica de varredura (MEV), do ligante, dos quelatos precursores e das supermoléculas}

Na FIG. 5.7 apresentam-se as micrografias do ligante e dos quelatos percusores e na FIG. 5.8 apresentam-se as micrografias das supermoléculas estudadas.

O octaacetato calix[8]areno (FIG. 5.7 a) é um material heterogêneo com tamanho menor que $20 \mu \mathrm{m}$ na sua maioria. Ele tem aparência cristalina e está empacotado na forma de paralelepípedos aglomerados. Na FIG. 5.7: b, c e d, apresentam-se as micrografias dos quelatos precursores mostrando a higroscopicidade destes materiais. Os cristais para todos os quelatos apresentam-se agregados, com heterogeneidade de tamanho e formas.

Já as supermoléculas têm tamanho heterogêneo e apresentam formas lamelares observando-se um aglomerado de placas e higroscopicidade no caso da supermolécula de $\mathrm{Tb}^{3+}$. Na FIG. 5.8 g, observa-se a higroscopicidade acentuada do material em questão.

Como se pretende usar os sistemas como marcadores ópticos e FIA, pois estes são luminescentes e têm grande estabilidade, este ensaio estende a possibilidade de no futuro fazer um monitoramento de síntese, avaliando características morfológicas como tamanho de partículas, homogeneidade e forma cristalina. 

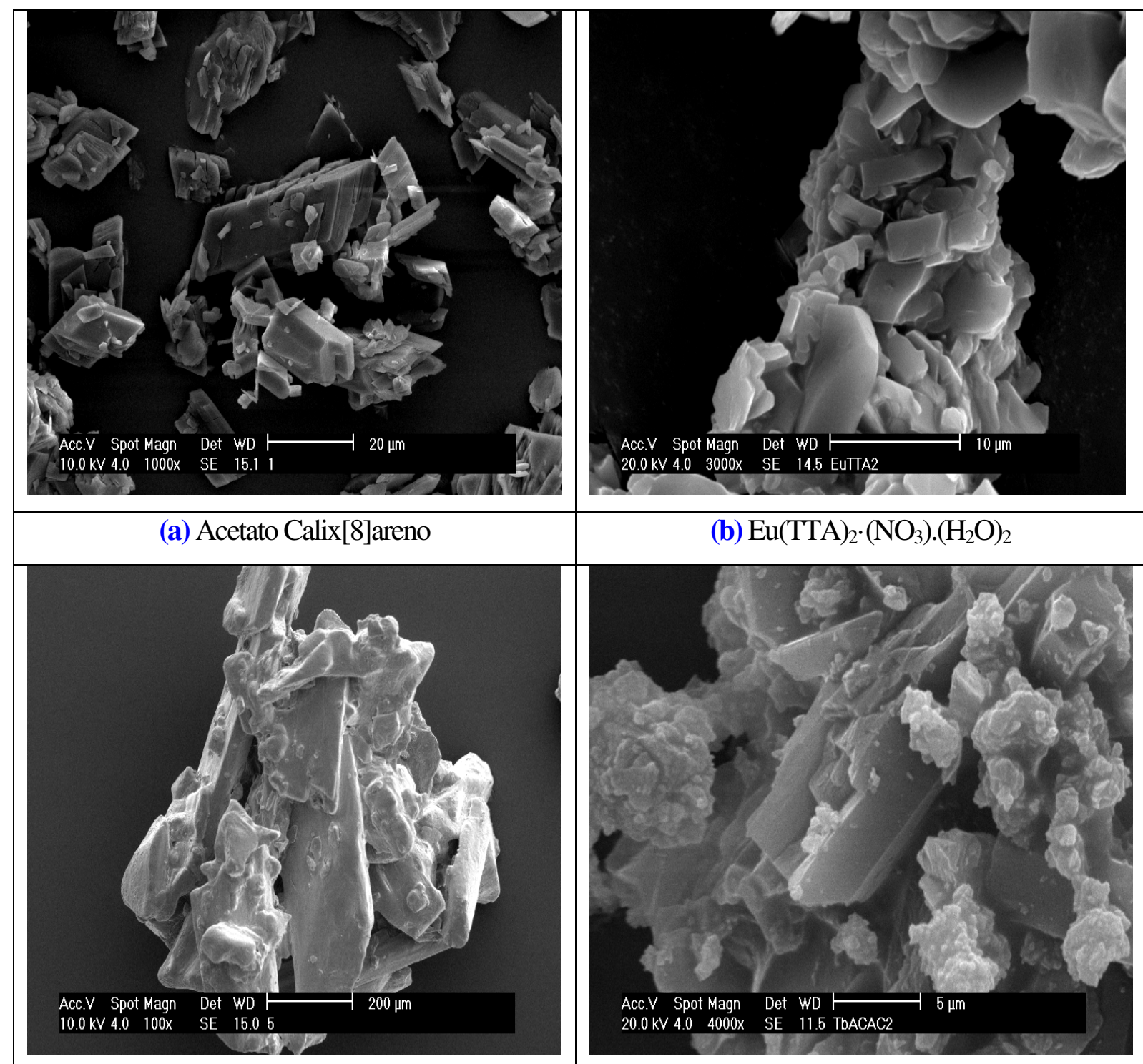

(b) $\mathrm{Eu}(\mathrm{TTA})_{2} \cdot\left(\mathrm{NO}_{3}\right) \cdot\left(\mathrm{H}_{2} \mathrm{O}\right)_{2}$

(c) $\mathrm{Eu}(\mathrm{ACAC})_{2} \cdot\left(\mathrm{NO}_{3}\right) \cdot\left(\mathrm{H}_{2} \mathrm{O}\right)_{2}$

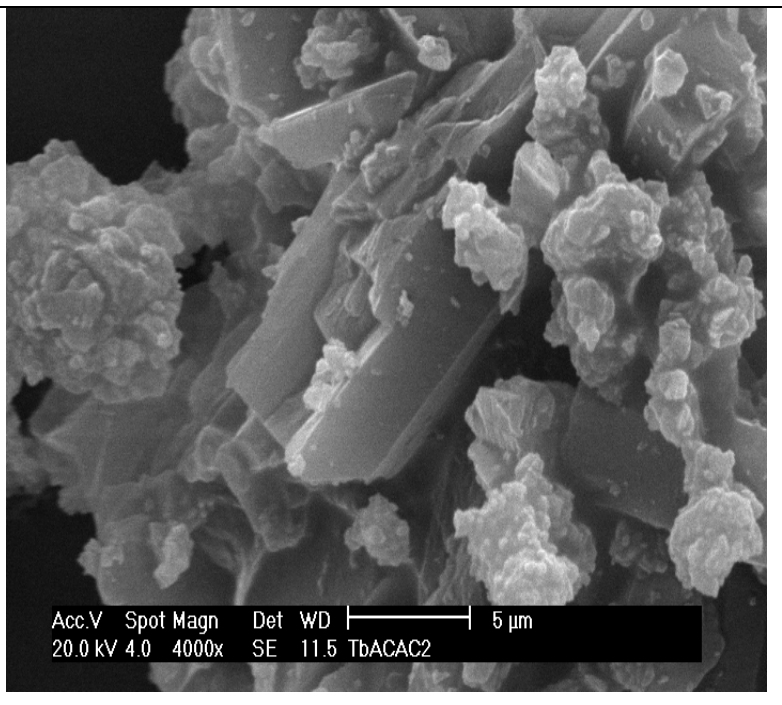

(d) $\mathrm{Tb}(\mathrm{ACAC})_{2} \cdot\left(\mathrm{NO}_{3}\right) \cdot\left(\mathrm{H}_{2} \mathrm{O}\right)_{2}$

FIGURA 5.7. Micrografias do (a) Acetato Calix[8]areno e (b,c e d) dos quelatos precursores. 


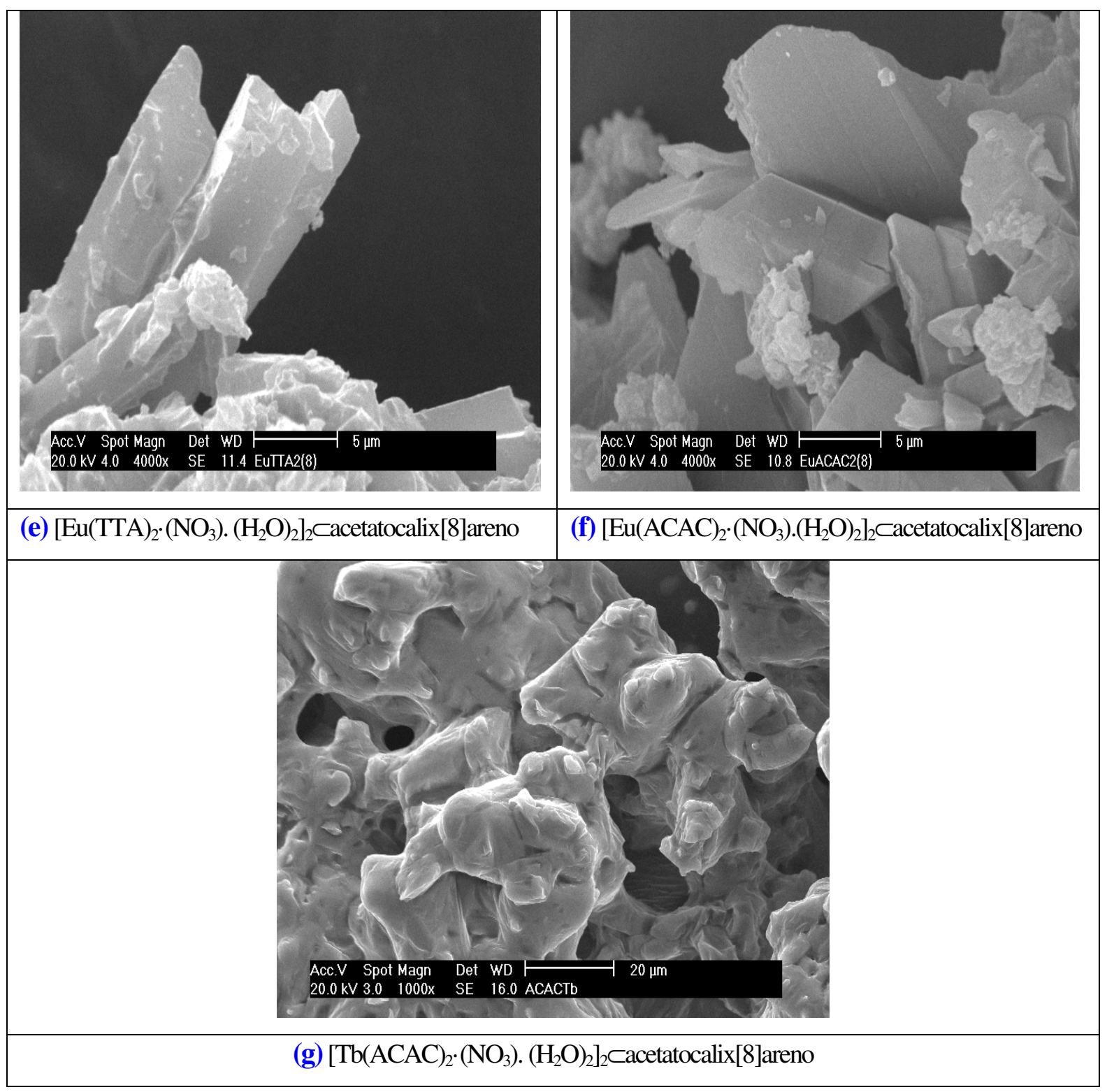

FIGURA 5.8. Micrografias das supermoléculas (e, f e g). 


\subsection{Estudos fotoluminescentes}

\subsubsection{Estudo fotoluminescente dos complexos de $\mathrm{Eu}^{3+}$}

Os compostos contendo o íon $\mathrm{Eu}^{3+}$ (configuração [Xe]4f $\mathrm{f}^{6}$ ) têm sido extensivamente estudados por apresentarem alta luminescência monocromática de cor vermelha. Além disso, a partir de seus espectros de emissão podem-se obter informações sobre o desdobramento do campo ligante, processos de transferência de energia e eficiência quântica do estado emissor. Os espectros exibidos pelos complexos de $\mathrm{Eu}^{3+}$ apresentam, principalmente, bandas oriundas das transições intraconfiguracionais ${ }^{5} \mathrm{D}_{0} \rightarrow{ }^{7} \mathrm{~F}_{\mathrm{J}}$ (onde $\mathrm{J}=0,1,2,3,4,5$ e 6 ), sendo que as transições ${ }^{5} \mathrm{D}_{0} \rightarrow{ }^{7} \mathrm{~F}_{5}$ e ${ }^{5} \mathrm{D}_{0} \rightarrow{ }^{7} \mathrm{~F}_{6}$ apresentam intensidade muito baixa e dificilmente são observadas nos espectros dos compostos de coordenação. Como pode ser notado, o principal nível emissor, ${ }^{5} \mathrm{D}_{0}$, é não degenerado e não se desdobra em qualquer simetria em torno do íon metálico ${ }^{[6]}$, ao contrário, por exemplo, do estado emissor do íon $\mathrm{Tb}^{3+}\left({ }^{5} \mathrm{D}_{4}\right)$ que tem uma degenerescência máxima igual a nove. Portanto, o número máximo de bandas resultantes de uma transição ${ }^{5} \mathrm{D}_{0} \rightarrow{ }^{7} \mathrm{~F}_{\mathrm{J}}$ é dado pela regra de $(2 \mathrm{~J}+1)$-componentes. O número de bandas associado a cada transição depende da simetria pontual ao redor do íon $\mathrm{TR}^{3+}$ e pode ser facilmente determinada usando a teoria de grupos ${ }^{[7]}$.

Quando um espectro apresenta número de picos maior do que da regra (2J+1)-componentes isto evidencia ou a presença de mais de um sítio de simetria para o íon metálico ou que o composto está impuro, por exemplo, em sistemas dinucleares sem centro de inversão, ou mistura de isômeros, ou ainda o aparecimento de transições vibrônicas devido à interação dos níveis eletrônicos e estados de densidade fônons. Este último fenômeno resulta na presença de "bandas satélites" e é observado

principalmente nas transições ${ }^{5} \mathrm{D}_{0} \rightarrow{ }^{7} \mathrm{~F}_{2}$, considerando que o nível ${ }^{7} \mathrm{~F}_{2}$ encontra-se na região espectral correspondente as frequiências de estiramentos $v(C=O), v(C=C)$ e $v(N=O)$ presentes nos ligantes orgânicos.

As transições ${ }^{5} \mathrm{D}_{0} \rightarrow{ }^{7} \mathrm{~F}_{0,3,5}$ são proibidas pelas regras de seleção de dipolo-elétrico forçado e dipolo-magnético. No entanto, a primeira regra pode ser relaxada pelo campo ligante conduzindo aos efeitos de misturas dos J's e, conseqüentemente, apesar de pequeno, existe um momento de transição diferente de zero. A intensidade da transição ${ }^{5} \mathrm{D}_{0} \rightarrow{ }^{7} \mathrm{~F}_{0}$ tem sido caracterizada como sendo, principalmente, devido à mistura do estado ${ }^{7} \mathrm{~F}_{2}$ dentro do estado ${ }^{7} \mathrm{~F}_{0}$, e essa mistura é expressa em termos do parâmetro $\mathrm{R}_{02}$, definido como a razão entre as intensidades das bandas oriundas das transições ${ }^{5} \mathrm{D}_{0} \rightarrow \mathrm{F}_{0} \mathrm{e}^{5} \mathrm{D}_{0} \rightarrow{ }^{7} \mathrm{~F}_{2}$. Por outro lado, a transição ${ }^{5} \mathrm{D}_{0} \rightarrow{ }^{7} \mathrm{~F}_{1}$ é permitida somente por dipolomagnético e sua intensidade é praticamente insensível ao ambiente químico nas vizinhanças do íon $\mathrm{Eu}^{3+}$, por conseguinte, essa transição tem sido tomada como uma referência interna ${ }^{[8]}$. 
As transições ${ }^{5} \mathrm{D}_{0} \rightarrow{ }^{7} \mathrm{~F}_{2,4}$ são permitidas por dipolo-elétrico forçado, sendo que a transição ${ }^{5} \mathrm{D}_{0} \rightarrow{ }^{7} \mathrm{~F}_{2}(\sim 612 \mathrm{~nm})$, hipersensível ao ambiente químico ao redor do íon central, é geralmente dominante em compostos não-centrossimétricos. Estas transições fornecem informações se grupo o pontual em torno do íon $\mathrm{Eu}^{3+}$ apresenta centro de inversão, considerando que em compostos centrossimétricos as transições ${ }^{5} \mathrm{D}_{0} \rightarrow{ }^{7} \mathrm{~F}_{2,4}$ são estritamente proibidas por mecanismo de dipolo elétrico.

Uma vez que as bandas de emissão do íon $\mathrm{Eu}^{3+}$ na região do visível são de fácil interpretação, devido a estrutura dos seus níveis de energia, este íon tem sido utilizado como sonda espectroscópica na obtenção de valiosas informações em sistemas bioinorgânicos, tais como: i) a determinação do número de ambientes químicos ao redor do íon $\mathrm{Eu}^{3+}$ através do número de bandas relativo à transição ${ }^{5} \mathrm{D}_{0} \rightarrow{ }^{7} \mathrm{~F}_{0}$; ii) Constante de ligação dos íons biomolécula-Eu ${ }^{3+}$, determinada por curvas de titulação e iii) distância doador-receptor (R), normalmente assumindo o mecanismo de acoplamento dipolo-dipolo fraco ${ }^{[9]}$.

Também são observadas bandas vibrônicas fracas com magnitude de aproximadamente 1\%, menos intensas do que as atribuídas às transições zero-fônon.

Nesse trabalho os espectros de luminescência foram registrados à temperatura ambiente e do nitrogênio líquido, apresentando características espectrais semelhantes, exceto quanto à resolução dos perfis das transições, que a baixa temperatura mostram-se mais definidos, facilitando as suas atribuições.

\subsubsection{Nitrato de európio}

Na FIG. 5.9 têm-se os espectros de exitação (a) e emissão (b) do material de partida, o nitrato de európio. $\mathrm{O}$ espectro de excitação apresenta bandas atribuidas as transições intraconfiguracionais $4 \mathrm{f}-4 \mathrm{f}$ do íon $\mathrm{Eu}^{3+} 317 \mathrm{~nm}\left({ }^{7} \mathrm{~F}_{0} \rightarrow{ }^{5} \mathrm{H}_{3}\right), 350 \mathrm{~nm}\left({ }^{7} \mathrm{~F}_{0} \rightarrow{ }^{5} \mathrm{~L}_{10}\right), 357,8 \mathrm{~nm}\left({ }^{7} \mathrm{~F}_{0} \rightarrow{ }^{5} \mathrm{~L}_{9}\right), 361,4\left({ }^{7} \mathrm{~F}_{0} \rightarrow{ }^{5} \mathrm{D}_{4}\right), 366,3$ $\left({ }^{7} \mathrm{~F}_{0} \rightarrow{ }^{5} \mathrm{~L}_{8}\right), 375 \mathrm{~nm}\left({ }^{7} \mathrm{~F}_{0} \rightarrow{ }^{5} \mathrm{G}_{3}\right), 380,5\left({ }^{7} \mathrm{~F}_{0} \rightarrow{ }^{5} \mathrm{G}_{2}\right), 385,4\left({ }^{7} \mathrm{~F}_{0} \rightarrow{ }^{5} \mathrm{~L}_{7}\right), 394,9\left({ }^{7} \mathrm{~F}_{0} \rightarrow{ }^{5} \mathrm{~L}_{6}\right), 416,8\left({ }^{7} \mathrm{~F}_{0} \rightarrow{ }^{5} \mathrm{D}_{3}\right)$, $472,7\left({ }^{7} \mathrm{~F}_{0} \rightarrow{ }^{5} \mathrm{D}_{2}\right), 524,2\left({ }^{7} \mathrm{~F}_{0} \rightarrow{ }^{5} \mathrm{D}_{1}\right)$ e $578,5\left({ }^{7} \mathrm{~F}_{0} \rightarrow{ }^{5} \mathrm{D}_{0}\right)$. Os espectros de emissão foram registrados no intervalo de 560 a $800 \mathrm{~nm}$, a temperatura ambiente e $77 \mathrm{~K}$. Estes espectros exibem bandas finas atribuídas às transições ${ }^{5} \mathrm{D}_{0} \rightarrow{ }^{7} \mathrm{~F}_{\mathrm{J}}$ (onde $\mathrm{J}=0,1,2,3,4$ ), sendo a transição hipersensível ${ }^{5} \mathrm{D}_{0} \rightarrow{ }^{7} \mathrm{~F}_{2}$ a mais intensa FIG. 5.9 b. 


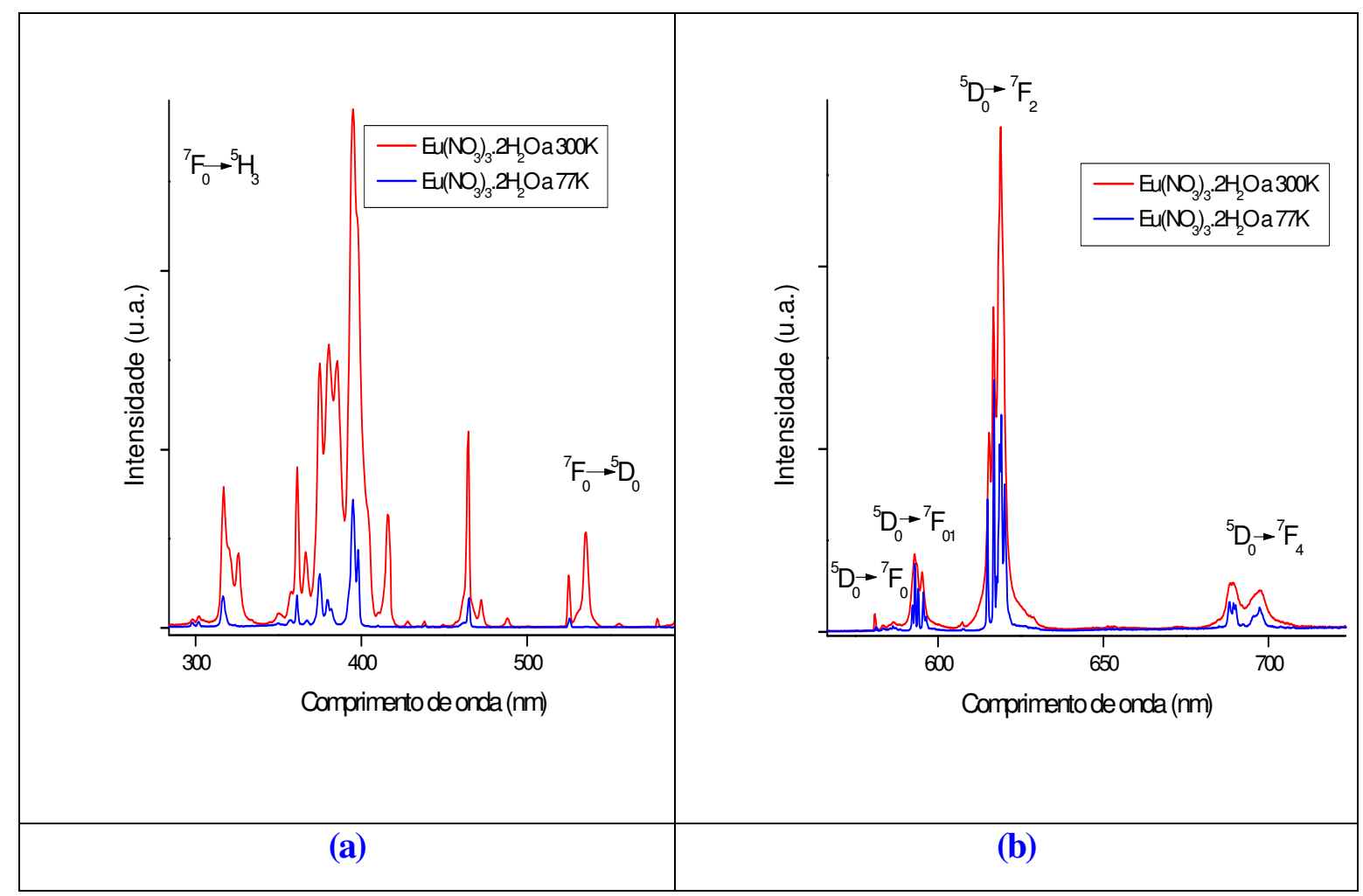

FIGURA 5.9. Espectros de excitação (a) e emissão (b) dos nitratos de $\mathrm{Eu}^{3+}$ a temperatura ambiente $(300 \mathrm{~K})$ e a temperatura do nitrogênio líquido $(77 \mathrm{~K})$. Excitação monitorada na ${ }^{5} \mathrm{D}_{0} \rightarrow{ }^{7} \mathrm{~F}_{2}\left(\lambda_{\text {exc }}=612 \mathrm{~nm}\right)$ e emissão monitorada em 394nm.

\subsubsection{Fotoluminescência das supermoléculas de $\beta$-dicetonados de európio e seus quelatos precussores.}

\subsection{Espectros de Excitação}

Os estudos fotoluminescentes das supermoléculas de $\beta$-dicetonados de európio foram feitos com base nos espectros de excitação e emissão registrados a temperatura ambiente $(\sim 300 \mathrm{~K})$ e a $77 \mathrm{~K}$. Os espectros de excitação foram registrados no intervalo de 250 a $590 \mathrm{~nm}$, com emissão monitorada na transição hipersensível ${ }^{5} \mathrm{D}_{0} \rightarrow{ }^{7} \mathrm{~F}_{2}(\sim 612 \mathrm{~nm})$, Enquanto que os espectros de emissão foram obtidos com excitação no íon $\mathrm{Eu}^{3+}(\sim 394$ $\mathrm{nm})$ e via banda do ligante $(\sim 350 \mathrm{~nm})$ no intervalo de 420 a $720 \mathrm{~nm}$, correspondente às transições intraconfiguracionais ${ }^{5} \mathrm{D}_{\mathrm{J}} \rightarrow{ }^{7} \mathrm{~F}_{0-4}$. É importante salientar, que não houve diferenças significativas entre os espectros registrados a 300 e $77 \mathrm{~K}$. No entanto, os espectros registrados a 77 K são mais resolvidos, devido ao menor acoplamento vibrônico, o que facilita uma melhor interpretação dos dados espectroscópicos, como é ilustrado neste trabalho FIG. 5.10-5.17. 
As FIG. 5.10 a 5.13 mostram os espectros de excitação das supermoléculas de TTA e ACAC e seus quelatos precussores. È observado que na região de 250 a $420 \mathrm{~nm}$, os espectros apresentam bandas largas sobrepostas as transições $4 \mathrm{f}-4 \mathrm{f}$ com máximos em torno de $\sim 350 \mathrm{~nm}$ associadas à transição permitida $\mathrm{S} \rightarrow \mathrm{S}_{0}$ pertencente aos ligantes TTA e ACAC. As bandas finas oriundas das transições intraconfiguracionais $4 \mathrm{f}^{6}{ }^{7} \mathrm{~F}_{0} \rightarrow{ }^{5} \mathrm{G}_{6},{ }^{5} \mathrm{H}_{4},{ }^{5} \mathrm{~L}_{6},{ }^{5} \mathrm{D}_{2} \mathrm{e}{ }^{5} \mathrm{D}_{1}$ apresentam-se sobrepostas com as bandas largas dos ligantes são atribuídas as transições do íon $\mathrm{Eu}^{3+}$. De um modo geral, é observado uma mudança significativa entre os espectros de excitação dos complexos hidratados e aqueles dos complexos contendo calixarenos. As diferenças estão, provavelmente, associadas a pequenas mudanças nos níveis de energia das $\beta$-dicetonas TTA e ACAC, devido a distorções causadas pelos ligantes calixarenos e, os quais são maiores do que a molécula de água.

É observado que os espectros de excitação das supermoléculas com TTA apresentam bandas de maior intensidade na região de absorção do ligante TTA quando comparadas com aquelas das transições ${ }^{7} \mathrm{~F}_{0} \rightarrow{ }^{5} \mathrm{D}_{\mathrm{J}}$ do íon $\mathrm{Eu}^{3+}$, evidenciando o grande potencial dos ligantes TTA em atuar como "antena" no processo de transferência de energia Ligante- $\mathrm{Eu}^{3+}$.

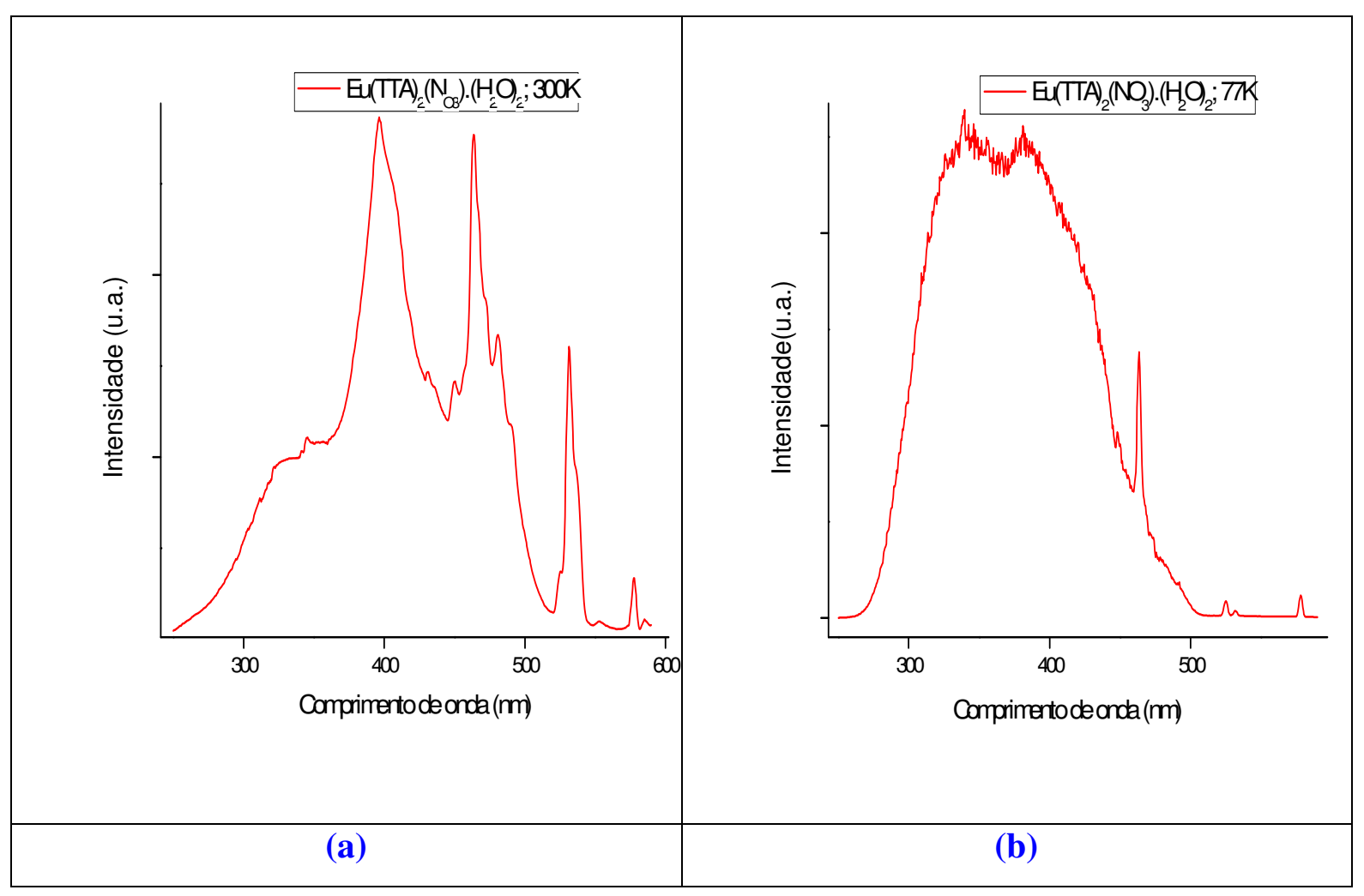

FIGURA 5.10. Espectros de excitação do quelato precursor: Eu(TTA $)_{2}\left(\mathrm{NO}_{3}\right) \cdot\left(\mathrm{H}_{2} \mathrm{O}\right)_{2}$ (a) temperatura ambiente $(300 \mathrm{~K})$ e (b) a temperatura do nitrogênio líquido $(77 \mathrm{~K})$. Emissão monitorada $\mathrm{em}^{5} \mathrm{D}_{0} \rightarrow{ }^{7} \mathrm{~F}_{2}\left(\lambda_{\text {emissão }}=612 \mathrm{~nm}\right)$. 


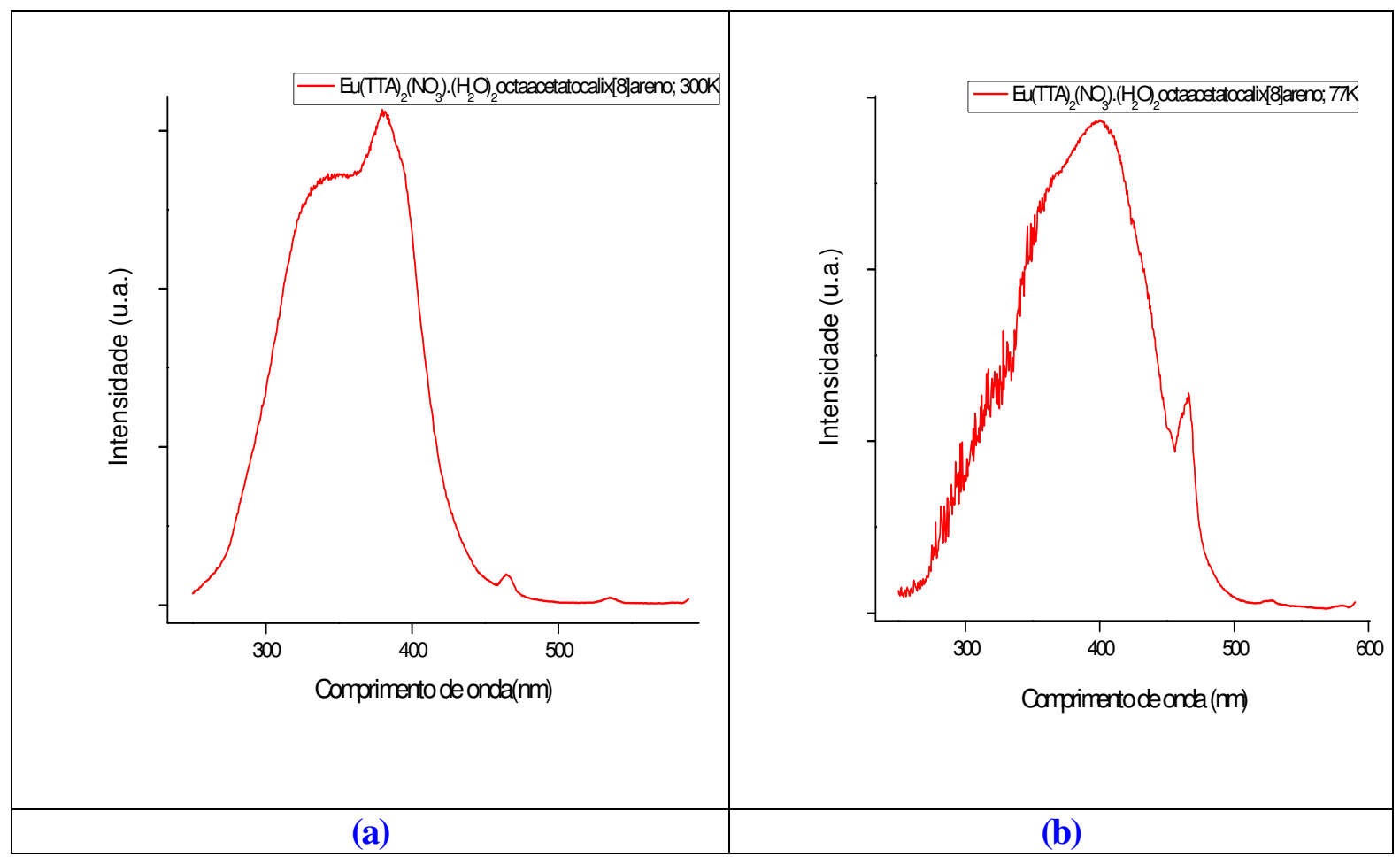

FIGURA 5.11. Espectros de excitação da supermolécula: $\left[\mathrm{Eu}(\mathrm{TTA})_{2}\left(\mathrm{NO}_{3}\right) \cdot 2 \mathrm{H}_{2} \mathrm{O}\right]_{2} \subset$ acetatocalix [8]areno (a) temperatura ambiente $(300 \mathrm{~K})$ e (b) a temperatura do nitrogênio líquido $(77 \mathrm{~K})$. Emissão monitorada $\mathrm{em}^{5} \mathrm{D}_{0} \rightarrow{ }^{7} \mathrm{~F}_{2}\left(\lambda_{\text {emissão }}=612 \mathrm{~nm}\right)$.

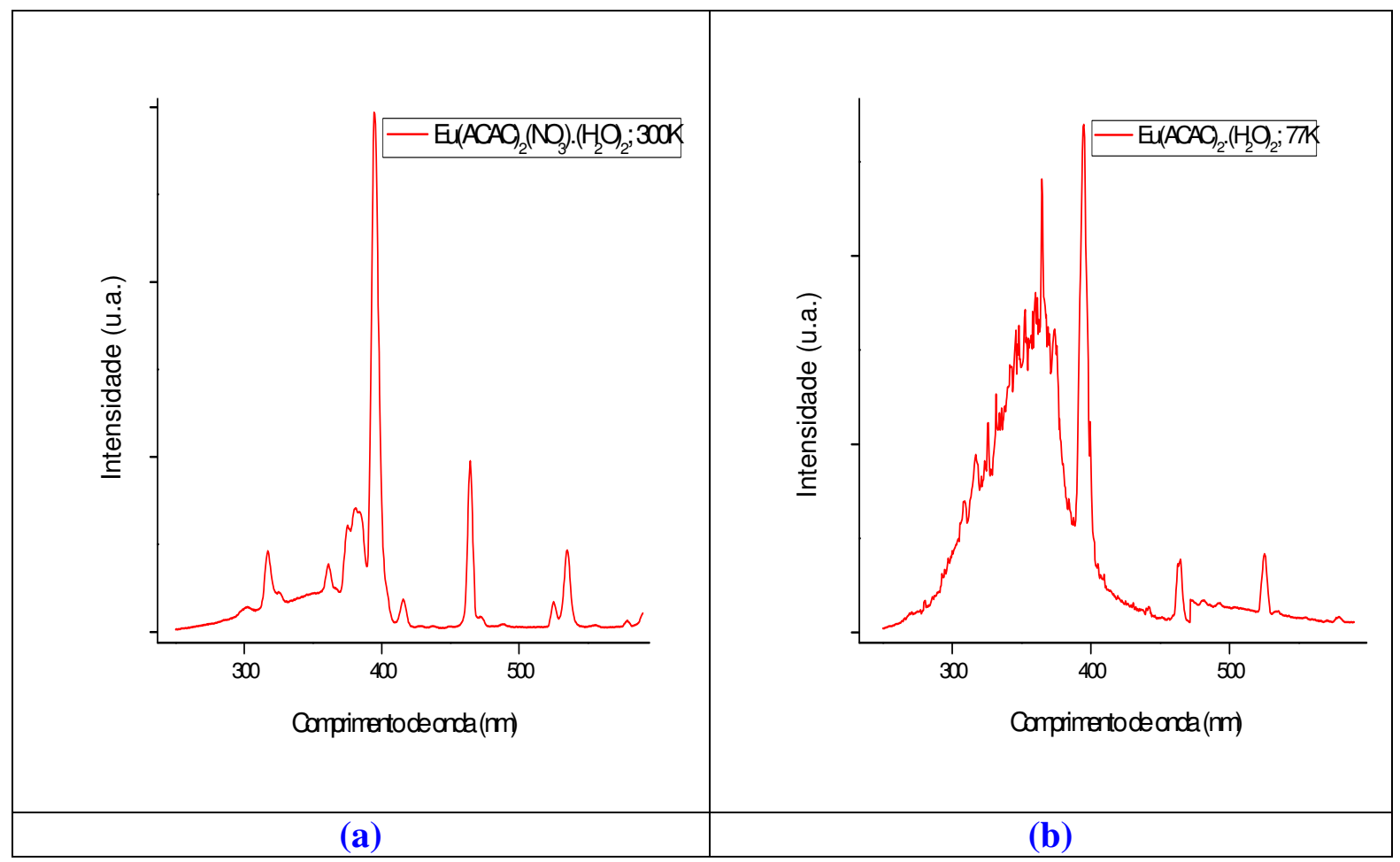

FIGURA 5.12. Espectros de excitação do quelato precursor: $\mathrm{Eu}(\mathrm{ACAC})_{2}\left(\mathrm{NO}_{3}\right) \cdot\left(\mathrm{H}_{2} \mathrm{O}\right)_{2}$, (a) temperatura ambiente $(300 \mathrm{~K})$ e (b) a temperatura do nitrogênio líquido $(77 \mathrm{~K})$. Emissão monitorada $\mathrm{em}^{5} \mathrm{D}_{0} \rightarrow{ }^{7} \mathrm{~F}_{2}\left(\lambda_{\text {emissão }}=612 \mathrm{~nm}\right)$. 


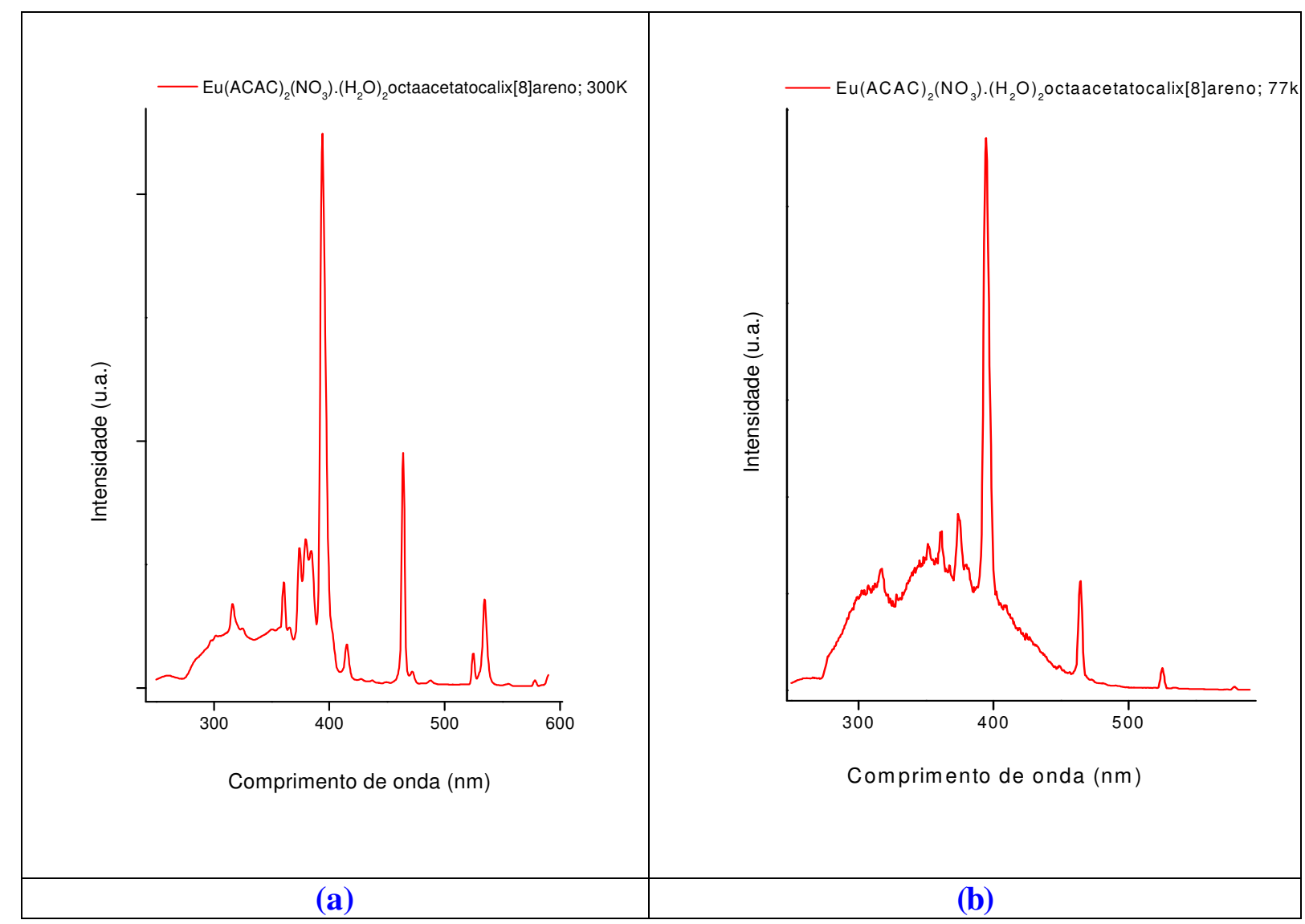

FIGURA 5.13. Espectros de excitação da supermolécula: [Eu(ACAC) $\left.)_{2}\left(\mathrm{NO}_{3}\right) \cdot 2 \mathrm{H}_{2} \mathrm{O}\right]_{2} \subset$ acetatocalix[8]areno (a) temperatura ambiente $(300 \mathrm{~K})$ e (b) a temperatura do nitrogênio líquido $(77 \mathrm{~K})$. Emissão monitorada $\mathrm{em}^{5} \mathrm{D}_{0} \rightarrow{ }^{7} \mathrm{~F}_{2}\left(\lambda_{\text {emissão }}=612 \mathrm{~nm}\right)$.

\subsection{Espectros de Emissão}

Os espectros de emissão das supermoléculas de terras raras com TTA, ACAC e calixareno são ilustrados nas FIG. 5.14 a 5.17. Eles foram registrados no intervalo de 420 a 720 nm, a temperatura ambiente $(300 \mathrm{~K})$ e do $\mathrm{N}_{2}$ líquido $(77 \mathrm{~K})$ e com $\lambda_{\text {ex }}$ monitorada em 310, 330, 350 e 394 nm, na transição $394\left({ }^{7} \mathrm{~F}_{0} \rightarrow{ }^{5} \mathrm{~L}_{6}\right)$, do íon $\mathrm{Eu}^{3+}$. Estes espectros exibem bandas finas atribuídas às transições ${ }^{5} \mathrm{D}_{0} \rightarrow{ }^{7} \mathrm{~F}_{\mathrm{J}}$ (onde $\mathrm{J}=0,1,2,3,4$ ), sendo a transição hipersensível ${ }^{5} \mathrm{D}_{0} \rightarrow{ }^{7} \mathrm{~F}_{2}$ a de intensidade predominante. As FIG. 5.14 a 5.15 (inseridas) também apresentam bandas finas na região espectral de 500 a $570 \mathrm{~nm}$ oriundas das transições, ${ }^{5} \mathrm{D}_{1} \rightarrow{ }^{7} \mathrm{~F}_{1}(\sim 539 \mathrm{~nm})$ e ${ }^{5} \mathrm{D}_{1} \rightarrow{ }^{7} \mathrm{~F}_{2}(\sim 561 \mathrm{~nm})$, no entanto, essas bandas apresentam intensidades muito baixas, sendo somente observadas com ampliação da escala espectral (figuras inseridas). É importante frisar que os espectros de emissão dos complexos de $\mathrm{Eu}^{3+}$ não apresentaram bandas largas oriundas da fosforescência do TTA (FIG. 5.16) no intervalo espectral de 420-600 nm. Esse resultado indica que os processos de transferência de energia do estado tripleto desses ligantes para 
os níveis excitados do európio são muito eficientes. Já para o espectro de supermolécula de ACAC as bandas de fosforescencoia do ligante aparecem nesta região tornando a luz visualizada na emissão, de cor azul. A presença da banda correspondente a transição ${ }^{5} \mathrm{D}_{0} \rightarrow{ }^{7} \mathrm{~F}_{0}$ nos espectros de emissão dos complexos e das supermoléculas de TTA e ACAC como um único pico ( $580 \mathrm{~nm})$, indica a existência de somente um único sítio de simetria em torno do ambiente químico do íon $\mathrm{Eu}^{3+}$ Além disso, de acordo com a regra de seleção por simetria, essa transição só é permitida quando o $\mathrm{Eu}^{3+}$ está classificado em uma dos grupos pontuais Cnv, Cn ou Cs. ${ }^{[10]}$. Adicionalmente, pode-se observar que as bandas correspondentes à transição ${ }^{5} \mathrm{D}_{0} \rightarrow{ }^{7} \mathrm{~F}_{2}$ estão desdobradas em no mínimo 3 componentes, indicando que os possíveis grupos pontuais estão limitados `aqueles de simetria, C3v,C2v, C2, C1 ou Cs. Uma característica marcante observada nos dados de luminescência destes compostos é que as transições ${ }^{5} \mathrm{D}_{0} \rightarrow{ }^{7} \mathrm{~F}_{2}$ são altamente intensas para corroborando com o seu caráter hipersensível, indicativo da ausência do centro de simetria. Também são observadas bandas vibrônicas fracas com magnitude de aproximadamente $1 \%$, menos intensas do que as atribuídas às transições zero-fônon. Os espectros de luminescência foram registrados à temperatura ambiente e do nitrogênio líquido, apresentando características espectrais semelhantes, exceto quanto à resolução dos perfis das transições, que a baixa temperatura mostram-se mais definidos, facilitando a atribuição dos desdobramentos ${ }^{5} \mathrm{D}_{0} \rightarrow{ }^{7} \mathrm{~F}_{\mathrm{J}}$. A TAB. 5.7 lista as energias das transições ${ }^{5} \mathrm{D}_{0} \rightarrow{ }^{7} \mathrm{~F}_{\mathrm{J}} \quad\left(\mathrm{J}=0,1,2\right.$, e 4) em $\mathrm{cm}^{-1}$ observadas nas supermoléculas e seus quelatos precursores .
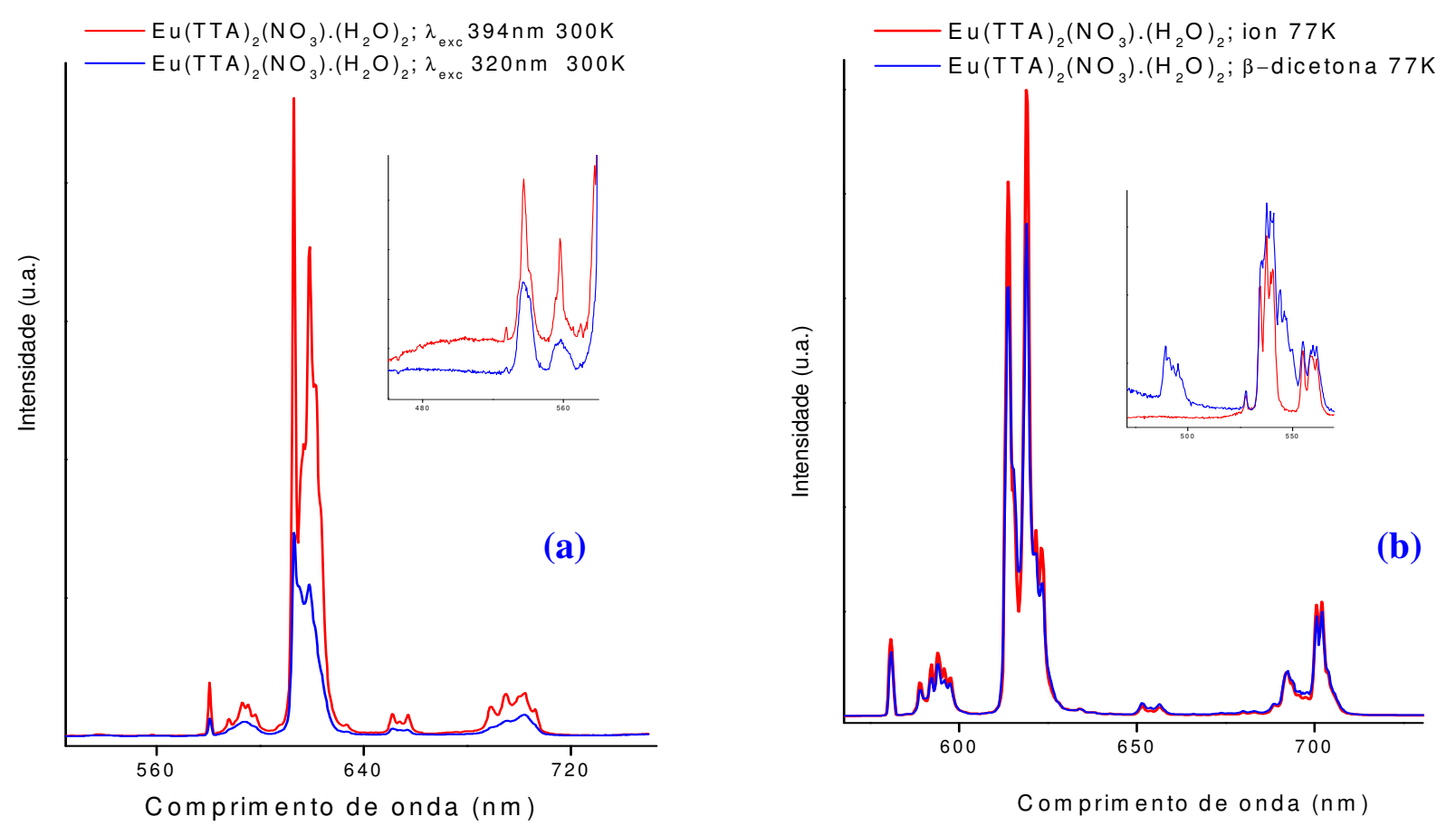

FIGURA 5.14. Espectros de emissão do quelato precursor: $\mathrm{Eu}(\mathrm{TTA})_{2}\left(\mathrm{NO}_{3}\right) \cdot\left(\mathrm{H}_{2} \mathrm{O}\right)_{2}$ (a) temperatura ambiente $(300 \mathrm{~K})$ e (b) a temperatura do nitrogênio líquido (77K). Emissão monitorada em ${ }^{5} \mathrm{D}_{0} \rightarrow{ }^{7} \mathrm{~F}_{2}\left(\lambda_{\text {exc. }}=394\right.$ e $\left.320 \mathrm{~nm}\right)$. 


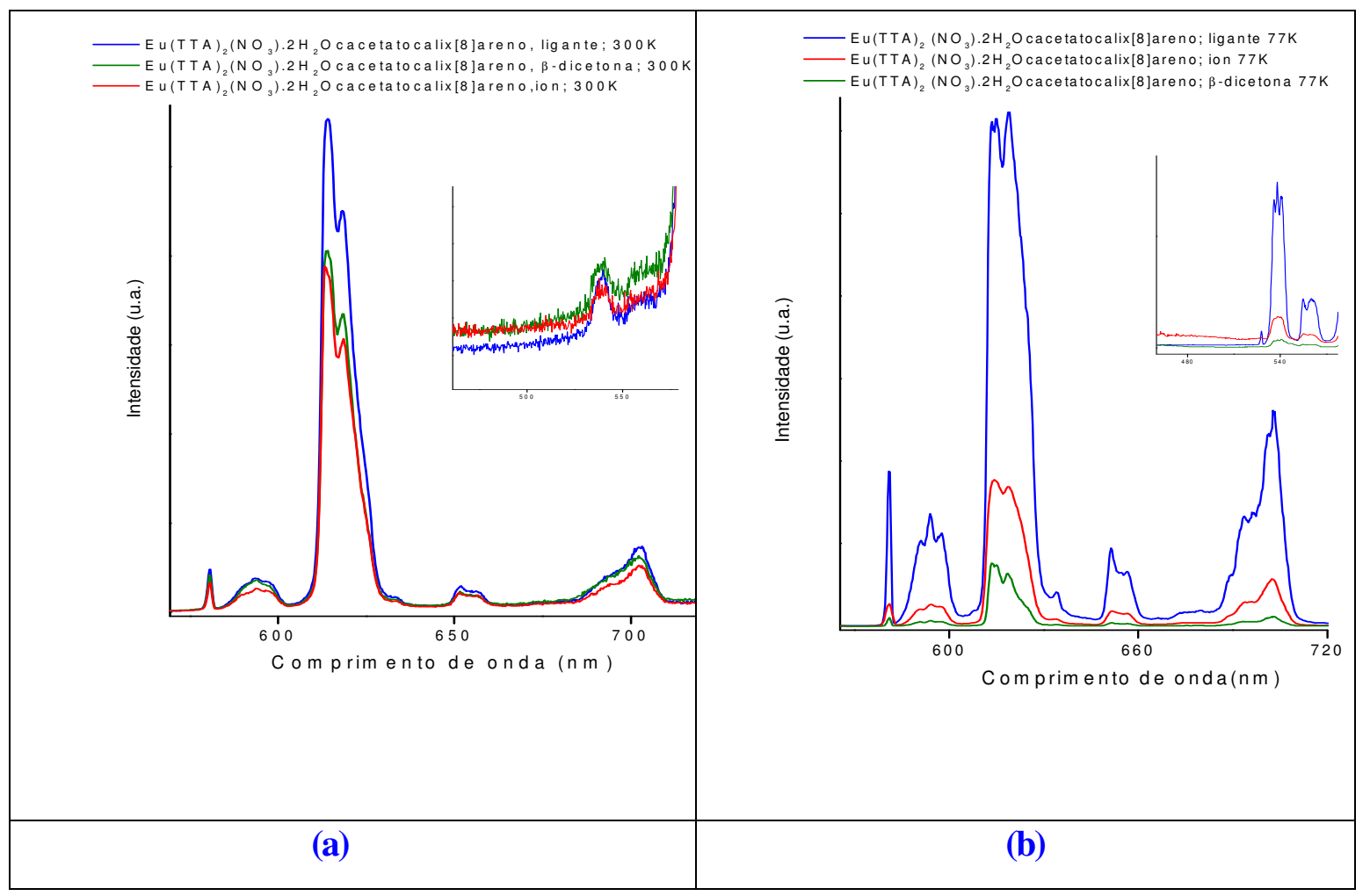

FIGURA 5.15. Espectros de emissão da supermolécula: [Eu(TTA $\left.)_{2}\left(\mathrm{NO}_{3}\right) \cdot\left(\mathrm{H}_{2} \mathrm{O}\right)_{2}\right]_{2} \subset$ acetatocalix [8]areno (a) temperatura ambiente $(300 \mathrm{~K})$ e (b) a temperatura do nitrogênio líquido (77K). Emissão monitorada $\mathrm{em}^{5} \mathrm{D}_{0} \rightarrow{ }^{7} \mathrm{~F}_{2}\left(\lambda_{\text {emissão }}=612 \mathrm{~nm}\right)$.

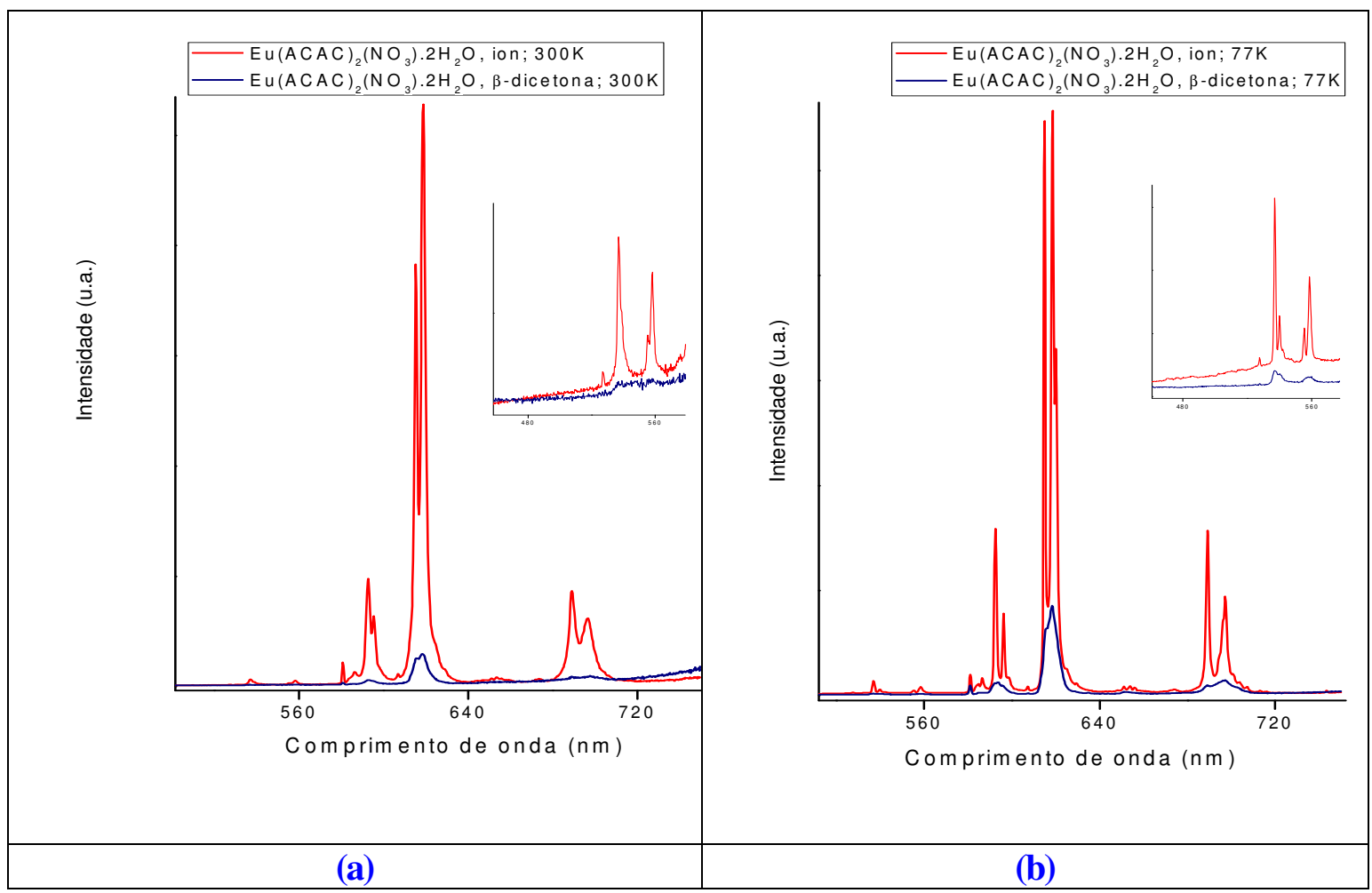

FIGURA 5.16. Espectros de emissão do quelato precursor: $\mathrm{Eu}(\mathrm{ACAC})_{2}\left(\mathrm{NO}_{3}\right) \cdot 2 \mathrm{H}_{2} \mathrm{O}$. (a) temperatura ambiente $(300 \mathrm{~K})$ e (b) a temperatura do nitrogênio líquido $(77 \mathrm{~K})$. Emissão monitorada em ${ }^{5} \mathrm{D}_{0} \rightarrow{ }^{7} \mathrm{~F}_{2}\left(\lambda_{\text {emissão }}=612 \mathrm{~nm}\right)$. 


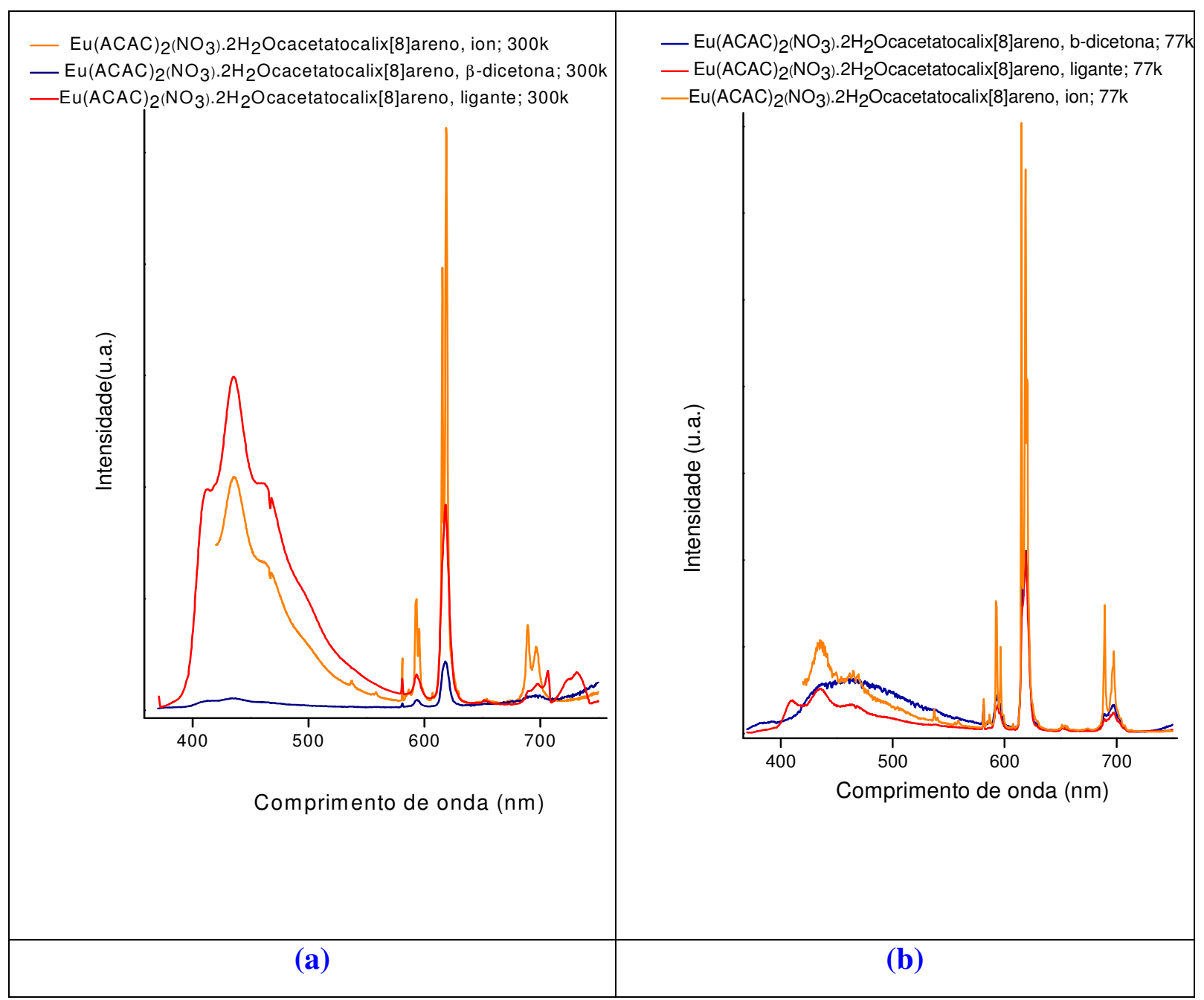

FIGURA 5.17. Espectros de emissão da supermolécula: [Eu(ACAC $\left.)_{2}\left(\mathrm{NO}_{3}\right) \cdot\left(\mathrm{H}_{2} \mathrm{O}\right)_{2}\right]_{2} \subset$ acetatocalix[8]areno (a) temperatura ambiente $(300 \mathrm{~K})$ e (b) a temperatura do nitrogênio líquido $(77 \mathrm{~K})$. Emissão monitorada $\mathrm{em}^{5} \mathrm{D}_{0} \rightarrow{ }^{7} \mathrm{~F}_{2}\left(\lambda_{\text {emissão }}=612 \mathrm{~nm}\right)$. 


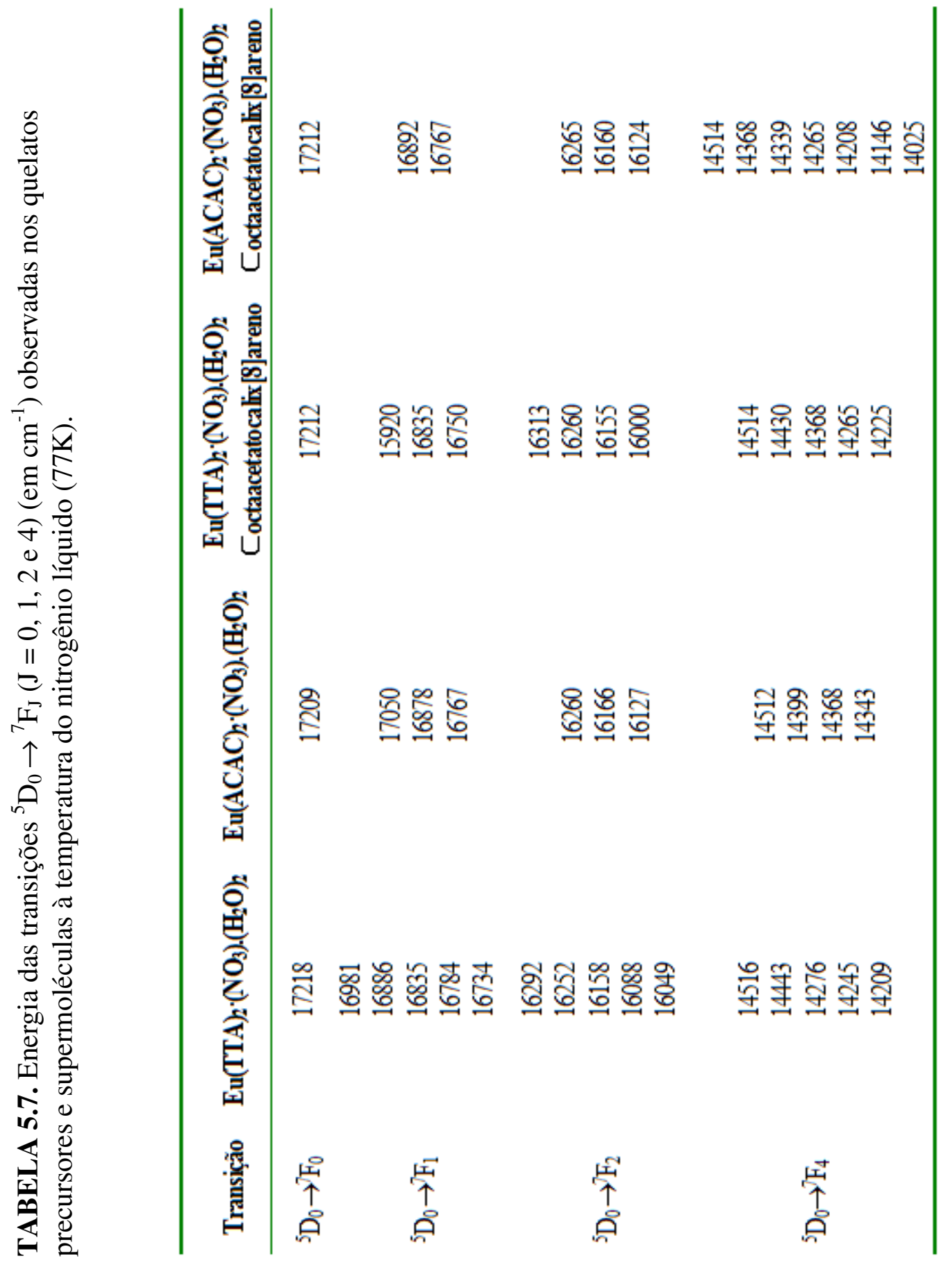




\subsubsection{Estudo fotoluminescente dos complexos de $\mathbf{T b}^{3+}$}

$\mathrm{O}$ íon térbio trivalente tem a configuração eletrônica $4 \mathrm{f}^{8}$ e contém os níveis Stark do íon $\mathrm{Eu}^{3+}\left(4 \mathrm{f}^{6}\right)$, porém invertidos. Por exemplo, o nível fundamental é ${ }^{7} \mathrm{~F}_{6}$ e seu estado emissor de menor energia é ${ }^{5} \mathrm{D}_{4}$, FIG. 9. Devido à grande degenerescência desses níveis, ambos os espectros de excitação e emissão do íon $\mathrm{Tb}^{3+}$ tendem a ser mais complicados de identificação quando comparados aos do íon európio. Os íons $\mathrm{Eu}^{3+} \mathrm{e}^{\mathrm{Tb}^{3+}}$ são os que apresentam uma maior intensidade luminescente. $\mathrm{O}$ estudo das propriedades espectroscópicas dos compostos derivados do íon $\mathrm{Tb}^{3+}$, do ponto de vista teórico tem atraído uma atenção modesta quando comparado com o íon $\mathrm{Eu}^{3+}$. Isso provavelmente se deve ao fato de que o principal nível emissor do íon $\operatorname{Eu}^{3+}\left({ }^{5} \mathrm{D}_{0}\right)$ é não degenerado (momento angular total $\mathrm{J}=0$ ), o que leva a espectros de emissão mais fáceis de serem interpretados. A alta degenerescência dos níveis emissores do íon $\mathrm{Tb}^{3+}$ torna difícil a interpretação dos seus espectros de emissão, como também de absorção e excitação ${ }^{[9]}$.

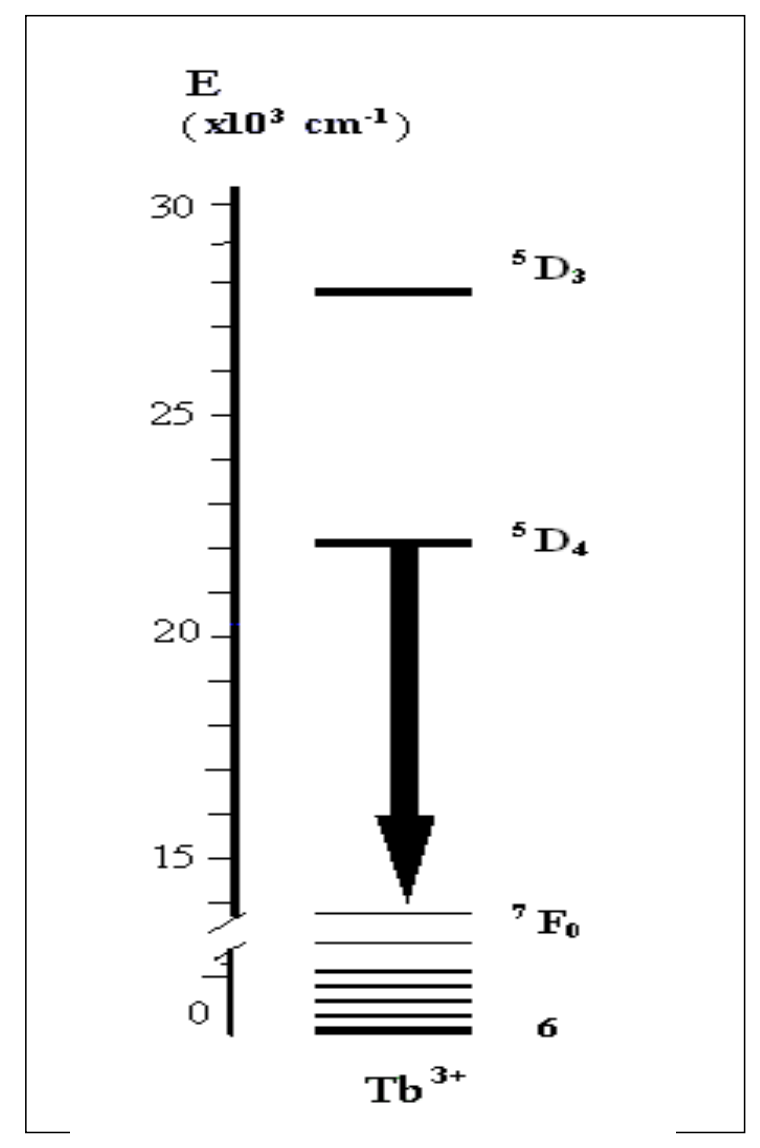

FIGURA 5.18. Diagrama de nível de energia para o íon $\mathrm{Tb}^{3+}$. Somente alguns níveis são apresentados. 
As FIGs. 5.19 e 5.20 apresentam os espectros de excitação dos compostos de $\mathrm{Tb}^{3+}$, $\mathrm{Tb}(\mathrm{ACAC})_{2}\left(\mathrm{NO}_{3}\right) \cdot\left(\mathrm{H}_{2} \mathrm{O}\right)_{2}$ e $\left[\mathrm{Tb}(\mathrm{ACAC})_{2}\left(\mathrm{NO}_{3}\right) \cdot\left(\mathrm{H}_{2} \mathrm{O}\right)_{2}\right]_{2} \subset$ octaacetatocalix[8]areno com emissão monitorada em $546 \mathrm{~nm}$. Observa-se uma banda larga na região de 275 a $410 \mathrm{~nm}$, com máximo ao redor de $300 \mathrm{~nm}$ que pode ser atribuída à banda de transferência de carga $\mathrm{O} \rightarrow \mathrm{Tb}$. Por outro lado, as linhas finas em overlap com essa banda são atribuídas às transições intraconfiguracionais f-f características do íon $\mathrm{Tb}^{3+}$.

$\mathrm{O}$ intervalo de energia entre os níveis ${ }^{7} \mathrm{~F}_{0}$ e o ${ }^{5} \mathrm{D}_{4}$ e ${ }^{5} \mathrm{D}_{3}\left(14000\right.$ e $20000 \mathrm{~cm}^{-1}$, respectivamente) coloca quase todas as transições ${ }^{5} \mathrm{D}_{3,4} \rightarrow{ }^{7} \mathrm{~F}_{0-6}$ na região visível do espectro (com exceção da transição ${ }^{5} \mathrm{D}_{3} \rightarrow{ }^{7} \mathrm{~F}_{6}$ situada na região do UV próximo). Todas transições são relativamente fortes, em contraste com as transições ${ }^{5} \mathrm{D}_{\mathrm{J}} \rightarrow{ }^{7} \mathrm{~F}_{5-6}$ do íon $\mathrm{Eu}^{3+}$ que geralmente são muito fracas e situadas na região do infravermelho ${ }^{[7,8,9]}$.

A FIG. 5.20 apresenta o espectro de emissão do $\mathrm{Tb}(\mathrm{ACAC})_{2}\left(\mathrm{NO}_{3}\right)_{2}\left(\mathrm{H}_{2} \mathrm{O}\right)_{2}$ com excitação monitorada no íon $\mathrm{Tb}^{3+}(379 \mathrm{~nm})$, apresentando transições ${ }^{5} \mathrm{D}_{4} \rightarrow{ }^{7} \mathrm{~F}_{\mathrm{J}},\left(\mathrm{J}^{\prime}=0-6\right)$ no intervalo entre 480 e $720 \mathrm{~nm}$ (TAB. 5.8) e na FIG. 5.21 tem-se o espectro da supermolécula na mesma região .

A relaxação não-radiativa entre estados eletrônicos dos íons $\mathrm{TR}^{3+}$ em sólidos ocorre geralmente por emissão multi-fóton ou por processo de relaxação cruzada. O último envolve a interação entre um íon ativador excitado e um (ou mais) íons do estado fundamental vizinhos que tenha transições aproximadamente ressonantes com o intervalo através do qual a relaxação poderia ocorrer. O fenômeno de relaxação cruzada tem sido usado para explicar o "self-quenching" da emissão do íon $\mathrm{Tb}^{3+},{ }^{5} \mathrm{D}_{3} \rightarrow{ }^{7} \mathrm{~F}_{\mathrm{J}}$, em sistemas concentrados com íons térbio. Em baixas concentrações do íon $\mathrm{Tb}^{3+}(\leq 0,1 \%)$ o decaimento do estado ${ }^{5} \mathrm{D}_{3}$ é principalmente radiativo, resultando em uma emissão predominantemente azul. Conforme a concentração do íon $\mathrm{Tb}^{3+}$ aumenta, o decaimento não-radiativo do estado ${ }^{5} \mathrm{D}_{3}$ para o estado ${ }^{5} \mathrm{D}_{4}$ via processos de relaxação cruzada se torna mais provável, dando surgimento a uma forte emissão verde ${ }^{[11,12]}$.

A ocorrência de relaxação cruzada é explicada pelo fato de existir um grande número de transições entre os componentes do campo cristalino do estado fundamental ${ }^{7} \mathrm{~F}_{6}$ do íon $\mathrm{Tb}^{3+}$ e os estados ${ }^{7} \mathrm{~F}_{1}$ e ${ }^{7} \mathrm{~F}_{0}$, que são quase ressonantes com a transição ${ }^{5} \mathrm{D}_{3} \rightarrow{ }^{5} \mathrm{D}_{4}$.

Vale salientar que também para a supermolécula de $\mathrm{Tb}^{3+}$ bandas da fosforescência do ligante tornam a emissão deste composto azul corroborando com os dados do íon $\mathrm{Eu}^{3+}$. 


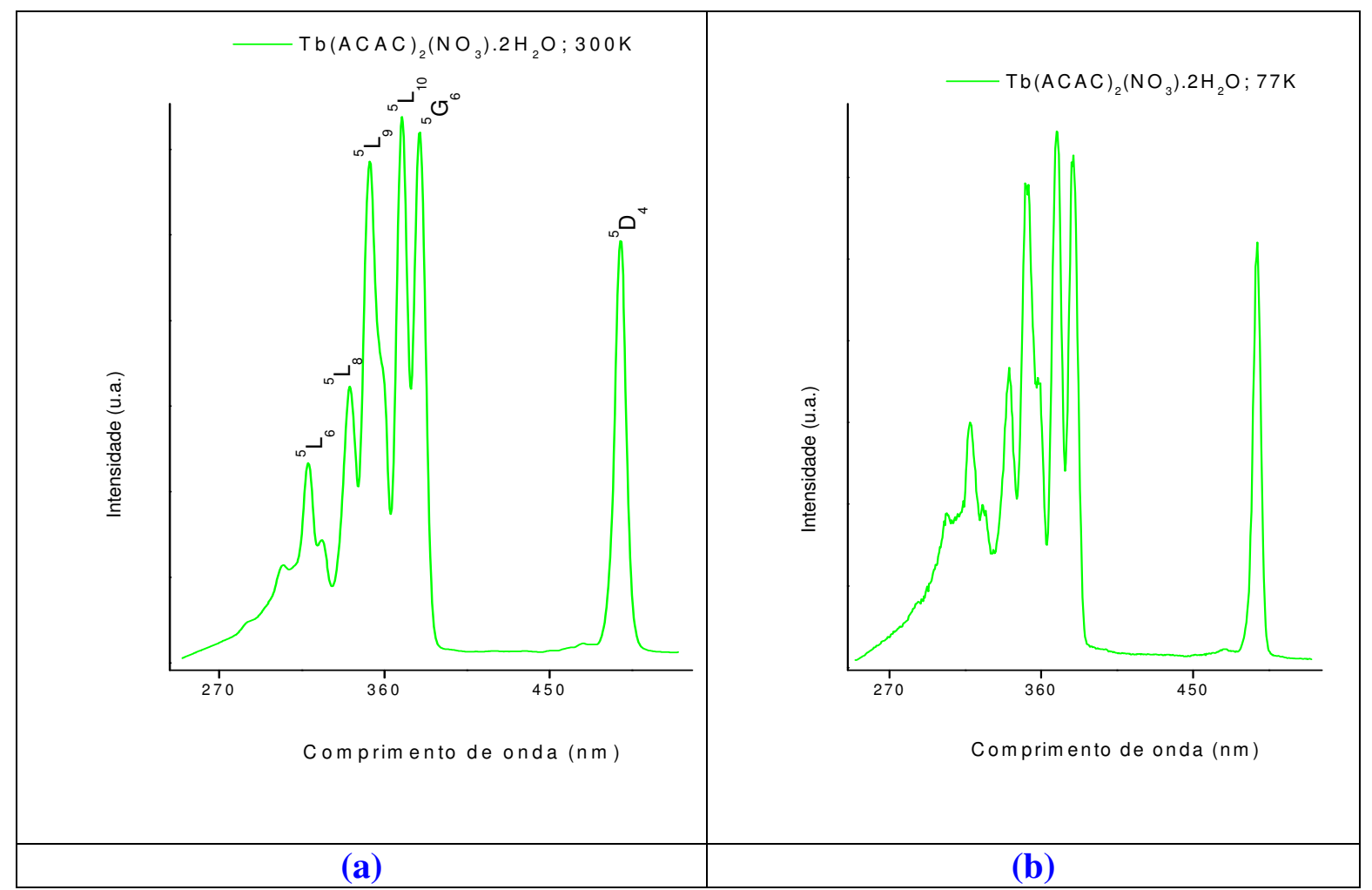

FIGURA 5.19. Espectros de excitação do quelato precursor: $\mathrm{Tb}(\mathrm{ACAC})_{2}\left(\mathrm{NO}_{3}\right) \cdot\left(\mathrm{H}_{2} \mathrm{O}\right)_{2}(\mathbf{a})$ temperatura ambiente $(300 \mathrm{~K})$ e (b) a temperatura do nitrogênio líquido $(77 \mathrm{~K})$. Emissão monitorada em ${ }^{5} \mathrm{D}_{0} \rightarrow{ }^{7} \mathrm{~F}_{2}\left(\lambda_{\text {emissão }}=546 \mathrm{~nm}\right)$.

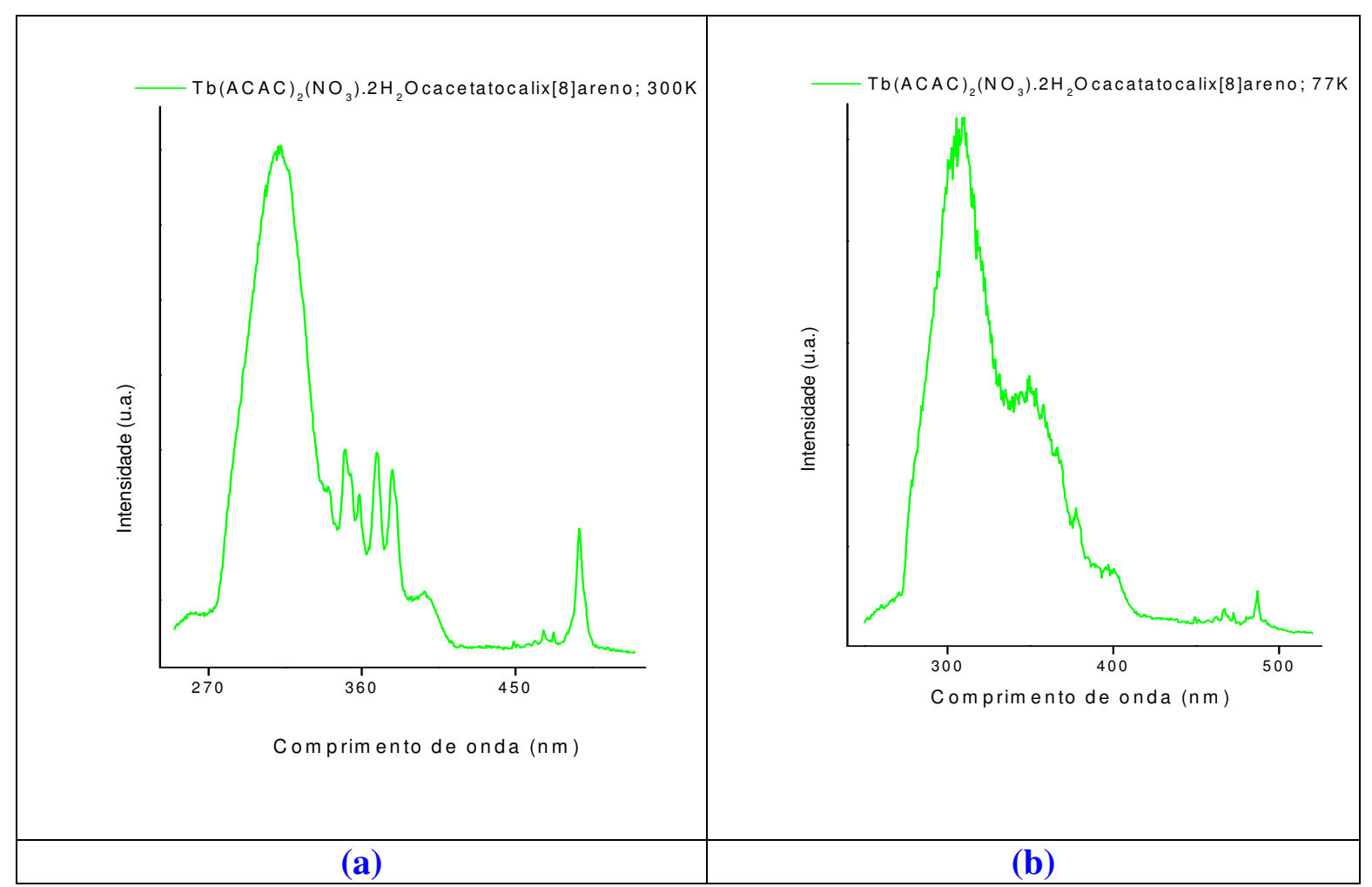

FIGURA 5.20. Espectros de excitação da supermolécul: $\left[\mathrm{Tb}(\mathrm{ACAC})_{2}\left(\mathrm{NO}_{3}\right) \cdot\left(\mathrm{H}_{2} \mathrm{O}\right)_{2}\right] \subset$ octaacetatocalix[8]areno (a) temperatura ambiente $(300 \mathrm{~K})$ e (b) a temperatura do nitrogênio líquido (77K). Emissão monitorada $\mathrm{em}^{5} \mathrm{D}_{0} \rightarrow{ }^{7} \mathrm{~F}_{2}\left(\lambda_{\text {emissão }}=546 \mathrm{~nm}\right)$. 


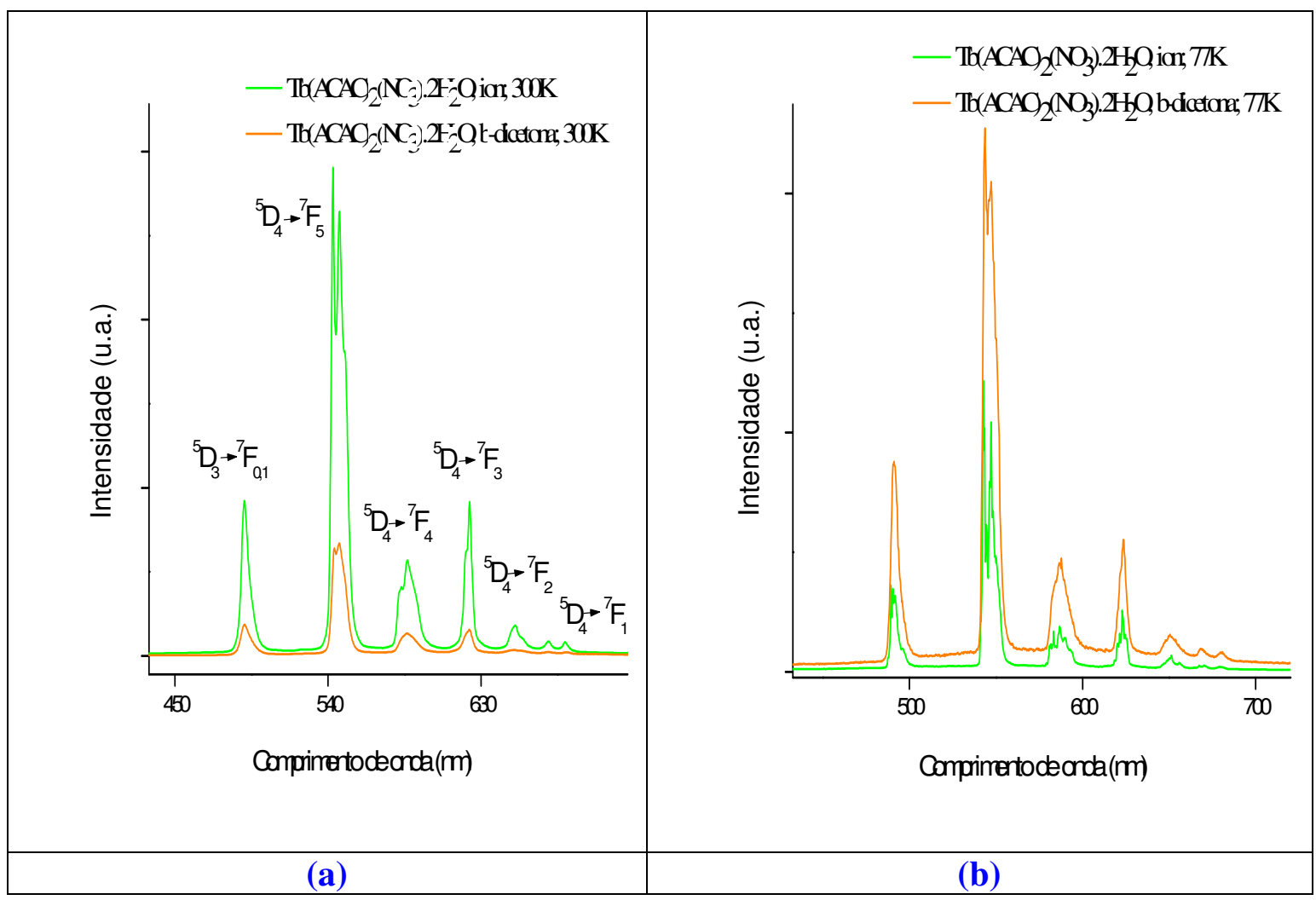

FIGURA 5.21. Espectros de emissão do quelato precursor: Tb(ACAC $)_{2}\left(\mathrm{NO}_{3}\right) \cdot\left(\mathrm{H}_{2} \mathrm{O}\right)_{2}$ (a) temperatura ambiente $(300 \mathrm{~K})$ e (b) a temperatura do nitrogênio líquido $(77 \mathrm{~K})$. Emissão monitorada em ${ }^{5} \mathrm{D}_{0} \rightarrow{ }^{7} \mathrm{~F}_{2}\left(\lambda_{\mathrm{ex}}=546 \mathrm{~nm}\right)$.

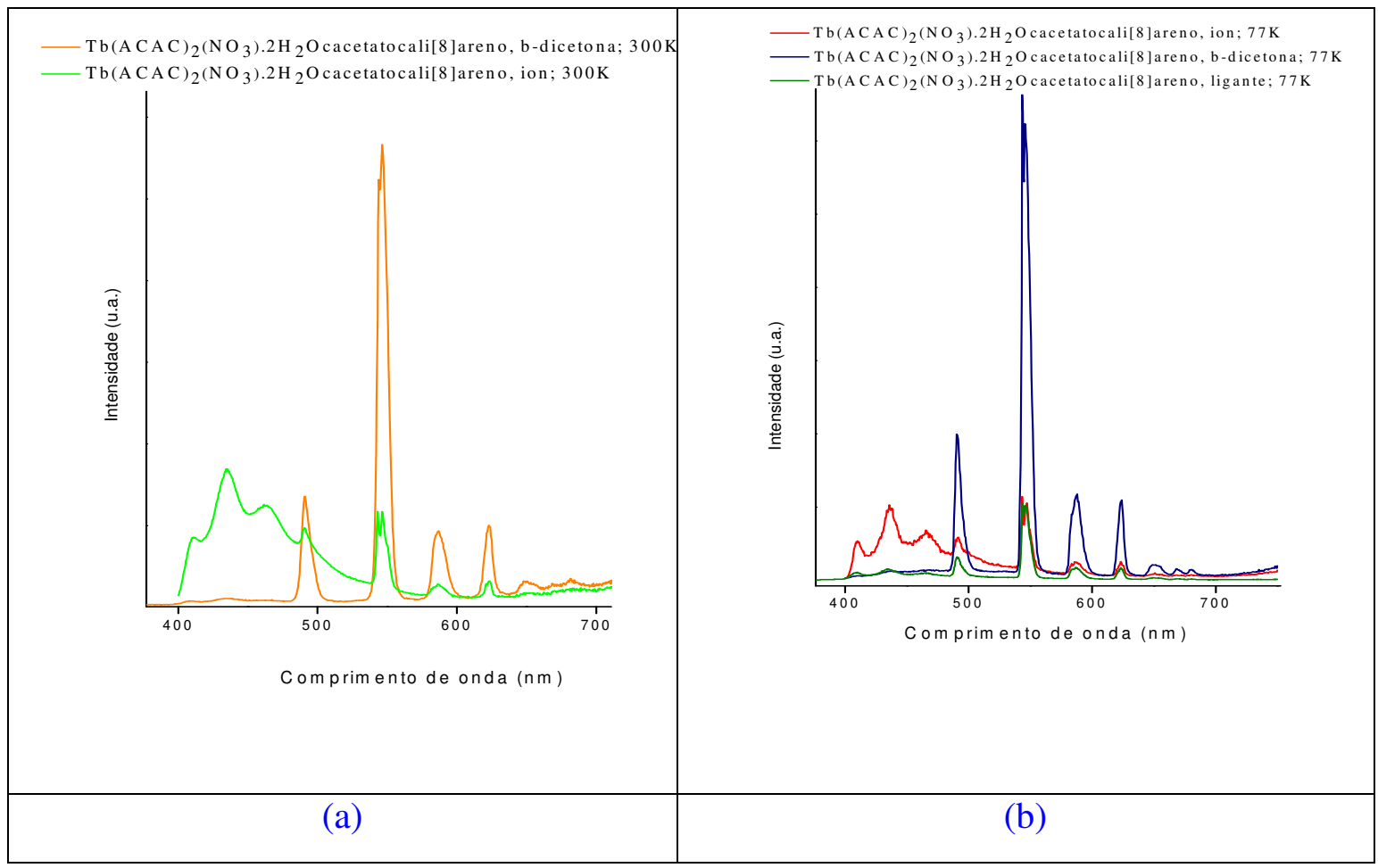

FIGURA 5.22. Espectros de emissão da supermolécula: $\left[\mathrm{Tb}(\mathrm{ACAC})_{2}\left(\mathrm{NO}_{3}\right) \cdot\left(\mathrm{H}_{2} \mathrm{O}\right)_{2}\right]_{2} \subset$ acetatocalix[8]areno (a) temperatura ambiente $(300 \mathrm{~K})$ e (b) a temperatura do nitrogênio líquido (77K). Emissão monitorada $\mathrm{em}^{5} \mathrm{D}_{0} \rightarrow{ }^{7} \mathrm{~F}_{2}\left(\lambda_{\text {emissão }}=546 \mathrm{~nm}\right)$. 
TABELA 5.8. Energias de transição dos níveis ${ }^{5} \mathrm{D}_{3,4} \rightarrow{ }^{7} \mathrm{~F}_{\mathrm{J}}$, $\left(\mathrm{J}^{\prime}=0-6\right)\left(\mathrm{em} \mathrm{cm}^{-1}\right)$ observados no espectro de emissão do quelato precursor $\mathrm{Tb}(\mathrm{ACAC})_{2} \cdot\left(\mathrm{NO}_{3}\right) \cdot\left(\mathrm{H}_{2} \mathrm{O}\right)_{2}$ a $77 \mathrm{~K}$.

\begin{tabular}{cccc}
\hline Transição & Energia $\left(\mathbf{c m}^{-1}\right)$ & Transição & Energia $\left(\mathbf{c m}^{-1}\right)$ \\
\hline${ }^{5} \mathrm{D}_{3} \rightarrow{ }^{7} \mathrm{~F}_{0,1}$ & 20433 & ${ }^{5} \mathrm{D}_{4} \rightarrow{ }^{7} \mathrm{~F}_{4}$ & 17215 \\
${ }^{5} \mathrm{D}_{4} \rightarrow{ }^{7} \mathrm{~F}_{6}$ & 20383 & & 17197 \\
& 20345 & & 17144 \\
& 20149 & & 17057 \\
${ }^{5} \mathrm{D}_{4} \rightarrow{ }^{7} \mathrm{~F}_{5}$ & 18423 & & 17039 \\
& 18403 & ${ }^{5} \mathrm{D}_{4} \rightarrow{ }^{7} \mathrm{~F}_{3}$ & 16961 \\
& 18362 & & 16943 \\
& 18302 & & 16866 \\
& 18272 & & 16832 \\
& 18232 & & \\
\hline
\end{tabular}

\subsubsection{Tempo de vida luminescente das supermoléculas de $\mathrm{Eu}^{3+}$ e $\mathrm{Tb}^{3+}$}

Para determinar os valores de tempo de vida para os compostos de $\mathrm{Eu}^{3+}$ estudados foram registradas as curvas de decaimento à temperatura de $300 \mathrm{~K}$ com emissão monitorada em $612 \mathrm{~nm}$ e excitação na transição $394 \mathrm{~nm}\left({ }^{7} \mathrm{~F}_{0} \rightarrow{ }^{5} \mathrm{~L}_{6}\right)$, do íon $\mathrm{Eu}^{3+}$. Estas curvas são apresentadas na FIG. 5.23 e ajustam-se a uma exponencial simples, sugerindo que não há outro canal de despopulação para o nível emissor ${ }^{5} \mathrm{D}_{0}$. Os tempos de vida maiores do nível ${ }^{5} \mathrm{D}_{0}$ nos compostos de $\beta$-dicetonatos dihidratados estão associados aos canais de desativação não radiativa em função do acoplamento vibrônico com as vibrações das moléculas de água (osciladores $\mathrm{OH}$ ) associadas com as moléculas de calixarenos ${ }^{[13]}$ nas supermoléculas. Este fato está associado à despopulação do nível emissor através do acoplamento vibrônico das moléculas de $\mathrm{H}_{2} \mathrm{O}$ e C-C e N-O.

Já para se determinar os valores de tempo de vida para os compostos de $\mathrm{Tb}^{3+}$ foram registradas as curvas de decaimento do nível emissor ${ }^{5} \mathrm{D}_{4}$ à temperatura de $300 \mathrm{~K}$ com emissão monitorada em 612 nm e excitação na transição $397 \mathrm{~nm}\left({ }^{7} \mathrm{~F}_{6} \rightarrow{ }^{5} \mathrm{D}_{4}\right)$, do íon $\mathrm{Tb}^{3+}$. Os dados concordam com os obtidos para o európio, onde os quelatos precursores possuem tempo de vida maiores que o da supermolécula. Estes dados encontram-se resumidos na TAB. 5.9 e FIG. 5.23. 


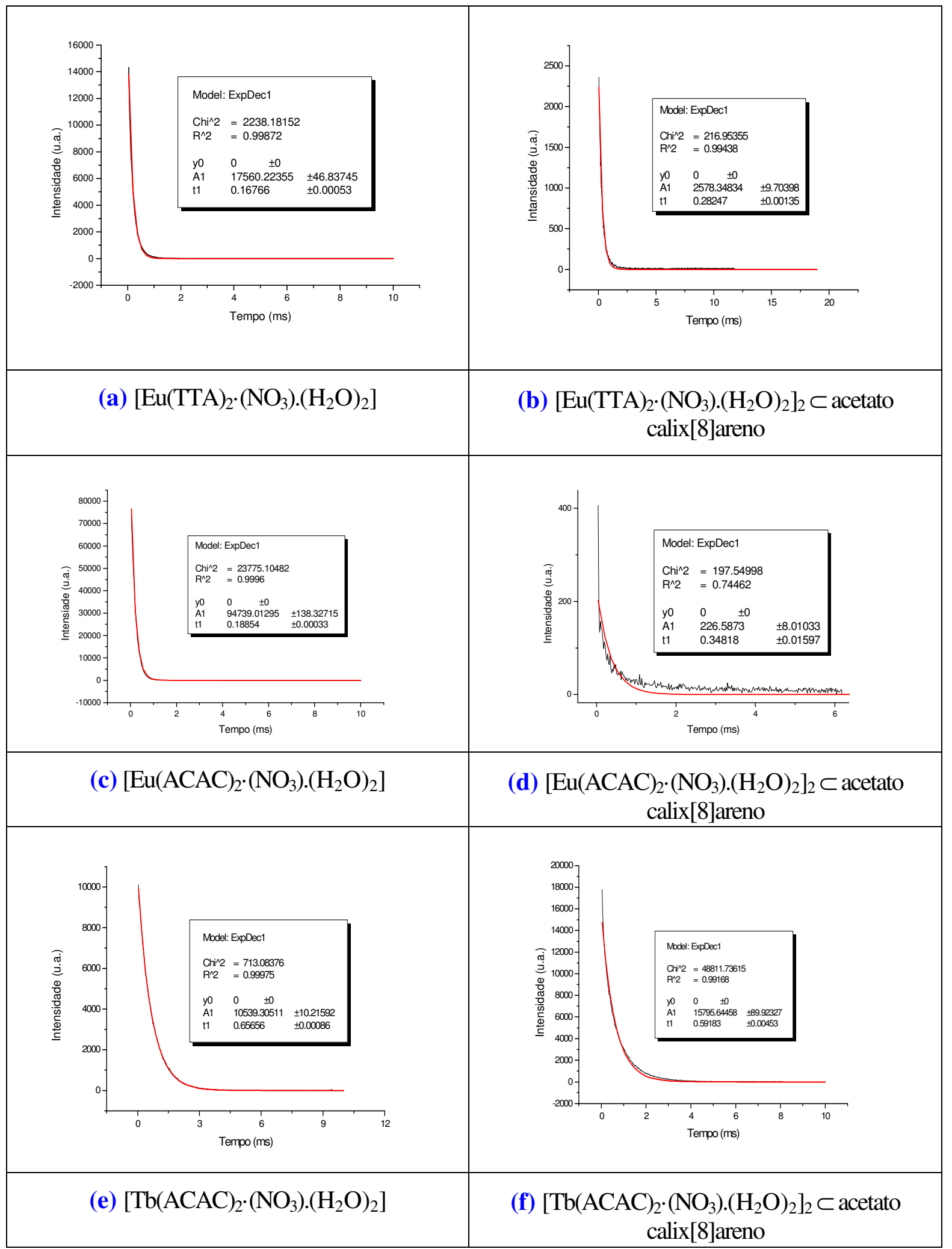

FIGURA 5.23. Curva de decaimento para os quelatos precursores e as supermoléculas de $\mathrm{Eu}^{3+}$ e $\mathrm{Tb}^{3+}$. 
TABELA 5.9. Valores de decaimento para os quelatos precursores e para as supermoléculas.

\begin{tabular}{lc}
\hline \multicolumn{1}{c}{ Compostos } & Tempo de vida $(\mathbf{m s})$ \\
\hline & \\
$\mathrm{Eu}(\mathrm{TTA})_{2}\left(\mathrm{NO}_{3}\right) \cdot\left(\mathrm{H}_{2} \mathrm{O}\right)_{2}$ & 0,167 \\
$\mathrm{Eu}(\mathrm{TTA})_{2}\left(\mathrm{NO}_{3}\right) \cdot\left(\mathrm{H}_{2} \mathrm{O}\right)_{2} \subset$ acetatocalix [8]areno & 0,282 \\
$\mathrm{Eu}(\mathrm{ACAC})_{2}\left(\mathrm{NO}_{3}\right) \cdot\left(\mathrm{H}_{2} \mathrm{O}\right)_{2}$ & 0,188 \\
$\mathrm{Eu}(\mathrm{ACAC})_{2}\left(\mathrm{NO}_{3}\right) \cdot\left(\mathrm{H}_{2} \mathrm{O}\right)_{2} \subset$ acetatocalix[8]areno & 0,348 \\
$\mathrm{~Tb}(\mathrm{ACAC})_{2}\left(\mathrm{NO}_{3}\right) \cdot\left(\mathrm{H}_{2} \mathrm{O}\right)_{2}$ & 0,656 \\
$\mathrm{~Tb}(\mathrm{ACAC})_{2}\left(\mathrm{NO}_{3}\right) \cdot\left(\mathrm{H}_{2} \mathrm{O}\right)_{2} \subset$ acetatocalix[8]areno & 0,591 \\
& \\
\hline
\end{tabular}

\subsection{Conjugação das espécies contendo $\mathrm{Eu}^{3+} \mathrm{e} \mathrm{Tb}^{3+}$ ao espaçador.}

Os complexos de Eu-TTA-glutaraldeído, Eu-ACAC-glutaraldeído e Tb-ACACglutaraldeído foram obtidos adicionando-se glutaraldeído a uma solução de $\operatorname{TR}^{3+}(25$ $\mu \mathrm{g} / \mathrm{mL}$ ) relação v/v 1:2. A solução foi encubada e deixou-se overnight a $4^{\circ} \mathrm{C}$ e foi posteriormente utilizada para conjugação e sinalização.

Nas FIGs 5.24 a 5.26 têm-se os espectros de excitação e emissão dos compostos de Eu-TTA-glutaraldeído, Eu-ACAC-glutaraldeído e Tb-ACAC-glutaraldeído onde se pode observar pelo perfil dos espectros que a conjugação foi efetiva para os complexos.

Os perfis dos espectros de excitação e de emissão dos marcadores luminescentes conjugados ao glutaraldeído diferem do perfil dos mesmos sem a conjugação. As bandas largas que estão presentes nos espectros de excitação e de emissão dos materiais luminescentes conjugados são indicativos da formação dessa espécie conjugada. 

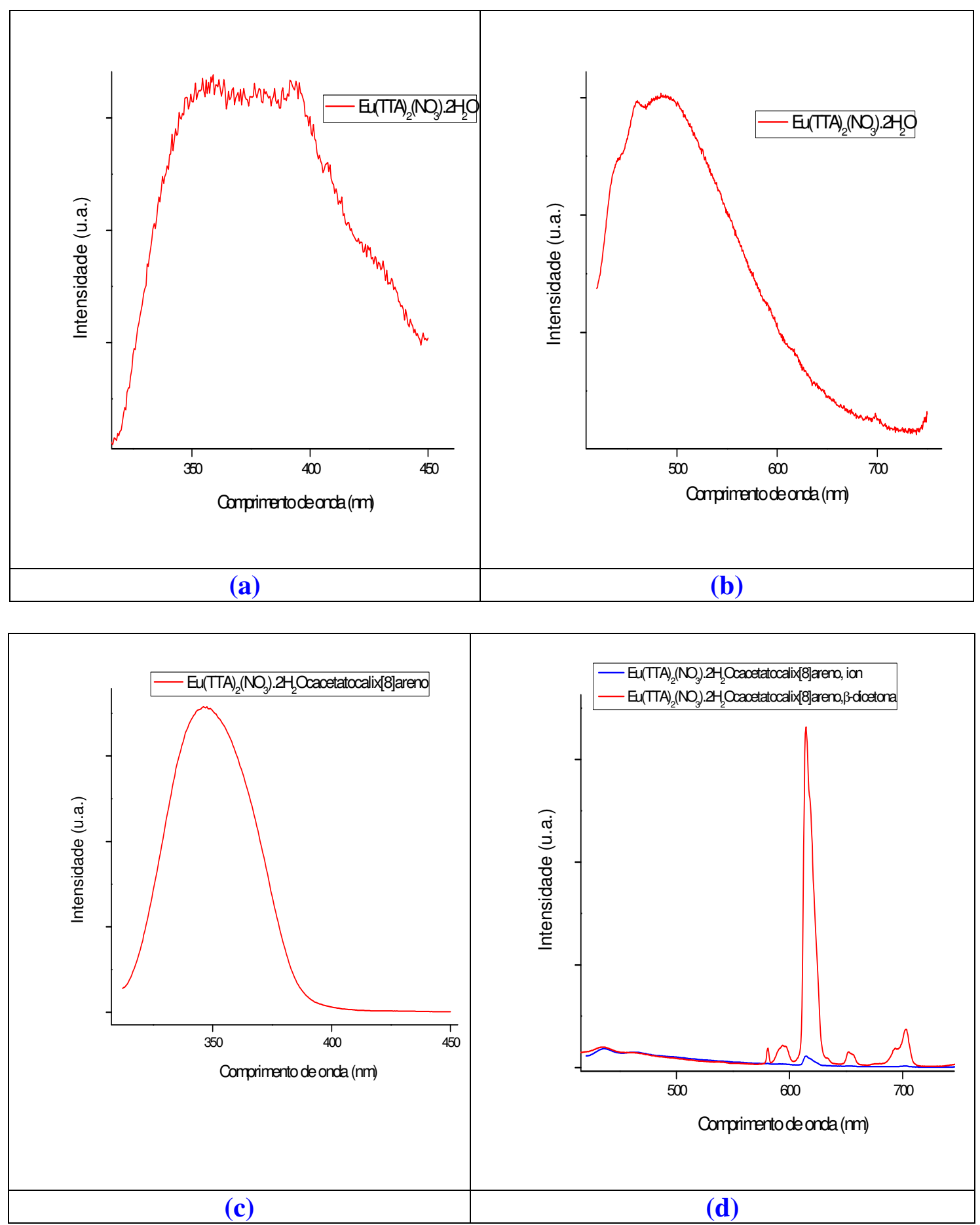

FIGURA 5.24. Espectros de excitação (a) e emissão (b) do quelato de Eu-TTAglutaraldeído. Espectros de excitação (c) e emissão (d) da supermolécula de Eu-TTAglutaraldeído. 

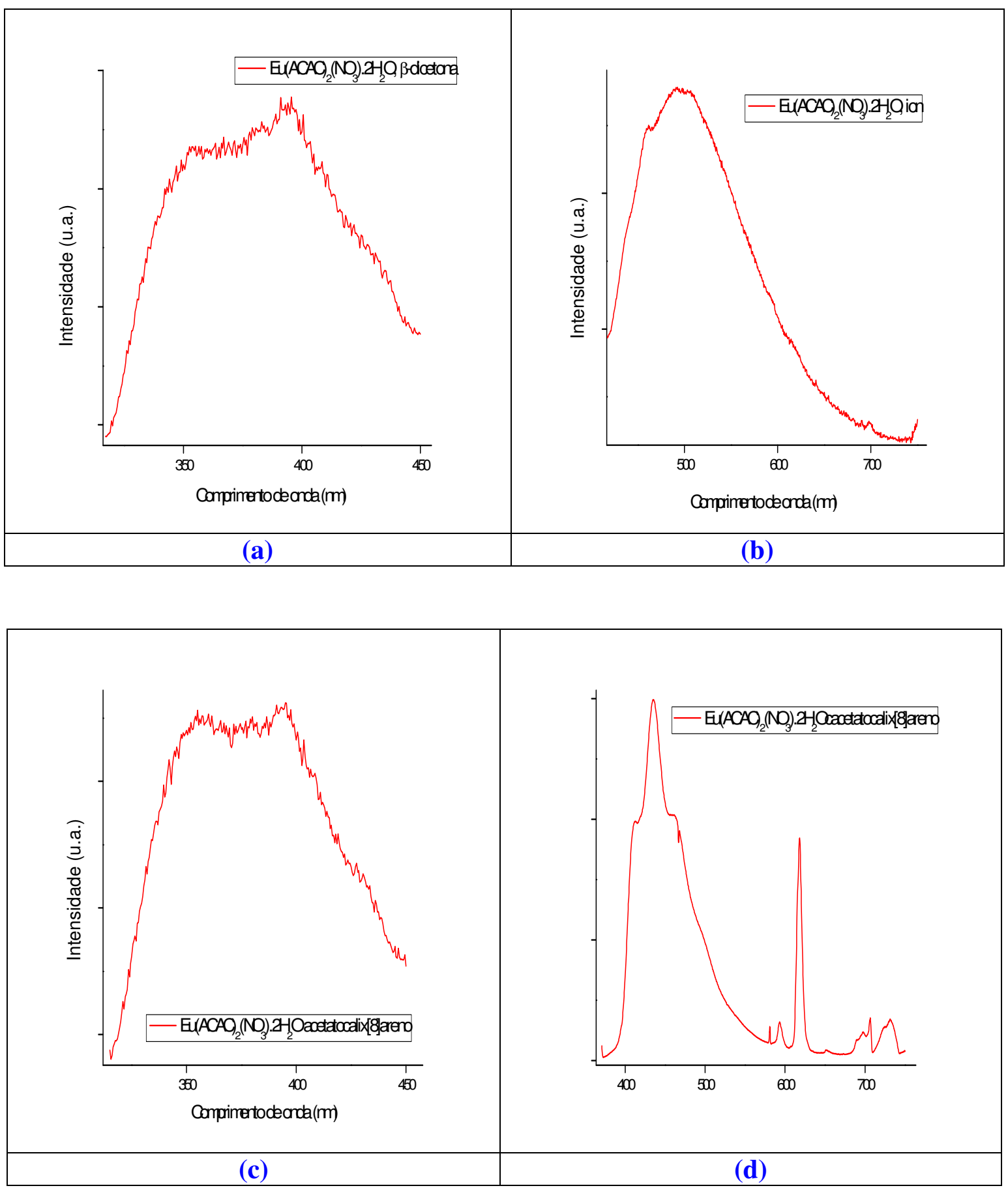

FIGURA 5.25. Espectros de excitação (a) e emissão (b) do quelato de Eu-ACACglutaraldeído. Espectros de excitação (c) e emissão (d) da supermolécula de Eu-ACACglutaraldeído. 

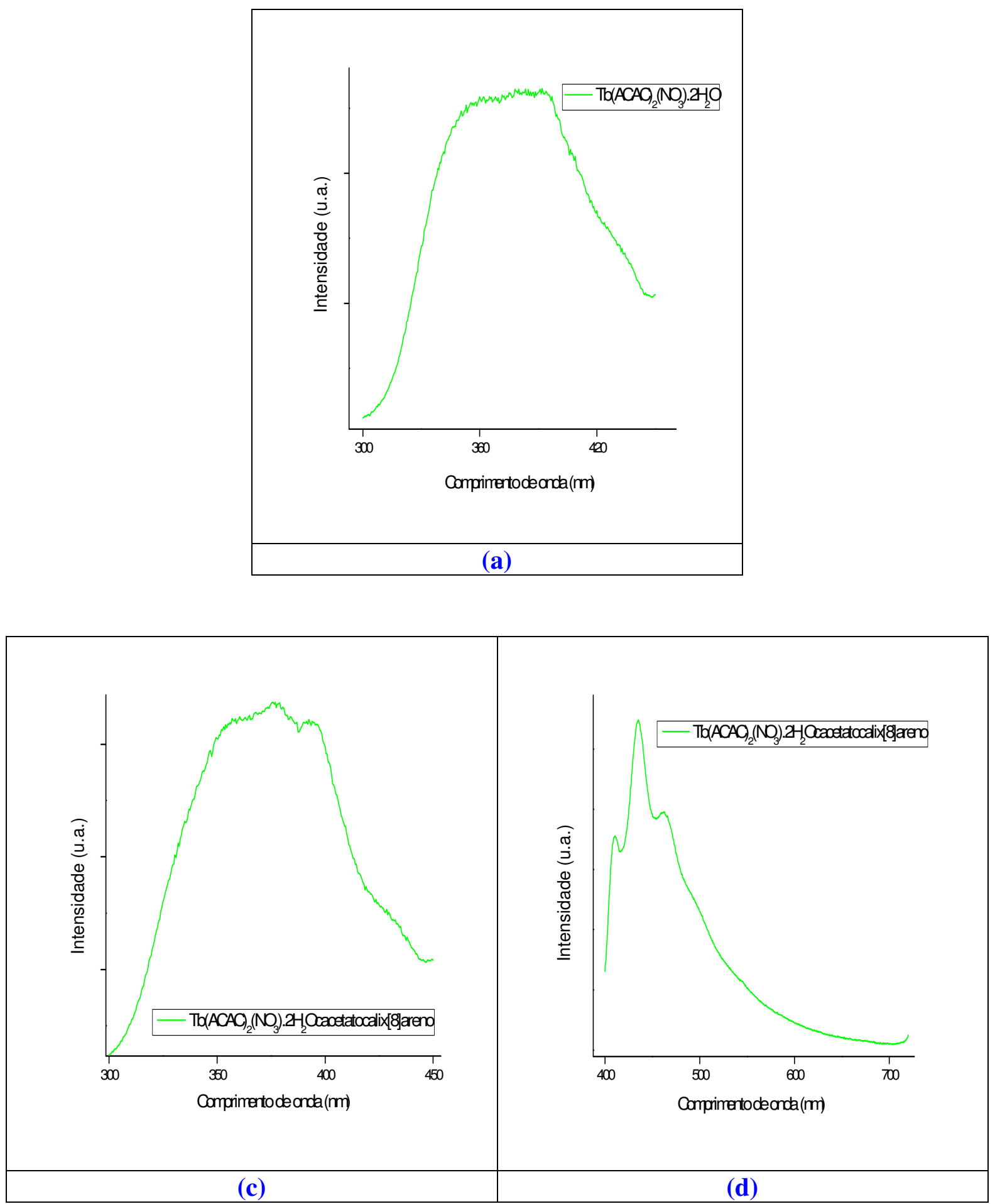

FIGURA 5.26. Espectros de excitação (a) do quelato de Tb-ACAC-glutaraldeído. Espectros de excitação (c) e emissão (d) da supermolécula de Tb-ACAC-glutaraldeído. 


\subsection{Fluoroimunoensaio}

\subsubsection{Curva de calibração dos aminoácidos}

Para testar o protocolo desenvolvido neste trabalho (item 4.3.8) cada determinação foi realizada em sextuplicatas para padrões e amostras. Primeiro construiu-se uma curva padrão para quantificação de valina e ácido glutâmico utilizando-se o marcador de EuTTA-Calix[8]areno (nc = não conjugado) e Eu-TTA-Calix[8]areno-glutaraldeído $(\mathrm{c}=$ conjugado com glutaraldeído). Estas curvas estão apresentadas na FIG. 5.27 podendo-se concluir que o melhor sinal é obtido com o marcador conjugado. Para a valina tem-se um comportamento crescente com o aumento da concentração enquanto que para o ácido glutâmico este comportamento é o inverso. Na FIG. 5.28 mostra-se a título de ilustração a placa de ELISA usada para fazer as contagens da curva de calibração da valina com os marcadores Eu-TTA-Calix[8]areno (nc) e Eu-TTA-Calix[8]areno-glutaraldeído (c).

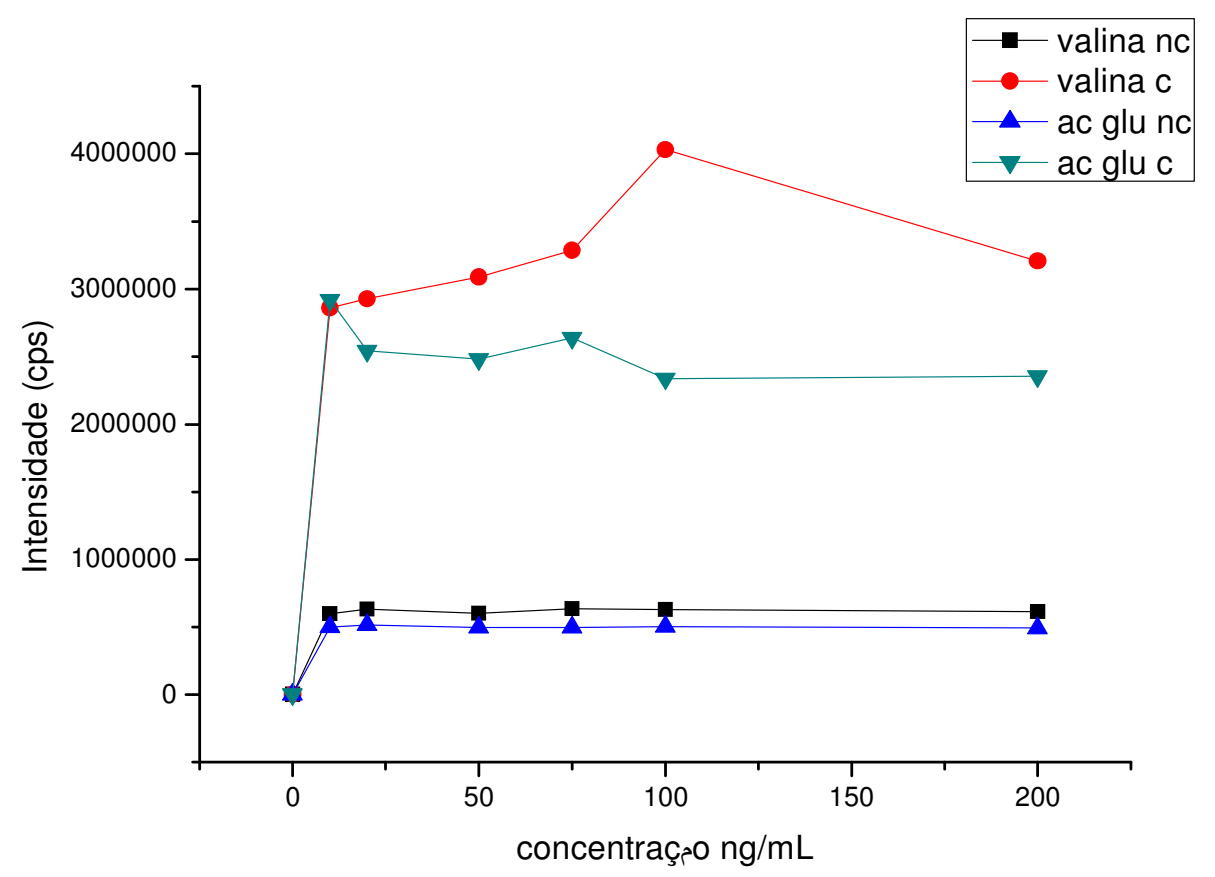

FIGURA 5.27. Curva de calibração do àcido glutâmico e da valina com os marcadores EuTTA-Calix[8]areno (nc) e Eu-TTA-Calix[8]areno-glutaraldeído (c). 


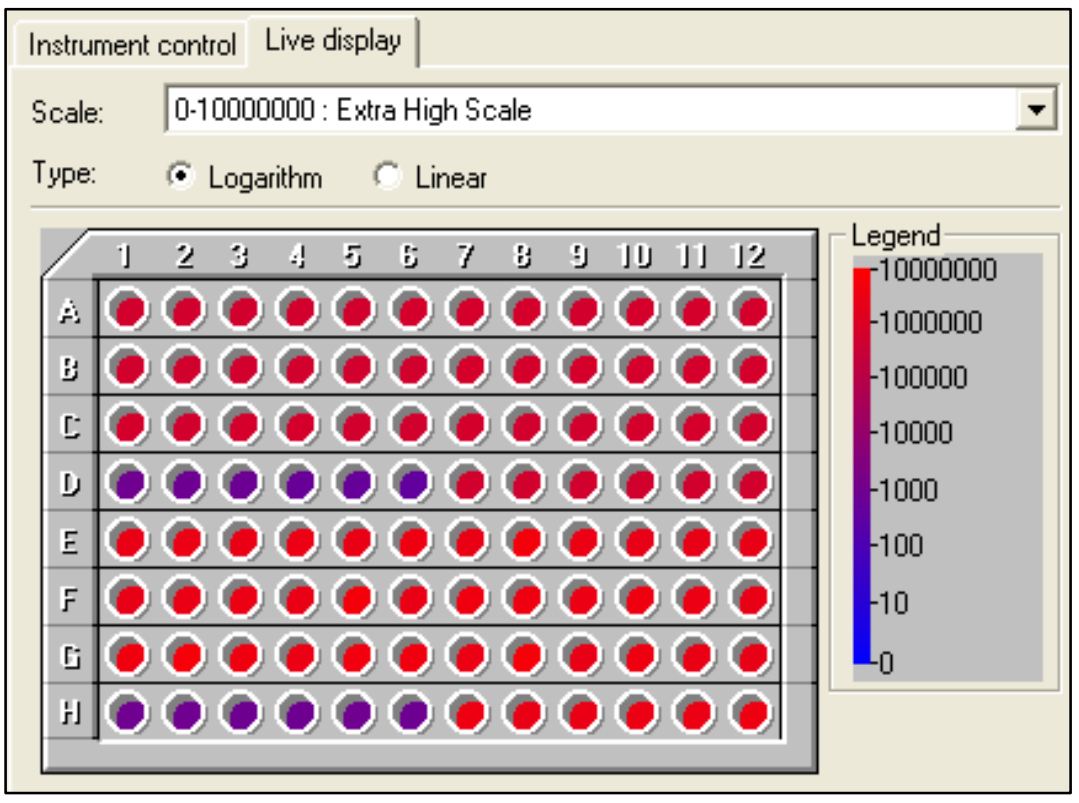

FIGURA 5.28. Imagem representativa da placa de ELISA usada para fazer as contagens da curva de calibração da valina com os marcadores Eu-TTA-Calix[8]areno (nc) e EuTTA-Calix[8]areno-glutaraldeído (c).

\subsubsection{Resultados preliminares dos testes do protocolo de análise para $\mathrm{HbS}$}

Prosseguiu-se as análises usando o protocolo descrito no item 4.3.8 e 4.3.8.1. Os resultados para 24 amostras positivas para $\mathrm{HbS}$ são apresentados na FIG. 5.29. Esta figura mostra uma avaliação de amostras de sangue $\mathrm{HbS}$ positivas e um padrao negativo (que é a amostra 25) utilizando-se o marcador conjugado e não conjugado. Observa-se que com o marcador conjugado se teve uma melhor resposta no sinal, o que atinge os objetivos preconizados nesse trabalho que foi a conjugação da valina com o marcador.

Pelos resultados mostrados na FIG. 5.29 e comparando-se as contagens obtidas com as do padrão (amostra 25) pode-se observar que as amostras $\mathrm{HbS}$ positivas estão com contagens acima do padrão negativo, que era o esperado. Testes com um número maior de HBS negativos serão efetuados futuramente para se ter uma população estatistica aceitável para validação do método. Um número maior de amostras de sangue $\mathrm{HbS}$ positivos e negativos serão necessárias para comfirmação da reprodutibilidade do método. E para se ter uma quantificação confiavel será necessário um padrão 100\% em HbS. 

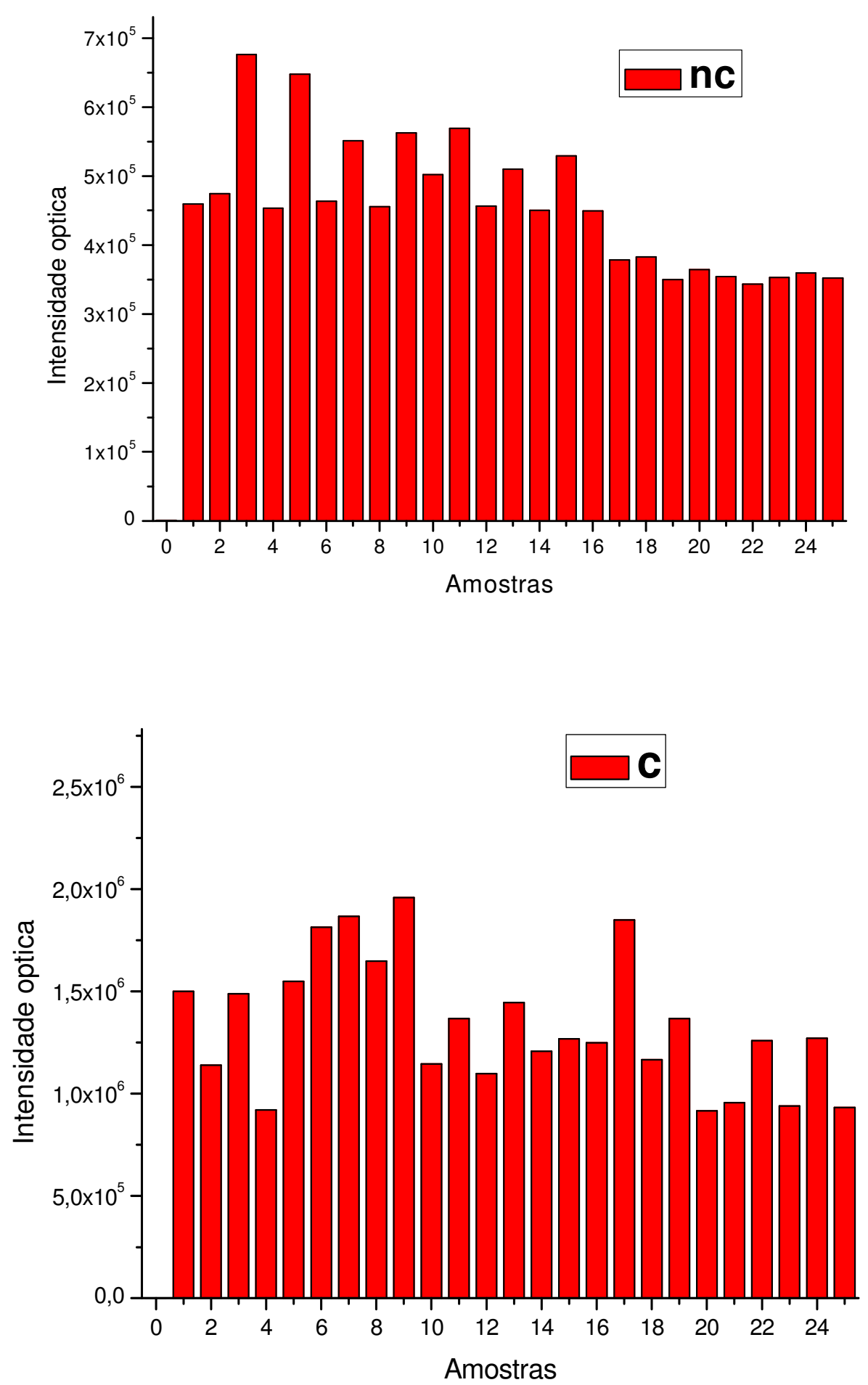

FIGURA 5.29. Fluoroimunoensaio com os marcadores Eu-TTA-Calix[8]areno (nc) e EuTTA-Calix[8]areno-glutaraldeído (c). 0 e 25: Controle negativo; 1-24: HbS em diferentes porcentagens conforme 7.0 ANEXO. 


\subsection{FTIR}

\subsubsection{Determinação dos aminoácidos valina e àcido glutâmico pela técnica de FTIR}

Para se ter uma comparação com os dados do fluoroimunoensaio, fez-se a determinação dos aminoácidos valina e àcido glutâmico, pela técnica de FTIR, nas amostras de sangue de grupos com anemia falciforme e outro grupo controle. Na FIG. 5.30 mostra-se o espectro em pastilha de $\mathrm{KBr}$ dos aminoácidos àcido glutâmico e valina que foram tomados como padrão. As bandas entre 3224 e $3402 \mathrm{~cm}^{-1}$ representam a deformação axial de $\mathrm{OH}$ associada a pontes de hidrogênio. As absorções na faixa de 2931 a $2854 \mathrm{~cm}^{-1}$ estão associadas à deformação axial de $\mathrm{C}-\mathrm{H}$ alifático. A banda em $2360 \mathrm{~cm}^{-1}$ é característica do gás $\mathrm{CO}_{2}$. O número de onda de $1735 \mathrm{~cm}^{-1}$ é representado pela deformação axial de grupos ésteres alifático, tal como, $\mathrm{C}=\mathrm{O}$ e C-O. A absorção em $1647 \mathrm{~cm}^{-1}$ referese à deformação axial de intensidade fraca da ligação insaturada de grupos etilenos $\mathrm{C}=\mathrm{C}$. A banda de absorção em $1465 \mathrm{~cm}^{-1}$ destaca a deformação angular dos grupos $\mathrm{C}-\mathrm{H}$ e $\mathrm{CH}_{2}$. Duas absorções de extrema importância são as que ocorrem em $1245 \mathrm{~cm}^{-1}$ e entre $723 \mathrm{e}$ $817 \mathrm{~cm}^{-1}$, pois representam a deformação axial de grupos fosfatos alifático $\mathrm{P}=\mathrm{O}, \mathrm{P}-\mathrm{O}$ e $\mathrm{P}-\mathrm{O}-\mathrm{C}$, respectivamente; característicos de fosfolipídeos. As bandas em $1064 \mathrm{~cm}^{-1} \mathrm{e}$ $1020 \mathrm{~cm}^{-1}$, representam respectivamente, a deformação axial de $\mathrm{C}-\mathrm{O}-\mathrm{C}$ e a deformação axial de amina primária $\mathrm{C}-\mathrm{N}^{[17]}$.

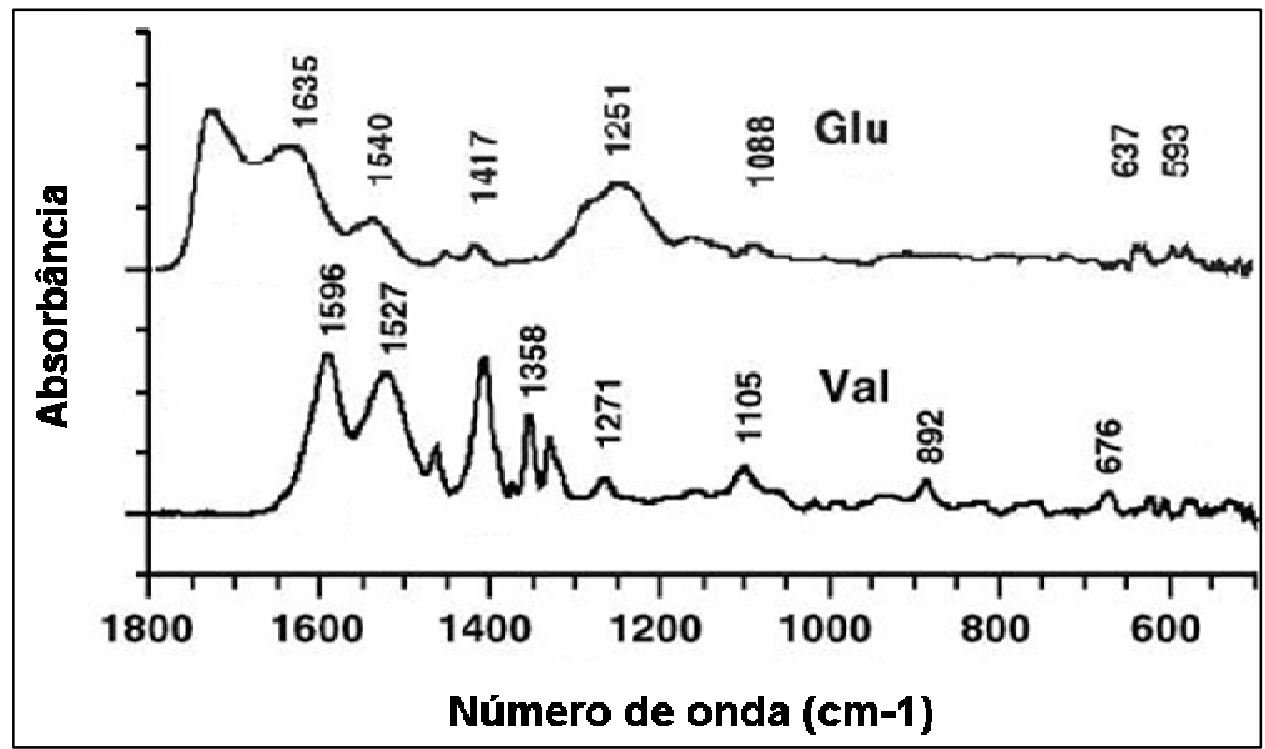

FIGURA 5.30. Espectro de infravermelho dos aminoácidos em pastilha de $\mathrm{KBr}^{[16]}$. 


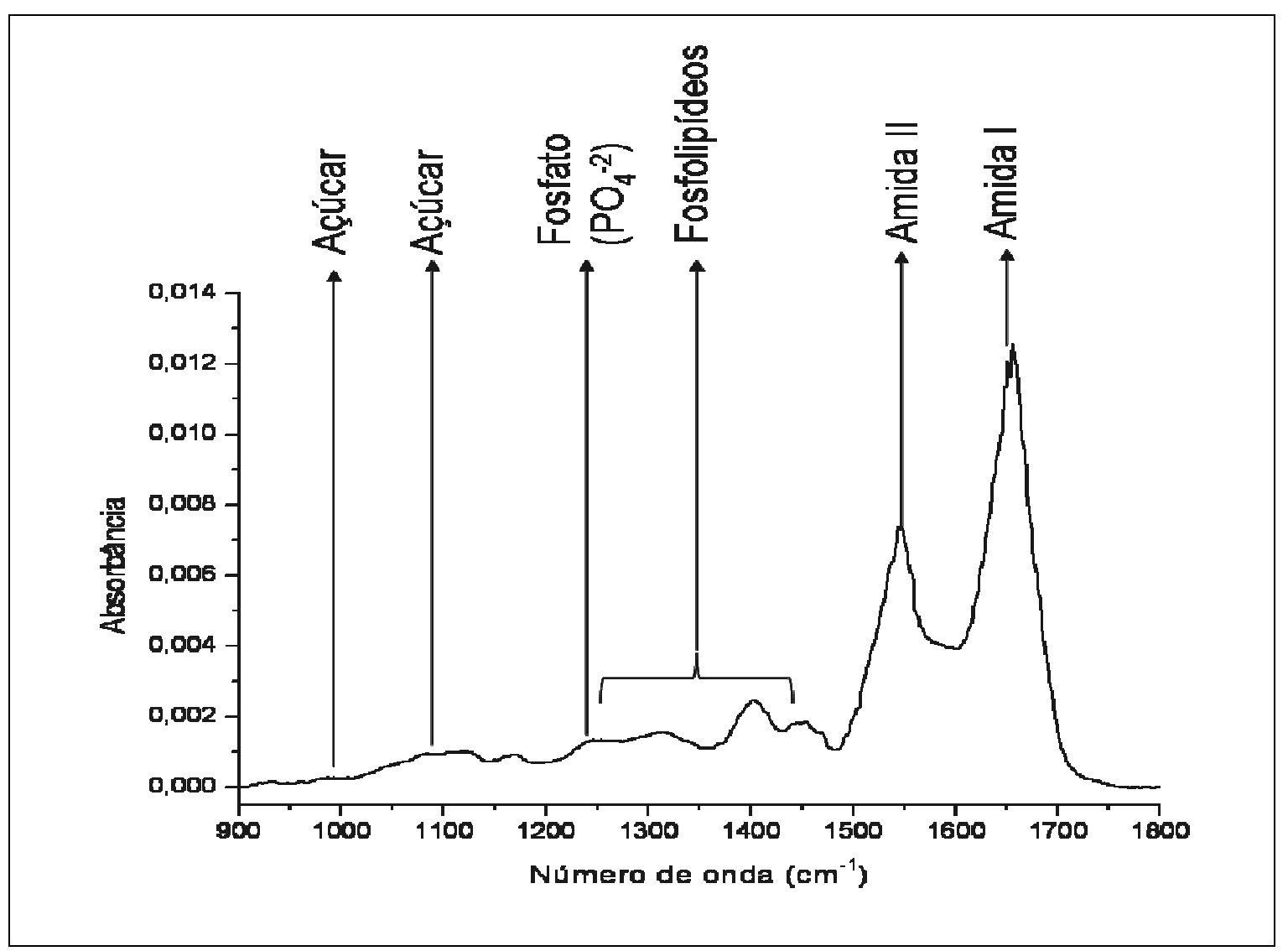

FIGURA 5.31. Espectro detalhando as características gerais das amostras de sangue analisadas por FTIR.

Na Figura acima, observa-se através da realização de estatítica multivariada, que a diferenciação está essencialmente entre as relações de amida I, amida II e fosfolipídeos.

\subsubsection{Resultados estatísticos das análises do grupo com anemia falciforme e do grupo controle por FTIR}

Dentre os métodos estatísticos convencionais, a Análise de Componentes Principais (PCA) tem sido de grande aplicação em diversas áreas, como a Física, a Matemática e a Geografia. A análise de componentes principais consiste essencialmente em reescrever as coordenadas das amostras em outro sistema de eixo mais conveniente para a análise dos dados. Em outras palavras, as n-variáveis originais, geram através de suas combinações lineares, n-componentes principais, cuja principal característica, além da ortogonalidade, é que são obtidos em ordem decrescente de máxima variância, ou seja, a componente principal 1 detém mais informação estatística que a componente principal 2, que por sua vez tem mais informação estatística que a componente principal 3 e assim por diante. Este 
método permite a redução da dimensionalidade dos pontos representativos das amostras, pois embora a informação estatística presente nas n-variáveis originais seja a mesma dos ncomponentes principais, é comum obter em apenas 2 ou 3 das primeiras componentes principais mais que $90 \%$ desta informação.

O gráfico da componente principal 1 versus a componente principal 2 fornece uma janela privilegiada (estatisticamente) para observação dos pontos no espaço n-dimensional e assim sucessivamente com fator 2 e 4,5 e 6 e outras combinações.

A análise de componentes principais também pode ser usada para julgar a importância das próprias variáveis originais escolhidas, ou seja, as variáveis originais com maior peso (loadings) na combinação linear dos primeiros componentes principais são as mais importantes do ponto de vista estatístico ${ }^{[14,15]}$.

Na FIG. 5.32 apresenta-se os gráficos PCA das amostras de sangue HbS positivas e os controles. Na FIG. 5.33 mostra-se o começo de uma diferenciação entres as amostras controle e aquelas que possuem a anemia falciforme abaixo de $50 \%$ de $\mathrm{HbS}$ e acima de $60 \%$ de $\mathrm{HbS}$. Na FIG. 5.34 mostra-se a diferenciação apenas entre o grupo de anemia falciforme.

Na FIG. 5.35 mostra-se a estatística geral das porcentagens de todo o grupo controle e todo o grupo falciforme.

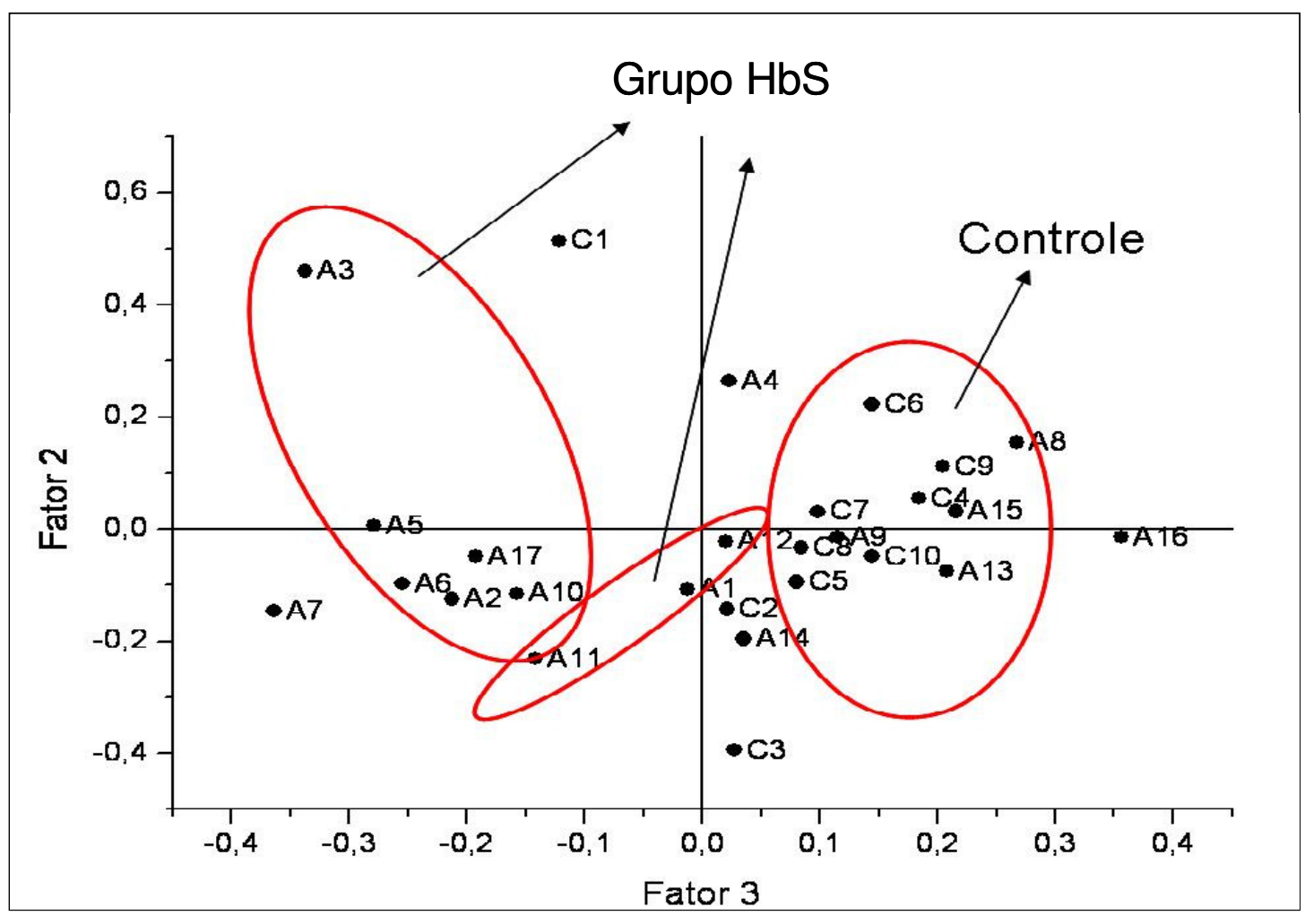

FIGURA 5.32. Gráfico de PCA da estatística multivariável. 


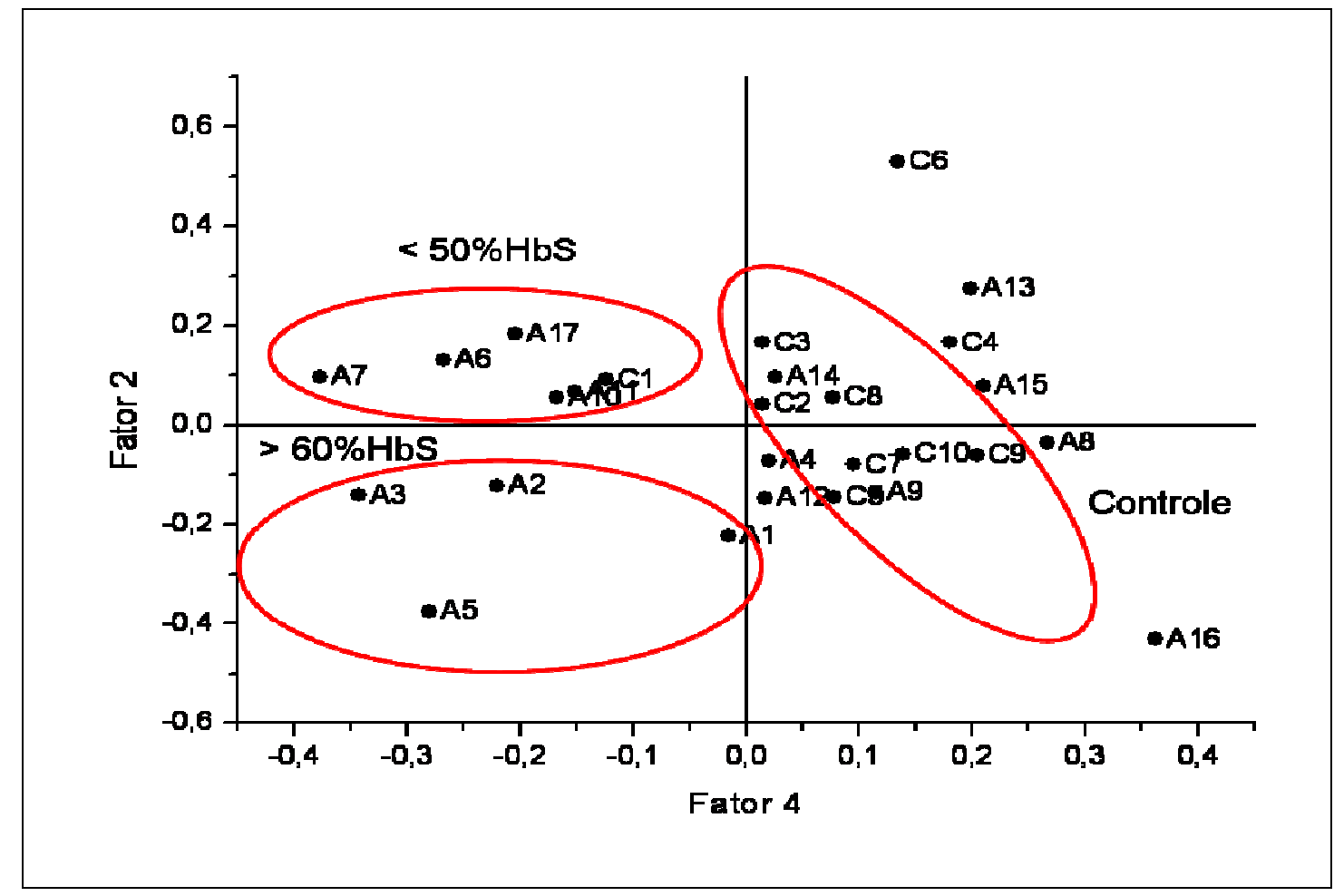

FIGURA 5.33. Gráfico PCA mostrando uma separação entre as amostras (abaixo de 50\% e acima de $60 \%$ de $\mathrm{HbS}$ ) em relação ao grupo controle.

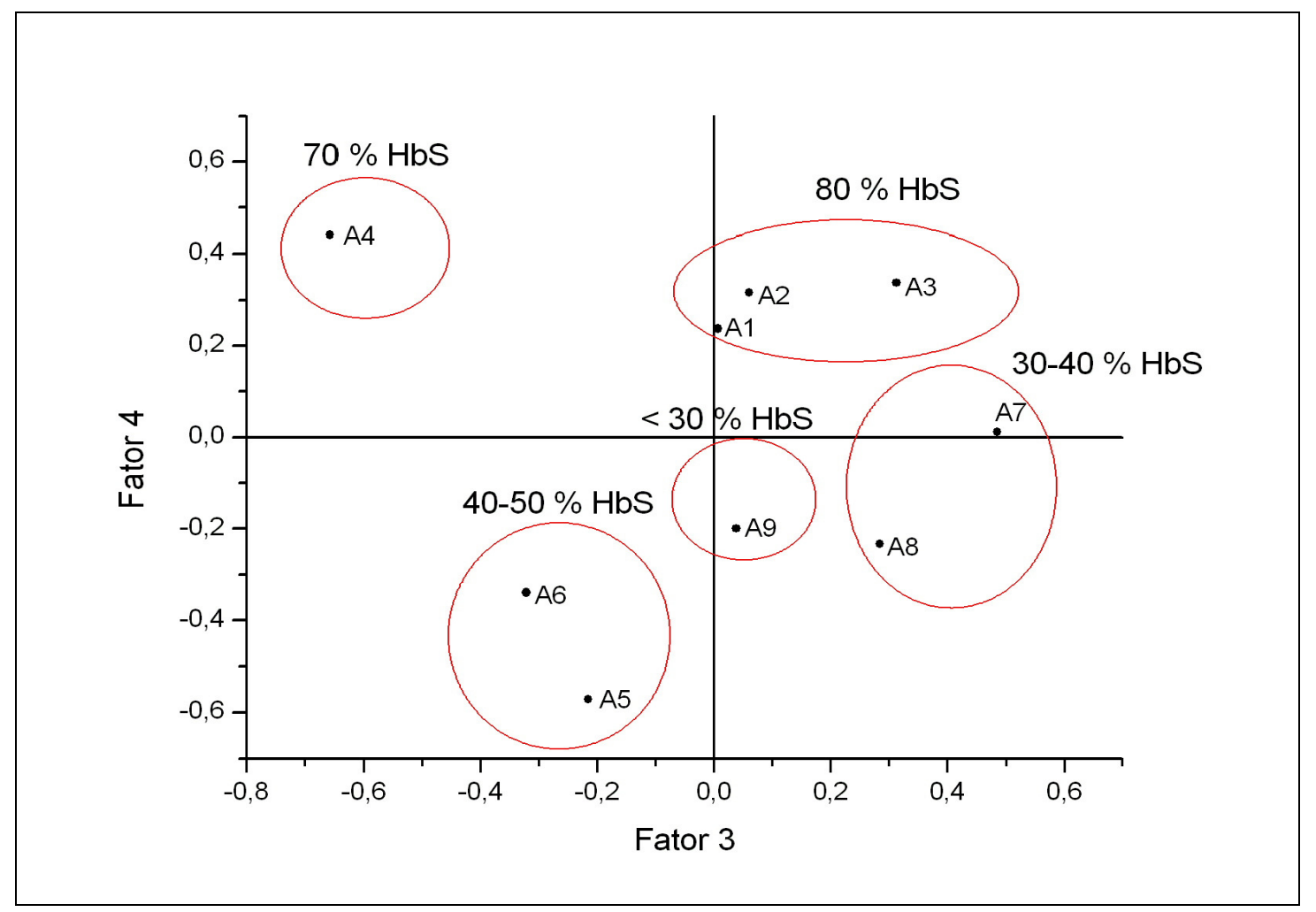

FIGURA 5.34. Gráfico PCA que utiliza somente a diferenciação entre as amostras HbS. 


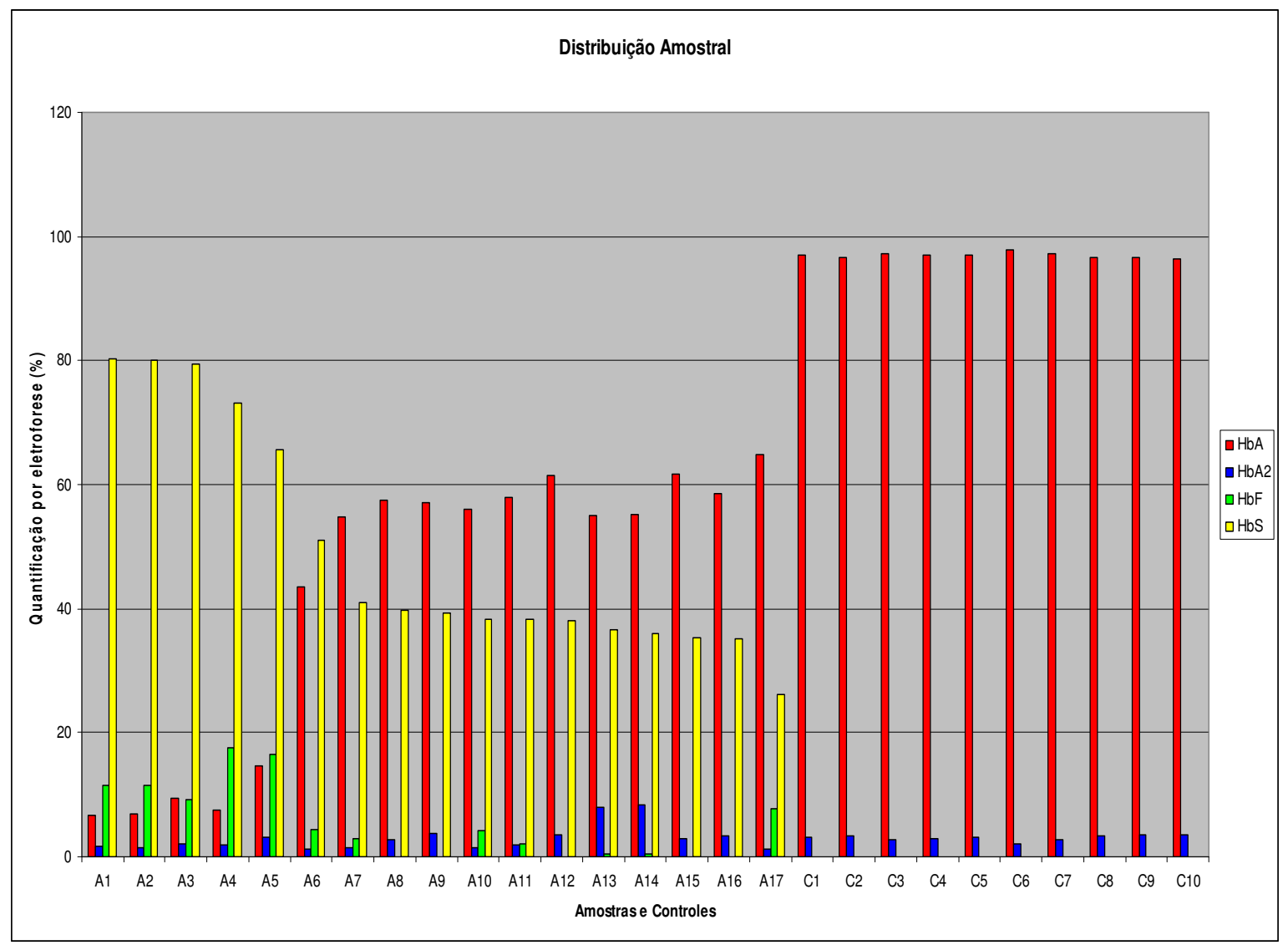

FIGURA 5.35. Estatística das porcentagens de $\mathrm{HbA}, \mathrm{HbA}_{2}, \mathrm{HbS}$ e $\mathrm{HbF}$. A intensidade é dada em unidades de absorbância em função do número de onda.

\subsection{Fase seguinte para obtenção do kit para análise de $\mathrm{HbS}$}

Esta metodologia quando concluída se destinará a dosagem da quantidade de $\mathrm{HbS}$ em amostras sanguíneas de recém-nascidos. Portanto será necessário o estabelecimento do protocolo com estudos de reprodutibilidade com uma amostragem maior, validação do método e continuação das análises com uma amostragem maior também para FTIR para posterior comparação dos métodos desenvolvidos neste trabalho. 


\section{REFERÊNCIAS BIBLIOGRÁFICAS}

[01] GUTSCHE, C. D. Calixarenes revisited. Cambridge: Royal Society of Chemistry, 1998.

[02] GUTSCHE, C. D.; NAM, K. C. Calixarenes: synthesis, propeties and and metal complexation of aminocalixarenes. J. of American Chem. Soc. v. 110, n. 18, p. 6153-6162, 1988.

[03] LECOMTE, J. Infra red adsorption spectra of metallic acetyl acetonates. Discussions on Faraday Soc. v. 9, p.125-131, 1950.

[04] MORGAN, H. W. Infrared absorption spectra of solid solutions. Spectrochim. Acta. v. 10, n. 2, p. 222, 1957.

[05] BELLAMY, I. J.; BRANCH, R. F. Infra red spectra of chelate compounds: metal chelate compounds of beta diketones and of salicyladehyde. J. of Chem. Soc. p. 4491-4494, 1954.

[06] MALTA, O. L.; BRITO, H. F.; MENEZES, J. F. S.; GONÇALVES E.; SILVA, F. R.; ALVES JR., S.; FARIAS JR., F. S.; ANDRADE, A. V. M. Spectroscopic properties of a new light-converting device $\mathrm{Eu}$ (thenoyltrifluoroacetonate) $3, \cdot 2$ (dibenzyl sulfoxide). A theoretical analysis based on structural data obtained from a sparkle model. J. of Lumin. v. 75, p. 255-268. 1997.

[07] COTTON, F. A. Chemical Application of Group Theory. New York: WileyIntercience. 1971.

[08] BÜNZLI, J.-C.G.; CHOPPIN, G.R. Lanthanide probes in life, chemical and earth sciences - theory and practice. Amsterdam: Elsevier, 1989.

[09] RICHARDSON, F. S. Terbium(III) and europium(III) ions as luminescent probes and stains for biomolecular systems. Chem. Rev. v. 82, p. 541-552. 1982.

[10] FOSBERG, J.H.; Coord. Chem. Rev., v. 10, p.195. 1973.

[11] P.A.M. Berdowski, M.J.J. Lammers e G. Blasse, Chem. Phys. Lett. 113 (1985) 387. 
[12] G.C. Kim, H.L. Park, T.W. Kim, Mater. Res. Bull, 36;1603, 2001.

[13] JUDD, B.R. Ionic transitions hypersensitive to environment. J. of Chem. Phys. v. 70, p. 4830-4833, 1979.

[14] SHAW, P. J. A. Multivariate statistics for the environmental sciences. London New York: Arnold ; Distributed in the U.S. by Oxford University Press; ix, p. 233, 2003.

[15] MACHADO, J. NETO, M.; MOITA, G.C. Uma Introdução À Análise Exploratória De Dados Multivariados. Química Nova, 21(4), 1998.

[16] WOLPERT, M.; HELLWIG, P. Infrared spectra and molar absorption coefficients of the 20 alpha amino acids in aqueous solutions in the spectral range from 1800 to $500 \mathrm{~cm}^{-1}$. Spectrochimica Acta Part A; 64 987-1001, 2006.

[17] SILVERSTEIN, R. M.; KIEMLE, D. J.; Webster, F. X. Identificação Espectrométrica de Compostos Orgânicos, LTC: 60-74, 2000. 


\subsection{CONCLUSÕES}

Este trabalho apresenta dados experimentais e espectroscópicos dos complexos $\beta$ dicetonatos de terras raras trivalentes $\left(\mathrm{TR}^{3+}=\mathrm{Eu}^{3+} \mathrm{e} \mathrm{Tb}^{3+}\right)$ com octaacetatocalix[8]areno como ligantes.

Os complexos preparados apresentaram fórmulas gerais [TR(TTA $\left.)_{2}\left(\mathrm{NO}_{3}\right)\left(\mathrm{H}_{2} \mathrm{O}\right)_{2}\right]$ e $\left.\left[\mathrm{TR}(\mathrm{TTA})_{2}\left(\mathrm{NO}_{3}\right)\left(\mathrm{H}_{2} \mathrm{O}\right)_{2}\right]_{2} \subset \mathrm{L}\right]$ (onde L é o ligante octaacetatocalix[8]areno), que reflete o efeito estérico exercido pelos grupos substituintes nos ânions $\beta$-dicetonatos e nitrato.

Os dados de espectroscopia de absorção na região do infravermelho evidenciaram a coordenação dos ligantes $\beta$-dicetonatos, nitrato e calixareno aos $\mathrm{TR}^{3+}$ através dos átomos de oxigênio. As análises termogravimétricas TGA/DTGA indicaram o caráter higroscópico dos complexos sintetizados corroborado com os dados de análise elementar de $\mathrm{C}, \mathrm{H}, \mathrm{N}$ e $\mathrm{TR}^{3+}$. As curvas TGA/DTGA mostram que os complexos têm uma alta estabilidade térmica.

As micrografias mostraram que os aglomerados são de tamanho micrométrico e apresentam certa heterogeneidade de tamanho. Partículas na forma esférica não foram obtidas.

Os espectros de emissão dos complexos de $\mathrm{Eu}^{3+}$ exibiram bandas finas oriundas das transições ${ }^{5} \mathrm{D}_{0} \rightarrow{ }^{7} \mathrm{~F}_{0-4}$, dominados pelas transições hipersensíveis ${ }^{5} \mathrm{D}_{0} \rightarrow{ }^{7} \mathrm{~F}_{2}(\sim 612 \mathrm{~nm})$. Os desdobramentos dessas transições, de um modo geral, estão concordantes com um ambiente químico de baixa simetria ao redor do íon $\mathrm{TR}^{3+}$. Os complexos de $\mathrm{Eu}^{3+}$ apresentam comportamento não centrossimétrico caracterizado pela alta intensidade luminescente da transição hipersensível, que é proibida por dipolo elétrico em sistemas com centro de inversão. 
Com base no número de componentes de cada uma das transições observadas ${ }^{5} \mathrm{D}_{0} \rightarrow{ }^{7} \mathrm{~F}_{\mathrm{J}}(\mathrm{J}=0$, $1,2,3$ e 4) nos espectros de emissão e pela presença de um único pico atribuído à transição ${ }^{5} \mathrm{D}_{0} \rightarrow{ }^{7} \mathrm{~F}_{0}$ pode-se sugerir que as supermoléculas de $\beta$-dicetonas, tenoiltrifluroacetonato (TTA) e acetil acetona $(\mathrm{ACAC})$ de $\mathrm{Eu}^{3+}$ estão consistentes com apenas um sítio de simetria.

Os espectros de emissão dos complexos de $\mathrm{Tb}^{3+}$ exibiram bandas finas oriundas das transições ${ }^{5} \mathrm{D}_{4} \rightarrow{ }^{7} \mathrm{~F}_{0-6}$, dominados pelas transições hipersensíveis ${ }^{5} \mathrm{D}_{4} \rightarrow{ }^{7} \mathrm{~F}_{5}(\sim 545 \mathrm{~nm})$. Os desdobramentos dessas transições, de um modo geral, estão concordantes com um ambiente químico de baixa simetria ao redor do íon $\mathrm{TR}^{3+}$.

Os resultados de tempo de vida indicam que nesses casos não há outro canal de despopulação do nível emissor ${ }^{5} \mathrm{D}_{0}$ e ${ }^{5} \mathrm{D}_{4}$ e os tempos de vida mais curtos do nível ${ }^{5} \mathrm{D}_{0} \mathrm{e}$ ${ }^{5} \mathrm{D}_{4}$ nas supermoléculas estão associados aos canais de desativação não radiativa em função do acoplamento vibrônico com as vibrações das moléculas de calixareno.

Os complexos estudados mostraram-se efetivos na detecção de materiais marcados com $\mathrm{Eu}^{3+}$ sendo os melhores resultados obtidos para o sistema com calixareno conjugado.

A conjugação dos materiais biológicos com o marcador mostrou-se eficiente. Os resultados obtidos usando o protocolo proposto para marcação de $\mathrm{HbS}$ mostrou-se viável quando comparado aos métodos comerciais existentes.

A análise de $\mathrm{HbS}$ por FTIR mostrou-se efetiva no reconhecimento dos aminoácidos ácido glutâmico e valina e a análise de componentes principais permitiu separar grupos portadores de anemia falciforme de acordo com as percentagens de hemoglobina $\mathrm{S}$ existente nas amostras biológicas. 


\subsection{PERSPECTIVAS FUTURAS}

Com base nos resultados apresentados nesse trabalho propõe-se:

- Validação da metodologia de fluoroimunoensaio com estudos de reprodutibilidade com uma amostragem maior.

- Continuação dos estudos e análises com uma maior amostragem para a técnica de FTIR.

- Comparação das respostas dos métodos desenvolvidos entre si e com outras metodologias existentes.

- Estudo através da caracterização química da $\mathrm{HbS}$ por meio da técnica da espectrometria de massas, especificamente via "Electro Spray - Tandem Mass Spectrometry - ES-MS/MS".

- Esta metodologia quando concluída se destinará a dosagem da quantidade de HbS em amostras sanguíneas de recém-nascidos. 
7.0 ANEXO. Amostras de anemia falciforme e amostras controle do material utilizado nas análises por FTIR.

\begin{tabular}{|c|c|c|c|c|c|c|c|c|c|}
\hline Amostras & HbA & $\mathbf{H b A}_{2}$ & HbF & $\mathbf{H b S}$ & Controles & HbA & $\mathbf{H b A}_{2}$ & HbF & $\mathbf{H b S}$ \\
\hline A1 & 6,7 & 1,6 & 11,4 & 80,3 & C1 & 96,9 & 3,1 & - & - \\
\hline$\overline{\mathrm{A2}}$ & 7 & 1,4 & 11,6 & 80 & $\mathrm{C2}$ & 96,6 & 3,4 & - & - \\
\hline A3 & 9,5 & 2 & 9,1 & 79,4 & $\mathrm{C3}$ & 97,3 & 2,7 & - & - \\
\hline A4 & 7,5 & 1,8 & 17,6 & 73,1 & C4 & 97,1 & 2,9 & - & - \\
\hline A5 & 14,6 & 3,2 & 16,6 & 65,6 & C5 & 96,9 & 3,1 & - & - \\
\hline A6 & 43,4 & 1,2 & 4,4 & 51 & C6 & 97,9 & 2,1 & - & - \\
\hline A7 & 54,7 & 1,4 & 2,9 & 41 & C7 & 97,3 & 2,7 & - & - \\
\hline A8 & 57,4 & 2,8 & - & 39,8 & C8 & 96,6 & 3,4 & - & - \\
\hline A9 & 57 & 3,7 & - & 39,3 & C9 & 96,5 & 3,5 & - & - \\
\hline A10 & 56,1 & 1,5 & 4,1 & 38,3 & C10 & 96,4 & 3,6 & - & - \\
\hline A11 & 58 & 1,8 & 2 & 38,2 & & & & & \\
\hline A12 & 61,4 & 3,5 & - & 38,1 & & & & & \\
\hline $\mathbf{A 1 3}$ & 54,9 & 8 & 0,5 & 36,6 & & & & & \\
\hline A14 & 55,2 & 8,4 & 0,4 & 36 & & & & & \\
\hline A15 & 61,7 & 3 & - & 35,3 & & & & & \\
\hline A16 & 58,6 & 3,3 & - & 35,1 & & & & & \\
\hline A17 & 64,9 & 1,3 & 7,7 & 26,1 & & & & & \\
\hline
\end{tabular}

*HbA - Hemoglobina normal

$* \mathbf{H b A}_{2}-$ Hemoglobina normal 2

*HbF- Hemoglobina fetal

*HbS- Hemoglobina alterada 